\title{
High blood pressure and target-organ damage of the brain
}

Citation for published version (APA):

Henskens, L. H. G. (2008). High blood pressure and target-organ damage of the brain. [Doctoral Thesis, Maastricht University]. Datawyse / Universitaire Pers Maastricht. https://doi.org/10.26481/dis.20081127lh

Document status and date:

Published: 01/01/2008

DOI:

10.26481/dis.20081127lh

Document Version:

Publisher's PDF, also known as Version of record

\section{Please check the document version of this publication:}

- A submitted manuscript is the version of the article upon submission and before peer-review. There can be important differences between the submitted version and the official published version of record.

People interested in the research are advised to contact the author for the final version of the publication, or visit the DOI to the publisher's website.

- The final author version and the galley proof are versions of the publication after peer review.

- The final published version features the final layout of the paper including the volume, issue and page numbers.

Link to publication

\footnotetext{
General rights rights.

- You may freely distribute the URL identifying the publication in the public portal. please follow below link for the End User Agreement:

www.umlib.nl/taverne-license

Take down policy

If you believe that this document breaches copyright please contact us at:

repository@maastrichtuniversity.nl

providing details and we will investigate your claim.
}

Copyright and moral rights for the publications made accessible in the public portal are retained by the authors and/or other copyright owners and it is a condition of accessing publications that users recognise and abide by the legal requirements associated with these

- Users may download and print one copy of any publication from the public portal for the purpose of private study or research.

- You may not further distribute the material or use it for any profit-making activity or commercial gain

If the publication is distributed under the terms of Article $25 \mathrm{fa}$ of the Dutch Copyright Act, indicated by the "Taverne" license above, 
High blood pressure and

target-organ damage of the brain 
(c) Léon Henskens, Maastricht 2008

ISBN: 978-90-5278-774-9

Layout: Tiny Wouters

Cover: Jean Scheijen | vierdrie.nl

Production: Datawyse | Universitaire Pers Maastricht

Printing of this thesis was financially supported by Astellas Pharma B.V., AstraZeneca B.V., Boehringer B.V., Bristol-Myers Squibb B.V., Merck Sharp \& Dohme B.V., Novartis Pharma B.V., Schering-Plough B.V. 


\section{High blood pressure and}

\section{target-organ damage of the brain}

\section{PROEFSCHRIFT}

ter verkrijging van de graad van doctor aan de Universiteit Maastricht, op gezag van de Rector Magnificus,

Prof. dr. G.P.M.F. Mols

volgens besluit van het College van Decanen

in het openbaar te verdedigen

op donderdag 27 november 2008 om 14.00uur

door

Léon Henskens 


\section{Promotores}

Prof. dr. P.W. de Leeuw

Prof. dr. J. Lodder

\section{Copromotores}

Dr. A.A. Kroon

Dr. R.J. van Oostenbrugge

\section{Beoordelingscommissie}

Prof. dr. H.A.J. Struijker Boudier (voorzitter)

Prof. dr. P.J. Koudstaal, Erasmus MC, Rotterdam

Dr. G.A. van Montfrans, AMC, Amsterdam

Dr. H.J.M. Smeets

Prof. dr. J. Wilmink

Financial support by the Netherlands Heart Foundation for the publication of this thesis is gratefully acknowledged 
Voor Marian

voor mijn ouders 



\section{Contents}

List of abbreviations $\quad 9$

$\begin{array}{lll}\text { Chapter } 1 & \text { Introduction and outline of the thesis }\end{array}$

Chapter 2 Different classifications of nocturnal blood pressure dipping 31 affect the prevalence of dippers and nondippers and the relation with target-organ damage

Chapter 3 White matter hyperintensity volumes relate to ambulatory blood pressure levels in hypertensive patients

Chapter $4 \quad$ Silent lacunar but not territorial brain infarcts are related to ambulatory blood pressure levels in hypertensive patients

Chapter 5 Brain microbleeds are associated with ambulatory blood pressure levels in a hypertensive population

Chapter 6 Associations of the angiotensin II type 1 receptor $A^{1166} \mathrm{C}$ and the endothelial NO synthase $\mathrm{G}^{894} \mathrm{~T}$ gene polymorphisms with silent subcortical white matter lesions in essential hypertension

Chapter 7 Renin-angiotensin system and nitric oxide synthase gene polymorphisms in relation to stroke

Chapter 8 Aortic stiffness is associated with silent cerebral small-vessel disease in hypertensive patients

Chapter 9 Ambulatory blood pressure, asymptomatic cerebrovascular 131 damage and cognitive function in essential hypertension

Chapter 10 Detection of silent cerebrovascular disease refines risk stratification of hypertensive patients

Chapter 11 General discussion

Appendix (A-E)

Summary

Samenvatting

Dankwoord

Curriculum vitae 



\section{List of abbreviations}

$\begin{array}{ll}\text { ABPM } & \text { ambulatory blood pressure monitoring } \\ \text { ACE } & \text { angiotensin converting enzyme } \\ \text { AGT } & \text { angiotensinogen } \\ \text { AGTR1 } & \text { angiotensin-Il type 1 receptor } \\ \text { ANOVA } & \text { analysis of variance } \\ \text { BMBS } & \text { brain microbleeds } \\ \text { BMI } & \text { body mass index } \\ \text { BP } & \text { blood pressure } \\ \text { CBF } & \text { cerebral blood flow } \\ \text { CBP } & \text { clinic blood pressure } \\ \text { CI } & \text { confidence interval } \\ \text { CST } & \text { concept shifting task } \\ \text { CT } & \text { computed tomography } \\ \text { DBP } & \text { diastolic blood pressure } \\ \text { DM } & \text { diabetes mellitus } \\ \text { DWMH } & \text { deep white matter hyperintensities } \\ \text { DWMHV } & \text { deep white matter hyperintensity volume } \\ \text { ESH } & \text { European Society of Hypertension } \\ \text { FLAIR } & \text { fluid-attenuated inversion recovery } \\ \text { GE } & \text { gradient echo } \\ \text { GLM } & \text { general linear model } \\ \text { HDL } & \text { high density lipoprotein } \\ \text { HR } & \text { hazard ratio } \\ \text { HWE } & \text { Hardy-Weinberg equilibrium } \\ \text { ICC } & \text { intraclass correlation coefficient } \\ \text { ICD-9 } & \text { International Classification of Diseases, Ninth Revision } \\ \text { IDEE } & \text { Instrument Development Engineering and Evaluation } \\ \text { IQR } & \text { interquartile range } \\ \text { LACS } & \text { lacunar infarcts } \\ \text { LV } & \text { left ventricular } \\ \text { LVH } & \text { left ventricular hypertrophy } \\ \text { LVM } & \text { left ventricular mass } \\ \text { LVMI } & \text { left ventricular mass index } \\ \text { MAP } & \text { mean arterial pressure } \\ \text { MRI } & \text { magnetic resonance imaging } \\ \text { ND } & \text { narrow diary time method } \\ \text { NF } & \text { narrow fixed time method } \\ \text { NO } & \text { nitric oxide } \\ \text { NOS } & \text { nitric oxide synthase } \\ \text { PD } & \text { proton density } \\ & \end{array}$




$\begin{array}{ll}\text { PP } & \text { pulse pressure } \\ \text { PROGRESS } & \text { Perindopril pROtection aGainst REcurrent Stroke Study } \\ \text { PVH } & \text { periventricular hyperintensities } \\ \text { PWMHV } & \text { periventricular white matter hyperintensity volume } \\ \text { PWV } & \text { pulse wave velocity } \\ \text { RAS } & \text { renin-angiotensin system } \\ \text { ROI } & \text { region of interest } \\ \text { SBIs } & \text { silent brain infarcts } \\ \text { SBP } & \text { systolic blood pressure } \\ \text { SCD } & \text { silent cerebrovascular disease } \\ \text { SCWT } & \text { stroop color word test } \\ \text { SD } & \text { standard deviation } \\ \text { SVD } & \text { small-vessel disease } \\ \text { TIA } & \text { transient ischemic attack } \\ \text { TIS } & \text { territorial infarcts } \\ \text { UAE } & \text { urinary albumin excretion } \\ \text { WD } & \text { wide diary time method } \\ \text { WF } & \text { wide fixed time method } \\ \text { WHO } & \text { World Health Organisation } \\ \text { WLT } & \text { word learning task } \\ \text { WMHs } & \text { white matter hyperintensities } \\ \text { WMHV } & \text { white matter hyperintensity volume } \\ \text { WMLS } & \text { white matter lesions }\end{array}$




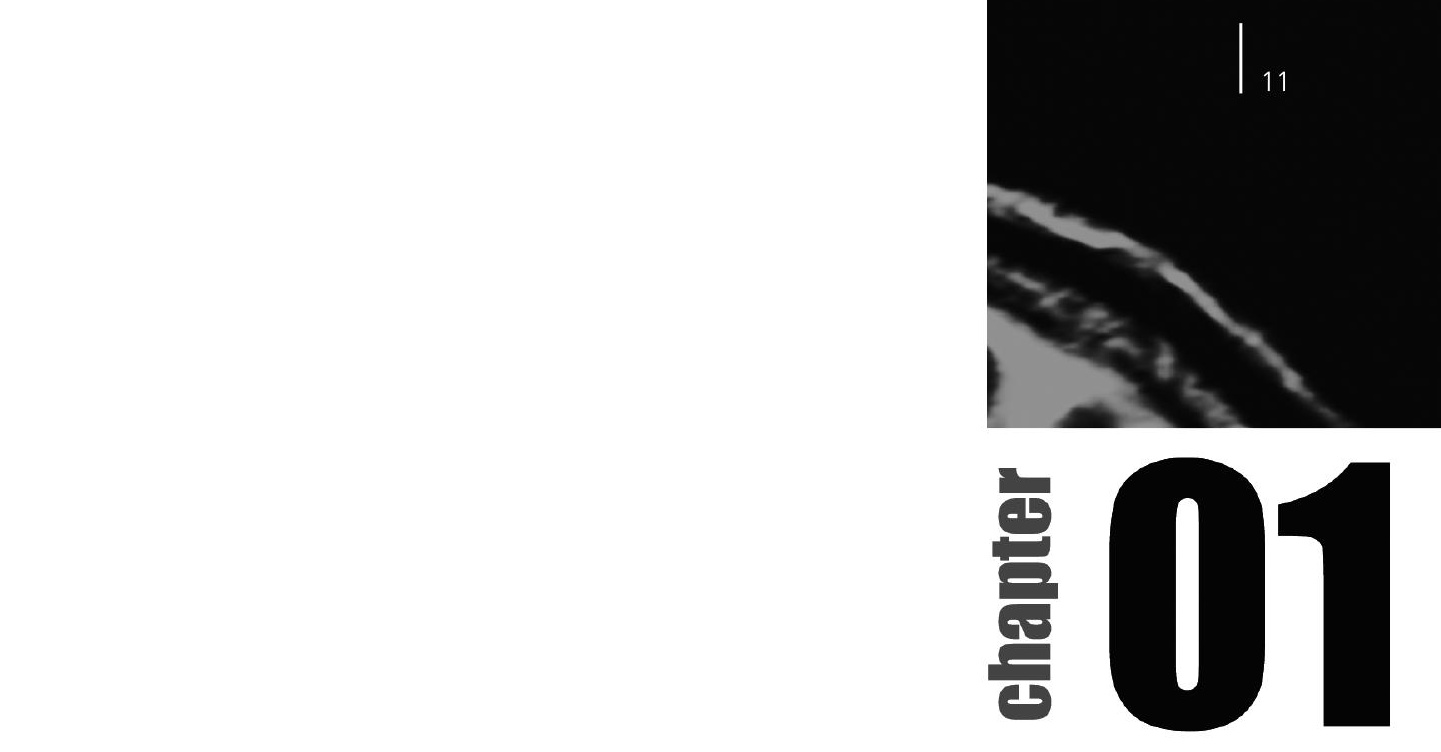

Introduction and outline of the thesis 
$12 \mid$ Chapter 1 
Hypertension is an important, worldwide public-health challenge because of its high frequency and concomitant risks of cardiovascular, renal and cerebrovascular disease, and death. ${ }^{1}$ The main goal of treating hypertension is to reduce hypertension-related complications, for example myocardial infarction and stroke. ${ }^{2,3}$ A necessary step in this endeavor is to identify those patients who are most at risk of cardiovascular events. The detection of preclinical hypertensionrelated target-organ damage, besides the assessment of traditional cardiovascular risk factors, is becoming increasingly important in the stratification of cardiovascular risk. ${ }^{4}$ Current guidelines for the management of arterial hypertension mainly recommend the search for preclinical damage to the heart and kidneys. ${ }^{2,3}$ However, extending this search to other organs, for instance the brain, might improve risk stratification, might optimize antihypertensive therapy and might, in the end, help to further reduce the burden of disease attributable to hypertension.

\section{The global burden of hypertension}

Current guidelines for the management of arterial hypertension define hypertension as an untreated blood pressure (BP) $\geq 140 \mathrm{mmHg}$ systolic or $\geq 90 \mathrm{mmHg}$ diastolic as measured in the office. ${ }^{3}$ Globally, hypertension affects $25-30 \%$ of the adult population, and even up to $60-70 \%$ of those beyond the seventh decade of life. ${ }^{5}$ Moreover, the incidence of hypertension is still increasing, and estimates forecast the number of adults with hypertension to increase by about $60 \%$ to over 1.5 billion in the year 2025. ${ }^{1}$ Investigators from the Framingham Heart Study showed that in their group of non-hypertensive participants below the age of 65 years $5.3 \%$ of those with optimum blood pressure (BP), $17.6 \%$ of those with normal $\mathrm{BP}$, and $37.3 \%$ of the subjects with high normal BP progressed to hypertension over a period of four years. Corresponding 4-year rates of progression to hypertension in participants of 65 years and older were $16.0 \%, 25.5 \%$, and $49.5 \%$, respectively. ${ }^{6}$ Furthermore, they estimated a lifetime risk of developing hypertension of $90 \%$ for participants who were normotensive at 55 years of age. ${ }^{7}$

According to the World Health Organization (WHO), hypertension is estimated to cause over seven million premature deaths and $4.5 \%$ of the total disease burden worldwide, its impact being higher than that of e.g. tobacco use and alcohol consumption. ${ }^{8}$ Data from the WHO also indicate that about $62 \%$ of cerebrovascular disease and $49 \%$ of ischemic heart disease are attributable to non-optimal BP levels. ${ }^{8,9}$ Furthermore, it has become clear that the risk of cardiovascular complications is not confined to subsets of patients with particularly high levels of $\mathrm{BP}$, but rather that the risk occurs in a continuum, affecting even those with below average levels of BP. ${ }^{10,11}$ Also, hypertension often 
coexists with other cardiovascular risk factors, such as tobacco use, diabetes, dyslipidemia and obesity, which add to the cardiovascular risk attributable to hypertension.

High BP is the most prevalent, most important, and best modifiable vascular risk factor for cardio- and cerebrovascular disease in general. Besides BP reduction, the main purpose of antihypertensive treatment is to prevent the concomitant cardiovascular, cerebrovascular and renal complications, to extend longevity, and to improve quality of life. ${ }^{5}$ Treating hypertension substantially reduces the risk of cardiovascular morbidity and death. For instance, pooled data from prospective observational studies showed that a long-term reduction of five to six $\mathrm{mmHg}$ in usual DBP was associated with a 35-40\% risk reduction in stroke, a $20-25 \%$ risk reduction in coronary heart disease, and a $21 \%$ risk reduction in vascular mortality. ${ }^{12}$

Taken together, hypertension is a global, important condition, not only because of its high frequency and concomitant morbidity, but also because it is probably the best treatable vascular risk factor.

\section{Hypertensive target-organ damage}

Hypertension causes structural and functional alterations in the vasculature in general and in target organs such as the heart, kidneys and brain in particular. ${ }^{4,13}$ Although initially these changes are compensatory in nature, they will invariably lead to compromised organ function in patients with untreated or uncontrolled hypertension. Importantly, once organ involvement has developed cardiovascular prognosis worsens. ${ }^{3}$ Moreover, the presence of target-organ damage may also determine the choice for a specific drug or drug combination in the treatment of hypertension. ${ }^{3}$

Current guidelines for the management of hypertension mainly recommend the search for preclinical cardiac and renal damage, i.e., detection of left ventricular hypertrophy $(\mathrm{LVH})$ and microalbuminuria or impaired renal function, respectively. ${ }^{2,3}$ Both conditions have been associated with an increased incidence of cardiovascular complications. ${ }^{14,15}$ The detection of injury to the vasculature by means of measuring arterial stiffness and the presence of vascular hypertrophy or atherosclerosis, has been recognized only recently by some ${ }^{3}$ but not all guidelines. ${ }^{2}$ Cuspidi et al. demonstrated the importance of assessing whether target-organ damage is present or not. They observed a marked change in cardiovascular risk when the presence of LVH and/or vascular damage were taken into consideration: up to $50 \%$ of the hypertensive patients who were initially classified at low-medium risk on routine examinations were found to be at high absolute risk after considering target-organ damage. ${ }^{16}$ Moreover, treatment of hypertension without assessing organ damage may lead to suboptimal BP 
control. $^{3,4}$ For example, according to the current guidelines for the management of arterial hypertension of the European Society of Hypertension (ESH) ${ }^{3}$ a patient with BP levels up to $180 \mathrm{mmHg}$ systolic or $110 \mathrm{mmHg}$ diastolic and one or two coexisting risk factors such as high cholesterol levels or smoking, is classified as having a low to moderate added cardiovascular risk and lifestyle changes are recommended for at least several weeks before starting drug treatment. However, when in the same patient target-organ damage has been detected, antihypertensive treatment should be initiated immediately. In other words, the decision of drug intervention depends for a large part on the presence of targetorgan involvement, particularly in patients with a mild to moderate hypertension (BP levels up to $180 / 110 \mathrm{mmHg}$ ). In view of this, one may question whether the detection of preclinical cardiac and renal damage sufficiently covers the risk associated with hypertension, or leaves a significant number of high-risk patients unnoticed, e.g., because silent damage to other organs such as the brain remains undetected.

Hypertension guidelines only recognize symptomatic stroke or transient ischemic attack (TIA) as markers of established hypertensive organ damage of the brain. ${ }^{2,3}$ Stroke has been associated with a high rate of disability, coexisting morbidity and a high risk of death. ${ }^{17,18}$ About a quarter of stroke patients die within one month, about a third within six months, and about a half are dead by one year, figures illustrating the dramatic course of stroke. ${ }^{18}$ Compared with the general population, stroke patients lose, on average, 8.6 years of life expectancy. ${ }^{19}$ Moreover, in view of the aging population and rising prevalence of hypertension, estimates forecast a continuing increase in the incidence, prevalence and mortality of stroke in the next decades. ${ }^{17,19}$ Therefore, it is important to estimate or predict the risk of future stroke. To this end, risk scores, based on the presence of common cardiovascular risk factors including the level of BP, have been developed. 3,20,21 These risk scores are, however, not without methodological limitations. ${ }^{22}$ With the introduction of neuroimaging techniques, i.e., computed tomography $(\mathrm{CT})$ and later magnetic resonance imaging (MRI), it has become possible to detect cerebrovascular disease already in a preclinical phase.23,24 Several large and prospective, population-based studies demonstrated that silent cerebrovascular disease harbors prognostic relevance, reporting a two to five times higher risk of future stroke in the presence of silent ischemic brain damage. ${ }^{25-27}$ Despite this, hypertension guidelines do not yet recommend the assessment of preclinical cerebrovascular disease to estimate the risk of stroke, next to and in the same way as for instance the presence of LVH is recommended in cardiovascular risk stratification. ${ }^{2,3}$ Furthermore, whether the use of silent cerebrovascular disease as a marker of hypertensive brain involvement, in addition to cardiac and renal risk markers, improves the identification of hypertensive patients most at risk of cardiovascular complications, remains to be investigated. 


\section{Hypertension and the cerebral circulation}

The mechanisms leading to silent cerebrovascular damage are complex and not well understood. Partly, this results from the heterogeneous presentation of brain lesions, which can be present as extensive lesions of chronic ischemia, small, mostly deep infarcts, or small bleedings. Nevertheless, all these changes appear to be caused by a shared, generalized cerebral small-vessel disease (SVD). ${ }^{28}$

Hypertension leads to both functional and structural (adaptive as well as degenerative) changes in the cerebral microvasculature. A variety of small-vessel pathologies have been observed in the hypertensive brain. ${ }^{28}$ Despite this heterogeneity, the main vessel pathology associated with hypertension is a socalled arteriolosclerosis, i.e., hyaline wall thickening with luminal narrowing, and ultimately elongation, tortuosity and rarefaction of small arteries and arterioles. ${ }^{28-30}$ This compromises cerebral perfusion, impairs cerebrovascular function, and initiates blood-brain barrier dysfunction with extravasation of blood or plasma constituents. ${ }^{28,31-33}$

To some degree arteriolosclerosis is seen in most of the aged brains. It begins in the fourth decade, increases in severity with increasing age thereafter, and is exacerbated principally by hypertension. With increasing severity, arteriolosclerosis may be accompanied by other wall abnormalities, such as atherosclerotic changes (microatheroma) and fibrinoid necrosis (lipohyalinosis). ${ }^{28,34}$ Recently, a number of molecular changes, such as endothelial dysfunction, hemostatic activation, and vascular inflammation have been implicated in the pathogenesis of cerebral SVD $^{35-40}$, changes that are also related to hypertension. ${ }^{41}$

Functionally, hypertension impairs cerebrovascular autoregulation, which, in general, compensates for decreases in total cerebral blood flow (CBF) to keep brain perfusion pressure constant. ${ }^{31}$ Autoregulation is effective over a wide range of perfusion pressures with the lower and upper limits estimated to be at the systemic mean arterial pressure (MAP) level of about 60 and $150 \mathrm{mmHg}$, respectively. ${ }^{31}$ In uncomplicated hypertension autoregulation of CBF is preserved, but the limits are shifted towards higher levels of systemic arterial pressure. In other words, the tolerance of the cerebral circulation to increases in BP is improved, but at the expense of an increased risk of cerebral hypoperfusion and subsequent ischemia when systemic BP drops below the lower limit of autoregulation. ${ }^{31,42}$ Moreover, as a consequence of the structural vessel wall changes, which continue to develop as a result of the hypertension, the capacity of the resistance vessels for maximal vasodilatation is reduced, and, hence, the tolerance to decreases in systemic BP is further impaired. ${ }^{31}$ Accordingly, studies found $\mathrm{CBF}$ to be reduced in hypertensive patients as compared to normotensive controls $s^{43,44}$, and a decline in total CBF was associated with increasing severity of silent ischemic brain lesions. ${ }^{45}$ 
Antihypertensive therapy may reverse impaired cerebrovascular function, but probably only in those hypertensive patients with compensatory vessel wall changes (i.e., adaptive muscular hypertrophy). In patients with long-standing or severe hypertension, i.e., those with degenerative vessel wall damage, cerebrovascular function may not improve or only partial. ${ }^{31}$

\section{Hypertension and silent cerebrovascular disease: white matter hyperintensities, silent brain infarcts and brain microbleeds}

By definition, silent cerebrovascular disease occurs in the absence of stroke-like symptoms. The most frequently reported manifestations of silent cerebrovascular damage on MRI associated with hypertension are white matter hyperintensities (WMHs), silent brain infarcts (SBIs), and brain microbleeds (BMBs). ${ }^{46-48}$ In the following paragraphs these silent brain lesions are discussed in more detail.

\section{White matter hyperintensities}

White matter hyperintensities, also referred to as leukoaraiosis (from the Greek words leukos $=$ white, and ariosis $=$ rarefied) or white matter lesions (WMLs) are believed to develop as a result of chronic cerebral hypoperfusion and subsequent ischemia associated with generalized cerebral SVD and impaired cerebrovascular function. ${ }^{49}$ On brain MRI these lesions are reflected as areas of high intensity in the white matter of the brain on T2-weighted and fluid-attenuated inversion recovery (FLAIR) sequences (Figure A.1, Appendix A). Early lesions are small and develop mainly around the frontal and occipital horns of the lateral ventricles, the central cerebrospinal fluid spaces. This so-called periventricular white matter rather than the more distal or deep white matter seems particularly vulnerable as this region is vascularized by long, penetrating end-arteries with a relatively low perfusion pressure, that lack appropriate anastomoses and supply blood to arterial watershed zones. ${ }^{49-51}$ Small periventricular hyperintensities are often found in the elderly, and are believed to reflect the effects of normal ageing. ${ }^{52}$ However, with increasing ischemia, for example in the presence of hypertension, lesions enlarge and extend from the periventricular white matter into the deep white matter, causing large confluent lesions (for an example of such severe WMHs see Figure A.1, Appendix A). ${ }^{53}$ Histopathological studies have demonstrated a parallel increase in severity of ischemic tissue damage, ranging from mild perivascular alterations, i.e., altered fluid dynamics, to large areas with variable loss of fibers, multiple small cavitations indicating tissue loss, and marked arteriolosclerosis of the supplying microvasculature, but without frank infarction. ${ }^{52,54}$ 
On the basis of the differences in vascularization patterns between the periventricular and deep white matter as described above, some investigators distinguished periventricular from deep WMHs. ${ }^{49}$ Studies documenting differences in susceptibility to (vascular) risk factors ${ }^{55,56}$, clinical consequences ${ }^{57}$, and progression rates $^{58}$ between these two WMH subtypes suggest that such a distinction is clinically relevant.

The prevalence of WMHs is relatively high, but varies across different populations and is highly age-dependent. The frequency of any grade of WMHs in otherwise healthy elderly of 55 years of age or older is almost $90 \% .{ }^{59-61}$ Severe lesions, i.e., confluent WMHs involving both the periventricular and deep white matter, are found in about $20-30 \% .60-62$ In the presence of hypertension the frequency of WMHs further increases ${ }^{63}$, partly as a result of interactive effects with age, and possibly also other risk factors, e.g., genetic factors. ${ }^{64,65}$ Importantly, the risk of WMHs is even higher in patients with untreated and poorly controlled hypertension. ${ }^{63,66}$ In hypertensive cohorts, the reported frequencies of WMHs ranged between $12 \%$ and $55 \% .{ }^{67-71}$ However, and apart from differences in risk factor profiles between populations, the use of different and rather crude visual $\mathrm{WMH}$ rating scales, which do not quantify the volume of damage and have limited observer reliability, makes comparison of frequencies across different study populations difficult. ${ }^{72}$

As indicated by the term silent, WMHs initially develop without symptoms. Nevertheless, hyperintensities have been associated with gait disturbances ${ }^{73,74}$, depression ${ }^{75}$, cognitive decline and dementia ${ }^{57,76}$, and an increased risk of future stroke. ${ }^{26,27}$. Furthermore, the available evidence strongly suggests that most of the cognitive and functional consequences observed in hypertensive patients ${ }^{77-79}$ are mediated by the development of WMHs, and account for a substantial part of disability encountered in hypertensive patients. ${ }^{80}$ Hence, the term silent is not undisputed.

\section{Silent brain infarcts}

In addition to WMHs, SBls are the most frequently encountered manifestation of preclinical cerebrovascular disease. A recently published systematic review showed that SBIs are detected in about 20\% (range 8-28\%) of healthy elderly people and in up to $50 \%$ of patients in selected series. ${ }^{47}$ The prevalence of SBIs increases steeply with advancing age. In hypertensive patients, the overall frequency was estimated to be $43 \%$ (range $20-86 \%$ ), supporting the importance of high BP as a risk factor for SBls besides ageing. ${ }^{47}$

The majority of SBls are lacunar infarcts (LACS). ${ }^{81}$ They are located deep in the brain and in the brainstem ${ }^{82}$, and are thought to result from a similar hypertension-related arteriolosclerosis as found in the presence of WMHs. Indeed, SBls and WMHs often occur in concert. ${ }^{83}$ However, in contrast to WMHs, LACs are 
caused by occlusion of single, small, perforating arteries supplying the deep subcortical areas of the brain, leading to local tissue loss and the formation of small lacunae. ${ }^{28,34,84}$ These lacunae, which measure up to 15 to $20 \mathrm{~mm}$ in diameter, are detectable on the same T2-weighted and FLAIR images on which also WMHs are visible (for an example of a LAC see Figure A.2.1, Appendix A). Besides LACs, but less frequently, silent infarcts can occur also in other brain areas, for instance in the cortex or the cerebellum ${ }^{81}$ (for an example see Figure A.2.2, Appendix A).

Similar to WMHs, SBls usually develop without symptoms, but they have been related to functional impairment ${ }^{85,86}$, cognitive decline and dementia ${ }^{87}$, as well as to an increased risk of stroke. ${ }^{25,27}$ It has been calculated that, based on the prevalence and annual risk of symptomatic stroke in subjects with SBIs, more than half of all ischemic strokes annually may be preceded by SBIs. ${ }^{88}$ Notably, the prevalence of SBIs is substantially higher than the estimated three to five percent prevalence of ischemic stroke in both Europe and the United States. ${ }^{89,90}$ Furthermore, exploratory analyses of SBI incidence suggested that over 10 million Americans developed new SBIs in 1998 compared to only 700,000 new ischemic strokes. ${ }^{91}$

\section{Brain microbleeds}

Brain microbleeds are, next to WMHs and SBls, emerging as a potential new marker of silent cerebrovascular damage. These small hemorrhages were described for the first time in the mid-1990s. ${ }^{92}$ Microbleeds are focal accumulations of macrophages that contain hemosiderin, a blood breakdown product, in the perivascular space of small brain vessels. They are indicative of previous extravasation of blood and can be identified as small, punctate $(<5 \mathrm{~mm}$ in diameter) areas of signal loss on haem-sensitive $\mathrm{T} 2{ }^{*}$-weighted gradient echo (GE) MRI (for examples of BMBs see Figure A.3, Appendix A). ${ }^{93}$ Because the hemosiderin-laden macrophages remain in situ, BMBs stay visible for years. ${ }^{24}$ Histopathological studies found evidence of arteriolosclerosis and lipohyalinosis in the deep perforating arteries supplying the areas of the brain harboring microbleeds. ${ }^{93,94}$ This type of cerebral SVD is also referred to as bleeding-prone microangiopathy. ${ }^{93}$

In Caucasian populations, the prevalence of BMBs is about $5 \%$ in healthy, mostly elderly individuals, increases to around $25 \%$ in ischemic stroke patients and goes even beyond $50 \%$ in patients affected by intracerebral hemorrhage; even higher frequencies have been reported in populations of Asian descent. ${ }^{48,95}$ A systematic review recently showed that in the presence of hypertension the risk of BMBs increased almost fourfold. ${ }^{48}$ Currently, no data are available on the frequency of BMBs in hypertensive patients, but one might expect their prevalence to be in between the frequencies observed in healthy elderly and patients with ischemic 
stroke. The presence of BMBs has been associated with cognitive impairment, independent of coexisting ischemic brain damage (i.e., WMHs). ${ }^{96,97}$ Moreover, prospective data suggest that BMBs predict the recurrence of both ischemic and hemorrhagic stroke ${ }^{98-100}$, emphasizing, similarly as WMHs and SBIs, their potential clinical relevance.

\section{Silent cerebrovascular disease and blood pressure}

Although hypertension is the major, modifiable risk factor associated with WMHs, SBIs and BMBs, little is known about the relation between these silent lesions and BP levels per se.

For the diagnosis of hypertension and control of BP-lowering treatment, doctors mainly rely on auscultatory BP measurements, obtained in the office. ${ }^{2,3}$ Nowadays, automated BP measurements, and in particular those in the usual situation outside the hospital (ambulant), are increasingly used in clinical practice. Fully automated ambulatory BP monitoring (ABPM), which measures the BP every 15 to 30 minutes throughout the day and the night, substantially refines the risk stratification provided by conventional office measurements because of the greater number of readings, the absence of digit preference and observer bias, the reduction of the white-coat effect, and the ability to assess the diurnal BP rhythm. ${ }^{101,102}$ Prospective studies have demonstrated that BP obtained by 24-hour ABPM, whether daytime, nighttime or 24-hour, is a strong predictor of cardiovascular complications (including stroke) and death, and is considered to be superior to office pressure. ${ }^{102}$ Moreover, there is growing evidence to support the importance of the BP during the night, and in particular an absent as well as extreme reduction of the usual nocturnal BP (so-called nondipping and extreme dipping, respectively), over and above the daytime BP. ${ }^{103-106}$ In 1988, O'Brien and colleagues were the first to report that hypertensive patients with a nondipping pattern had a significantly higher frequency of stroke, and suggested that nondippers had an additionally increased risk of cerebrovascular disease. ${ }^{107}$ However, the claim that abnormal day-night BP variations are associated with an elevated cardiovascular risk and a worse prognosis ${ }^{108}$ is still controversial, not the least because the dipping status has been found to be poorly reproducible. Moreover, a large number of classifications has been used, and its (additional) prognostic meaning depends on the prevailing 24-hour BP level and treatment status. $^{109}$

Population-based studies reported an increase in the number and extent of SBIs and WMHs with higher BP levels as measured in the office by sphygmomanometry. ${ }^{110-112}$ However, and in spite of the superiority of ambulatory over office BP in terms of cardiovascular risk, relatively few studies have assessed the relation between BP obtained by ABPM and WMHs or SBIs $5^{67,71,113-124}$ Of these 
studies, only three were carried out in hypertensive populations. ${ }^{67,71,123}$ Furthermore, and although subjects displaying BMBs were found to have higher office BP levels 125,126 , so far no study has primarily focused on the BP-microbleed relationship.

Studies using ABPM have shown that besides an increased daytime BP a raised BP during sleep is also associated with severe WMHs and higher frequencies of SBIs. ${ }^{71,113,114,116-118,120,122,124}$ In addition to the nocturnal BP level per se, several studies specifically focused on abnormal day-night BP variations as a possible cause of WMHs and SBls, yielding conflicting results. While most investigators found that an absent BP reduction during sleep was associated with severe WMHs and the presence of SBIs ${ }^{114,117-119,122}$, others failed to find such associations ${ }^{71,113}$, or reported the opposite, i.e., more severe WMLs and more infarcts in the presence of extreme nocturnal BP dips (the so-called J-curved relationship between nocturnal BP dipping and silent cerebrovascular disease). ${ }^{67,106,121}$ The associations with nondipping can be ascribed to the adverse effects of a high nocturnal BP, and hence a high 24-hour BP load, on the cerebral microcirculation as mentioned above. ${ }^{28}$ The relations with extreme dipping have been explained in terms of an increased risk of cerebral hypoperfusion. Because in hypertensive patients the cerebrovascular autoregulation is impaired and the lower limit is shifted towards higher pressure levels, it is possible that marked BP falls, as seen in extreme dipping, lead to an excessive reduction in CBF, which cannot be compensated for. ${ }^{31,127,128}$ In this respect, several investigators have questioned the safety of indiscriminate BP-lowering, particularly in hypertensive patients with (silent) cerebrovascular disease. ${ }^{129-131}$

\section{Summary}

The frequencies of WMHs, SBls and BMBs are high and, importantly, all substantially higher than the estimated prevalence of stroke. This suggests that stroke is just the "tip of the iceberg". Moreover, and despite the heterogeneity in presentation on MRI - WMHs, SBIs and BMBs frequently co-occur, but not necessarily one-on-one - their underlying vascular pathology is quite similar, with high BP besides age being the major determinant. However, the relationship with the BP level per se is complex and not well understood. Finally, the clinical and prognostic implications of these preclinical lesions are now emerging. Hence, the term silent is not without dispute. Therefore, screening of hypertensive patients for silent cerebrovascular damage with brain MRI, besides assessing cardiac and renal damage, may be useful in stratifying the risk of future cardio- and cerebrovascular disease. 


\section{Outline of this thesis}

The general aim of this thesis is to assess the role of silent cerebrovascular disease as a marker of hypertensive organ damage of the brain. The different studies address the relationships between ambulatory measured BP and WMHs, SBIs, and BMBs as markers of hypertension-related silent cerebrovascular disease, focusing specifically on the nocturnal BP. They also consider the role of genetic factors that might influence the susceptibility of the brain to hypertension, and, finally, discuss the clinical relevance of detecting silent cerebrovascular disease in terms of cognitive function and the risk of future cardio- and cerebrovascular complications.

Several lines of evidence suggest that the absence of the usual nocturnal BP decline predicts the risk of future cardiovascular events. However, the reportedly poor reproducibility and a lack of consensus about the definition of nondipping complicate its use as a determinant of cardiovascular risk. Accordingly, Chapter 2 evaluates the effects of different dipping classifications on the extent of the nocturnal BP dip, the classification into dippers and nondippers, and their reproducibility on duplicate ABPMs. The clinical relevance of the different nondipper states, i.e., their association with measures of cardiac and renal targetorgan damage, is discussed as well. The chapters 3 to 5 describe the relationships of circadian BP patterns, i.e., the daytime, nighttime and 24-hour BP levels, and the nocturnal BP dip, with WMHs, SBIs and BMBs. In Chapter 3 we study the dose-effect of ambulatory BP on the volume of WMHs and determine whether there are distinct thresholds in the BP-WMH relationship. Chapter 4 focuses on the differential effects of high BP levels on specific subtypes of SBIs. In Chapter 5 we assess the relationship between ambulatory BP levels and the presence of BMBs. Chapter 6 describes a genetic association study linking polymorphisms of the renin-angiotensin system (RAS) and the endothelial nitric-oxide (NO) synthase (NOS3) with WMHs. Genetic variants of molecular pathways mediating vascular function and morphology might influence the susceptibility of the brain to hypertension. The potential significance of some of these genetic variants is further investigated in Chapter 7 where we relate them to the risk of stroke in a prospective, population-based, case-cohort study in more than 1,500 women. The effects of high BP, ageing, genetic and other (vascular) risk factors ultimately result in vascular changes, for example, arterial stiffening. The study presented in Chapter 8 was undertaken to assess the association between aortic pulse wave velocity, a measure of arterial stiffness, and the presence of WMHs, LACs and BMBs, linking systemic large-vessel disease to cerebral small-vessel disease. To evaluate the clinical relevance of silent cerebrovascular damage in hypertensive patients, we assessed, as described in Chapter 9, the effects of hypertensionrelated WMHs and LACs on several domains of cognitive performance. This is followed, in Chapter 10, by a study investigating whether the detection of WMHs, 
SBls and BMBs, as markers of target-organ damage of the brain, may refine the identification of hypertensive patients most at risk of cardiovascular complications, over and above the currently recommended cardiac and renal risk markers. Finally, in Chapter 11, we summarize our findings, discuss their clinical relevance and speculate on their implications for future research. 


\section{References}

1. Kearney PM, Whelton M, Reynolds K, Muntner P, Whelton PK, He J. Global burden of hypertension: Analysis of worldwide data. Lancet 2005;365:217-23.

2. Chobanian AV, Bakris GL, Black HR, Cushman WC, Green LA, Izzo JL, Jr., Jones DW, Materson BJ, Oparil S, Wright JT, Jr., Roccella EJ. The seventh report of the joint national committee on prevention, detection, evaluation, and treatment of high blood pressure: The JNC 7 report. JAMA 2003;289:2560-72.

3. Mancia G, De Backer G, Dominiczak A, Cifkova R, Fagard R, Germano G, Grassi G, Heagerty AM, Kjeldsen SE, Laurent S, Narkiewicz K, Ruilope L, Rynkiewicz A, Schmieder RE, Boudier HA, Zanchetti A. 2007 guidelines for the management of arterial hypertension: The task force for the management of arterial hypertension of the European Society of Hypertension (ESH) and of the European Society of Cardiology (ESC). J Hypertens 2007;25:1105-87.

4. Mensah GA, Croft JB, Giles WH. The heart, kidney, and brain as target organs in hypertension. Cardiol Clin 2002;20:225-47.

5. Staessen JA, Wang J, Bianchi G, Birkenhager WH. Essential hypertension. Lancet 2003;361: 1629-41.

6. Vasan RS, Larson MG, Leip EP, Kannel WB, Levy D. Assessment of frequency of progression to hypertension in non-hypertensive participants in the Framingham Heart Study: A cohort study. Lancet 2001;358:1682-6.

7. Vasan RS, Beiser A, Seshadri S, Larson MG, Kannel WB, D'Agostino RB, Levy D. Residual lifetime risk for developing hypertension in middle-aged women and men: The Framingham Heart Study. JAMA 2002;287:1003-10.

8. Whitworth JA. 2003 World Health Organization (WHO)/International Society of Hypertension (ISH) statement on management of hypertension. J Hypertens 2003;21:1983-92.

9. Lawes CM, Vander Hoorn S, Law MR, Elliott P, MacMahon S, Rodgers A. Blood pressure and the global burden of disease 2000. Part II: Estimates of attributable burden. J Hypertens 2006;24:423-30.

10. Lewington S, Clarke R, Qizilbash N, Peto R, Collins R. Age-specific relevance of usual blood pressure to vascular mortality: A meta-analysis of individual data for one million adults in 61 prospective studies. Lancet 2002;360:1903-13.

11. MacMahon S, Peto R, Cutler J, Collins R, Sorlie P, Neaton J, Abbott R, Godwin J, Dyer A, Stamler J. Blood pressure, stroke, and coronary heart disease. Part 1, prolonged differences in blood pressure: Prospective observational studies corrected for the regression dilution bias. Lancet 1990;335:765-74.

12. Collins R, Peto R, MacMahon S, Hebert P, Fiebach NH, Eberlein KA, Godwin J, Qizilbash N, Taylor JO, Hennekens $\mathrm{CH}$. Blood pressure, stroke, and coronary heart disease. Part 2, short-term reductions in blood pressure: Overview of randomised drug trials in their epidemiological context. Lancet 1990;335:827-38.

13. Persu A, De Plaen JF. Recent insights in the development of organ damage caused by hypertension. Acta Cardio/2004;59:369-81.

14. Rosa TT, Palatini P. Clinical value of microalbuminuria in hypertension. J Hypertens 2000;18: 645-54.

15. Vakili BA, Okin PM, Devereux RB. Prognostic implications of left ventricular hypertrophy. $A m$ Heart J 2001;141:334-41.

16. Cuspidi C, Ambrosioni E, Mancia G, Pessina AC, Trimarco B, Zanchetti A. Role of echocardiography and carotid ultrasonography in stratifying risk in patients with essential hypertension: The assessment of prognostic risk observational survey. J Hypertens 2002;20: 1307-14.

17. Feigin VL, Lawes CM, Bennett DA, Anderson CS. Stroke epidemiology: A review of populationbased studies of incidence, prevalence, and case-fatality in the late 20th century. Lancet Neurol 2003;2:43-53.

18. Donnan GA, Fisher M, Macleod M, Davis SM. Stroke. Lancet 2008;371:1612-23. 
19. Struijs JN, van Genugten ML, Evers SM, Ament AJ, Baan CA, van den Bos GA. Modeling the future burden of stroke in the Netherlands: Impact of aging, smoking, and hypertension. Stroke 2005;36:1648-55.

20. D'Agostino RB, Wolf PA, Belanger AJ, Kannel WB. Stroke risk profile: Adjustment for antihypertensive medication. The Framingham Study. Stroke 1994;25:40-3.

21. Pocock SJ, McCormack V, Gueyffier F, Boutitie F, Fagard RH, Boissel JP. A score for predicting risk of death from cardiovascular disease in adults with raised blood pressure, based on individual patient data from randomised controlled trials. BMJ 2001;323:75-81.

22. Blacher J, Asmar R, Djane S, London GM, Safar ME. Aortic pulse wave velocity as a marker of cardiovascular risk in hypertensive patients. Hypertension 1999;33:1111-7.

23. Fazekas F, Chawluk JB, Alavi A, Hurtig HI, Zimmerman RA. MR signal abnormalities at $1.5 \mathrm{~T}$ in alzheimer's dementia and normal aging. Am J Roentgeno/ 1987;149:351-6.

24. Roob G, Fazekas F. Magnetic resonance imaging of cerebral microbleeds. Curr Opin Neurol 2000;13:69-73.

25. Bernick C, Kuller L, Dulberg C, Longstreth WT, Jr., Manolio T, Beauchamp N, Price T. Silent MRI infarcts and the risk of future stroke: The Cardiovascular Health Study. Neurology 2001;57: 1222-9.

26. Kuller LH, Longstreth WT, Jr., Arnold AM, Bernick C, Bryan RN, Beauchamp NJ, Jr. White matter hyperintensity on cranial magnetic resonance imaging: A predictor of stroke. Stroke 2004;35:1821-5.

27. Vermeer SE, Hollander M, van Dijk EJ, Hofman A, Koudstaal PJ, Breteler MM. Silent brain infarcts and white matter lesions increase stroke risk in the general population: The Rotterdam Scan Study. Stroke 2003;34:1126-9.

28. Lammie GA. Hypertensive cerebral small vessel disease and stroke. Brain Patho/2002;12:358-70.

29. Brown WR, Moody DM, Challa VR, Thore CR, Anstrom JA. Venous collagenosis and arteriolar tortuosity in leukoaraiosis. J Neuro/ Sci 2002;203-204:159-63.

30. Moody DM, Thore CR, Anstrom JA, Challa VR, Langefeld CD, Brown WR. Quantification of afferent vessels shows reduced brain vascular density in subjects with leukoaraiosis. Radiology 2004;233:883-90.

31. Paulson OB, Waldemar G, Schmidt JF, Strandgaard S. Cerebral circulation under normal and pathologic conditions. Am J Cardio/ 1989;63:2C-5C.

32. Johansson BB. Hypertension mechanisms causing stroke. Clin Exp Pharmacol Physiol 1999;26:563-5.

33. Wardlaw JM, Sandercock PA, Dennis MS, Starr J. Is breakdown of the blood-brain barrier responsible for lacunar stroke, leukoaraiosis, and dementia? Stroke 2003;34:806-12.

34. Fisher CM. The arterial lesions underlying lacunes. Acta Neuropathol (Berl) 1968;12:1-15.

35. Hoshi T, Kitagawa K, Yamagami H, Furukado S, Hougaku H, Hori M. Relations of serum highsensitivity C-reactive protein and interleukin-6 levels with silent brain infarction. Stroke 2005;36:768-72.

36. Hassan A, Hunt BJ, O'Sullivan M, Parmar K, Bamford JM, Briley D, Brown MM, Thomas DJ, Markus HS. Markers of endothelial dysfunction in lacunar infarction and ischaemic leukoaraiosis. Brain 2003;126:424-32.

37. Markus HS, Hunt B, Palmer K, Enzinger C, Schmidt H, Schmidt R. Markers of endothelial and hemostatic activation and progression of cerebral white matter hyperintensities. Longitudinal results of the Austrian Stroke Prevention Study. Stroke 2005;36:1410-4.

38. van Dijk EJ, Prins ND, Vermeer SE, Vrooman HA, Hofman A, Koudstaal PJ, Breteler MM. C-reactive protein and cerebral small-vessel disease: The Rotterdam Scan Study. Circulation 2005;112:900-5.

39. Pretnar-Oblak J, Sabovic M, Pogacnik T, Sebestjen M, Zaletel M. Flow-mediated dilatation and intima-media thickness in patients with lacunar infarctions. Acta Neurol Scand 2006;113:273-7.

40. Pretnar-Oblak J, Zaletel M, Zvan B, Sabovic M, Pogacnik T. Cerebrovascular reactivity to L-arginine in patients with lacunar infarctions. Cerebrovasc Dis 2006;21:180-6.

41. Watson T, Goon PK, Lip GY. Endothelial progenitor cells, endothelial dysfunction, inflammation, and oxidative stress in hypertension. Antioxid Redox Signa/2008;10:1079-88. 
42. Strandgaard S, Paulson OB. Cerebrovascular consequences of hypertension. Lancet 1994;344:519-21.

43. Beason-Held LL, Moghekar A, Zonderman AB, Kraut MA, Resnick SM. Longitudinal changes in cerebral blood flow in the older hypertensive brain. Stroke 2007;38:1766-73.

44. Jennings JR, Muldoon MF, Ryan C, Price JC, Greer P, Sutton-Tyrrell K, van der Veen FM, Meltzer CC. Reduced cerebral blood flow response and compensation among patients with untreated hypertension. Neurology 2005;64:1358-65.

45. ten Dam VH, van den Heuvel DM, de Craen AJ, Bollen EL, Murray HM, Westendorp RG, Blauw GJ, van Buchem MA. Decline in total cerebral blood flow is linked with increase in periventricular but not deep white matter hyperintensities. Radiology 2007;243:198-203.

46. Sierra C. Cerebral white matter lesions in essential hypertension. Curr Hypertens Rep 2001;3:429-33.

47. Vermeer SE, Longstreth WT, Jr., Koudstaal PJ. Silent brain infarcts: A systematic review. Lancet Neuro/ 2007;6:611-9.

48. Cordonnier C, Al-Shahi Salman R, Wardlaw J. Spontaneous brain microbleeds: Systematic review, subgroup analyses and standards for study design and reporting. Brain 2007;130:1988-2003.

49. Pantoni L, Garcia JH. Pathogenesis of leukoaraiosis: A review. Stroke 1997;28:652-9.

50. De Reuck J. The human periventricular arterial blood supply and the anatomy of cerebral infarctions. Eur Neuro/ 1971;5:321-34.

51. Minkner K, Lovblad KO, Yilmaz H, Alimenti A, Sekoranja L, Delavelle J, Sztajzel R, Rufenacht DA. White matter lesions in watershed territories studied with MRI and parenchymography: $A$ comparative study. Neuroradiology 2005;47:425-30.

52. Fazekas F, Kleinert R, Offenbacher $H$, Schmidt R, Kleinert G, Payer F, Radner $H$, Lechner $H$. Pathologic correlates of incidental MRI white matter signal hyperintensities. Neurology 1993;43:1683-9.

53. DeCarli C, Fletcher E, Ramey V, Harvey D, Jagust WJ. Anatomical mapping of white matter hyperintensities (WMH): Exploring the relationships between periventricular $\mathrm{WMH}$, deep $\mathrm{WMH}_{\text {, }}$ and total WMH burden. Stroke 2005;36:50-5.

54. van Swieten JC, van den Hout JH, van Ketel BA, Hijdra A, Wokke JH, van Gijn J. Periventricular lesions in the white matter on magnetic resonance imaging in the elderly. A morphometric correlation with arteriolosclerosis and dilated perivascular spaces. Brain 1991;114:761-74.

55. Lazarus R, Prettyman R, Cherryman G. White matter lesions on magnetic resonance imaging and their relationship with vascular risk factors in memory clinic attenders. Int J Geriatr Psychiatry 2005;20:274-9.

56. Lindgren A, Roijer A, Rudling O, Norrving B, Larsson EM, Eskilsson J, Wallin L, Olsson B, Johansson BB. Cerebral lesions on magnetic resonance imaging, heart disease, and vascular risk factors in subjects without stroke. A population-based study. Stroke 1994;25:929-34.

57. de Groot JC, de Leeuw FE, Oudkerk M, van Gijn J, Hofman A, Jolles J, Breteler MM. Cerebral white matter lesions and cognitive function: The Rotterdam Scan Study. Ann Neurol 2000;47:145-51.

58. Sachdev P, Wen W, Chen X, Brodaty H. Progression of white matter hyperintensities in elderly individuals over 3 years. Neurology 2007;68:214-22.

59. de Leeuw FE, de Groot JC, Achten E, Oudkerk M, Ramos LM, Heijboer R, Hofman A, Jolles J, van Gijn J, Breteler MM. Prevalence of cerebral white matter lesions in elderly people: A population based magnetic resonance imaging study. The Rotterdam Scan Study. J Neurol Neurosurg Psychiatry 2001;70:9-14.

60. Liao D, Cooper L, Cai J, Toole J, Bryan N, Burke G, Shahar E, Nieto J, Mosley T, Heiss G. The prevalence and severity of white matter lesions, their relationship with age, ethnicity, gender, and cardiovascular disease risk factors: The ARIC study. Neuroepidemiology 1997;16:149-62.

61. Longstreth WT, Jr., Manolio TA, Arnold A, Burke GL, Bryan N, Jungreis CA, Enright PL, O'Leary D, Fried L. Clinical correlates of white matter findings on cranial magnetic resonance imaging of 3301 elderly people. The Cardiovascular Health Study. Stroke 1996;27:1274-82. 
62. Breteler MM, van Swieten JC, Bots ML, Grobbee DE, Claus JJ, van den Hout JH, van Harskamp F, Tanghe HL, de Jong PT, van Gijn J, et al. Cerebral white matter lesions, vascular risk factors, and cognitive function in a population-based study: The Rotterdam Study. Neurology 1994;44: 1246-52.

63. de Leeuw FE, de Groot JC, Oudkerk M, Witteman JC, Hofman A, van Gijn J, Breteler MM. Hypertension and cerebral white matter lesions in a prospective cohort study. Brain 2002; $125: 765-72$.

64. Strassburger TL, Lee HC, Daly EM, Szczepanik J, Krasuski JS, Mentis MJ, Salerno JA, DeCarli C, Schapiro MB, Alexander GE. Interactive effects of age and hypertension on volumes of brain structures. Stroke 1997;28:1410-7.

65. de Leeuw FE, Richard F, de Groot JC, van Duijn CM, Hofman A, Van Gijn J, Breteler MM. Interaction between hypertension, apoE, and cerebral white matter lesions. Stroke 2004;35:1057-60.

66. Liao D, Cooper L, Cai J, Toole JF, Bryan NR, Hutchinson RG, Tyroler HA. Presence and severity of cerebral white matter lesions and hypertension, its treatment, and its control. The ARIC study. Atherosclerosis Risk in Communities study. Stroke 1996;27:2262-70.

67. Kario K, Matsuo T, Kobayashi H, Imiya M, Matsuo M, Shimada K. Nocturnal fall of blood pressure and silent cerebrovascular damage in elderly hypertensive patients. Advanced silent cerebrovascular damage in extreme dippers. Hypertension 1996;27:130-5.

68. Kohara K, Jiang Y, Igase M, Takata Y, Fukuoka T, Okura T, Kitami Y, Hiwada K. Postprandial hypotension is associated with asymptomatic cerebrovascular damage in essential hypertensive patients. Hypertension 1999;33:565-8.

69. Kohara K, Zhao B, Jiang Y, Takata Y, Fukuoka T, Igase M, Miki T, Hiwada K. Relation of left ventricular hypertrophy and geometry to asymptomatic cerebrovascular damage in essential hypertension. Am J Cardio/ 1999;83:367-70.

70. Kurata M, Okura T, Watanabe S, Higaki J. Association between carotid hemodynamics and asymptomatic white and gray matter lesions in patients with essential hypertension. Hypertens Res 2005;28:797-803.

71. Sierra C, de La Sierra A, Mercader J, Gomez-Angelats E, Urbano-Marquez A, Coca A. Silent cerebral white matter lesions in middle-aged essential hypertensive patients. J Hypertens 2002;20:519-24.

72. Mantyla R, Erkinjuntti T, Salonen O, Aronen HJ, Peltonen T, Pohjasvaara T, StandertskjoldNordenstam CG. Variable agreement between visual rating scales for white matter hyperintensities on MRI. Comparison of 13 rating scales in a poststroke cohort. Stroke 1997;28:1614-23.

73. Whitman GT, Tang Y, Lin A, Baloh RW. A prospective study of cerebral white matter abnormalities in older people with gait dysfunction. Neurology 2001;57:990-4.

74. Baezner $H$, Blahak C, Poggesi A, Pantoni L, Inzitari D, Chabriat H, Erkinjuntti T, Fazekas F, Ferro JM, Langhorne P, O'Brien J, Scheltens P, Visser MC, Wahlund LO, Waldemar G, Wallin A, Hennerici MG. Association of gait and balance disorders with age-related white matter changes: The LADIS study. Neurology 2008;70:935-42.

75. Krishnan MS, O'Brien JT, Firbank MJ, Pantoni L, Carlucci G, Erkinjuntti T, Wallin A, Wahlund LO, Scheltens P, van Straaten EC, Inzitari D. Relationship between periventricular and deep white matter lesions and depressive symptoms in older people. The LADIS study. Int J Geriatr Psychiatry 2006;21:983-9.

76. Prins ND, van Dijk EJ, den Heijer T, Vermeer SE, Jolles J, Koudstaal PJ, Hofman A, Breteler MM. Cerebral small-vessel disease and decline in information processing speed, executive function and memory. Brain 2005;128:2034-41.

77. Manolio TA, Olson J, Longstreth WT. Hypertension and cognitive function: Pathophysiologic effects of hypertension on the brain. Curr Hypertens Rep 2003;5:255-61.

78. Tzourio C. Hypertension, cognitive decline, and dementia: An epidemiological perspective. Dialogues Clin Neurosci 2007;9:61-70.

79. Cherubini A, Lowenthal DT, Paran E, Mecocci P, Williams LS, Senin U. Hypertension and cognitive function in the elderly. Am J Ther 2007;14:533-54. 
80. Inzitari M, Pozzi C, Rinaldi LA, Masotti G, Marchionni N, Di Bari M. Cognitive and functional impairment in hypertensive brain microangiopathy. J Neurol Sci 2007;257:166-73.

81. Vermeer SE, Koudstaal PJ, Oudkerk M, Hofman A, Breteler MM. Prevalence and risk factors of silent brain infarcts in the population-based Rotterdam Scan Study. Stroke 2002;33:21-5.

82. Boiten J, Lodder J, Kessels F. Two clinically distinct lacunar infarct entities? A hypothesis. Stroke 1993;24:652-6.

83. Longstreth WT, Jr., Diehr P, Manolio TA, Beauchamp NJ, Jungreis CA, Lefkowitz D. Cluster analysis and patterns of findings on cranial magnetic resonance imaging of the elderly: The Cardiovascular Health Study. Arch Neuro/2001;58:635-40.

84. Fisher CM. Lacunes: Small, deep cerebral infarcts. Neurology 1965;15:774-84

85. Boiten J, Lodder J. Lacunar infarcts. Pathogenesis and validity of the clinical syndromes. Stroke 1991;22:1374-8.

86. Gold G, Kovari E, Herrmann FR, Canuto A, Hof PR, Michel JP, Bouras C, Giannakopoulos P. Cognitive consequences of thalamic, basal ganglia, and deep white matter lacunes in brain aging and dementia. Stroke 2005;36:1184-8.

87. Vermeer SE, Prins ND, den Heijer T, Hofman A, Koudstaal PJ, Breteler MM. Silent brain infarcts and the risk of dementia and cognitive decline. N Eng/ J Med 2003;348:1215-22.

88. Prabhakaran S, Wright CB, Yoshita M, Delapaz R, Brown T, DeCarli C, Sacco RL. Prevalence and determinants of subclinical brain infarction: The Northern Manhattan Study. Neurology 2008;70:425-30.

89. Di Carlo A, Launer LJ, Breteler MM, Fratiglioni L, Lobo A, Martinez-Lage J, Schmidt R, Hofman A. Frequency of stroke in Europe: A collaborative study of population-based cohorts. ILSA working group and the neurologic diseases in the elderly research group. Italian Longitudinal Study on Aging. Neurology 2000;54:S28-33.

90. Rosamond W, Flegal K, Furie K, Go A, Greenlund K, Haase N, Hailpern SM, Ho M, Howard V, Kissela B, Kittner S, Lloyd-Jones D, McDermott M, Meigs J, Moy C, Nichol G, O'Donnell C, Roger V, Sorlie P, Steinberger J, Thom T, Wilson M, Hong Y. Heart disease and stroke statistics-2008 update: A report from the American Heart Association statistics committee and stroke statistics subcommittee. Circulation 2008;117:e25-e146.

91. Leary MC, Saver JL. Annual incidence of first silent stroke in the United States: A preliminary estimate. Cerebrovasc Dis 2003;16:280-5.

92. Offenbacher H, Fazekas F, Schmidt R, Koch M, Fazekas G, Kapeller P. MR of cerebral abnormalities concomitant with primary intracerebral hematomas. $A m$ J Neuroradiol 1996; 17:573-8.

93. Fazekas F, Kleinert R, Roob G, Kleinert G, Kapeller P, Schmidt R, Hartung HP. Histopathologic analysis of foci of signal loss on gradient-echo $T 2{ }^{*}$-weighted $M R$ images in patients with spontaneous intracerebral hemorrhage: Evidence of microangiopathy-related microbleeds. $\mathrm{Am} J$ Neuroradiol 1999;20:637-42.

94. Tanaka A, Ueno Y, Nakayama Y, Takano K, Takebayashi S. Small chronic hemorrhages and ischemic lesions in association with spontaneous intracerebral hematomas. Stroke 1999;30:1637-42.

95. Koennecke HC. Cerebral microbleeds on MRI: Prevalence, associations, and potential clinical implications. Neurology 2006;66:165-71.

96. Werring DJ, Frazer DW, Coward LJ, Losseff NA, Watt H, Cipolotti L, Brown MM, Jager HR. Cognitive dysfunction in patients with cerebral microbleeds on T2*-weighted gradient-echo MRI. Brain 2004; $127: 2265-75$.

97. Won Seo S, Hwa Lee B, Kim EJ, Chin J, Sun Cho Y, Yoon U, Na DL. Clinical significance of microbleeds in subcortical vascular dementia. Stroke 2007;38:1949-51.

98. Boulanger JM, Coutts SB, Eliasziw M, Gagnon AJ, Simon JE, Subramaniam S, Sohn CH, Scott J, Demchuk AM. Cerebral microhemorrhages predict new disabling or fatal strokes in patients with acute ischemic stroke or transient ischemic attack. Stroke 2006;37:911-4.

99. Fan YH, Zhang L, Lam WW, Mok VC, Wong KS. Cerebral microbleeds as a risk factor for subsequent intracerebral hemorrhages among patients with acute ischemic stroke. Stroke 2003;34:2459-62. 
100. Jeon SB, Kang DW, Cho AH, Lee EM, Choi CG, Kwon SU, Kim JS. Initial microbleeds at MR imaging can predict recurrent intracerebral hemorrhage. J Neuro/ 2007;254:508-12.

101. Pickering TG, Shimbo D, Haas D. Ambulatory blood-pressure monitoring. N Eng/ J Med 2006;354:2368-74.

102. Staessen JA, Asmar R, De Buyzere M, Imai Y, Parati G, Shimada K, Stergiou G, Redon J, Verdecchia P. Task force II: Blood pressure measurement and cardiovascular outcome. Blood Press Monit 2001;6:355-70.

103. Dolan E, Stanton A, Thijs L, Hinedi K, Atkins N, McClory S, Den Hond E, McCormack P, Staessen JA, O'Brien E. Superiority of ambulatory over clinic blood pressure measurement in predicting mortality: The Dublin outcome study. Hypertension 2005;46:156-61.

104. Staessen JA, Thijs L, Fagard R, O'Brien ET, Clement D, de Leeuw PW, Mancia G, Nachev C, Palatini P, Parati G, Tuomilehto J, Webster J. Predicting cardiovascular risk using conventional vs ambulatory blood pressure in older patients with systolic hypertension. Systolic hypertension in Europe trial investigators. JAMA 1999;282:539-46.

105. Fagard RH, Celis H, Thijs L, Staessen JA, Clement DL, De Buyzere ML, De Bacquer DA. Daytime and nighttime blood pressure as predictors of death and cause-specific cardiovascular events in hypertension. Hypertension 2008;51:55-61.

106. Kario K, Pickering TG, Matsuo T, Hoshide S, Schwartz JE, Shimada K. Stroke prognosis and abnormal nocturnal blood pressure falls in older hypertensives. Hypertension 2001;38:852-7.

107. O'Brien E, Sheridan J, O'Malley K. Dippers and non-dippers. Lancet 1988;2:397.

108. White WB. Ambulatory blood pressure monitoring: Dippers compared with non-dippers. Blood Press Monit 2000;5 Suppl 1:S17-23.

109. Parati G, Staessen JA. Day-night blood pressure variations: Mechanisms, reproducibility and clinical relevance. J Hypertens 2007;25:2377-80.

110. de Leeuw FE, de Groot JC, Oudkerk M, Witteman JC, Hofman A, van Gijn J, Breteler MM. A follow-up study of blood pressure and cerebral white matter lesions. Ann Neurol 1999;46: 827-33.

111. Longstreth WT, Jr., Bernick C, Manolio TA, Bryan N, Jungreis CA, Price TR. Lacunar infarcts defined by magnetic resonance imaging of 3660 elderly people: The Cardiovascular Health Study. Arch Neurol 1998;55:1217-25.

112. Veldink JH, Scheltens P, Jonker C, Launer LJ. Progression of cerebral white matter hyperintensities on MRI is related to diastolic blood pressure. Neurology 1998;51:319-20.

113. Chamorro A, Pujol J, Saiz A, Vila N, Vilanova JC, Alday M, Blanc R. Periventricular white matter lucencies in patients with lacunar stroke. A marker of too high or too low blood pressure? Arch Neuro/ 1997; 54:1284-8.

114. Goldstein IB, Bartzokis G, Hance DB, Shapiro D. Relationship between blood pressure and subcortical lesions in healthy elderly people. Stroke 1998;29:765-72.

115. O'Sullivan C, Duggan J, Lyons S, Thornton J, Lee M, O'Brien E. Hypertensive target-organ damage in the very elderly. Hypertension 2003;42:130-5.

116. Puisieux F, Monaca P, Deplanque D, Delmaire C, di Pompeo C, Monaca C, Leys D, Pruvo JP, Dewailly P. Relationship between leuko-araiosis and blood pressure variability in the elderly. Eur Neuro/2001;46:115-20.

117. Sander D, Winbeck K, Klingelhofer J, Conrad B. Extent of cerebral white matter lesions is related to changes of circadian blood pressure rhythmicity. Arch Neuro/2000;57:1302-7.

118. Schwartz GL, Bailey KR, Mosley T, Knopman DS, Jack CR, Jr., Canzanello VJ, Turner ST. Association of ambulatory blood pressure with ischemic brain injury. Hypertension 2007;49:1228-34.

119. Shimada K, Kawamoto A, Matsubayashi K, Nishinaga M, Kimura S, Ozawa T. Diurnal blood pressure variations and silent cerebrovascular damage in elderly patients with hypertension. J Hypertens 1992;10:875-8.

120. Shimada K, Kawamoto A, Matsubayashi K, Ozawa T. Silent cerebrovascular disease in the elderly. Correlation with ambulatory pressure. Hypertension 1990;16:692-9.

121. Watanabe N, Imai Y, Nagai K, Tsuji I, Satoh H, Sakuma M, Sakuma H, Kato J, Onodera-Kikuchi N, Yamada M, Abe F, Hisamichi S, Abe K. Nocturnal blood pressure and silent cerebrovascular lesions in elderly Japanese. Stroke 1996;27:1319-27. 
122. Yamamoto $Y$, Akiguchi I, Oiwa K, Hayashi M, Kimura J. Adverse effect of nighttime blood pressure on the outcome of lacunar infarct patients. Stroke 1998;29:570-6.

123. Fagher $B$, Valind $S$, Thulin $T$. End-organ damage in treated severe hypertension: Close relation to nocturnal blood pressure. J Hum Hypertens 1995;9:605-10.

124. Kohara K, Igase M, Yinong J, Fukuoka T, Maguchi M, Okura T, Kitami Y, Hiwada K. Asymptomatic cerebrovascular damages in essential hypertension in the elderly. Am J Hypertens 1997; 10:829-35.

125. Roob G, Schmidt R, Kapeller P, Lechner A, Hartung HP, Fazekas F. MRI evidence of past cerebral microbleeds in a healthy elderly population. Neurology 1999;52:991-4.

126. Viswanathan A, Guichard JP, Gschwendtner A, Buffon F, Cumurcuic R, Boutron C, Vicaut E, Holtmannspotter $M$, Pachai $C$, Bousser MG, Dichgans $M$, Chabriat $H$. Blood pressure and haemoglobin $\mathrm{A} 1 \mathrm{C}$ are associated with microhaemorrhage in CADASIL: A two-centre cohort study. Brain 2006;129:2375-83.

127. Shimada K, Kario K. Altered circadian rhythm of blood pressure and cerebrovascular damage. Blood Press Monit 1997;2:333-38.

128. Siennicki-Lantz A, Reinprecht F, Axelsson J, Elmstahl S. Cerebral perfusion in the elderly with nocturnal blood pressure fall. Eur J Neuro/2007;14:715-20.

129. Birns J, Morris R, Donaldson N, Kalra L. The effects of blood pressure reduction on cognitive function: A review of effects based on pooled data from clinical trials. I Hypertens 2006;24:1907-14.

130. Nakamura K, Oita J, Yamaguchi T. Nocturnal blood pressure dip in stroke survivors. A pilot study. Stroke 1995;26:1373-8.

131. Birns J, Markus H, Kalra L. Blood pressure reduction for vascular risk: Is there a price to be paid? Stroke 2005;36:1308-13. 
Different classifications of nocturnal blood pressure dipping affect the prevalence of dippers and nondippers and the relation with target-organ damage

Léon H.G. Henskens

Abraham A. Kroon

Robert J. van Oostenbrugge

Rutger J.P. Haest

Jan Lodder

Peter W. de Leeuw

J Hypertens 2008;26:691-8
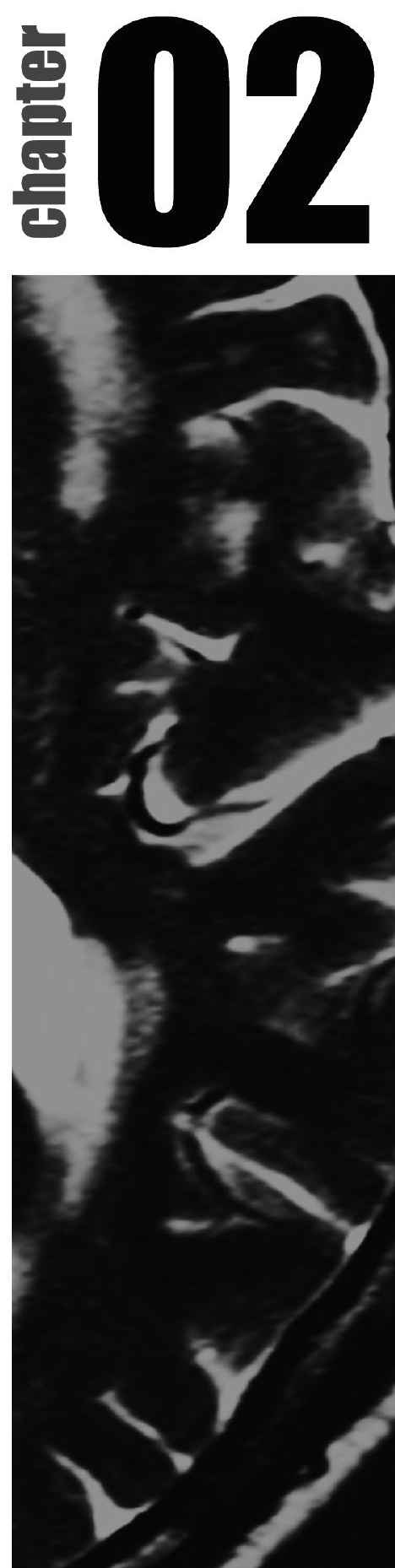


\section{Summary}

We assessed how different definitions of the awake and asleep periods and the use of various blood pressure indices affect the extent of the nocturnal blood pressure dip, the prevalence of dippers and nondippers, their respective reproducibilities and the relation of nondipping with target-organ damage.

We performed 24-hour ambulatory blood pressure monitoring twice and determined left ventricular mass index and urinary albumin excretion as indices of target-organ damage in 150 hypertensive patients (off-medication). Awake and asleep periods were assessed using fixed and diary time methods, covering all readings available (wide) or excluding the morning and evening transition hours (narrow). Nondipping (blood pressure dip <10\%) was established for systolic and diastolic blood pressure, their combinations (and/or), and mean arterial pressure.

The different awake-asleep definitions caused significant variation in both the extent of the blood pressure dip and the number of dippers and nondippers in comparison with the wide diary definition (i.e., use of actual awake and sleep periods). The prevalences of dippers and nondippers also varied significantly by the blood pressure index. Reproducibility analyses of the blood pressure dip and the dipping status yielded repeatability coefficients (expressed as percentages of nearly maximal variation) between $42.39 \%$ and $48.71 \%$, and Kappa values between 0.323 and 0.459 , respectively. Some classifications, but not all, discriminated significantly between consistent dippers and nondippers in terms of left ventricular mass index or urinary albumin excretion.

In conclusion, the use of different definitions of awake-asleep and blood pressure indices affects significantly the classification of nocturnal blood pressure dipping and its relation with hypertensive target-organ damage. 


\section{Introduction}

Prospective studies have demonstrated that blood pressure (BP) obtained by 24-hour ambulatory BP monitoring (ABPM) is a strong predictor of cardiovascular morbidity and mortality. ${ }^{1}$ In terms of prognosis, there is growing evidence to support the importance of BP during sleep, and the blunting or absence of the usual nocturnal BP reduction (so-called nondipping) in particular, over and above the awake BP. 2,3 The claim that nondipping is associated with an elevated cardiovascular risk and a worse prognosis ${ }^{4}$, however, is not undisputed. ${ }^{5}$ This issue has been complicated mainly by observations questioning the reproducibility of the dipping status $5^{6-8}$ and the use of different classifications of nondipping, i.e. various definitions of 'awake' and 'asleep', different threshold values and a variety of BP indices. ${ }^{9-11}$ Nevertheless, ABPM is increasingly being used in clinical practice and recently authorative guidelines recommended its use for the evaluation of the dipping status in hypertensive patients. ${ }^{12}$ Neither researchers nor clinicians, however, reached consensus concerning the definition of nondipping. Moreover, it remains unclear how different classifications affect the reproducibility of the nocturnal BP dip and the clinical relevance of the nondipper status, i.e. its association with target-organ damage. The present study, therefore, aimed to assess how different definitions of awake and asleep and the use of various BP indices affect the extent of the nocturnal BP dip, the prevalence of dippers and nondippers, their respective reproducibilities, and the association of nondipping with left ventricular mass index (LVMI) and urinary albumin excretion (UAE).

\section{Methods}

\section{Participants}

From July 2004 to January 2006, we have asked all patients referred to our outpatient department for the evaluation of their hypertension to participate in this BP monitoring study. As part of the routine work-up, patients underwent ABPM and echocardiography, and collected urine over a 24-hour period. Patients who were using antihypertensive medication were instructed to discontinue treatment at least two weeks prior to the BP measurements. To be eligible for inclusion in the present study, patients had to consent to a second ABPM, preferably within one week after the first routine measurement, and also offmedication. In addition, participants had to fulfill the following criteria: men or women aged 18-90 years; no indication from history-taking, physical examination or routine laboratory tests of secondary hypertension; no evidence of chronic renal failure (serum creatinine concentration $>150 \mu \mathrm{mol} / \mathrm{l}$ ); no diabetes, i.e. the current use of oral antidiabetic drugs or insulin; no clinically documented ischemic 
or valvular heart disease or electrocardiographic evidence of atrial fibrillation; no history of transient ischemic attacks and ischemic or hemorrhagic stroke; no diagnosis of obstructive sleep apnea syndrome.

All participants gave written informed consent and the Medical Ethics Committee of the Maastricht University Medical Centre approved the study.

\section{Evaluation of blood pressure}

Conventional clinic BP (CBP) was measured at the hospital by sphygmomanometry (Korotkoff phases I and V). After at least five minutes of rest, three consecutive measurements were taken at the non-dominant arm, with the participant seated, and always by the same investigator (L.H.). Heart rate was obtained by palpation of the radial artery.

Hypertension was defined as an untreated conventional CBP $\geq 140 \mathrm{mmHg}$ systolic or $\geq 90 \mathrm{mmHg}$ diastolic, or both. In addition, apparent hypertension was graded as mild, moderate or severe according to the current guidelines of the European Society of Hypertension. ${ }^{13}$

Ambulatory BP was monitored non-invasively on two occasions over a 24-hour period using an oscillometric SpaceLabs 90207 or 90217 device (SpaceLabs Medical Inc., Redmond, Washington, USA). Both monitors were programmed to obtain BP recordings every 15 minutes from 0700 to 2300 hours and every 30 minutes thereafter, and set to reject automatically readings with an SBP $>240$ or $<70 \mathrm{mmHg}$, a DBP $>150$ or $<40 \mathrm{mmHg}$, a mean arterial pressure (MAP) >200 or $<40 \mathrm{mmHg}$ or a heart rate $>200$ or $<20$ beats per minute. ${ }^{14}$ Blood pressure was recorded at the non-dominant arm using an appropriately sized cuff. Monitoring sessions started at the hospital, always on a weekday and preferably in the morning. We encouraged participants to adhere to their usual daily activities and regular sleeping hours, but instructed them to keep their arm and fingers motionless during a recording. Furthermore, they completed a diary card documenting their actual awake and asleep times.

Spacelabs data files were transferred to a Windows-based PC system and analyzed using the Pressure Import and Export software version 1.3.0. (Instrument Development Engineering and Evaluation (IDEE), Maastricht University, 2005; http://www-id.unimaas.nl). Data files were not edited manually, as this can substantially affect the diurnal BP rhythm and ABPM reproducibility. ${ }^{14}$

Participant's awake (or daytime) and asleep (or nighttime) periods were determined according to the following definitions (Figure 2.1): (1) wide fixed time method (WF), which defines daytime from 0700 to 2300 hours and nighttime from 2300 to 0700 hours; (2) narrow fixed time method (NF), defining daytime from 0900 to 2100 hours and nighttime from 0100 to 0600 hours (NF-1) ${ }^{13}$, or defining daytime from 1000 to 2000 hours and nighttime from 0000 to 0600 hours (NF-2). ${ }^{15}$ Narrow fixed time methods eliminate the morning and evening 
transition hours during which BP shows considerable variation; (3) wide diary time method (WD), assessing the actual awake and asleep periods from the diary card entries; (4) narrow diary time method (ND), which assesses the awake and asleep periods by excluding a 2-hour transition period around the reported rising and retiring times.

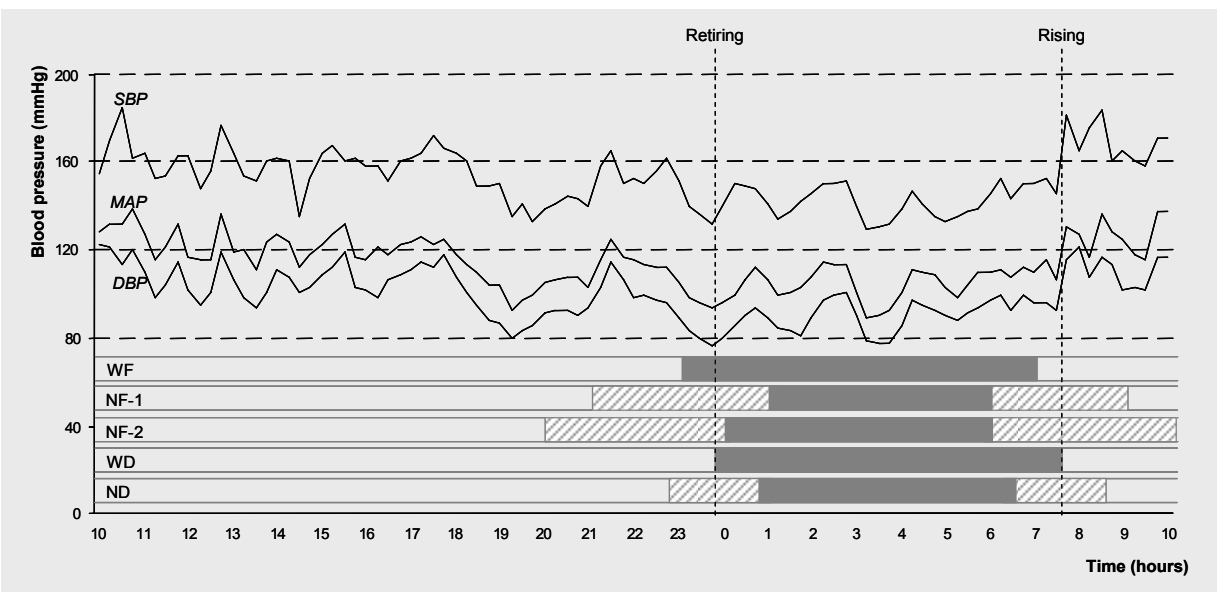

Figure 2.1 Definition of awake (daytime) and asleep (nighttime) periods.

$\mathrm{SBP}$ indicates systolic blood pressure (BP); DBP, diastolic BP; MAP, mean arterial pressure; $W F$, wide fixed time method; NF, narrow fixed time method; WD, wide diary time method; ND, narrow diary time method.

On the basis of these four definitions, the nocturnal BP dip was quantified as the relative decline in mean $\mathrm{BP}$ from awake (daytime) to asleep (nighttime) periods and calculated for SBP, DBP and MAP separately using the following equation: ((mean awake BP - mean asleep BP) / mean awake BP) x 100\%. Dipping status, defining nondipping as a nocturnal BP dip $<10 \%{ }^{16}$, was assessed for SBP, DBP, the combinations of SBP-and-DBP and SBP-or-DBP, as well as for MAP.

\section{Evaluation of the heart}

The left ventricular (LV) mass, assessed by two-dimensional M-mode and Doppler echocardiography (Sonos 5500, Hewlett-Packard, Andover, MA), was estimated by a team of four cardiologists (as part of the routine investigations) according to Devereux's formula (Penn convention) ${ }^{17}$ and indexed to body surface area. ${ }^{18}$ The LV dimensions and wall thicknesses were measured according to current recommendations. ${ }^{19}$ A fifth cardiologist, not involved in the routine assessments and blinded to the participants' clinical status, re-analyzed 30 randomly selected echocardiograms (which included echo's of all four cardiologists) to evaluate the 
intra- and inter-rater agreement of the LVMI assessment by calculating intraclass correlation coefficients (ICCS). ${ }^{20}$

\section{Evaluation of the kidneys}

The UAE was measured in a timed 24-hour urine collection by means of nephelometry (BN ProSpec ${ }^{\circledR}$ System, Dade Behring Inc.), with a detection limit of $2.2 \mathrm{mg} / \mathrm{l}$. In our laboratory, intra- and inter-assay coefficients of variation are $<7.0 \%$. In a random sample of 30 participants we repeated the 24-hour urine collection (i.e., 48-hour collection period) to evaluate the within-subject reproducibility by calculating the coefficient of repeatability according to Bland and Altman (for detailed statistical explanation see below). ${ }^{21}$

\section{Statistical analysis}

Using the WD definition as reference (i.e., the actual awake and asleep BP) ${ }^{22}$, we tested whether differences in relative nocturnal BP dip or proportions of dippers and nondippers according to the other definitions of awake-asleep were statistically significant. For that purpose, the paired-samples $t$-test or McNemar's test for correlated proportions was applied. The same approach was followed with regard to the different BP indices, using the SBP-and-DBP index as reference. ${ }^{16}$

We assessed the reproducibility of the relative nocturnal BP dip according to Bland and Altman by calculating coefficients of repeatability, defined as twice the standard deviation (SD) of the differences between the duplicate recordings. ${ }^{21}$ For comparison of the reproducibility of the different awake-asleep definitions, the repeatability coefficients were expressed as a percentage of the nearly maximal variation, calculated as four times the SD of the average of the two recordings. ${ }^{23}$ High repeatability coefficients and high percentages of nearly maximal variation indicate considerable variation between the repeated recordings, reflecting lower reproducibility. To determine the reproducibility of the dipping status we investigated the number of participants who confirmed their initial classification on the second ABPM, assigning them as consistent dippers or consistent nondippers, or as variable dipper/nondippers. ${ }^{8}$ Kappa statistics were applied to evaluate the consistency of this classification. ${ }^{24}$ Kappa values below 0.40 signify poor, 0.40 to 0.59 signify moderate, 0.60 to 0.79 signify substantial, and values above 0.80 signify outstanding reproducibility.

To assess how the different awake-asleep definitions and BP indices affected the relation between nocturnal BP dipping and LVMI, we performed one-way analysis of variance (ANOVA) to test for significant differences in LVMI between consistent dippers, variable dippers/nondippers and consistent nondippers. This was done on the assumption that significant results indicate those combinations of awakeasleep definitions and BP indices that classify dippers and nondippers most 
accurately. The same approach was used to investigate the relation between the dipping status and UAE.

Normally distributed variables are presented as mean \pm SD, variables with skewed distributions as median (interquartile range) or as the geometric mean $\pm \mathrm{SD}$, and categorical variables as frequencies. A two-tailed probability value $<0.05$ was considered statistically significant. Analyses were performed using the statistical software packages SPSS (version 11.5 for Windows; SPSS Inc., Chicago, Illinois, USA) and Prism (version 4.00 for Windows; GraphPad Software Inc., San Diego, California, USA).

\section{Results}

\section{Study population}

We included 157 patients into the study. The ambulatory BP recordings of seven patients were not suited for analysis because 30\% or more of the expected number of readings were not available ${ }^{13}$, the entire recording period covered less than 20 hours $^{25}$ or there were no valid measurements in any 2-hour period ${ }^{15}$. In the remaining 150 participants, monitoring sessions were repeated with a median interval of seven days (range 2-28 days). Echocardiographic examinations were technically satisfactory for 143 subjects and data on UAE were available in 140 participants. The characteristics of the study population are summarized in Table 2.1.

Table 2.1 Characteristics of the study population.

\begin{tabular}{|c|c|}
\hline Characteristics & Data \\
\hline $\begin{array}{l}\text { Sex, male } \\
\text { Age, years } \\
\text { Weight, kg } \\
\text { BMI, kg/m² } \\
\text { Conventional CBP systolic, mmHg } \\
\text { Conventional CBP diastolic, mmHg } \\
\text { Heart rate, bpm } \\
\text { BP classification: } \\
\text { Normotension } \\
\text { Grade } 1 \text { hypertension (mild) } \\
\text { Grade } 2 \text { hypertension (moderate) } \\
\text { Grade } 3 \text { hypertension (severe) } \\
\text { LVMI, g/m² } \\
\text { UAE, mg/24 h }\end{array}$ & $\begin{array}{c}74(49.3) \\
52.2 \pm 11.7 \\
82.1 \pm 16.3 \\
28.0(25.3-30.4) \\
168 \pm 23 \\
104 \pm 12 \\
75 \pm 11 \\
9(6.0) \\
29(19.3) \\
48(32.0) \\
64(42.7) \\
86.1 \pm 19.7 \\
12.6(7.9-22.3)\end{array}$ \\
\hline
\end{tabular}




\section{Relative nocturnal blood pressure dip}

The effects of the various awake-asleep definitions on the relative nocturnal SBP, DBP and MAP dip are summarized in Table 2.2. The WF definition significantly underestimated the actual nocturnal BP dip (i.e., as compared to the WD definition), whereas this was overestimated significantly by the other definitions. Differences in the BP dip between the first and second ABPM were small and not statistically significant. Reproducibility analyses yielded coefficients of repeatability (expressed as percentages of nearly maximal variation) between $42.4 \%$ and $48.7 \%$. Coefficients appeared lowest when applying diary time methods and the SBP as BP index, signifying higher reproducibility.

Table 2.2 The relative nocturnal blood pressure dip according to the various definitions of awakeasleep $(n=150)$.

\begin{tabular}{|c|c|c|c|c|c|c|c|}
\hline \multirow[b]{2}{*}{ Definition } & \multirow[b]{2}{*}{ BP index } & \multicolumn{2}{|c|}{ Relative nocturnal BP dip } & \multicolumn{2}{|c|}{ Difference versus WD definition ${ }^{a}$} & \multicolumn{2}{|c|}{ Reproducibility } \\
\hline & & ABPM 1 & $\mathrm{ABPM} 2^{\mathrm{b}}$ & ABPM 1 & ABPM2 & CR (\%) & NMV (\%) \\
\hline \multirow[t]{3}{*}{ WD } & SBP & $14.24 \pm 7.04$ & $14.56 \pm 6.48$ & reference & reference & 10.57 & 42.39 \\
\hline & DBP & $17.35 \pm 7.24$ & $17.26 \pm 7.00$ & reference & reference & 11.75 & 45.39 \\
\hline & MAP & $15.98 \pm 6.93$ & $16.08 \pm 6.59$ & reference & reference & 10.77 & 43.32 \\
\hline \multirow[t]{3}{*}{ WF } & SBP & $12.84 \pm 7.20$ & $13.10 \pm 6.36$ & $-1.40 \pm 3.12^{\mathrm{e}}$ & $-1.46 \pm 3.19^{e}$ & 10.98 & 43.87 \\
\hline & DBP & $15.68 \pm 7.80$ & $15.72 \pm 7.04$ & $-1.67 \pm 4.05^{e}$ & $-1.54 \pm 3.48^{e}$ & 12.50 & 46.40 \\
\hline & MAP & $14.44 \pm 7.36$ & $14.58 \pm 6.55$ & $-1.54 \pm 3.57^{e}$ & $-1.50 \pm 3.27^{e}$ & 11.21 & 43.96 \\
\hline \multirow[t]{3}{*}{ NF-1 } & SBP & $15.17 \pm 8.44$ & $16.05 \pm 7.62$ & $0.93 \pm 3.37^{d}$ & $1.49 \pm 3.18^{e}$ & 13.08 & 44.46 \\
\hline & DBP & $18.24 \pm 9.13$ & $18.69 \pm 8.27$ & $0.89 \pm 4.13^{d}$ & $1.43 \pm 3.50^{\mathrm{e}}$ & 15.00 & 47.76 \\
\hline & MAP & $16.91 \pm 8.57$ & $17.54 \pm 7.76$ & $0.92 \pm 3.69^{d}$ & $1.46 \pm 3.20^{e}$ & 13.55 & 45.50 \\
\hline \multirow[t]{3}{*}{ NF-2 } & SBP & $14.69 \pm 8.55$ & $15.44 \pm 7.54$ & $0.45 \pm 3.66$ & $0.88 \pm 3.40^{d}$ & 13.45 & 45.88 \\
\hline & DBP & $18.14 \pm 9.24$ & $18.41 \pm 8.16$ & $0.78 \pm 4.45^{c}$ & $1.15 \pm 3.74^{e}$ & 15.27 & 48.71 \\
\hline & MAP & $16.63 \pm 8.68$ & $17.11 \pm 7.67$ & $0.65 \pm 4.01^{c}$ & $1.03 \pm 3.47^{e}$ & 13.79 & 46.37 \\
\hline \multirow[t]{3}{*}{ ND } & SBP & $15.53 \pm 7.94$ & $16.05 \pm 7.09$ & $1.29 \pm 1.69^{e}$ & $1.49 \pm 1.84^{\mathrm{e}}$ & 11.81 & 42.65 \\
\hline & DBP & $18.77 \pm 8.37$ & $18.77 \pm 7.48$ & $1.42 \pm 2.02^{\mathrm{e}}$ & $1.51 \pm 2.06^{e}$ & 13.28 & 46.15 \\
\hline & MAP & $17.36 \pm 7.94$ & $17.59 \pm 7.10$ & $1.38 \pm 1.78^{e}$ & $1.51 \pm 1.86^{e}$ & 11.89 & 43.08 \\
\hline
\end{tabular}

Data are presented as mean \pm SD or percentages. BP indicates blood pressure; ABPM, ambulatory BP monitoring; WD, wide diary time method; WF, wide fixed time method; NF-1, narrow fixed time method, daytime from 0900 to 2100 and night time from 0100 to 0600 hours; NF-2, narrow fixed time method, daytime from 1000 to 2000 and night time from 0000 to 0600 hours; ND, narrow diary time method; SBP, systolic BP; DBP, diastolic BP; MAP, mean arterial pressure; CR, coefficient of repeatability; NMV, nearly maximal variation.

a The signed difference in relative nocturnal BP dip between the definitions of awake-asleep, using the WD method as reference; ${ }^{b}$ All definitions $P>0.05$ versus ABPM 1 (paired-samples $t$-test).

c $P<0.05$, d $P<0.01,{ }^{\text {e }} P<0.001$ versus the relative nocturnal $B P$ dip of the WD definition (pairedsamples $t$-test). 


\section{Dipping status}

Table 2.3 presents the frequencies of dippers and nondippers on the first and second ABPM. The wide fixed variant, in keeping with the underestimated actual nocturnal BP dip, more frequently classified participants as nondippers than the WD definition. The NF time definitions yielded equal results, and the narrow diary variant tended towards lower frequencies of nondippers. The number of dippers and nondippers also varied according to the BP index chosen. Both the SBP-or-DBP combination and the SBP overestimated significantly the prevalence of nondippers in comparison with the SBP-and-DBP combination, whereas the DBP, and in most instances also the MAP, yielded similar proportions of dippers and nondippers.

The Kappa values indicated poor to moderate reproducibility of the dipping status, regardless of the awake-asleep definitions or BP indices used (Table 2.3). Table 2.4 summarizes the consistency of dipping classifications. Overall, at least $70 \%$ of the participants reproduced their initial dipping classification. However, the nondipper status was less reproducible (range according to classifications, $36.8 \%$ to $59.4 \%$ ) than the dipper status (range, $80.9 \%$ to $94.7 \%$ ).

\section{Associations with the left ventricular mass index and urinary albumin excretion}

For the LVMI, the agreement analyses yielded intra- and inter-rater ICCS of 0.90 and 0.87 , respectively; interpretation of ICCS is similar to kappa. ${ }^{24}$ For UAE, the within-subject reproducibility was $19.1 \%$ (repeatability coefficient, expressed as a percentage of nearly maximal variation).

Table 2.5 and Table 2.6 display the relation between the dipping status (consistent dippers - variable dippers/nondippers - consistent nondippers) and $L V M I$ and $U A E$, respectively. Significant results indicate those combinations of awake-asleep definitions and BP indices that discriminate most accurately between consistent dippers and consistent nondippers in terms of LVMI and UAE. 


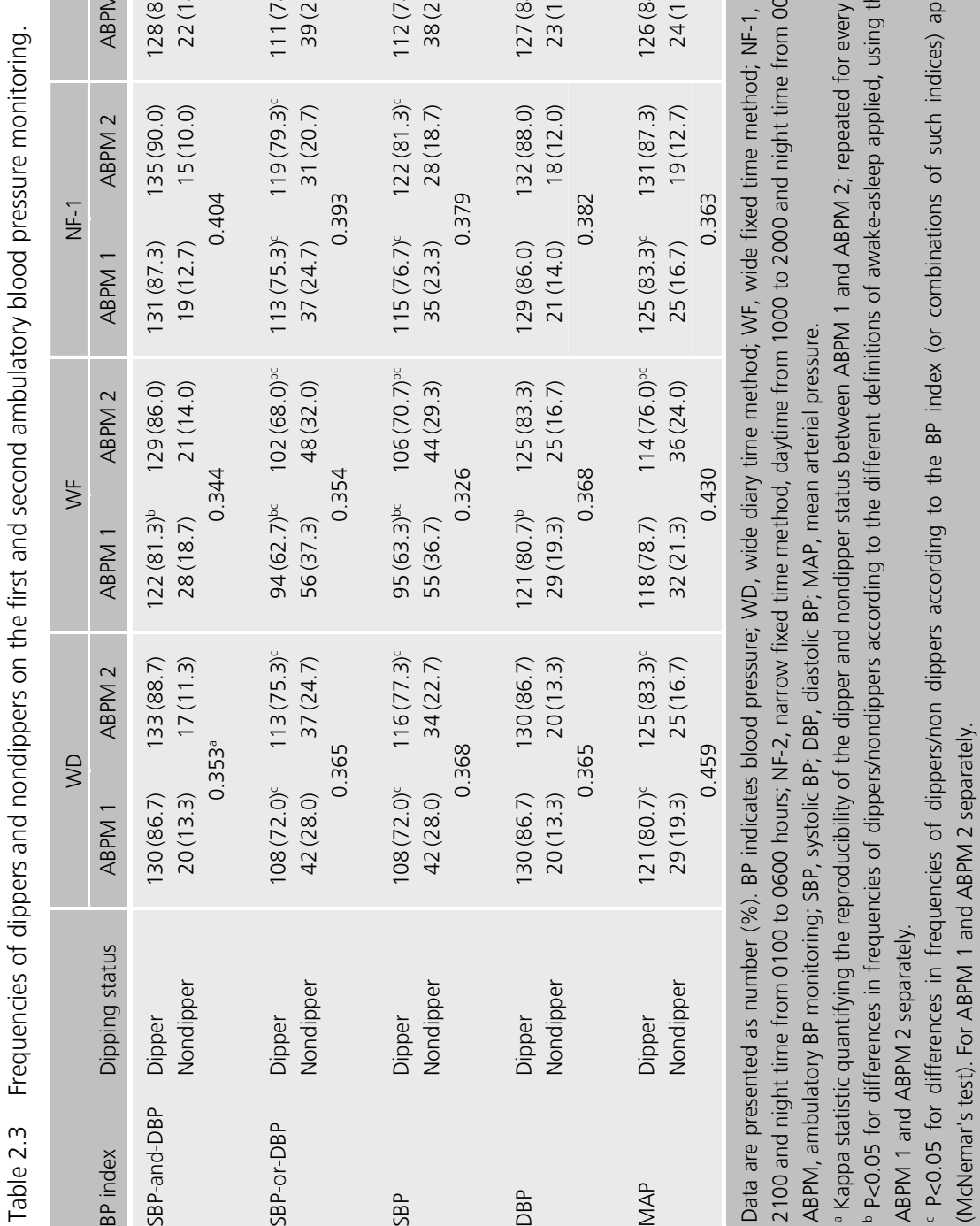

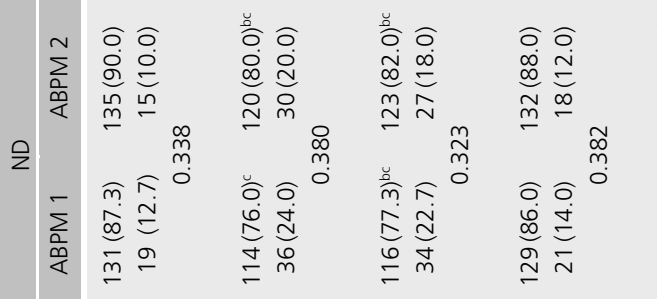

$\stackrel{\bar{n}}{\mathrm{~m}}$

$\infty$

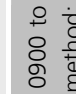

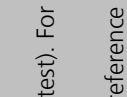

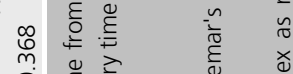

กิ

है $\frac{\pi}{0}$

$\underset{\infty}{\infty} \stackrel{\sim}{=}$

స

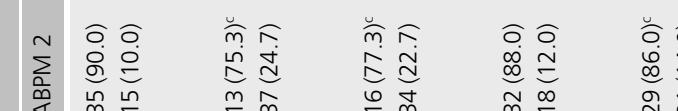

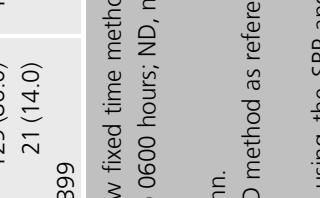

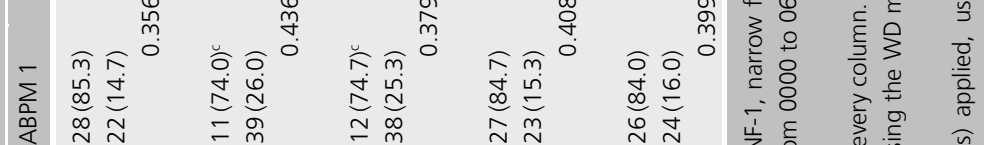




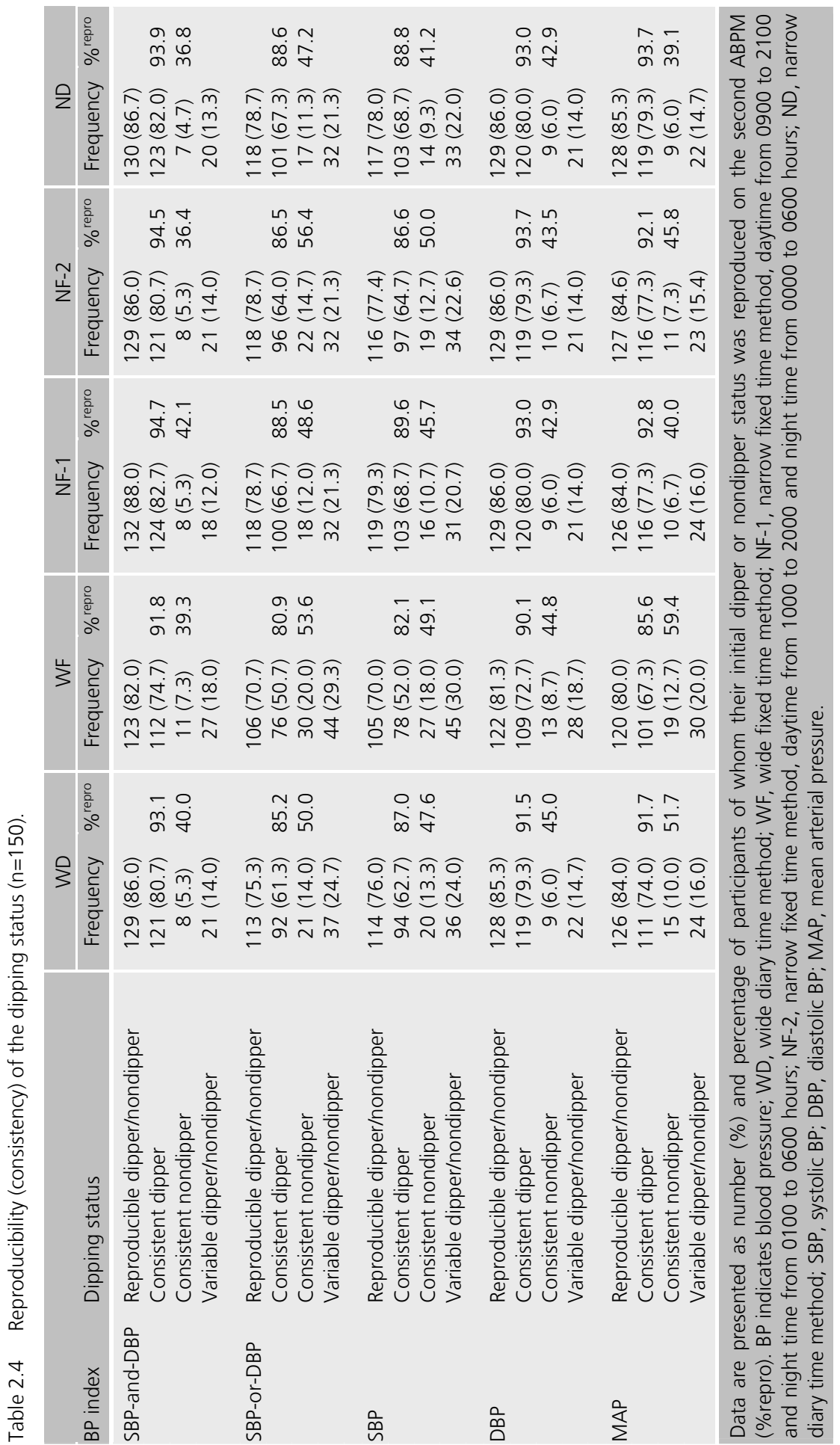




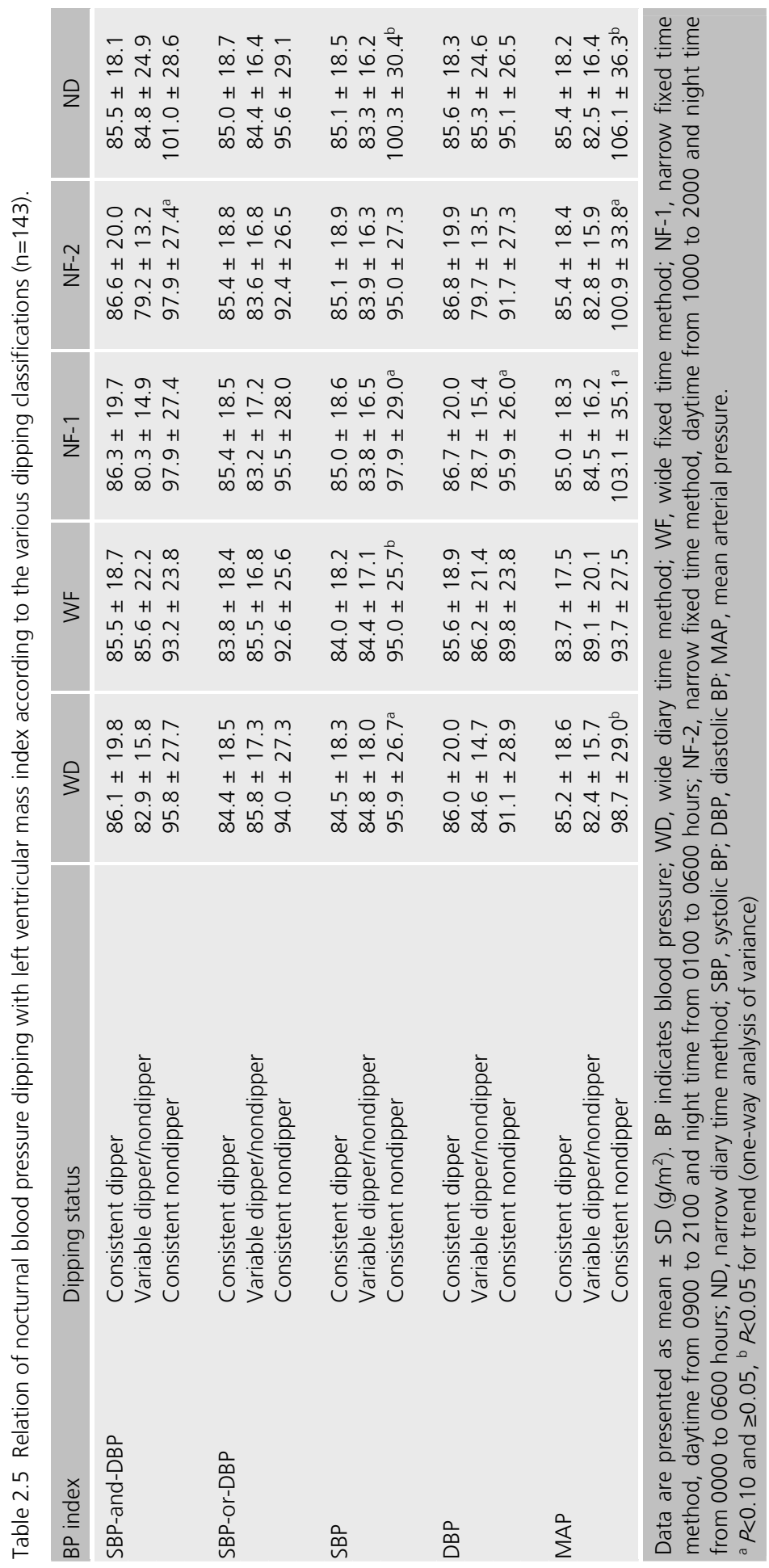




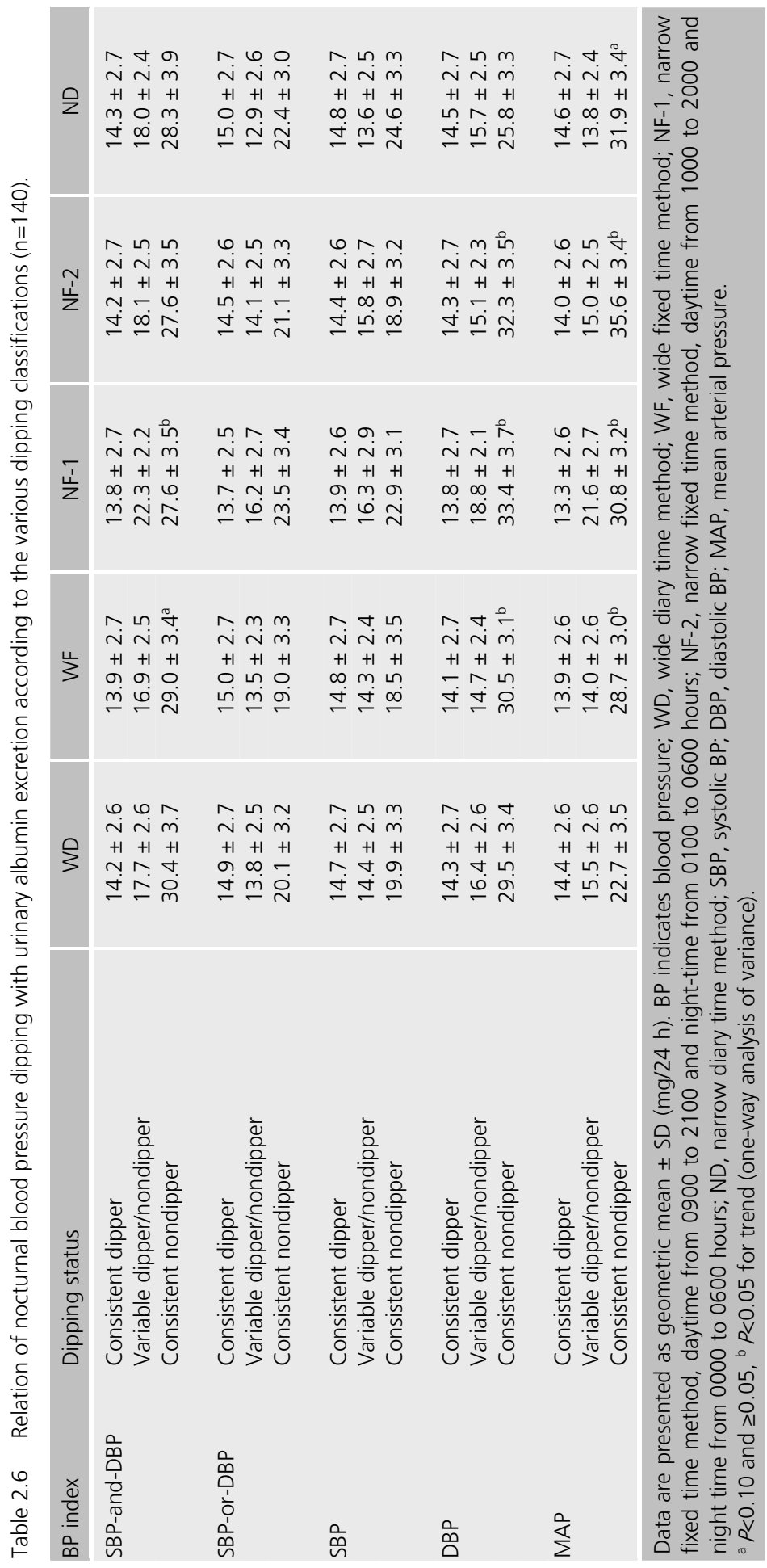




\section{Discussion}

This study demonstrates that the use of different definitions of awake-asleep and BP indices significantly affects the classification of nocturnal BP dipping and its relation with hypertensive target-organ damage.

Previously, several studies evaluated the reproducibility of nocturnal BP dipping, but none of them compared the data of different classifications. ${ }^{6-8,23,26-35}$ Taken together, the results of these studies indicate that, comparable to our findings, the repeatability of the nocturnal BP dip is about $50 \%$ of nearly maximal variation, ranging from 36 to $72 \%$ depending on the awake-asleep definition and BP-index chosen. 8,23,26,29-31,33,34

The reproducibility of dippers and nondippers varied in a similar way, being reproducible in 35 to $85 \%$ of the studied populations. . $^{6-8,26-28,32,35}$ Nevertheless, the repeatability of the relative nocturnal $B P$ dip is reportedly less than that of the mean awake, asleep and 24-hour BP. For these BP indices the nearly maximal variation is about 20\% lower, independent of the classification applied. $23,29,31,33,34$

Our observations support the notion that the WF method is inappropriate to determine the awake and asleep periods. Wide fixed time methods are reliable only when subjects rise and retire within predefined periods ${ }^{15}$, overestimate the actual nighttime BP, and as our data also showed, underestimate the related nocturnal BP decline and increase the number of subjects who are being (mis)classified as nondipper. ${ }^{15,36,37}$ Narrow fixed time methods, on the other hand, approximate the actual awake and asleep BP by excluding the morning and evening transition hours. ${ }^{37}$ Accordingly, both NF methods yielded proportions of dippers and nondippers comparable to those of the WD definition, in spite of the overestimated actual nocturnal BP dip. This provides further evidence in favor of the NF method as a practical definition of the awake and asleep BP. ${ }^{10}$ Other advantages are that the NF definition can be applied without the disruption of a person's regular sleeping hours, and that it is easy to use in contrast to the rather time-consuming wide and narrow diary methods. ${ }^{10}$

Few studies have investigated the impact of the BP index on the classification of nocturnal BP dipping. In keeping with some of these studies we found the systolic BP dip to be more reproducible than the diastolic dip.,26,34 Other studies, however, showed no difference or reported the opposite. ${ }^{23,29,31}$ Furthermore, our data show that the choice of the BP index can significantly influence the proportions of dippers and nondippers. Stenehjem et al., investigating the same $\mathrm{BP}$ indices as we did, observed a similar variation in the reproducibility of the dipping status. ${ }^{32}$ While these investigators found the SBP-or-DBP combination to be most reproducible, we noted the highest numbers of reproducible dippers and nondippers with the use of the SBP-and-DBP index. The use of different ambulatory BP monitors - they used an auscultatory device - may account for this 
discrepancy. Yet, the optimal BP index, taking into account the measurement technique, remains to be determined.

An important observation in the present study is that the nondipper status was less reproducible than the dipper status, regardless of the awake-asleep definition or BP index used. Apparently, it is more difficult to ascertain nondipping than dipping. ${ }^{38}$ This may also explain the poor overall reproducibility of the dipping status.

Considering the good reproducibility of dippers, one might hypothesize that a person who dips more than $10 \%$ on the initial ABPM is a real dipper; in this subject nondipping will occur only occasionally, for instance due to a disturbed sleep. Nondippers, however, have a chance of at least $40 \%$ to dip more than $10 \%$ on a next monitoring session; they failed to dip by occasion on the first ABPM. Consequently, being a nondipper on two occasions increases the probability of being a real nondipper. The fact that variable dippers/nondippers and consistent dippers yielded a comparable amount of LVMI and UAE for most of the classifications supports this notion. This is consistent with previous observations that defining nondipping on the basis of a single ABPM is less reliable. 6,28 Therefore, we propose that persons who display a nondipping pattern on a first ABPM should always be re-monitored. Whether dippers need a reexamination may depend on the magnitude of the BP dip; for instance, one may decide to re-examine a borderline dipper more quickly than an extreme dipper.

Finally, some but not all combinations of awake-asleep definitions and BP indices yielded classifications that discriminated significantly between consistent dippers and nondippers in terms of LVMI or UAE. Although in the present study the interrater agreement of the LVMI assessments was good, we cannot rule out that some heterogeneity, introduced as a result of several observers, might have influenced our findings. Similarly, the relation between nocturnal BP dipping and UAE could have been influenced as a consequence of incorrectly timed urine collections, despite acceptable repeatability of UAE measurements. On the other hand, as we have compared various dipping classifications in a single group of subjects, we believe that the relative differences in LVMI or UAE between classifications depend on the awake-asleep definitions and BP indices used, rather than on the target-organ measures. This once more demonstrates the variation caused by the classification chosen and may explain, at least in part, the contradicting results from studies concerning the clinical relevance of the nondipping phenomenon. ${ }^{39}$ 
In conclusion, the classification of nocturnal BP dipping and its relation with hypertensive target-organ damage depend on both the definition of the awake and asleep periods and the BP index (or combinations of such indices) used. Narrow fixed time methods seem most practical to determine daytime and nighttime periods, whereas the optimal BP index remains to be determined. Nevertheless, nocturnal BP dipping is a poorly reproducible phenomenon, irrespective of the classification used. 


\section{References}

1. Staessen JA, Asmar R, De Buyzere M, Imai Y, Parati G, Shimada K, Stergiou G, Redon J, Verdecchia P. Task force II: Blood pressure measurement and cardiovascular outcome. Blood Press Monit 2001;6:355-70.

2. Dolan E, Stanton A, Thijs L, Hinedi K, Atkins N, McClory S, Den Hond E, McCormack P, Staessen JA, O'Brien E. Superiority of ambulatory over clinic blood pressure measurement in predicting mortality: The dublin outcome study. Hypertension 2005;46:156-61.

3. Staessen JA, Thijs L, Fagard R, O'Brien ET, Clement D, de Leeuw PW, Mancia G, Nachev C, Palatini P, Parati G, Tuomilehto J, Webster J. Predicting cardiovascular risk using conventional vs ambulatory blood pressure in older patients with systolic hypertension. Systolic hypertension in Europe trial investigators. JAMA 1999;282:539-46.

4. White WB. Ambulatory blood pressure monitoring: Dippers compared with nondippers. Blood Press Monit 2000;5 Suppl 1:S17-23.

5. Fagard R, Staessen JA, Thijs $L$. The relationships between left ventricular mass and daytime and nighttime blood pressures: A meta-analysis of comparative studies. J Hypertens 1995;13:823-9.

6. Manning G, Rushton L, Donnelly R, Millar-Craig MW. Variability of diurnal changes in ambulatory blood pressure and nocturnal dipping status in untreated hypertensive and normotensive subjects. Am J Hypertens 2000;13:1035-8.

7. Mochizuki Y, Okutani M, Donfeng Y, Iwasaki H, Takusagawa M, Kohno I, Mochizuki S, Umetani $\mathrm{K}$, Ishii $\mathrm{H}$, ljiri $\mathrm{H}$, Komori $\mathrm{S}$, Tamura $\mathrm{K}$. Limited reproducibility of circadian variation in blood pressure dippers and nondippers. Am J Hypertens 1998;11:403-9.

8. Omboni S, Parati G, Palatini P, Vanasia A, Muiesan ML, Cuspidi C, Mancia G. Reproducibility and clinical value of nocturnal hypotension: Prospective evidence from the SAMPLE study. Study on ambulatory monitoring of pressure and lisinopril evaluation. J Hypertens 1998;16:733-8.

9. Butkevich A, Phillips RA, Sheinart KF, Tuhrim $S$. The effects of various definitions of dipping and daytime and nighttime on the characterization of $24 \mathrm{~h}$ profiles of blood pressure. Blood Press Monit 2000;5:19-22.

10. Fagard RH, Staessen JA, Thijs L. Optimal definition of daytime and nighttime blood pressure. Blood Press Monit 1997;2:315-21.

11. Rosansky SJ, Menachery SJ, Wagner CM, Jackson K. The effect of sleep intervals on analysis of 24-h ambulatory blood pressure data. Am J Hypertens 1995;8:672-5.

12. O'Brien E, Asmar R, Beilin L, Imai Y, Mancia G, Mengden T, Myers M, Padfield P, Palatini P, Parati G, Pickering T, Redon J, Staessen J, Stergiou G, Verdecchia P. Practice guidelines of the European Society of Hypertension for clinic, ambulatory and self blood pressure measurement. J Hypertens 2005;23:697-701.

13. 2003 European Society of Hypertension-European Society of Cardiology guidelines for the management of arterial hypertension. J Hypertens 2003;21:1011-53.

14. Winnicki M, Canali C, Mormino P, Palatini P. Ambulatory blood pressure monitoring editing criteria: Is standardization needed? Hypertension and ambulatory recording venetia study (harvest) group, italy. Am J Hypertens 1997;10:419-27.

15. Fagard R, Brguljan J, Thijs L, Staessen J. Prediction of the actual awake and asleep blood pressures by various methods of $24 \mathrm{~h}$ pressure analysis. J Hypertens 1996;14:557-63.

16. Verdecchia P, Schillaci G, Guerrieri M, Gatteschi C, Benemio G, Boldrini F, Porcellati C. Circadian blood pressure changes and left ventricular hypertrophy in essential hypertension. Circulation 1990;81:528-36.

17. Devereux RB, Reichek N. Echocardiographic determination of left ventricular mass in man. Anatomic validation of the method. Circulation 1977;55:613-8.

18. Mosteller RD. Simplified calculation of body-surface area. N Eng/ J Med 1987;317:1098. 
19. Lang RM, Bierig M, Devereux RB, Flachskampf FA, Foster E, Pellikka PA, Picard MH, Roman MJ, Seward J, Shanewise JS, Solomon SD, Spencer KT, Sutton MS, Stewart WJ. Recommendations for chamber quantification: A report from the American Society of Echocardiography's guidelines and standards committee and the chamber quantification writing group, developed in conjunction with the European Association of Echocardiography, a branch of the European Society of Cardiology. J Am Soc Echocardiogr 2005;18:1440-63.

20. Bartko JJ. Measurement and reliability: Statistical thinking considerations. Schizophr Bull 1991;17:483-9.

21. Bland JM, Altman DG. Statistical methods for assessing agreement between two methods of clinical measurement. Lancet 1986;1:307-10.

22. O'Brien E, Asmar R, Beilin L, Imai $Y$, Mallion JM, Mancia G, Mengden T, Myers $M$, Padfield $P$, Palatini P, Parati G, Pickering T, Redon J, Staessen J, Stergiou G, Verdecchia P. European Society of Hypertension recommendations for conventional, ambulatory and home blood pressure measurement. J Hypertens 2003;21:821-48.

23. Staessen J, Bulpitt CJ, O'Brien E, Cox J, Fagard R, Stanton A, Thijs L, Van Hulle S, Vyncke G, Amery A. The diurnal blood pressure profile. A population study. Am J Hypertens 1992;5:38692.

24. Landis JR, Koch GG. The measurement of observer agreement for categorical data. Biometrics 1977;33:159-74.

25. Staessen JA, Bieniaszewski L, O'Brien E, Gosse P, Hayashi H, Imai Y, Kawasaki T, Otsuka K, Palatini P, Thijs L, Fagard R. Nocturnal blood pressure fall on ambulatory monitoring in a large international database. The "Ad hoc' working group. Hypertension 1997;29:30-9.

26. Ben-Dov IZ, Ben-Arieh L, Mekler J, Bursztyn M. Blood pressure dipping is reproducible in clinical practice. Blood Press Monit 2005; 10:79-84.

27. Cuspidi C, Macca G, Michev I, Salerno M, Fusi V, Severgnini B, Corti C, Meani S, Valerio C, Magrini $F$, Zanchetti A. Short-term reproducibility of nocturnal nondipping pattern in recently diagnosed essential hypertensives. Blood Press 2002;11:79-83.

28. Cuspidi C, Meani S, Salerno M, Valerio C, Fusi V, Severgnini B, Lonati L, Magrini F, Zanchetti A. Reproducibility of nocturnal blood pressure fall in early phases of untreated essential hypertension: A prospective observational study. J Hum Hypertens 2004;18:503-9.

29. James MA, Fotherby MD, Potter JF. Reproducibility of the circadian systolic blood pressure variation in the elderly. J Hypertens 1995;13:1097-103.

30. Palatini P, Mormino P, Canali C, Santonastaso M, De Venuto G, Zanata G, Pessina AC. Factors affecting ambulatory blood pressure reproducibility. Results of the HARVEST trial. Hypertension and ambulatory recording venetia study. Hypertension 1994;23:211-6.

31. Stanton A, Cox J, Atkins N, O'Malley K, O'Brien E. Cumulative sums in quantifying circadian blood pressure patterns. Hypertension 1992;19:93-101.

32. Stenehjem AE, Os I. Reproducibility of blood pressure variability, white-coat effect and dipping pattern in untreated, uncomplicated and newly diagnosed essential hypertension. Blood Press 2004;13:214-24.

33. Thijs L, Amery A, Clement D, Cox J, de Cort P, Fagard R, Fowler G, Guo C, Mancia G, Marin R, et al. Ambulatory blood pressure monitoring in elderly patients with isolated systolic hypertension. J Hypertens 1992;10:693-9.

34. Thijs L, Celis H, Clement D, Gil-Extremera B, Kawecka-Jaszcz K, Mancia G, Parati G, Salvetti A, Sarti C, van den Meiracker AH, O'Brien E, Staessen JA, Fagard R. Conventional and ambulatory blood pressure measurement in older patients with isolated systolic hypertension:Second progress report on the ambulatory blood pressure monitoring project in the syst-eur trial. Blood Press Monit 1996;1:95-103.

35. van der Steen MS, Lenders JW, Graafsma SJ, den Arend J, Thien T. Reproducibility of ambulatory blood pressure monitoring in daily practice. J Hum Hypertens 1999;13:303-8.

36. Gatzka CD, Schmieder RE. Improved classification of dippers by individualized analysis of ambulatory blood pressure profiles. Am J Hypertens 1995;8:666-71

37. van Ittersum FJ, ljzerman RG, Stehouwer CD, Donker AJ. Analysis of twenty-four-hour ambulatory blood pressure monitoring: What time period to assess blood pressures during waking and sleeping? J Hypertens 1995;13:1053-8. 
38. Cuspidi C, Meani S, Valerio C, Sala C, Fusi V, Masaidi M, Zanchetti A, Mancia G. Reproducibility of dipping/nondipping pattern in untreated essential hypertensive patients: Impact of sex and age. Blood Press Monit 2007;12:101-06.

39. Pickering TG, Kario K. Nocturnal nondipping: What does it augur? Curr Opin Nephrol Hypertens 2001;10:611-6. 
${ }_{50} 0$ 
White matter hyperintensity volumes relate to ambulatory blood pressure levels in hypertensive patients

Léon H.G. Henskens

Abraham A. Kroon

Robert J. van Oostenbrugge

Ed H.B.M. Gronenschild

Paul A.M. Hofman

Jan Lodder

Peter W. de Leeuw
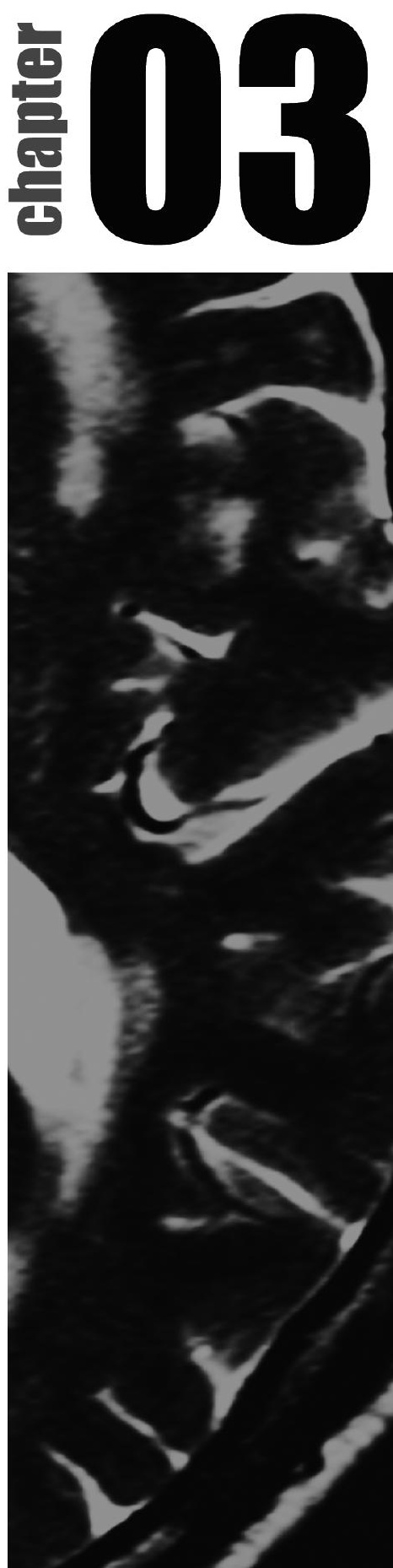


\section{Summary}

High daytime and nighttime blood pressure levels, and apparently also an abnormal nocturnal blood pressure dip, coincide with a greater extent of cerebral white matter hyperintensities. Previous studies applied rather crude and less reliable visual rating scales to categorize white matter hyperintensities instead of quantifying the actual lesion volume. We aimed to assess the relationship between ambulatory blood pressure and volumes of white matter hyperintensities, and distinguished between periventricular and deep hyperintensities because of a supposedly different etiology.

A total of 210 hypertensive patients (110 males) without manifest cardio- and cerebrovascular disease, a mean age of $52.5 \pm 12.5$ years, and untreated office blood pressure levels of $170 \pm 24 / 104 \pm 12 \mathrm{mmHg}$, underwent duplicate 24-hour ambulatory blood pressure monitoring (off-medication) and brain magnetic resonance imaging to quantify the white matter hyperintensity (total, periventricular and deep) and brain volumes. We performed linear regression analyses to relate the mean 24-hour, awake and asleep blood pressures, and the relative nocturnal blood pressure dip to the different volumes of white matter hyperintensities, while adjusting for age, sex, brain volume and vascular risk factors. Higher 24-hour, awake and asleep blood pressure levels were independently associated with a greater volume of total (all models $P<0.001)$, periventricular $(P<0.001)$ and, to a lesser extent, deep $(P<0.05)$ white matter hyperintensities. Although the relationship between the nocturnal blood pressure dip and the volume of white matter hyperintensities appeared to be J-curved, i.e., higher volumes with smaller as well as extreme ( $>25-30 \%)$ blood pressure dips, this was not statistically significant.

In conclusion, white matter hyperintensity volumes are independently associated with higher 24-hour, daytime and nighttime blood pressure levels. The relation with nocturnal blood pressure dipping, however, remains undetermined. 


\section{Introduction}

Cerebral white matter hyperintensities (WMHs) are a common finding on magnetic resonance imaging (MRI) of the brain in the elderly. However, in the presence of hypertension WMHs tend to occur earlier in life and appear to be more severe. ${ }^{1}$ Although WMHs initially develop without symptoms, their presence (especially when severe) has been associated with an increased risk of cognitive impairment, stroke and death. ${ }^{2-4}$

Ambulatory blood pressure (BP) monitoring (ABPM) has shown that, in addition to an increased daytime BP, a raised BP during sleep and an abnormal nocturnal pressure decline are associated with more severe WMHs. ${ }^{5-17}$ The majority of studies ${ }^{5-9,12-17}$, however, estimated the extent of WMHs using visual rating scales instead of quantifying the actual lesion volume. ${ }^{10,11}$ Visual rating scales apply arbitrary cut-offs to define lesion severity, display ceiling effects and poor discrimination of absolute lesion volumes, and have limited observer reliability. ${ }^{18,19}$ Consequently, they may be less sensitive to detect (small) differences between clinical groups. ${ }^{19}$ Furthermore, the use of different rating scales has complicated the comparison of results between studies. ${ }^{20}$ Contrary, the quantification of WMH volumes (WMHVs) will enable us to examine the dose-effect of BP on the extent of WMHs and to determine whether there are distinct thresholds in the BPWMHV relationship.

The aim of the present study was to assess the relationship between the ambulatory BP profile and the volume of WMHs in a cohort of hypertensive patients without a history of cardio- and cerebrovascular disease. Furthermore, we distinguished periventricular hyperintensities from those in the deep white matter because the etiology of these WMH subtypes may actually differ. ${ }^{21}$

\section{Methods}

\section{Participants}

Screening, selection and inclusion of patients have been described in detail elsewhere (Figure B.1, Appendix B). ${ }^{22}$ Briefly, 218 patients, referred for evaluation of their hypertension and currently off anti-hypertensive treatment, were included in the present study. In addition to the routine work-up, which included 24-hour ABPM, standard 12-lead electrocardiography, echocardiography, and routine laboratory investigations (for details on these investigations see elsewhere ${ }^{22,23}$ ), patients consented to a repeat ABPM (also off-medication) and an MRI of the brain. All participants, aged 20-82 years, had no indication of secondary hypertension or chronic renal failure, no documented diabetes, no ischemic or 
valvular heart disease, no atrial fibrillation, no history of transient ischemic attacks or stroke, and no diagnosis of obstructive sleep apnea syndrome.

The Medical Ethics Committee of the Maastricht University Medical Centre approved the study and written informed consent was obtained from all participants.

\section{Blood pressure}

Conventional office BP was measured at the hospital by sphygmomanometry (Korotkoff phases I and V). After at least five minutes of rest, three consecutive measurements were taken at the non-dominant arm, with the participant seated, and always by the same trained investigator (L.H.). We calculated the mean arterial pressure (MAP) from the corresponding systolic BP (SBP) and diastolic BP (DBP) using the following equation: $\mathrm{MAP}=\mathrm{DBP}+((\mathrm{SBP}-\mathrm{DBP}) / 3)$. For analysis we used the mean of the second and third measurements.

Ambulatory BP was monitored non-invasively over a 24-hour period using validated SpaceLabs 90207 or 90217 devices (SpaceLabs Medical Inc., Redmond, Washington, USA), as described in detail elsewhere.22 The monitoring sessions were repeated with a median time interval of seven (interquartile range 5-9) days, because the assessment of the 24-hour BP profile on the basis of a single ABPM has been shown to be less reliable. ${ }^{24}$ Participant's awake (daytime) and asleep (nighttime) periods were determined by excluding a 2-hour transition period around the reported rising and retiring times. ${ }^{23}$ According to this narrow diary time definition and based on both ABPMs (for reproducibility data see Appendix C) we calculated the mean 24-hour, awake and asleep SBP, MAP and DBP, and quantified the relative nocturnal BP (MAP) dip (equation: ((mean awake MAP mean asleep MAP) / mean awake MAP) * 100\%), as detailed previously. ${ }^{22}$

We defined hypertension as an untreated office BP $\geq 140 \mathrm{mmHg}$ systolic and/or $\geq 90 \mathrm{mmHg}$ diastolic. ${ }^{25}$

\section{Magnetic resonance imaging}

Brain MRI (Intera 1.5-T, Philips Medical Systems, Best, The Netherlands) was performed to obtain axial T2-weighted and fluid-attenuated inversion recovery (FLAIR) images (for details on the imaging protocol see Appendix D).

All imaging data were transferred to a Macintosh workstation and analyzed for WMH and brain volumes, using the in-house developed (E.G.) image-processing software package GIANT (General Imaging and Analysis Tools; Department of Psychiatry and Neuropsychology, Maastricht University, Maastricht, The Netherlands).

White matter hyperintensities were identified as hyperintense areas on T2weighted and FLAIR images (for an example see Figure A.1, Appendix A). We defined WMHs connected to the lateral ventricles as periventricular (PWMHs) 
otherwise we considered them to be deep (DWMHs) (Figure D.1, Appendix D). The actual quantification of the WMH volume (WMHV) was performed semiautomatically. A detailed description of this procedure, including fully automatic brain volume (BV) measurements, is given in Appendix D. Reliability analyses for WMHV and BV measurements yielded very good inter- and intra-observer agreement with intraclass correlation coefficients ranging between 0.96 and 0.99 (Table D.1, Appendix D).

\section{Risk factors}

Information on lifestyle habits (smoking), past and current morbidity, and hypertension history (including the duration of hypertension, previous and current use of cardiovascular medication, and duration of treatment) were obtained by interview and verified by inspection of recently started medical records. The duration of hypertension was estimated as the time (in months) passed since the self-reported age of diagnosis until inclusion in the study. Smoking was classified as never, past or current.

Height and weight were measured without shoes and wearing light indoor clothing to determine body mass index (BMI, $\left.\mathrm{kg} / \mathrm{m}^{2}\right)$.

Venous blood samples, routinely drawn after an overnight fast, were analyzed for serum creatinine, serum total and high-density lipoprotein (HDL) cholesterol levels, and plasma glucose levels using standard laboratory procedures.

Hypercholesterolemia was considered to be present in subjects who either used lipid-lowering drugs or had untreated total cholesterol levels $>6.5 \mathrm{mmol} / \mathrm{l} .{ }^{25}$

Left ventricular (LV) hypertrophy (LVH) was assessed by means of electro- and echocardiography. We defined electrocardiographic LVH as a Sokolow-Lyons index $\left(\mathrm{SV}_{1}+\mathrm{RV}_{5-6}\right)>38 \mathrm{~mm} .^{25}$ Left ventricular mass was assessed by twodimensional M-mode and Doppler echocardiography (Sonos 5500, HewlettPackard, Andover, MA, USA) as detailed recently. ${ }^{23}$ Echocardiographic LVH was defined as an LV mass index (LVMI) $>115 \mathrm{~g} / \mathrm{m}^{2}$ for men and $>95 \mathrm{~g} / \mathrm{m}^{2}$ for women. The assessments of LVMI were good reproducible; the intra- and inter-observer intraclass correlation coefficients ${ }^{26}$ were 0.90 and 0.87 , respectively. ${ }^{23}$

\section{Statistical analysis}

Before analyzing the relationship between ambulatory BP and WMHs we tested the reproducibility of the duplicate ambulatory BP recordings. A detailed description is given in Appendix $C$.

To detect group differences between unpaired data we applied the independent samples $t$-test for normally distributed variables, the Mann-Whitney $U$ test for variables with skewed distributions, and the Pearson $\chi^{2}$ statistic or Fisher's exact test for categorical variables. 
We modeled the relation between the aforementioned BP measurements and total, periventricular and deep WMHVs, while controlling for age, sex and BV. Statistical significance of these relationships was assessed using linear regression analyses, after WMHVs had been logarithmically transformed because of skewed distributions. Models were adjusted for age, sex and BV (model 1), and additionally for the duration of hypertension, previous antihypertensive treatment, smoking of cigarettes, fasting plasma glucose levels, fasting serum creatinine levels and LVH (model 2), factors previously reported to be associated with the volume of WMHs. ${ }^{3,11,27-29}$ Covariates were forced into the models simultaneously (enter procedure).

To illustrate the relationships between the BP level and the volume of WMHs, we produced plots of the predicted WMHVs versus the office, 24-hour, awake and asleep BP levels. The predicted WMHVs are the volumes predicted by the regression equation between $\mathrm{BP}$ and the untransformed WMHVs, adjusted for age, sex and BV.

Normally distributed variables are presented as mean \pm standard deviation (SD), variables with skewed distributions as median and interquartile ranges (IQR), and categorical variables as frequencies. Unstandardized regression coefficients and odds ratios are presented with corresponding $95 \%$ confidence intervals. A twotailed probability value $<0.05$ was considered statistically significant. Analyses were performed using the statistical software packages SPSS (version 11.0.4 for Macintosh, SPSS Inc., Chicago, Illinois, USA) and Prism (version 4.00 for Windows, GraphPad Software Inc., San Diego, California, USA).

\section{Results}

\section{Characteristics}

Of the 218 participants 213 (98\%) had duplicate ABPMs. In three subjects BVs could not be obtained because of insufficient scan quality, thus leaving 210 participants for statistical analysis.

The characteristics of the study population, specified for men and women, are summarized in Table 3.1.

At inclusion, the median duration of hypertension was 45 (IQR 14-147) months, during which $180(86 \%)$ patients had been on antihypertensive treatment for a median duration of 24 (IQR 6-65) months. Based on the untreated office BPs, 200 (95\%) participants were diagnosed with hypertension. Ten $(5 \%)$ participants appeared to have normal BP levels, even though the referring diagnosis was hypertension. Seventy (34\%) participants had hypercholesterolemia of whom 25 used lipid-lowering medication. Fourteen subjects were receiving antithrombotic treatment. 
Table 3.1 Characteristics of the study population according to sex.

\begin{tabular}{l|c|c|c|}
\hline Characteristics & All (210) & Men (106) & Women (104) \\
\hline Age, years & $52.5 \pm 12.5$ & $52.6 \pm 11.5$ & $52.3 \pm 13.4$ \\
\hline Height, cm & $169.6 \pm 9.8$ & $176.2 \pm 7.2$ & $162.8 \pm 7.1$ \\
\hline BMl, kg/m2 & $28.2 \pm 4.9$ & $28.6 \pm 4.2$ & $27.9 \pm 5.5$ \\
\hline Office BP, mmHg: & & & \\
SBP & $170 \pm 24$ & $169 \pm 23$ & $170 \pm 25$ \\
\hline MAP & $126 \pm 14$ & $127 \pm 14$ & $125 \pm 15$ \\
\hline DBP & $104 \pm 12$ & $105 \pm 11$ & $102 \pm 13$ \\
\hline Heart rate, bpm & $75 \pm 12$ & $74 \pm 13$ & $76 \pm 10$ \\
\hline Smoking of cigarettes: & & & \\
$\quad$ Never & $85(40)$ & $28(26)$ & $57(55)$ \\
\hline Past & $90(43)$ & $56(53)$ & $34(33)$ \\
$\quad$ Current & $38(17)$ & $22(21)$ & $13(12)$ \\
\hline Glucose, mmol/l & $5.4 \pm 0.6$ & $5.5 \pm 0.6$ & $5.3 \pm 0.7$ \\
Creatinine, $\mu \mathrm{mol} / \mathrm{l}$ & $82(71-93)$ & $90(82-102)$ & $73(65-80)$ \\
\hline Total cholesterol, mmol/l & $5.8(5.2-6.5)$ & $5.7(5.0-6.4)$ & $6.0(5.2-6.7)$ \\
\hline LVH & $45(21)$ & $14(13)$ & $31(30)$
\end{tabular}

Data are presented as mean $\pm \mathrm{SD}$, number (\%), or median (interquartile range). $\mathrm{BMI}$ indicates body mass index; BP, blood pressure; SBP, systolic BP; MAP, mean arterial pressure; DBP, diastolic BP; bpm, beats per minute; LVH, left ventricular hypertrophy.

\section{Ambulatory blood pressure and white matter hyperintensities}

Brain MRI was performed with a median interval of 10 (IQR 7-16) days from the first ABPM. The total WMHV of the study population ranged from 0.02 to $68.93 \mathrm{~cm}^{3}$ with a median of 0.84 (IQR $\left.0.36-2.86\right) \mathrm{cm}^{3}$. Periventricular WMHVs (PWMHVs) ranged from 0.01 to $38.86 \mathrm{~cm}^{3}$ (median 0.67 [IQR $0.33-2.23$ ] $\mathrm{cm}^{3}$ ) and deep WMHVs (DWMHVs) from 0 to $30.07 \mathrm{~cm}^{3}$ (median 0.05 [IQR 0.002-0.32] $\mathrm{cm}^{3}$ ). The participants' mean BV was $1265.42 \pm 123.22 \mathrm{~cm}^{3}$. The median WMHV increased with increasing age while the mean BV declined (Table 3.2).

Table 3.2 White matter hyperintensity and brain volumes according to age.

\begin{tabular}{l|c|c|c|}
\hline \multicolumn{3}{|c|}{} & \multicolumn{3}{|c|}{ Age categories, years } \\
\hline Parameter & $<40$ & $40-60$ & $\geq 60$ \\
\hline $\mathrm{n}$ & 34 & 115 & 61 \\
\hline WMHV, $\mathrm{cm}^{3}:$ & & & \\
$\quad$ Total & $0.35(0.13-0.82)$ & $0.60(0.35-1.55)$ & $2.93(0.95-9.99)$ \\
$\quad$ Periventricular & $0.35(0.13-0.79)$ & $0.57(0.30-1.40)$ & $2.33(0.64-9.54)$ \\
$\quad$ Deep & $0.00(0.00-0.03)$ & $0.04(0.00-0.20)$ & $0.42(0.05-1.20)$ \\
\hline BV, $\mathrm{cm}^{3}$ & $1319 \pm 113$ & $1272 \pm 124$ & $1223 \pm 115$ \\
\hline Data are presented as mean \pm SD, number, or median (interquartile range). $\mathrm{n}$ indicates number; \\
\hline WMHV, white matter hyperintensity volume; BV, brain volume
\end{tabular}

Reproducibility data of the duplicate ABPMs are presented in Appendix C. In accordance with the results of the reproducibility analyses all BP data are based on the average of both recordings. 
Because of the large number of BP variables we only report the results associated with the MAP, as this BP component relates to both SBP and DBP, and is only slightly modified by age. The results were, however, similar for the systolic and diastolic BPs.

The panels A to D of Figure 3.1 depict the relation between BP and WMHs while adjusting for age, sex and BV.
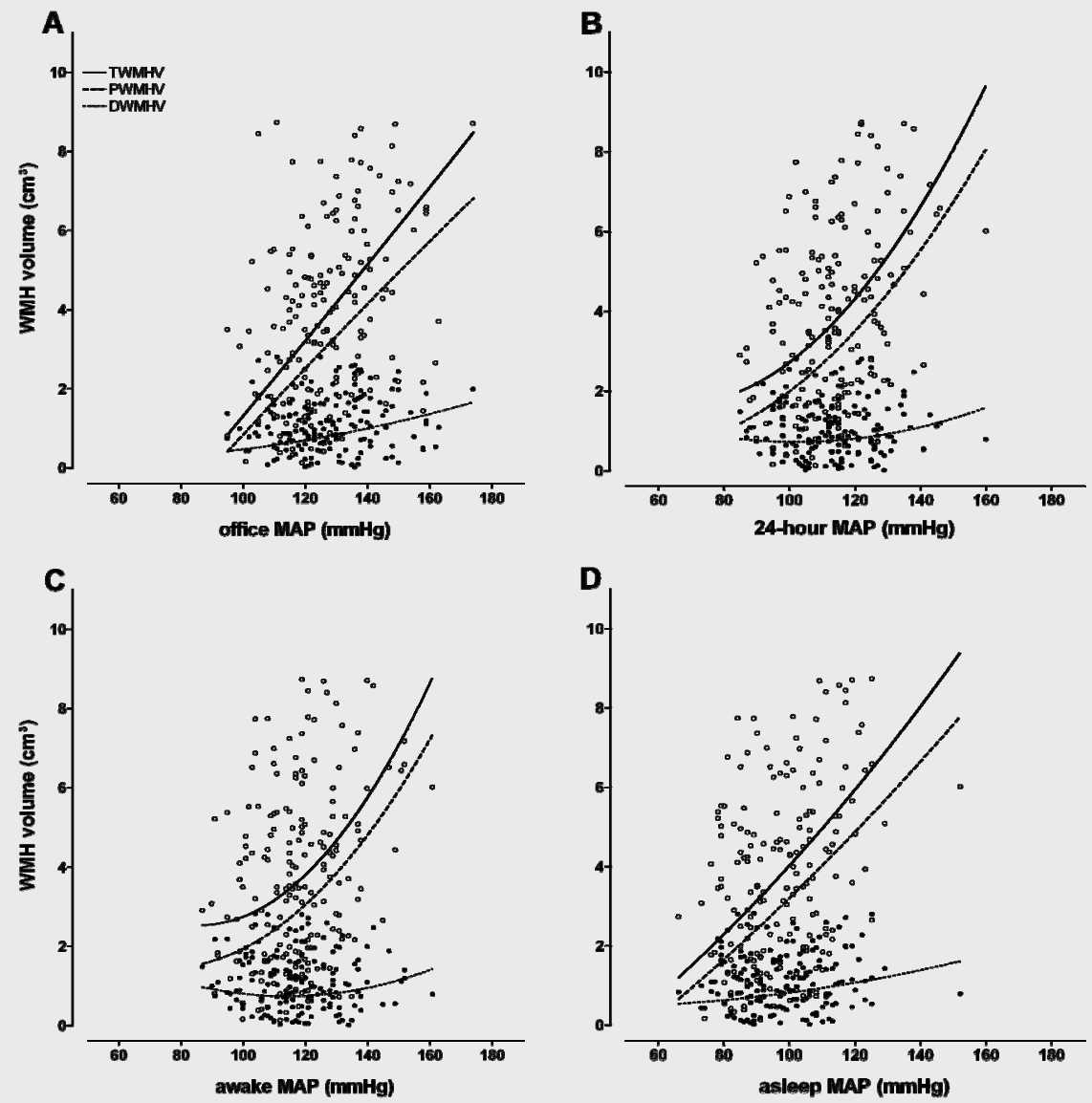

Figure 3.1 Relationships between ambulatory blood pressure components and the predicted volumes of white matter hyperintensities.

MAP indicates mean arterial pressure; WMH, white matter hyperintensity; TWMHV, total WMH volume; PWMHV, periventricular WMH volume; DWMHV, deep WMH volume. Circles indicate the age, sex and brain volume adjusted periventricular (open circles) and deep (closed circles) predicted WMHVs associated with increasing levels of MAP. 
The volumes of total, periventricular and, to a lesser extent, deep WMHs increased with increasing levels of office, 24-hour, awake or asleep BP. The spread in distribution of WMHVs was greater for periventricular than for deep WMHs. In line with the figures, the linear regression analyses showed that higher office, 24-hour, awake and asleep pressures were significantly associated with a greater volume of total (all models $P<0.001)$, periventricular $(P<0.001)$ and, to a lesser extent, deep $(P<0.05)$ WMHs, independent of age, sex and BV (Table 3.3, model 1). Additional adjustments for vascular risk factors did not change the associations (Table 3.3, model 2).

Although the relationship between nocturnal BP dipping and the volume of WMHs appeared to be J-curved, i.e., higher volumes associated with smaller as well as extreme (>25-30\%) BP dips (Figure 3.2), the corresponding adjusted linear regression models were not statistically significant (Table 3.3, all adjusted models P>0.05).

Table 3.3 Mean arterial pressure components in relation to white matter hyperintensity volumes $(n=210)$.

\begin{tabular}{|c|c|c|c|c|c|c|c|}
\hline WMHVs & MAP & & Unadjusted & & Model 1 & & Model 2 \\
\hline \multirow[t]{5}{*}{ Total } & Office & 0.013 & $(0.008-0.020)^{d}$ & 0.011 & $(0.006-0.016)^{d}$ & 0.012 & $(0.006-0.017)^{d}$ \\
\hline & 24-hour & 0.013 & $(0.006-0.020)^{d}$ & 0.015 & $(0.009-0.020)^{d}$ & 0.015 & $(0.009-0.022)^{d}$ \\
\hline & Awake & 0.011 & $(0.004-0.018)^{c}$ & 0.014 & $(0.008-0.019)^{d}$ & 0.014 & $(0.008-0.021)^{d}$ \\
\hline & Asleep & 0.014 & $(0.007-0.021)^{d}$ & 0.013 & $(0.008-0.019)^{d}$ & 0.013 & $(0.008-0.019)^{d}$ \\
\hline & Nocturnal dip & -0.017 & $(-0.030--0.004)^{c}$ & -0.009 & $(-0.020-0.001)$ & -0.009 & $(-0.020-0.002)$ \\
\hline \multirow[t]{5}{*}{ Periventricular } & Office & 0.014 & $(0.008-0.020)^{d}$ & 0.012 & $(0.007-0.017)^{d}$ & 0.012 & $(0.007-0.018)^{d}$ \\
\hline & 24-hour & 0.014 & $(0.007-0.021)^{d}$ & 0.015 & $(0.009-0.021)^{d}$ & 0.016 & $(0.010-0.022)^{d}$ \\
\hline & Awake & 0.012 & $(0.005-0.019)^{c}$ & 0.014 & $(0.009-0.020)^{d}$ & 0.015 & $(0.009-0.021)^{d}$ \\
\hline & Asleep & 0.015 & $(0.008-0.021)^{d}$ & 0.014 & $(0.008-0.019)^{d}$ & 0.014 & $(0.008-0.019)^{d}$ \\
\hline & Nocturnal dip & -0.016 & $(-0.029--0.004)^{b}$ & -0.009 & $(-0.020-0.002)$ & -0.009 & $(-0.020-0.003)$ \\
\hline \multirow[t]{5}{*}{ Deep } & Office & 0.015 & $(0.004-0.026)^{c}$ & 0.009 & $(0.000-0.018)$ & 0.010 & $(0.000-0.020)^{b}$ \\
\hline & 24-hour & 0.011 & $(-0.002-0.023)$ & 0.013 & $(0.003-0.024)^{b}$ & 0.014 & $(0.003-0.026)^{b}$ \\
\hline & Awake & 0.007 & $(-0.005-0.020)$ & 0.012 & $(0.001-0.022)^{b}$ & 0.012 & $(0.001-0.024)^{b}$ \\
\hline & Asleep & 0.014 & $(0.002-0.026)^{b}$ & 0.013 & $(0.003-0.023)^{b}$ & 0.014 & $(0.004-0.025)^{b}$ \\
\hline & Nocturnal dip & -0.026 & $(-0.048--0.003)^{b}$ & -0.013 & $(-0.032-0.007)$ & -0.015 & $(-0.034-0.005)$ \\
\hline
\end{tabular}

Data are presented as unstandardized regression coefficients (95\% confidence interval). WMHVs indicates white matter hyperintensity volumes; MAP, mean arterial pressure.

a WMHVs were log-transformed.

Model 1: adjusted for age, sex and total brain volume.

Model 2: additionally adjusted for duration of hypertension, previous antihypertensive treatment, smoking status, fasting plasma glucose levels, fasting serum creatinine levels, and LVH.

${ }^{\mathrm{b}} P<0.05 ;{ }^{c} P<0.01 ;{ }^{\mathrm{d}} P<0.001$. 


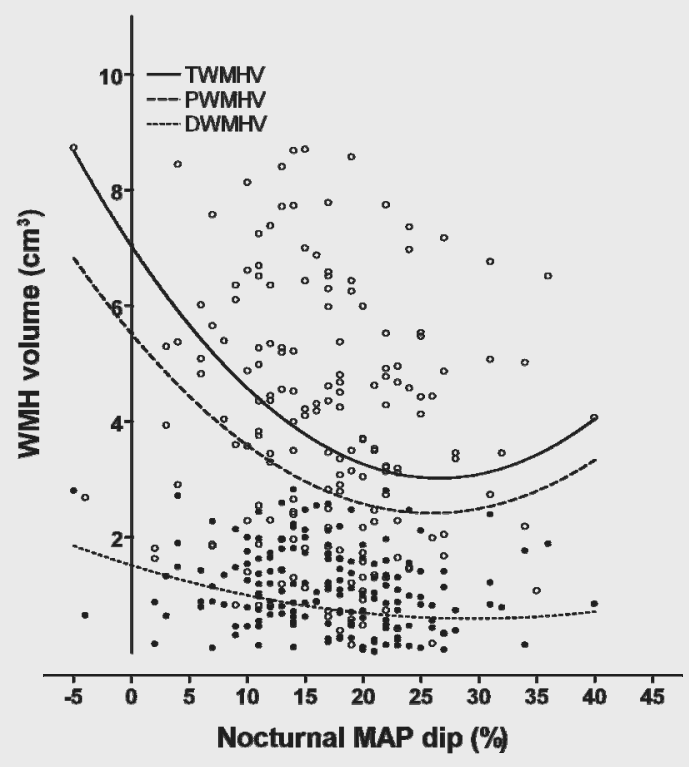

Figure 3.2 Relationships between nocturnal blood pressure dipping and the predicted volumes of white matter hyperintensities.

MAP indicates mean arterial pressure; WMH, white matter hyperintensity; TWMHV, total WMH volume; PWMHV, periventricular WMH volume; DWMHV, deep WMH volume. Circles indicate the age, sex and brain volume adjusted periventricular (open circles) and deep (closed circles) predicted WMHVs associated with changing levels of MAP dip.

\section{Discussion}

The present study, carried out in a cohort of hypertensive patients without manifest cardio- and cerebrovascular disease, demonstrated that higher, untreated awake, asleep and 24-hour BP levels were related to a greater volume of periventricular and, to a lesser extent, deep WMHs. The relationships were continuous, without evidence of distinct thresholds and continued down to BP levels well within the normotensive range.

Schwartz et al. were the first, and the only investigators so far, to report on an independent contribution of higher ambulatory BP levels to greater WMHV. ${ }^{11}$ Our data confirm their observations and extend them by showing a clear distinction between hyperintensities of the periventricular and deep white matter in their relation with ambulatory BP levels. While the PWMHV increased steeply with higher BP levels, the volume of DWMHs did so only modestly. 
Hypertension leads to microvascular arteriolosclerosis (i.e., thickening of the vessel wall with luminal narrowing), lengthening and tortuosity of microvessels, and impairs cerebrovascular autoregulation. ${ }^{30,31}$ This increases the risk of cerebral hypoperfusion and subsequent white matter ischemia. The periventricular rather than the deep white matter seems particularly vulnerable to these adverse effects of high BP, as this region is vascularized by long end-arteries with a relatively low perfusion pressure, that lack appropriate anastomoses and supply blood to arterial watershed zones..$^{32}$ Besides, observations that periventricular and deep WMHs are differentially influenced by vascular risk factors, have different clinical consequences, and have different progression rates, further support the existence of WMH-subtypes.,21,33 Other investigators, however, criticized that a distinction between deep and periventricular WMHs is arbitrary and failed to identify distinct subtypes using anatomical mapping techniques. ${ }^{34}$ Notwithstanding, future studies should preferably report their data specified for hyperintensities of the periventricular and deep white matter, enabling us to further evaluate the pathological and clinical relevance of subtyping WMHs.

Consistent with the results of the few earlier studies on ambulatory BP and (mainly categorical) $\mathrm{WMH}^{5}, 6,8,9,11,13,14,16$ we found the absolute nocturnal BP level, in addition to the daytime pressure, to be positively associated with WMHVs. Large, prospective outcome studies have shown that the nighttime BP is a better predictor of cardiovascular events (including stroke) and mortality than is the daytime pressure, although the underlying mechanisms continue to be speculative. ${ }^{35}$ Whether the nocturnal BP is indeed more important in the development of WMHs than the daytime BP remains to be determined.

In addition to the nocturnal BP level per se, some studies have focused on abnormal nocturnal BP falls as a possible cause of WMHs. While some investigators found that an absent BP decline during sleep was associated with advanced $\mathrm{WMHs}^{6,10-12,16}$, others failed to find such an association ${ }^{5,14,17}$ or reported the opposite, i.e., more severe hyperintensities in the presence of extreme nocturnal BP dips. ${ }^{7,15}$ Contrary to the results of Schwartz et al. we did not find an independent relation between smaller nocturnal BP dips and greater WMHV. ${ }^{11}$ Their study, however, was carried out on a sample of mostly drug-treated hypertensive subjects, and had a median time difference of almost one year between the performance of MRI and the ambulatory BP measurements. We observed a more or less J-curved relation between nocturnal BP dipping and the volume of PWMHs, suggesting that in excess to smaller BP dips also extreme BP falls beyond $25-30 \%$ are associated with greater PWMHV. Associations between extreme dipping and the extent of WMHs have been observed before, but only in two, rather small, Japanese populations.7.15 Moreover, and as pointed out recently by experts in ABPM, the clinical value of abnormal nocturnal dipping patterns remains controversia ${ }^{36}$. 
It has been shown that the associations between BP and the risk of stroke are continuous and without any evidence of thresholds, continuing down to normal BP levels as low as $115 \mathrm{mmHg}$ systolic and $75 \mathrm{mmHg}$ diastolic. ${ }^{37}$ We observed similar patterns for preclinical manifestations of cerebrovascular disease. Such continuous relationships, starting already at below average BP levels, suggest that WMHs develop gradually and with increasing severity. Histopathological data have shown a gradual increase of ischemic tissue damage parallel to an increase from small punctate lesions to large confluent WMHs. ${ }^{38}$ Recent imaging studies, using diffusion tensor techniques, found that subtle white matter changes, such as altered fluid dynamics, are already present in the normal appearing white matter of patients who display WMHs on conventional T2-weighted and FLAIR images. ${ }^{39}$ In other words, the WMHs visible on T2-weighted and FLAIR images probably represent the more severe lesions of a broader white matter disease that is not detectable yet on conventional neuroimaging.

The present study has limitations. Because of its cross-sectional design we cannot infer a cause-effect relationship between increasing BP levels and greater WMHVs. Hence, our observations need to be extended in longitudinal and adequately powered studies. Furthermore, the associations between ambulatory BP levels and DWMHV might have been underestimated, as we classified large confluent lesions extending into the deep white matter but connected to the lateral ventricles as periventricular rather than deep (even though this classification is generally accepted).

Strengths of our study are firstly that BP was measured by ABPM and, importantly, on two occasions. Secondly, the assessments of the WMHVs showed very good intra-rater, inter-rater and scan-rescan agreement. Thirdly, we studied $\mathrm{BP}$ and WMHs as continuous variables rather than using arbitrary cut-offs. The observed associations were robust and not biased by concurrent antihypertensive treatment or a history of symptomatic cerebrovascular disease. Moreover, we did not include subjects with manifest vascular disease, thereby reducing the possibility that our observations result from reverse causality.

In conclusion, the observed relationships between increasing BP levels and greater WMHV, though cross-sectional, were continuous, without evidence of distinct thresholds and continued down to BP levels within the normotensive range. This is important in view of the possibility that lowering BP may prevent the development of new or the progression of existing WMHs. Data from the Perindopril Protection Against Recurrent Stroke Study suggest that an active BP-lowering regimen stops or delays the progression of WMHs in patients with a history of stroke or TIA. ${ }^{40}$ However, the safety of indiscriminate BP reduction (i.e., risk of cerebral hypoperfusion) has been questioned, particularly in hypertensive patients with (silent) cerebrovascular disease. ${ }^{41}$ Accordingly, there is a need for adequately powered intervention trials in hypertensive patients, who display different rates of WMHs and who have not had a stroke yet. These trials should assess the effects 
and safety of antihypertensive (and also other cardiovascular) treatment on the development and/or progression of WMHs, with a special focus on the nocturnal $\mathrm{BP}$ and its (abnormal) patterns. 


\section{References}

1. de Leeuw FE, de Groot JC, Oudkerk M, Witteman JC, Hofman A, van Gijn J, Breteler MM. Hypertension and cerebral white matter lesions in a prospective cohort study. Brain 2002;125:765-72.

2. de Groot JC, de Leeuw FE, Oudkerk M, van Gijn J, Hofman A, Jolles J, Breteler MM. Cerebral white matter lesions and cognitive function: The Rotterdam Scan Study. Ann Neurol 2000;47:145-51.

3. Ikram MA, Vernooij MW, Vrooman HA, Hofman A, Breteler MM. Brain tissue volumes and small vessel disease in relation to the risk of mortality. Neurobiol Aging 2007; epub.

4. Vermeer SE, Hollander M, van Dijk EJ, Hofman A, Koudstaal PJ, Breteler MM. Silent brain infarcts and white matter lesions increase stroke risk in the general population: The Rotterdam Scan Study. Stroke 2003;34:1126-9.

5. Chamorro A, Pujol J, Saiz A, Vila N, Vilanova JC, Alday M, Blanc R. Periventricular white matter lucencies in patients with lacunar stroke. A marker of too high or too low blood pressure? Arch Neuro/ 1997;54:1284-8

6. Goldstein IB, Bartzokis G, Hance DB, Shapiro D. Relationship between blood pressure and subcortical lesions in healthy elderly people. Stroke 1998;29:765-72.

7. Kario K, Matsuo T, Kobayashi H, Imiya M, Matsuo M, Shimada K. Nocturnal fall of blood pressure and silent cerebrovascular damage in elderly hypertensive patients. Advanced silent cerebrovascular damage in extreme dippers. Hypertension 1996;27:130-5.

8. O'Sullivan C, Duggan J, Lyons S, Thornton J, Lee M, O'Brien E. Hypertensive target-organ damage in the very elderly. Hypertension 2003;42:130-5.

9. Puisieux F, Monaca P, Deplanque D, Delmaire C, di Pompeo C, Monaca C, Leys D, Pruvo JP, Dewailly P. Relationship between leuko-araiosis and blood pressure variability in the elderly. Eur Neuro/2001;46:115-20.

10. Sander D, Winbeck K, Klingelhofer J, Conrad B. Extent of cerebral white matter lesions is related to changes of circadian blood pressure rhythmicity. Arch Neuro/2000;57:1302-7.

11. Schwartz GL, Bailey KR, Mosley T, Knopman DS, Jack CR, Jr., Canzanello VJ, Turner ST. Association of ambulatory blood pressure with ischemic brain injury. Hypertension 2007:49:1228-34.

12. Shimada K, Kawamoto A, Matsubayashi K, Nishinaga M, Kimura S, Ozawa T. Diurnal blood pressure variations and silent cerebrovascular damage in elderly patients with hypertension. $J$ Hypertens 1992;10:875-8.

13. Shimada K, Kawamoto A, Matsubayashi K, Ozawa T. Silent cerebrovascular disease in the elderly. Correlation with ambulatory pressure. Hypertension 1990;16:692-9.

14. Sierra C, de La Sierra A, Mercader J, Gomez-Angelats E, Urbano-Marquez A, Coca A. Silent cerebral white matter lesions in middle-aged essential hypertensive patients. J Hypertens 2002;20:519-24.

15. Watanabe N, Imai Y, Nagai K, Tsuji I, Satoh H, Sakuma M, Sakuma H, Kato J, Onodera-Kikuchi N, Yamada M, Abe F, Hisamichi $\mathrm{S}$, Abe K. Nocturnal blood pressure and silent cerebrovascular lesions in elderly Japanese. Stroke 1996;27:1319-27.

16. Yamamoto Y, Akiguchi I, Oiwa K, Hayashi M, Kimura J. Adverse effect of nighttime blood pressure on the outcome of lacunar infarct patients. Stroke 1998;29:570-6.

17. van Boxtel MP, Henskens LH, Kroon AA, Hofman PA, Gronenschild EH, Jolles J, de Leeuw PW. Ambulatory blood pressure, asymptomatic cerebrovascular damage and cognitive function in essential hypertension. J Hum Hypertens 2006;20:5-13.

18. Prins ND, van Straaten EC, van Dijk EJ, Simoni M, van Schijndel RA, Vrooman HA, Koudstaal PJ, Scheltens $P$, Breteler MM, Barkhof F. Measuring progression of cerebral white matter lesions on MRI: Visual rating and volumetrics. Neurology 2004;62:1533-9.

19. van Straaten EC, Fazekas F, Rostrup E, Scheltens P, Schmidt R, Pantoni L, Inzitari D, Waldemar G, Erkinjuntti T, Mantyla R, Wahlund LO, Barkhof F. Impact of white matter hyperintensities scoring method on correlations with clinical data. The LADIS study. Stroke 2006;37:836-40. 
20. Mantyla R, Erkinjuntti T, Salonen O, Aronen HJ, Peltonen T, Pohjasvaara T, StandertskjoldNordenstam CG. Variable agreement between visual rating scales for white matter hyperintensities on MRI. Comparison of 13 rating scales in a poststroke cohort. Stroke 1997;28:1614-23.

21. Lazarus R, Prettyman R, Cherryman G. White matter lesions on magnetic resonance imaging and their relationship with vascular risk factors in memory clinic attenders. Int J Geriatr Psychiatry 2005;20:274-9.

22. Henskens LH, van Oostenbrugge RJ, Kroon AA, de Leeuw PW, Lodder J. Brain microbleeds are associated with ambulatory blood pressure levels in a hypertensive population. Hypertension 2008;51:62-68.

23. Henskens LH, Kroon AA, van Oostenbrugge RJ, Haest RJ, Lodder J, de Leeuw PW. Different classifications of nocturnal blood pressure dipping affect the prevalence of dippers and nondippers and the relation with target-organ damage. J Hypertens 2008;26:691-98.

24. Manning G, Rushton L, Donnelly R, Millar-Craig MW. Variability of diurnal changes in ambulatory blood pressure and nocturnal dipping status in untreated hypertensive and normotensive subjects. Am J Hypertens 2000;13:1035-8.

25. Mancia G, De Backer G, Dominiczak A, Cifkova R, Fagard R, Germano G, Grassi G, Heagerty AM, Kjeldsen SE, Laurent S, Narkiewicz K, Ruilope L, Rynkiewicz A, Schmieder RE, Boudier HA, Zanchetti A. 2007 guidelines for the management of arterial hypertension: The task force for the management of arterial hypertension of the European Society of Hypertension (ESH) and of the European Society of Cardiology (ESC). J Hypertens 2007;25:1105-87.

26. Bartko JJ. Measurement and reliability: Statistical thinking considerations. Schizophr Bull 1991;17:483-9.

27. DeCarli C, Miller BL, Swan GE, Reed T, Wolf PA, Garner J, Jack L, Carmelli D. Predictors of brain morphology for the men of the NHLBI twin study. Stroke 1999;30:529-36.

28. Jeerakathil T, Wolf PA, Beiser A, Massaro J, Seshadri S, D'Agostino RB, DeCarli C. Stroke risk profile predicts white matter hyperintensity volume: The Framingham study. Stroke 2004;35:1857-61.

29. Ikram MA, Vernooij MW, Hofman A, Niessen WJ, van der Lugt A, Breteler MM. Kidney function is related to cerebral small vessel disease. Stroke 2008;39:55-61.

30. Lammie GA. Hypertensive cerebral small vessel disease and stroke. Brain Patho/2002;12:358-70.

31. Paulson OB, Waldemar G, Schmidt JF, Strandgaard S. Cerebral circulation under normal and pathologic conditions. Am J Cardio/ 1989;63:2C-5C.

32. De Reuck J. The human periventricular arterial blood supply and the anatomy of cerebral infarctions. Eur Neuro/ 1971;5:321-34.

33. ten Dam VH, van den Heuvel DM, de Craen AJ, Bollen EL, Murray HM, Westendorp RG, Blauw GJ, van Buchem MA. Decline in total cerebral blood flow is linked with increase in periventricular but not deep white matter hyperintensities. Radiology 2007;243:198-203.

34. DeCarli C, Fletcher E, Ramey V, Harvey D, Jagust WJ. Anatomical mapping of white matter hyperintensities $(\mathrm{WMH})$ : Exploring the relationships between periventricular $\mathrm{WMH}$, deep $\mathrm{WMH}_{\text {, }}$ and total WMH burden. Stroke 2005;36:50-5.

35. Fagard RH, Celis H, Thijs L, Staessen JA, Clement DL, De Buyzere ML, De Bacquer DA. Daytime and nighttime blood pressure as predictors of death and cause-specific cardiovascular events in hypertension. Hypertension 2008;51:55-61.

36. Parati G, Staessen JA. Day-night blood pressure variations: Mechanisms, reproducibility and clinical relevance. J Hypertens 2007;25:2377-80.

37. MacMahon S, Peto R, Cutler J, Collins R, Sorlie P, Neaton J, Abbott R, Godwin J, Dyer A, Stamler J. Blood pressure, stroke, and coronary heart disease. Part 1, prolonged differences in blood pressure: Prospective observational studies corrected for the regression dilution bias. Lancet 1990;335:765-74.

38. Fazekas F, Kleinert R, Offenbacher $H$, Schmidt R, Kleinert $G$, Payer F, Radner $H$, Lechner $H$. Pathologic correlates of incidental MRI white matter signal hyperintensities. Neurology 1993;43:1683-9. 
39. Taylor WD, Bae JN, MacFall JR, Payne ME, Provenzale JM, Steffens DC, Krishnan KR. Widespread effects of hyperintense lesions on cerebral white matter structure. Am J Roentgenol 2007; 188:1695-704.

40. Dufouil C, Chalmers J, Coskun O, Besancon V, Bousser MG, Guillon P, MacMahon S, Mazoyer B, Neal B, Woodward M, Tzourio-Mazoyer N, Tzourio C. Effects of blood pressure lowering on cerebral white matter hyperintensities in patients with stroke: The PROGRESS (Perindopril Protection Against Recurrent Stroke Study) magnetic resonance imaging substudy. Circulation 2005; 112:1644-50

41. Birns J, Markus H, Kalra L. Blood pressure reduction for vascular risk: Is there a price to be paid? Stroke 2005;36:1308-13. 
Silent lacunar but not territorial brain infarcts are related to ambulatory blood pressure levels in hypertensive patients

Léon H.G. Henskens

Robert J. van Oostenbrugge

Abraham A. Kroon

Peter W. de Leeuw

Jan Lodder

submitted
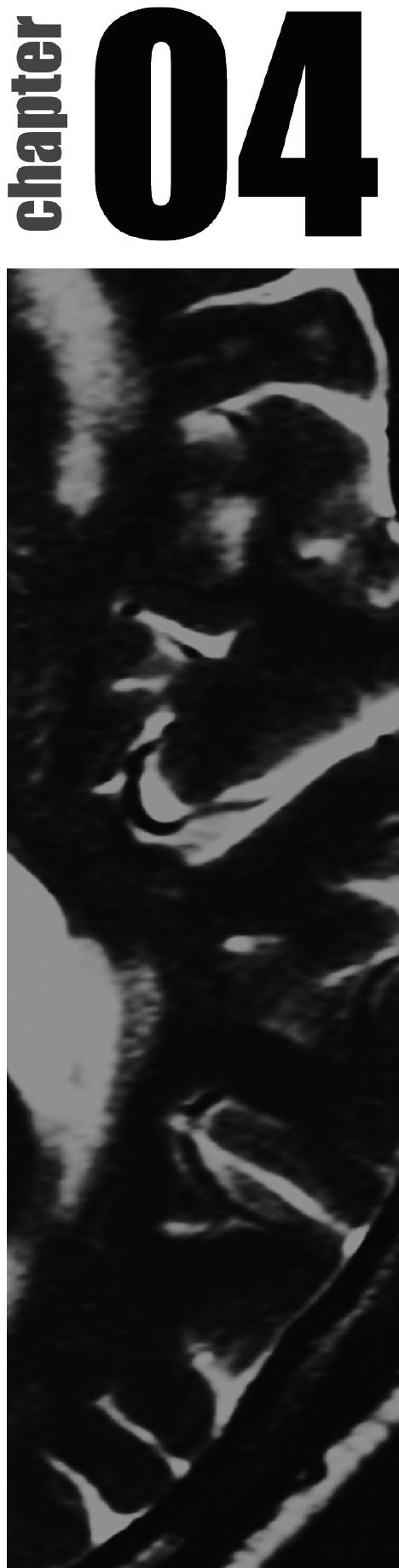


\section{Summary}

Although silent brain infarcts occur frequently in patients with hypertension, little is known about the relation of subtypes of silent brain infarcts and blood pressure levels per se.

In 213 stroke-free hypertensive patients (110 males, age 52.5 \pm 12.6 years) we performed duplicate 24-hour ambulatory blood pressure monitoring (off-medication) and brain magnetic resonance imaging to detect silent brain infarcts. Lacunar infarcts were distinguished from territorial infarcts. We performed logistic regression analyses to relate ambulatory blood pressure levels to silent brain infarcts and their subtypes.

Silent brain infarcts were present in 61 (29\%) participants of whom 42 had lacunar infarcts and 25 had territorial infarcts (i.e., six patients displayed both subtypes). On logistic regression analyses, adjusted for age, sex and cardiovascular risk factors, higher 24-hour, awake and asleep blood pressure levels were significantly associated with lacunar infarcts but not territorial infarcts.

In conclusion, these data show that lacunar infarcts but not territorial infarcts are associated with ambulatory measured blood pressure. This differential effect stresses the need for adequately powered trials, which specifically assess the effects of lowering blood pressure on the risk of lacunar infarcts, territorial infarcts and other silent ischemic brain lesions. 


\section{Introduction}

Silent brain infarcts (SBIs) occur frequently in patients with hypertension. ${ }^{1}$ Nevertheless, the relation between SBIs and blood pressure (BP) as a quantitative variable has not been studied in detail. Studies into subtypes of SBls are lacking, despite observations that some brain areas may be more vulnerable to the adverse effects of high BP than other regions. ${ }^{2}$ Furthermore, a better understanding of how BP relates to SBI-subtypes is also relevant in view of the potential benefits of lowering BP in the primary and secondary prevention of (silent) stroke. ${ }^{3}$

In the present study, carried out in a cohort of stroke-free hypertensive patients, we aimed to further detail the BP-SBI relationship, by relating ambulatory measured BP to SBIs in subtype-specific analyses.

\section{Methods}

\section{Participants}

Selection of participants has been described in detail elsewhere (Figure B.1, Appendix B). ${ }^{4}$ Briefly, 218 patients referred for evaluation of their hypertension (office BP $\geq 140 / 90 \mathrm{mmHg}$ ) and currently off anti-hypertensive treatment were included in the present study. All participants, aged 20-82 years, had no signs of secondary hypertension or chronic renal failure, no documented diabetes, ischemic or valvular heart disease, no atrial fibrillation, and no history of symptomatic cerebrovascular disease (i.e., transient ischemic attacks or stroke). Interviews (lifestyle habits, treatment and hypertension history), physical examinations (including office BP measurements) and routine laboratory investigations (including echocardiography and urinalysis to test for the presence of left ventricular hypertrophy and microalbuminuria, respectively) were performed as published recently. 4,5

All participants gave written informed consent and the Medical Ethics Committee of the Maastricht University Medical Centre approved the study.

\section{Ambulatory blood pressure monitoring}

Blood pressure (off-medication) was monitored non-invasively over a 24-hour period and on two occasions using ambulatory BP monitoring (ABPM; SpaceLabs 90207 or 90217 devices [SpaceLabs Medical Inc., Redmond, Washington, USA]). We performed duplicate recordings (median time interval of seven [interquartile range 5-9] days) because the assessment of the diurnal BP profile on the basis of a single recording is less reliable. ${ }^{6}$ Participant's awake (daytime) and asleep (nighttime) periods were determined by excluding a 2-hour transition period around the reported rising and retiring times. According to this narrow diary time 
definition and based on both ABPMs (for reproducibility analyses see Appendix C) we calculated the mean 24-hour, awake and asleep systolic BP (SBP), mean arterial pressure (MAP), and diastolic BP (DBP), and quantified the relative nocturnal BP (MAP) dip (equation: ((mean awake MAP - mean asleep MAP) / mean awake MAP) * $100 \%$ ), as reported recently. ${ }^{4}$ We defined hypertension as an untreated office $\mathrm{BP} \geq 140 \mathrm{mmHg}$ systolic and/or $\geq 90 \mathrm{mmHg}^{\text {diastolic. }{ }^{7}}$

\section{Silent brain infarcts}

Brain MRI (1.5-T) was performed to obtain axial T2-weighted and fluid-attenuated inversion recovery (FLAIR) images (for details on the imaging protocol see Appendix D). ${ }^{4}$ We identified SBls as sharply demarcated hyperintense lesions on T2-weighted images, with corresponding foci of FLAIR low signal intensity. Small infarcts were distinguished from perivascular spaces using the FLAIR images, infarcts being characterized by a central cavitation of low signal intensity with a surrounding higher-intensity rim of gliotic tissue. We distinguished lacunar infarcts (LACs; diameter 3-15 mm) situated in the basal ganglia, internal capsule, thalamus (i.e., those sites limited to the vascular territories of the lenticulostriate, anterior choroidal and thalamoperforant arteries) and/or brainstem, from territorial infarcts (TIs) located in the cerebral hemispheres, cerebellum and/or brainstem (for examples of LACs and TIs see Figure A.2.1 and A.2.2, respectively, Appendix A). Two vascular neurologists (R.v.O and J.L.) independently rated all scans. In case of disagreement, infarcts were ascertained by consensus.

\section{Statistical analysis}

To assess the relation between ambulatory BP and silent infarcts we performed logistic regression analyses, adjusted for age and sex, and additionally (i.e., exploration) for the self-reported duration of hypertension, previous antihypertensive treatment, smoking status and the ratio of total to high-density lipoprotein cholesterol. Covariates were forced into the models simultaneously (enter procedure). We applied the same approach to evaluate the relation between ambulatory BP and measures of hypertensive cardiac and renal organ damage.

A two-tailed probability value $<0.05$ was considered statistically significant. Analyses were performed using the statistical software package SPSS (version 11.0.4 for Macintosh, SPSS Inc., Chicago, Illinois, USA).

\section{Results}

Of the 218 participants, 213 (98\%) had duplicate ABPMs and complete MRI data. Their characteristics are presented in Table 4.1. Reproducibility data of the 
duplicate ABPMs are presented in Appendix C. In accordance with the results of the reproducibility analyses all BP data are based on the average of both recordings.

Table 4.1 Characteristics of the study population.

\begin{tabular}{|c|c|}
\hline Characteristics & All (213) \\
\hline Sex, male & $108(51)$ \\
\hline Age, years & $52.5 \pm 12.6$ \\
\hline $\mathrm{BMI}, \mathrm{kg} / \mathrm{m}^{2}$ & $28.2 \pm 4.9$ \\
\hline \multicolumn{2}{|l|}{ Office $\mathrm{BP}, \mathrm{mmHg}$ : } \\
\hline SBP & $170 \pm 24$ \\
\hline DBP & $104 \pm 12$ \\
\hline Heart rate, bpm & $75 \pm 12$ \\
\hline Current smoker & $36(17)$ \\
\hline \multicolumn{2}{|l|}{ Cholesterol, mmol/l: } \\
\hline Total & $5.9 \pm 1.2$ \\
\hline $\mathrm{HDL}$ & $1.4 \pm 0.4$ \\
\hline Ratio total/HDL cholesterol & $4.6 \pm 1.4$ \\
\hline Creatinine, $\mu \mathrm{mol} / /$ & $82(71-93)$ \\
\hline \multicolumn{2}{|l|}{ Hypertension history: } \\
\hline Duration of hypertension, months & $45(14-145)$ \\
\hline Previous antihypertensive treatment & $173(81)$ \\
\hline \multicolumn{2}{|l|}{ Silent brain infarcts: } \\
\hline Total & $61(29)$ \\
\hline Lacunar & $42(20)$ \\
\hline Territorial & $25(12)$ \\
\hline \multicolumn{2}{|c|}{$\begin{array}{l}\text { Data are presented as mean } \pm \mathrm{SD} \text {, number }(\%) \text {, or median (interquartile range). } \mathrm{BMI} \text { indicates body } \\
\text { mass index; BP, blood pressure; } \mathrm{SBP} \text {, systolic BP; DBP, diastolic BP; bpm, beats per minute; HDL, high- } \\
\text { density lipoprotein. }\end{array}$} \\
\hline
\end{tabular}

We observed 84 SBIs in 61 (29\%) participants. Forty-two (20\%) patients had LACs and $25(12 \%)$ subjects had Tls (Table 4.1). In six participants we observed both subtypes.

The diurnal (24-hour, awake and asleep) systolic, mean and diastolic BP levels of patients with LACs were higher than those measured in patients with TIs, while there was no difference in terms of nocturnal BP dipping (Table 4.2). Ambulatory $\mathrm{BP}$ levels were significantly associated with the presence of SBls and in particular LACs, independent of age and sex (Table 4.2). Additional adjustments for cardiovascular risk factors did not change the results (data not shown). No associations were found between ambulatory BP and Tls (Table 4.2).

In agreement with the above, we found that hypertensive cardio-renal damage, i.e., damage resulting from longstanding high BP levels, was also related to LACs only (Table 4.2). 


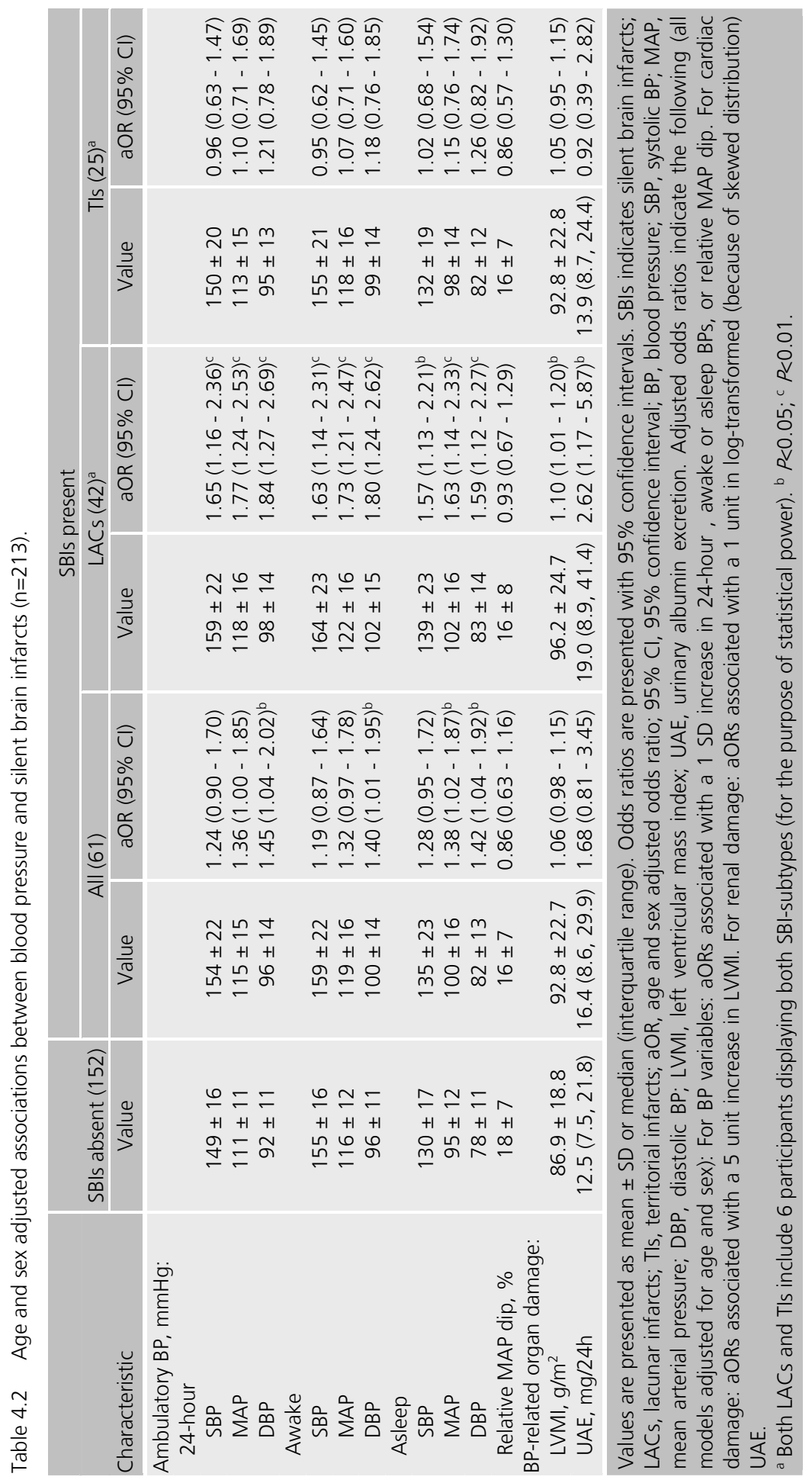




\section{Discussion}

Our analyses show that the relation between ambulatory BP levels and SBIs is determined solely by LACS. Moreover, the inclusion of TIs in the SBI-definition resulted in weak or even non-significant associations between BP and SBIs.

The distinction between LACs and Tls suggests a differential effect of high BP on the brain circulation, fitting within the concept of small vs. large vessel disease. Histopathological and clinical studies have related asymptomatic LACs to hypertension-induced arteriolosclerosis, which particularly occurs in the smallest arteries (diameter <200 $\mu \mathrm{m}$ ).,9 In larger vessels, however, other mechanisms, e.g., atherothrombosis and cardio-embolism, may play a more prominent role, causing (silent) non-lacunar infarcts. ${ }^{2}$ The independent associations with cardio-renal damage further support a role for high BP in the etiology of LACs. Yet, the observed distinction between SBI-subtypes may also result from the small number of TIs, which limits the statistical power to detect modest associations with BP.

Our findings have implications for future research and clinical practice. First, our observations need confirmation in adequately powered and longitudinal studies, being able to establish risk factor profiles for both LACs and TIs (and if possible their subtypes). This is important in view of developing prevention strategies. For instance, reducing BP may mainly lower the risk of new LACs. Territorial infarcts, on the other hand, may require different or additional preventive measures, e.g., cholesterol lowering and/or antithrombotic treatment. Second, data from the Perindopril Protection Against Recurrent Stroke Study (PROGRESS) suggest that active BP reduction stops or delays the progression of SBls (most of which were LACs) in patients with a history of stroke. ${ }^{10}$ However, the safety of BP lowering in patients with (silent) cerebrovascular disease has been questioned. ${ }^{3}$ Therefore, clinical trials in asymptomatic hypertensive patients should evaluate the effects and safety of antihypertensive (and also other cardiovascular) treatment on the development and/or progression of LACs, TIs, and other markers of hypertensionrelated silent brain damage.

In conclusion, our data suggest that high BP differentially affects the risk of LACs and Tls. There is a need for adequately powered intervention trials in hypertensive patients, which specifically assess the effects of lowering BP on the risk of LACs, TIs and other silent ischemic brain lesions. 


\section{References}

1. Vermeer SE, Longstreth WT, Jr., Koudstaal PJ. Silent brain infarcts: A systematic review. Lancet Neuro/ 2007;6:611-9.

2. Jackson C, Sudlow C. Are lacunar strokes really different? A systematic review of differences in risk factor profiles between lacunar and nonlacunar infarcts. Stroke 2005;36:891-901.

3. Birns J, Markus H, Kalra L. Blood pressure reduction for vascular risk: Is there a price to be paid? Stroke 2005;36:1308-13.

4. Henskens LH, van Oostenbrugge RJ, Kroon AA, de Leeuw PW, Lodder J. Brain microbleeds are associated with ambulatory blood pressure levels in a hypertensive population. Hypertension 2008;51:62-68.

5. Henskens LH, Kroon AA, van Oostenbrugge RJ, Haest RJ, Lodder J, de Leeuw PW. Different classifications of nocturnal blood pressure dipping affect the prevalence of dippers and nondippers and the relation with target-organ damage. J Hypertens 2008;26:691-98.

6. Manning G, Rushton L, Donnelly R, Millar-Craig MW. Variability of diurnal changes in ambulatory blood pressure and nocturnal dipping status in untreated hypertensive and normotensive subjects. Am J Hypertens 2000;13:1035-8.

7. Mancia G, De Backer G, Dominiczak A, Cifkova R, Fagard R, Germano G, Grassi G, Heagerty AM, Kjeldsen SE, Laurent S, Narkiewicz K, Ruilope L, Rynkiewicz A, Schmieder RE, Boudier HA, Zanchetti A. 2007 guidelines for the management of arterial hypertension: The task force for the management of arterial hypertension of the European Society of Hypertension (ESH) and of the European Society of Cardiology (ESC). J Hypertens 2007;25:1105-87.

8. Boiten J, Lodder J, Kessels F. Two clinically distinct lacunar infarct entities? A hypothesis. Stroke 1993;24:652-6.

9. Fisher CM. The arterial lesions underlying lacunes. Acta Neuropathol (Berl) 1968;12:1-15.

10. Hasegawa Y, Yamaguchi T, Omae T, Woodward M, Chalmers J. Effects of perindopril-based blood pressure lowering and of patient characteristics on the progression of silent brain infarct: The Perindopril Protection Against Recurrent Stroke Study (PROGRESS) CT substudy in Japan. Hypertens Res 2004;27:147-56 
Brain microbleeds are associated with ambulatory blood pressure levels in a hypertensive population

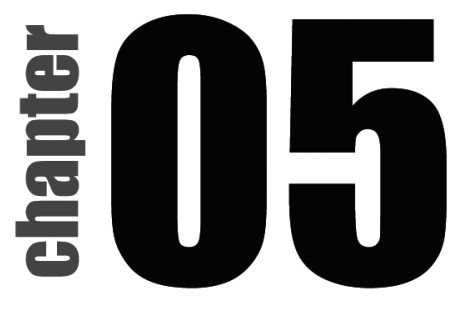

Léon H.G. Henskens

Robert J. van Oostenbrugge

Abraham A. Kroon

Peter W. de Leeuw

Jan Lodder

Hypertension 2008;51:62-8 


\section{Summary}

Brain microbleeds, indicative of cerebral small-vessel disease, may occur with increased frequency in patients with hypertension. However, little is known about the relation of these abnormalities with blood pressure levels. We assessed the relation between ambulatory measured blood pressure and the presence of microbleeds in a cohort of hypertensive patients without a history of cerebrovascular disease.

A total of 218 participants (110 males, age $52.5 \pm 12.6$ years) underwent 24-hour ambulatory blood pressure monitoring twice (off-medication) and brain magnetic resonance imaging to detect microbleeds and coexisting white matter hyperintensities. We performed logistic regression analyses to relate the following blood pressure components (based on both recordings) to microbleeds: the mean 24-hour, awake and asleep blood pressures; nocturnal hypertension (asleep pressure $\geq 120 / 70 \mathrm{mmHg}$ ); nocturnal blood pressure dipping. Models were adjusted for age and sex, and additionally for cardiovascular risk factors, and white matter hyperintensities.

We detected microbleeds in 35 participants $(16.1 \% ; 95 \%$ confidence interval $11.1-21.0 \%)$. On average, each standard deviation increment in blood pressure, whether 24-hour, awake or asleep, was significantly and independently associated with a 1.8- to 1.9-fold higher likelihood for microbleeds (all models $P<0.05$ ). Similarly, the adjusted odds ratio for microbleeds was five- to six-fold higher in subjects diagnosed with nocturnal hypertension (all models $P<0.05$ ). Microbleeds were not associated with nocturnal dipping. In conclusion, brain microbleeds are frequently found in hypertensive patients without a history of cerebrovascular disease, and are independently associated with higher daytime as well as nighttime blood pressure levels. 


\section{Introduction}

Brain microbleeds (BMBs) are focal accumulations of hemosiderin-containing macrophages in the perivascular space of small blood vessels in the brain, indicating previous extravasation of blood. ${ }^{1}$ These abnormalities, which were described in the mid-1990s for the first time², can be identified as small areas of signal loss on haem-sensitive $\mathrm{T}^{*}$-weighted gradient echo (GE) magnetic resonance imaging (MRI), and remain detectable for years. ${ }^{3}$

In Caucasian populations, the prevalence of BMBs is about $5 \%$ in healthy, mostly elderly individuals, increases to around $25 \%$ in ischemic stroke patients and goes even beyond $50 \%$ in patients affected by intracerebral hemorrhage; in populations of Asian descent even higher prevalences have been reported. ${ }^{4,5}$ The presence of BMBs has been associated with cognitive impairment, independent of coexisting ischemic brain damage (in particular white matter changes). ${ }^{6,7}$ Moreover, prospective data suggest that BMBs predict the recurrence of both ischemic and hemorrhagic stroke ${ }^{8-10}$, emphasizing their potential clinical relevance. Although BMBs may occur with increased frequency in patients with hypertension ${ }^{4,5}$ and, accordingly, in conjunction with hypertension-related damage of the heart and the brain ${ }^{11,12}$, little is know about their relation with blood pressure (BP) levels per se. Some studies have reported higher BP levels in subjects displaying $\mathrm{BMBs}^{9,13-15}$, but so far no study has primarily focused on the BP-microbleed relationship.

It has been shown that BP obtained by ambulatory BP monitoring (ABPM) correlates closely with hypertension-related organ damage, and that its prognostic value, whether daytime, nighttime or 24-hour, is superior to that of BP measured in the office. ${ }^{16-18}$ Therefore, the objective of the present study was to assess the relation between BMBs and BP measured by ABPM in a cohort of hypertensive patients without a history of cerebrovascular disease.

\section{Methods}

\section{Participants}

Between July 2004 and September 2006, all consecutive patients referred to our outpatient department for the evaluation of their hypertension have been screened for participation in the present study. As part of the routine work-up, patients underwent ABPM over a 24-hour period, standard 12-lead electrocardiography, and routine laboratory investigations. Patients who were using antihypertensive medication were also instructed to discontinue treatment at least two weeks prior to the BP measurements. An experienced internist decided, based on the patients' clinical information provided by the referring 
physician and independent of the study, whether it was possible to stop temporarily the antihypertensive medication. Accordingly, patients who continued treatment were excluded from participation.

Those patients who stopped or did not receive prior treatment had - to be eligible for inclusion in the present study - to consent to an MRI of the brain and a repeat ABPM, preferably within one week after the first one, and also off-medication. In addition, participants had to fulfill the following criteria: men or women aged 18-90 years; no indication from history-taking, physical examination or routine laboratory tests of secondary hypertension; no evidence of chronic renal insufficiency (serum creatinine concentration $>150 \mu \mathrm{mol} / \mathrm{L}$ ); no history of diabetes; no clinically documented ischemic or valvular heart disease or electrocardiographic evidence of atrial fibrillation; no history of transient ischemic attacks and ischemic or hemorrhagic stroke; no diagnosis of obstructive sleep apnea syndrome. All participants gave written informed consent and the Medical Ethics Committee of the Maastricht University Medical Centre approved the study. In this way, a total of 218 patients were included into the study. The flow diagram in Figure B.1 (Appendix B) displays the number of patients screened, those eligible for inclusion into the study, and those who eventually consented to participate.

\section{Evaluation of blood pressure}

Conventional office BP was measured at the hospital by sphygmomanometry (Korotkoff phases I and V). ${ }^{19}$ After at least five minutes of rest, three consecutive measurements were taken at the non-dominant arm, with the participant seated, and always by the same trained investigator (L.H.). Hypertension was defined as an untreated conventional office BP $\geq 140 \mathrm{mmHg}$ systolic or $\geq 90 \mathrm{mmHg}$ diastolic, or both. ${ }^{20}$

Ambulatory BP was monitored non-invasively on two occasions over a 24-hour period using an oscillometric SpaceLabs 90207 or 90217 device (SpaceLabs Medical Inc., Redmond, Washington, USA). Both monitors meet the accuracy criteria of the Association for the Advancement of Medical Instrumentation and the British Hypertension Society. The devices were programmed to obtain BP recordings every 15 minutes from 0700 to 2300 hours and every 30 minutes thereafter, and set to reject automatically readings with a systolic BP (SBP) >240 or $<70 \mathrm{mmHg}$, a diastolic BP (DBP) $>150$ or $<40 \mathrm{mmHg}$, a mean arterial pressure (MAP) $>200$ or $<40 \mathrm{mmHg}$ or a heart rate $>200$ or $<20$ beats per minute. We performed duplicate recordings because the assessment of the 24-hour BP profile on the basis of a single ABPM has been shown to be less reliable. ${ }^{21}$

Blood pressure was recorded at the non-dominant arm using an appropriately sized cuff. Monitoring sessions started at the hospital, always on a weekday and preferably in the morning. We encouraged participants to adhere to their usual daily activities and regular sleeping hours, but instructed them to keep their arm 
and fingers motionless during a recording. Furthermore, they completed a diary card documenting their actual awake and asleep times.

Spacelabs data files were transferred to a Windows-based PC system and analyzed using the Pressure Import and Export software version 1.4.0. (Instrument Development Engineering and Evaluation [IDEE], Maastricht University, 2005; http://www-id.unimaas.nl). Data files were not edited manually.

Participant's awake (daytime) and asleep (nighttime) periods were determined by excluding a 2-hour transition period around the reported rising and retiring times. On the basis of this narrow diary time approach we assessed the mean 24-hour, awake and asleep SBP, MAP and DBP. Furthermore, we investigated the asleep (nocturnal) BP in terms of: (1) nocturnal hypertension, defined as an average asleep $B P \geq 120 / 70 \mathrm{mmHg}^{19}$; (2) the nocturnal BP dip, quantified as the relative decline in MAP from the awake to asleep periods using the following equation: ((mean awake MAP - mean asleep MAP) / mean awake MAP) * 100\%; (3) nocturnal non-dipping, defined as a nocturnal MAP dip $<10 \%$. ${ }^{16}$

\section{Evaluation of microbleeds and white matter hyperintensities}

Brain MRI was performed on a 1.5-T clinical MR-system (Intera, Philips Medical Systems, Best, The Netherlands) using a standard quadrature head coil. The standardized imaging protocol consisted of T2-weighted fast spin echo (repetition time [TR] 4820 ms; echo time [TE] 100 ms; flip angle 90\%; field of view [FOV] 230 $\mathrm{mm}$; acquisition matrix 512X512), fluid-attenuated inversion recovery (FLAIR) (TR 8000 ms; TE 120 ms; inversion time 2000 ms; FOV 230 mm; acquisition matrix 256X256 [reconstructed to 512X512]) and T2*-weighted GE (TR 736 ms; TE 23 ms; flip angle 15; FOV 230 mm; acquisition matrix 256X256; in-plane spatial resolution $0.9 \times 0.9 \mathrm{~mm} /$ pixel [resolution may be actually higher because of the $\mathrm{T}^{*}{ }^{*}$-effect ${ }^{3}$ ) sequences in the axial plane, producing 24 slices with a thickness of $5 \mathrm{~mm}$ and a $0.5 \mathrm{~mm}$ interslice gap.

We defined BMBs as punctate (diameter $<5 \mathrm{~mm}$ ), homogeneous foci of low signal intensity on $\mathrm{T} 2{ }^{*}$-weighted GE images. ${ }^{22}$ The presence of BMBs was assessed throughout the brain, e.g. brainstem, cerebellum, basal ganglia, corona radiata and cortico-subcortical grey and white matter. Symmetric hypointensities in the globi pallidi, likely to represent calcification or iron deposition, and sulcal flow voids from cortical vessels were disregarded. Figure A.3 (Appendix A) depicts examples of BMBs in several brain areas.

White matter hyperintensities (WMHs) were identified on T2-weighted and FLAIR images and classified according to Fazekas et al. into hyperintensities of the deep and subcortical white matter (DWMH) and periventricular hyperintensities (PVH) (for an example see Figure A.1, Appendix A). ${ }^{23}$ For details on the Fazekas-scale to rate WMHs, see Table E.1 (Appendix E). We considered WMHs to be advanced in case of DWMH grades 2 or 3 (i.e. beginning confluence of foci or large confluent 
areas) and/or PVH grade 3 (i.e. irregular hyperintensities extending into the deep white matter). Histopathological and clinical data indicate that these advanced lesions reflect ischemic brain damage related to a cerebral small-vessel disease. ${ }^{24,25}$ Two independent raters (R.v.O. and J.L.), blinded to the participants' age, sex and clinical status (including BP data), rated all scans. The inter-rater reliability, expressed as Cohen's kappa, was 0.68 for the presence of BMBs and 0.76 for advanced WMHs. According to Landis and Koch, kappa values between 0.60 to 0.79 indicate substantial agreement. ${ }^{26}$ In case of disagreement, lesions were ascertained by consensus.

\section{Evaluation of risk factors}

Information on lifestyle habits, past and current morbidity (including current treatment), and hypertension history (including the self-reported age of diagnosis and previous use of antihypertensive medication), were obtained by interview and verified by inspection of recently started medical records. The duration of hypertension was estimated as the time (in months) passed since the self-reported age of diagnosis until inclusion into the study. Smoking was classified as never, past or current. Height and weight were measured to determine the body mass index (BMI, $\left.\mathrm{kg} / \mathrm{m}^{2}\right)$. Venous blood samples, routinely drawn after an overnight fast, were analyzed for serum total and high-density lipoprotein (HDL) cholesterol and serum creatinine using standard laboratory procedures. Hypercholesterolemia was considered to be present in subjects who either used lipid-lowering drugs or had untreated total cholesterol levels $>6.5 \mathrm{mmol} / \mathrm{l}$.

\section{Statistical analysis}

Before analyzing the relation between ambulatory BP and BMBs we tested the reproducibility of the duplicate ambulatory BP recordings. A detailed description is given in Appendix $C$.

To detect group differences between unpaired data we applied the independent samples $t$-test for normally distributed variables, the Mann-Whitney $U$ test for variables with skewed distributions, and the Pearson $\chi^{2}$ statistic or Fisher's exact test for categorical variables.

We performed logistic regression analyses to evaluate the relation between the aforementioned ambulatory BP components and the presence of BMBs. Models were adjusted for age and sex (model 1), and additionally (i.e. exploratory analyses) for cardiovascular risk factors, i.e., the duration of hypertension, previous antihypertensive treatment, smoking status ${ }^{5}$ and the ratio of total/HDL cholesterol $^{27}$ (model 2). Finally, we also adjusted for the presence of advanced WMHs (model 3).28 All covariates were forced into the model simultaneously (enter procedure). Normally distributed variables are presented as mean $\pm S D$, variables with skewed distributions as median with interquartile ranges (IQR), and 
categorical variables as frequencies. Odds ratios are presented with corresponding $95 \%$ confidence intervals. A two-tailed probability value $<0.05$ was considered statistically significant. Analyses were performed using the statistical software package SPSS (version 11.0.4 for Macintosh, SPSS Inc., Chicago, USA).

\section{Results}

\section{Participants}

Of the 389 patients eligible for inclusion into the study, 218 consented to participate (Figure B.1, Appendix B). The remainder $(n=171)$ did not differ significantly from the participants in terms of age $(50.4 \pm 14.4$ vs. $52.5 \pm 12.6$ years, $P=0.283)$ and sex (45.0\% male vs. $50.5 \%, P=0.287)$. The daytime MAP and DBP levels were slightly, yet significantly, higher in participants than in those who were not included into the study (MAP: $117 \pm 13$ vs. $114 \pm 13 \mathrm{mmHg}, P=0.045 ;$ DBP: $97 \pm 12$ vs. $94 \pm 12 \mathrm{mmHg}, P=0.016)$. However, refusal to participate was neither associated with the daytime systolic pressure $(156 \pm 18$ vs. $153 \pm 17 \mathrm{mmHg}$, $P=0.336)$ nor with the SBP, MAP as well as DBP levels during sleep (132/97/80 $\pm 20 / 15 / 13$ vs. $131 / 95 / 77 \pm 19 / 14 / 12 \mathrm{mmHg}, P=0.460 / 0.143 / 0.056)$.

\section{Characteristics according to microbleed status}

Microbleeds were observed in 35 of 218 participants $(16.1 \%$; 95\% confidence interval [Cl] 11.1-21.0\%). Twenty-two patients displayed a single microbleed, six patients had two, and seven patients showed three or more BMBs. The characteristics of the study population are summarized in Table 5.1. Participants with BMBs were older and had higher office BP levels than those without $(P<0.05)$. Based on the office pressures 207 (94.9\%) patients were diagnosed with hypertension. Eleven (5.1\%) participants had normal BP levels, and none of them displayed BMBs on MRI. We observed no differences in the duration of hypertension or cardiovascular treatment, i.e. previous antihypertensive treatment, or current use of antithrombotic and cholesterol lowering medication.

Advanced WMHs were present in 46 of 218 participants $(21.1 \% ; 95 \% \mathrm{Cl}$ 15.6-26.6\%), being more prevalent in subjects with BMBs than in those without (48.6\% vs. $15.8 \%$, respectively; $P<0.001)$.

\section{Ambulatory blood pressure and brain microbleeds}

Of the 218 participants who underwent ABPM, duplicate recordings were available in $213(97.7 \%)$. Monitoring sessions were repeated with a median interval of seven (IQR 5-9) days. Detailed reproducibility data are given in Appendix C. 
Table 5.1 Characteristics of the study population according to the microbleed status.

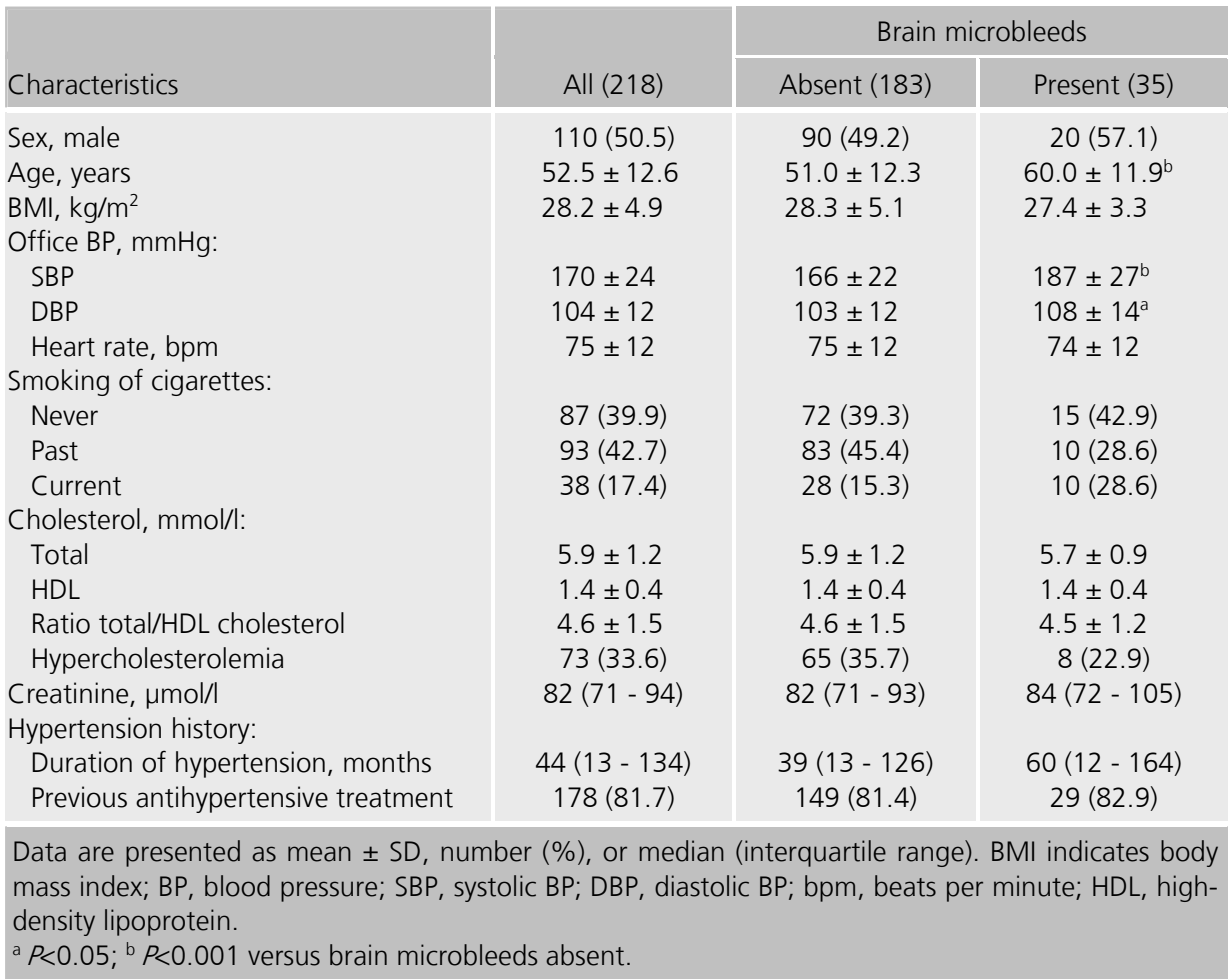

Brain MRI was performed with a median interval of 10 (IQR 7-16) days after the first ABPM. Odds ratios quantifying the relation between the different ambulatory BP components and BMBs are summarized in Table 5.2. Higher 24-hour, awake and asleep BP levels, and nocturnal hypertension were significantly associated with the presence of BMBs, independent of age and sex (Table 5.2, model 1; all $P<0.01)$. For every SD increase in SBP, MAP or DBP, the odds ratios ranged between 1.84 and 2.01 for the 24-hour period, between 1.75 and 1.87 for the awake period, and between 1.80 and 1.90 for the asleep period; a diagnosis of nocturnal hypertension was associated with a 5.45-fold higher likelihood for BMBs (Table 5.2, model 1). Additional adjustments (exploratory analyses) for cardiovascular risk factors, i.e., the duration of hypertension, previous antihypertensive treatment, smoking and the ratio of total/HDL cholesterol, did not affect the associations substantially (Table 5.2, model 2). Final adjustments for coexisting advanced WMHs modified the results of model 2 only slightly (Table 5.2, model 3). 


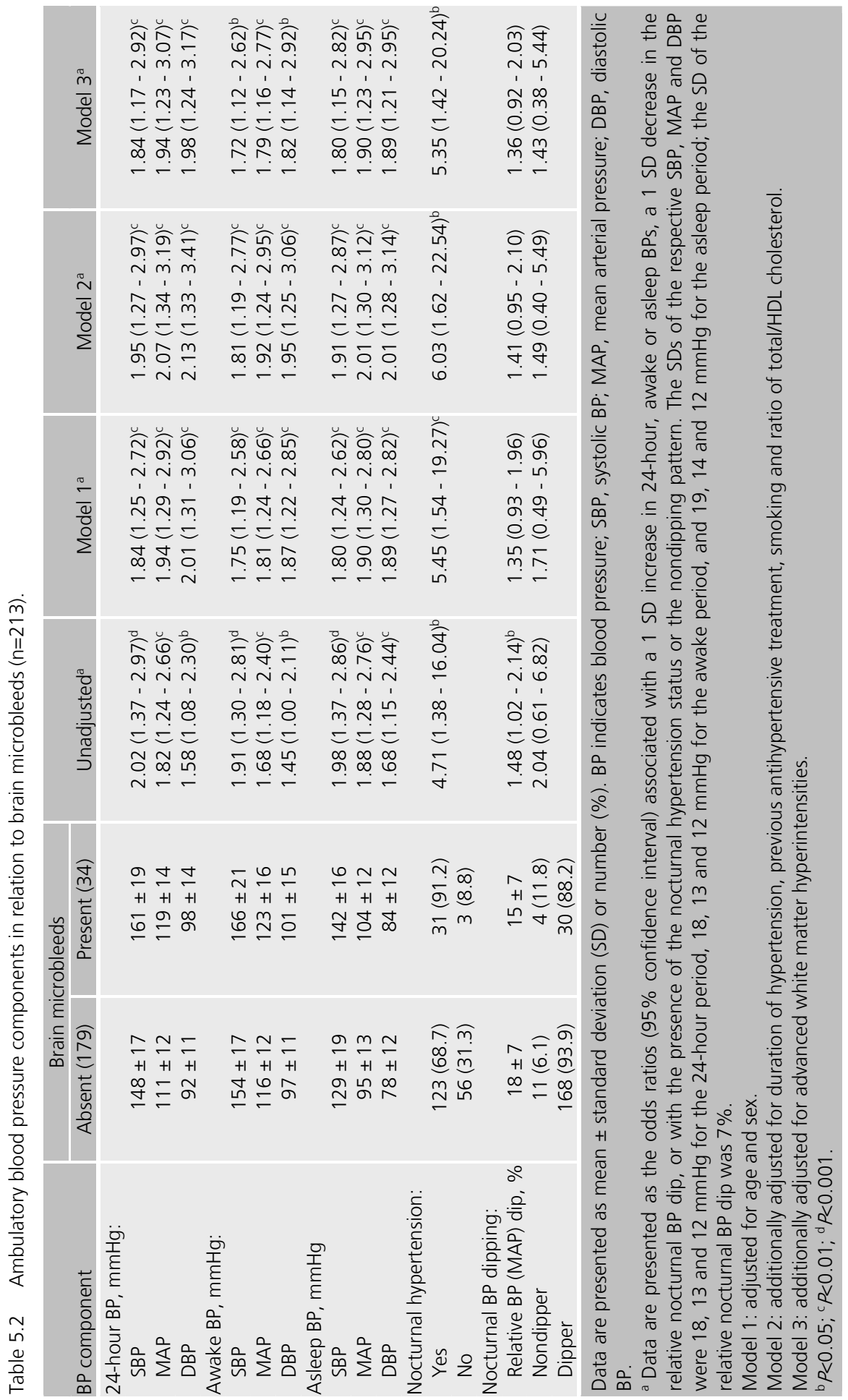




\section{Discussion}

The present study demonstrated that, in this hypertensive population without a history of cerebrovascular disease, the prevalence of microbleeds in the brain was $16.1 \%(95 \% \mathrm{Cl} 11.1-21.0 \%)$, and that the daytime, nighttime and 24-hour BP levels and a diagnosis of nocturnal hypertension were associated with the presence of BMBs, independent of age and sex, other cardiovascular risk factors, and coexisting ischemic brain damage.

The frequency of BMBs in our hypertensive cohort is approximately three times higher than that reported in the general population. ${ }^{4}$ Importantly, in our study the microbleed-count could not have been influenced by a history of symptomatic cerebrovascular disease as this was an exclusion criterion. ${ }^{29,30}$ This, together with the observed associations between ambulatory BP and BMBs, suggests that hypertension is a substantial and independent risk factor for the development of BMBs.

The associations between the various ambulatory BP components and the presence of BMBs were robust and independent of age and sex, other cardiovascular risk factors, and advanced WMHs. On average, every SD increment in BP, whether 24-hour, daytime or nighttime, was associated with a 1.8- to 1.9-fold higher likelihood for BMBs. In the adjusted models the asleep BP, in addition to the awake pressure, remained significantly related to the presence of BMBs. Moreover, the associations were even stronger, confirming earlier observations supporting the importance of a high nighttime BP. ${ }^{17,18}$ The finding that the likelihood for BMBs was five- to six-fold higher in subjects who were diagnosed with nocturnal hypertension further supports this.

Contrary, the nondipping status, in general considered to be a strong determinant of hypertension-related organ damage ${ }^{31}$, was not related to the presence of BMBs. Also when we analyzed the day-to-night BP decline as a continuous variable, adjusted associations were not significant. However, the prevalence of nondippers was small $(n=15,7.0 \%)$. This, along with the narrow and nearly significant $95 \% \mathrm{Cls}$ of the odds ratios for BMBs associated with the relative nocturnal BP dip, reflects the low statistical power of these analyses to detect associations with BP dipping.

The mechanism behind hypertension-related BMBs remains speculative. Histopathological studies have shown that BMBs consist of macrophages containing hemosiderin - a blood breakdown product - adjacent to small blood vessels affected by moderate to severe fibrohyalinosis or arteriolosclerosis. ${ }^{1,32}$ Hence, a high BP during the day and additionally at night, i.e., a higher cumulative 24-hour BP load, could induce structural changes of the brain microvasculature with subsequent extravasation of blood. A similar concept, i.e., blood-brain barrier leakage of plasma components with hypertension as a major risk factor, has been proposed previously as a cause of other types of small-vessel 
disease in the brain, namely WMHs and lacunar stroke. ${ }^{33}$ The associations between BMBs and ambulatory BP in our study were not explained by coexisting WMHs, suggesting that the occurrence and mechanisms of both abnormalities are, at least in part, independent.

The present study has limitations, such as the cross-sectional design and the relatively small number of participants displaying BMBs. Although the group size was sufficient to carry out the logistic regression analyses corrected for age and sex, the additional adjustments (models 2 and 3), having an exploratory nature, need to be interpreted within the context of their statistical limitations. Hence, our findings require confirmation in longitudinal and adequately powered studies. Another limitation is the lack of a local, preferably community based, control population. Such a control group would have enabled us to assess whether the prevalence of BMBs in our hypertensive cohort was really increased. Furthermore, it is possible that we failed to include patients with more severe hypertension, because they were not allowed to stop their antihypertensive medication. However, we would expect an even higher prevalence of BMBs and more robust associations with ambulatory BP when participants with more severe hypertension had been included.

On the other hand, we performed our study in a large cohort of well-defined hypertensive patients whose data were collected prospectively. Moreover, demographic and BP data of the participants were similar to those who did not consent to the study. Another strength of the study is that the BP was measured by $A B P M$ and, importantly, on two occasions. Based on the reproducibility analyses we used the data of both recordings. Other investigators previously have shown that this improves the reliability of the calculated BP components. ${ }^{21,34}$ Finally, the observed associations were not biased by concurrent antihypertensive treatment $^{35}$ or a history of symptomatic stroke. ${ }^{29,30}$ The latter implies that the detected BMBs in our participants were all silent.

In summary, our study showed that BMBs are a frequent finding in hypertensive patients without a history of cerebrovascular disease. Moreover, the data suggest that participants with a high daytime and especially nighttime BP, i.e., a high 24hour BP load, were more likely to display BMBs on MRI. In contrast to the general believe that BMBs are clinically silent, recently reported associations with cognitive impairment ${ }^{6,7}$ and an increased risk of stroke recurrence ${ }^{8,9}$ - processes that may be accelerated in the face of a persistently high BP - illustrate the potential clinical relevance of these small lesions. Considering all this, we postulate that BMBs should be considered as an additional (besides WMHs and lacunar infarcts) and independent marker of hypertensive target-organ damage of the brain. Our findings need, however, confirmation in adequately powered and preferably longterm follow-up studies, which also should address the role of BMBs in risk estimation and prevention of both future stroke and impairment of brain function. 


\section{References}

1. Fazekas F, Kleinert R, Roob G, Kleinert G, Kapeller P, Schmidt R, Hartung HP. Histopathologic analysis of foci of signal loss on gradient-echo $T 2^{*}$-weighted MR images in patients with spontaneous intracerebral hemorrhage: Evidence of microangiopathy-related microbleeds. $\mathrm{Am} J$ Neuroradio/ 1999;20:637-42.

2. Offenbacher H, Fazekas F, Schmidt R, Koch M, Fazekas G, Kapeller P. MR of cerebral abnormalities concomitant with primary intracerebral hematomas. $A m$ J Neuroradiol 1996;17:573-8.

3. Roob G, Fazekas F. Magnetic resonance imaging of cerebral microbleeds. Curr Opin Neurol 2000;13:69-73.

4. Koennecke HC. Cerebral microbleeds on MRI: Prevalence, associations, and potential clinical implications. Neurology 2006;66:165-71.

5. Cordonnier C, Al-Shahi Salman R, Wardlaw J. Spontaneous brain microbleeds: Systematic review, subgroup analyses and standards for study design and reporting. Brain 2007;130:1988-2003.

6. Werring DJ, Frazer DW, Coward LJ, Losseff NA, Watt H, Cipolotti L, Brown MM, Jager HR. Cognitive dysfunction in patients with cerebral microbleeds on $\mathrm{T} 2{ }^{*}$-weighted gradient-echo MRI. Brain 2004; $127: 2265-75$.

7. Won Seo S, Hwa Lee B, Kim EJ, Chin J, Sun Cho Y, Yoon U, Na DL. Clinical significance of microbleeds in subcortical vascular dementia. Stroke 2007;38:1949-51.

8. Boulanger JM, Coutts SB, Eliasziw M, Gagnon AJ, Simon JE, Subramaniam S, Sohn CH, Scott J, Demchuk AM. Cerebral microhemorrhages predict new disabling or fatal strokes in patients with acute ischemic stroke or transient ischemic attack. Stroke 2006;37:911-4.

9. Fan YH, Zhang L, Lam WW, Mok VC, Wong KS. Cerebral microbleeds as a risk factor for subsequent intracerebral hemorrhages among patients with acute ischemic stroke. Stroke 2003;34:2459-62.

10. Jeon SB, Kang DW, Cho AH, Lee EM, Choi CG, Kwon SU, Kim JS. Initial microbleeds at MR imaging can predict recurrent intracerebral hemorrhage. J Neuro/2007;254:508-12.

11. Kwa VI, Franke CL, Verbeeten B, Jr., Stam J. Silent intracerebral microhemorrhages in patients with ischemic stroke. Amsterdam vascular medicine group. Ann Neuro/ 1998;44:372-7.

12. Lee SH, Park JM, Kwon SJ, Kim H, Kim YH, Roh JK, Yoon BW. Left ventricular hypertrophy is associated with cerebral microbleeds in hypertensive patients. Neurology 2004;63:16-21.

13. Roob G, Schmidt R, Kapeller P, Lechner A, Hartung HP, Fazekas F. MRI evidence of past cerebral microbleeds in a healthy elderly population. Neurology 1999;52:991-4.

14. Werring DJ, Coward LJ, Losseff NA, Jager HR, Brown MM. Cerebral microbleeds are common in ischemic stroke but rare in TIA. Neurology 2005;65:1914-8.

15. Viswanathan A, Guichard JP, Gschwendtner A, Buffon F, Cumurcuic R, Boutron C, Vicaut E, Holtmannspotter M, Pachai C, Bousser MG, Dichgans M, Chabriat $H$. Blood pressure and haemoglobin A1C are associated with microhaemorrhage in CADASIL: A two-centre cohort study. Brain 2006;129:2375-83.

16. Verdecchia P, Schillaci G, Guerrieri M, Gatteschi C, Benemio G, Boldrini F, Porcellati C. Circadian blood pressure changes and left ventricular hypertrophy in essential hypertension. Circulation 1990;81:528-36.

17. Dolan E, Stanton A, Thijs L, Hinedi K, Atkins N, McClory S, Den Hond E, McCormack P, Staessen JA, O'Brien E. Superiority of ambulatory over clinic blood pressure measurement in predicting mortality: The Dublin outcome study. Hypertension 2005;46:156-61.

18. Staessen JA, Thijs L, Fagard R, O'Brien ET, Clement D, de Leeuw PW, Mancia G, Nachev C, Palatini P, Parati G, Tuomilehto J, Webster J. Predicting cardiovascular risk using conventional vs ambulatory blood pressure in older patients with systolic hypertension. Systolic hypertension in Europe trial investigators. JAMA 1999;282:539-46.

19. O'Brien E, Asmar R, Beilin L, Imai Y, Mallion JM, Mancia G, Mengden T, Myers M, Padfield P, Palatini P, Parati G, Pickering T, Redon J, Staessen J, Stergiou G, Verdecchia P. European Society of Hypertension recommendations for conventional, ambulatory and home blood pressure measurement. J Hypertens 2003;21:821-48. 
20. 2003 European Society of Hypertension-European Society of Cardiology guidelines for the management of arterial hypertension. J Hypertens 2003;21:1011-53.

21. Manning G, Rushton L, Donnelly R, Millar-Craig MW. Variability of diurnal changes in ambulatory blood pressure and nocturnal dipping status in untreated hypertensive and normotensive subjects. Am J Hypertens 2000;13:1035-8.

22. Wardlaw JM, Lewis SC, Keir SL, Dennis MS, Shenkin S. Cerebral microbleeds are associated with lacunar stroke defined clinically and radiologically, independently of white matter lesions. Stroke 2006;37:2633-6.

23. Fazekas F, Chawluk JB, Alavi A, Hurtig HI, Zimmerman RA. MR signal abnormalities at $1.5 \mathrm{~T}$ in Alzheimer's dementia and normal aging. Am J Roentgeno/ 1987;149:351-6.

24. Fazekas F, Kleinert R, Offenbacher $H$, Schmidt $R$, Kleinert $G$, Payer F, Radner $H$, Lechner $H$. Pathologic correlates of incidental MRI white matter signal hyperintensities. Neurology 1993;43:1683-9.

25. Pantoni L, Garcia JH. Pathogenesis of leukoaraiosis: A review. Stroke 1997;28:652-9.

26. Landis JR, Koch GG. The measurement of observer agreement for categorical data. Biometrics 1977;33:159-74.

27. Lee SH, Bae HJ, Yoon BW, Kim H, Kim DE, Roh JK. Low concentration of serum total cholesterol is associated with multifocal signal loss lesions on gradient-echo magnetic resonance imaging: Analysis of risk factors for multifocal signal loss lesions. Stroke 2002;33:2845-9.

28. Kim DE, Bae HJ, Lee SH, Kim H, Yoon BW, Roh JK. Gradient echo magnetic resonance imaging in the prediction of hemorrhagic vs ischemic stroke: A need for the consideration of the extent of leukoariosis. Arch Neuro/ 2002;59:425-9.

29. Kinoshita T, Okudera T, Tamura H, Ogawa T, Hatazawa J. Assessment of lacunar hemorrhage associated with hypertensive stroke by echo-planar gradient-echo T2*-weighted MRI. Stroke 2000;31:1646-50.

30. Lee SH, Kwon SJ, Kim KS, Yoon BW, Roh JK. Cerebral microbleeds in patients with hypertensive stroke. Topographical distribution in the supratentorial area. J Neuro/2004;251:1183-9.

31. Staessen JA, Asmar R, De Buyzere M, Imai Y, Parati G, Shimada K, Stergiou G, Redon J, Verdecchia P. Task force II: Blood pressure measurement and cardiovascular outcome. Blood Press Monit 2001;6:355-70.

32. Tanaka A, Ueno Y, Nakayama Y, Takano K, Takebayashi S. Small chronic hemorrhages and ischemic lesions in association with spontaneous intracerebral hematomas. Stroke 1999;30:1637-42.

33. Wardlaw JM, Sandercock PA, Dennis MS, Starr J. Is breakdown of the blood-brain barrier responsible for lacunar stroke, leukoaraiosis, and dementia? Stroke 2003;34:806-12.

34. Fotherby MD, Potter JF. Reproducibility of ambulatory and clinic blood pressure measurements in elderly hypertensive subjects. J Hypertens 1993;11:573-9.

35. Lee $\mathrm{SH}$, Heo JH, Yoon BW. Effects of microbleeds on hemorrhage development in leukoaraiosis patients. Hypertens Res 2005;28:895-9. 
${ }_{88} 1$ 
Associations of the angiotensin II type 1 receptor $A^{1166} \mathrm{C}$ and the endothelial nitric oxide synthase $\mathrm{G}^{894} \mathrm{~T}$ gene polymorphisms with silent subcortical white matter lesions in essential hypertension
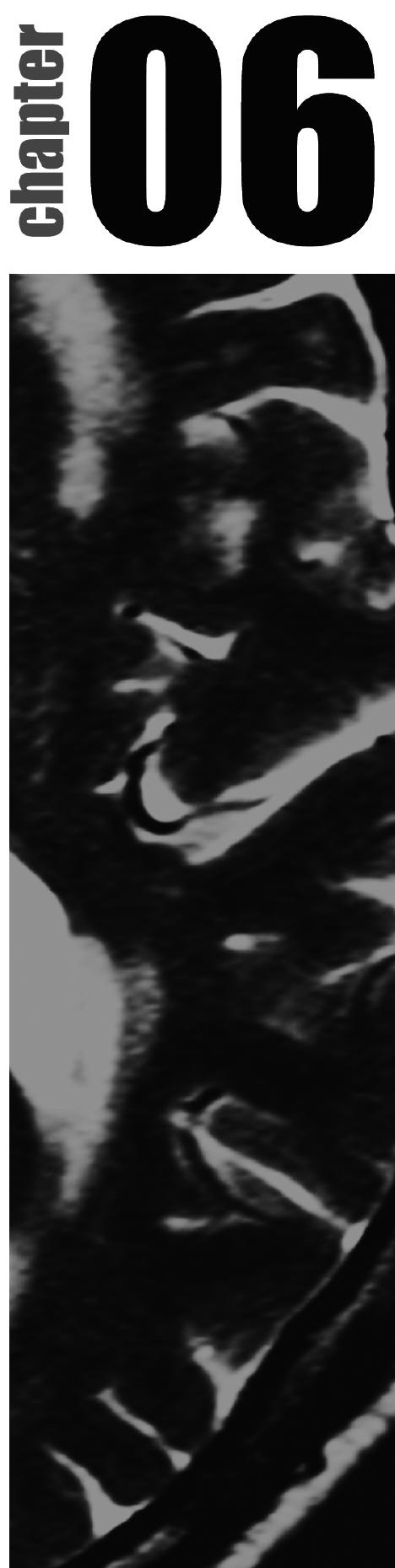

Léon H.G. Henskens

Abraham A. Kroon

Martin P.J. van Boxtel,

Paul A.M. Hofman

Peter W. de Leeuw

Stroke 2005;36:1869-73 


\section{Summary}

White matter lesions may represent early target-organ damage of the brain in patients with hypertension. Because these lesions may have a genetic background we assessed the associations between polymorphisms of the renin-angiotensin system and the endothelial nitric oxide synthase genes and white matter lesions.

Ninety-three hypertensive individuals were studied. Magnetic resonance imaging of the brain was performed to obtain estimates of the total volume of subcortical and the extent of periventricular white matter lesions. Patients were genotyped for the angiotensinogen (AGT $M^{235} T$ ), the angiotensin-converting enzyme (ACE insertion/deletion, $I / D$ ), the angiotensin II type 1 receptor (AGTR1 $A^{1166} \mathrm{C}$ ) and the endothelial nitric oxide synthase (NOS3 $\mathrm{G}^{894} \mathrm{~T}$ ) genes. A linear regression model was used to assess the relationship of these gene polymorphisms with both subtypes of white matter lesions.

When adjusted for age, diabetes mellitus and blood pressure, subcortical white matter lesion volume was lowest in the presence of one or two AGTR1 $\mathrm{C}$ alleles (unstandardized $\beta$ $-39.0 ; 95 \%$ confidence interval -66.4 to -11.7 , and $-114.2 ; 95 \%$ confidence interval -190.6 to -37.8 , respectively), whereas it was highest in the presence of an NOS3 T allele (31.1; $95 \%$ confidence interval, 3.6 to 58.5). No interaction between these polymorphisms on white matter lesions could be demonstrated. No associations were present with the other polymorphisms, either with subcortical or periventricular lesions.

In conclusion, we found the AGTR1 $A^{1166} \mathrm{C}$ as well as the NOS3 $\mathrm{G}^{894} \mathrm{~T}$ polymorphisms to be associated with white matter lesions in the subcortical area. 


\section{Introduction}

Asymptomatic white matter lesions (WMLs) on magnetic resonance imaging (MRI) of the brain may represent an early sign of target-organ damage in patients with hypertension. ${ }^{1}$ WMLs are thought to be caused by cerebral small-vessel disease (SVD), probably through endothelial dysfunction. ${ }^{2}$ Twin and family studies also suggest a strong genetic background. ${ }^{3,4}$ Among the potential candidate genes that can account for a genetic predisposition to WMLs, common genetic variants of the renin-angiotensin system (RAS) and the endothelial nitric oxide synthase (NOS3) rank high. ${ }^{5-11}$ Homozygosity of the deletion variant of the angiotensinconverting enzyme insertion/deletion (ACE I/D) polymorphism and the presence of one or two $C$ alleles of the $A^{1166} \mathrm{C}$ polymorphism of the angiotensin II type 1 receptor (AGTR1) gene, indeed, seem to increase the risk of WMLs. ${ }^{7-11}$ No evidence has been found for a role of the angiotensinogen (AGT) $M^{235} \mathrm{~T}$ and the NOS3 G ${ }^{894}$ T polymorphisms. 5,6,11

Previously, other investigators distinguished periventricular WMLs from those in the subcortical area on the basis of vascularisation patterns ${ }^{12}$, susceptibility to (vascular) risk factors ${ }^{13}$ and consequences, e.g., cognitive impairment. ${ }^{14}$ Moreover, the Rotterdam Scan Study suggests that the genetic predisposition to WMLs is confined to specific brain areas, i.e., to the subcortical but not the periventricular white matter. ${ }^{15}$ However, no data are available regarding the relationship between the aforementioned polymorphisms and this site-specificity. Moreover, WMLs have been studied predominantly as a qualitative (i.e., presence or absence) rather than as a quantitative trait (i.e., lesion quantity). This prompted us to assess the associations between polymorphisms of the RAS and the NOS3 genes and WMLs, in terms of well-characterized subtypes and lesion quantity, in otherwise healthy hypertensive individuals, aged between 30 and 80 years.

\section{Methods}

\section{Participants}

A total of 105 consecutive hypertensive patients aged between 30 and 80 years who attended the outpatient clinic of the University Hospital Maastricht were enrolled in the present study. Hypertension was defined as a systolic blood pressure (BP) $\geq 140 \mathrm{mmHg}$, or a diastolic $\mathrm{BP} \geq 90 \mathrm{mmHg}$, or both, as assessed on multiple occasions. Exclusion criteria were: clinical evidence of ischemic or valvular heart disease, congestive heart failure, cerebrovascular accidents or transient ischemic attacks, chronic renal failure (serum creatinine $>150 \mu \mathrm{mol} / \mathrm{l}$ ), indication of secondary hypertension, and contraindications for MRI. As part of the local protocol, ambulatory blood pressure monitoring (ABPM) was performed over a 
24-hour period and blood samples were drawn for routine laboratory investigations and genetic analysis. Brain MRI was performed for the present study only. All patients gave their written informed consent and the local Medical Ethics Committee approved the study.

\section{Risk factors}

Blood samples were drawn from fasting patients for assessment of serum creatinine, total cholesterol and glucose levels. Hypercholesterolemia was defined as a total cholesterol level exceeding $6.5 \mathrm{mmol} / \mathrm{l}$ and/or use of lipid-lowering drugs. Diabetes mellitus (DM) was considered to be present in case of fasting plasma glucose levels above $6.9 \mathrm{mmol} / \mathrm{l}$ and/or use of oral anti-diabetic drugs or insulin.

Non-invasive ABPM (SpaceLabs 90217; SpaceLabs Medical Inc., Redmond, Washington, USA) was performed at the non-dominant arm, every 15 minutes during the day and every 30 minutes during the night. Antihypertensive medication was discontinued three weeks prior to ABPM. For analysis, average levels of 24-hour systolic BP (SBP), diastolic BP (DBP), mean arterial pressure (MAP) and pulse pressure (PP) were calculated.

At their visit to the hospital, patients' height, weight and smoking status were obtained.

\section{White matter lesion scoring}

MRI scans were made on a 1.5 Tesla Philips Intera NT. The scan protocol consisted of axial proton density (PD), axial T2-weighted fast spin-echo (FSE), and axial T2weighted fluid-attenuated inversion recovery (FLAIR) sequences. Subcortical and periventricular WMLs were scored according to the Rotterdam Scan Study scale (Table E.2, Appendix E). ${ }^{14}$ For an example of WMLs see Figure A.1 (Appendix A). All scans were analyzed off-line using custom software (Ed Gronenschild; imageprocessing software package GIANT [General Imaging and Analysis Tools]; Department of Psychiatry and Neuropsychology, Maastricht University, Maastricht, The Netherlands). This program allowed a systematic inspection of side-by-side aligned axial PD, FSE, and FLAIR image stacks and manual demarcation of regions of interest (ROI). Subcortical WMLs were scored using predefined ROI masks, i.e. circles with a diameter of 2, 6, and $12 \mathrm{~mm}$, respectively. Lesions were first identified on the FLAIR image and then confirmed on both other images at the same level. If a lesion was present on all three images, the mask that matched the $\mathrm{ROI}$ best was fitted over the lesion. After inspection and delineation of all subcortical WMLs in a stack the program generated an output file with the number and size of all lesions at each level of the scan. In order to obtain the total subcortical WML volume for each patient, ROls were inflated to spheres with the same diameter, with corresponding volumes of 4.2, 113 and $905 \mathrm{~mm}^{3}$, 
respectively. Subcortical WMLs were processed by one medical investigator (M.v.B.) after satisfactory intra-class correlations (ICCs) between 0.81 and 0.98 had been reached, based on the independent assessments of subsequent series of 10 random stacks by this investigator and an experienced neuroradiologist (P.H.). Periventricular WML severity, ranging between 0 and 3, was scored for frontal and occipital regions ('caps') and the medial periventricular lining ('bands') separately, which were then summed to an overall periventricular WMLs score. ${ }^{14}$

\section{Genetic analysis}

DNA was extracted from whole blood with the use of the QIAamp ${ }^{\circledR}$ Blood Kit (Qiagen Inc.). The ACE I/D polymorphism was detected using the technique described by Rigat et al. ${ }^{16}$ A second PCR was performed to avoid misidentification of ID as DD. Genotyping of the AGT M ${ }^{235} T$, the AGTR1 $A^{1166} \mathrm{C}$ and the NOS3 $\mathrm{G}^{894} \mathrm{~T}$ polymorphisms was performed using a multilocus genotyping assay for candidate markers of cardiovascular disease risk (Roche Molecular Systems Inc.), and has been described in detail previously. ${ }^{17}$ Genetic analyses were performed after assessment of the MRI scans, so the investigators who scored WMLs were blinded for the genotypes.

\section{Statistical analysis}

Deviation from Hardy-Weinberg equilibrium (HWE) was assessed using $\chi^{2}$-statistics comparing expected against observed genotype frequencies. Allele frequencies were estimated by gene counting.

Because of skewed distribution of WMLs, associations between periventricular or subcortical WMLs and risk factors or demographics were determined by means of Spearman's correlations and the non-parametric Mann-Whitney $U$ test. Subsequently, WML data were log-transformed to achieve normality before further analysis.

Univariate and multivariate regression analyses were performed to evaluate the relationship between genotypes and WMLs, with adjustment for age, DM and ambulatory BP. For that purpose, dummy variables were created using the homozygous wild type genotype as reference category. All covariates were forced into the model simultaneously (enter procedure). In addition, for those models that reached statistical significance, the influence of the separate alleles on WMLs were assessed similarly.

Interactions between two polymorphisms with respect to WMLs were assessed using a linear regression model that included the alleles at risk, the interaction term between the two, and other covariates when applicable.

Normally distributed variables are presented as mean $\pm \mathrm{SD}$, variables with skewed distributions as median (interquartile ranges), and categorical variables as frequencies. A two-tailed probability value $<0.05$ was considered statistically 
significant. Because of the exploratory nature of the present study, no corrections for multiple testing were applied. Statistical analyses were performed using SPSS 11.5 for Windows (SPSS Inc., Chicago, Illinois, USA).

\section{Results}

\section{Patient characteristics}

Among the 105 patients available, MRI data of nine patients were inadequate because of claustrophobia (one), movement artifacts (four) or premature withdrawal from the study (four). Another three patients withdrew consent for genetic investigations leaving 93 patients for analysis. Patients who entered the study did not differ in baseline characteristics from those who did not.

Characteristics of the study population are summarized in Table 6.1. Twenty patients (22\%) had no, or only one small subcortical WML on their MRI scan, whereas periventricular WMLs were present in 61 patients (66\%). Age was associated with higher subcortical WML volume and periventricular WML score ( $r=0.587$ and $P<0.001$, and $r=0.485$ and $P<0.001$, respectively). Twenty-four-hour SBP, MAP and PP correlated with periventricular WMLs $(r=0.360$ and $P=0.001$, $r=0.231$ and $P=0.027$, and $r=0.463$ and $P<0.001$, respectively), whereas 24-hour PP correlated with subcortical WMLs $(r=0.294$ and $P=0.004)$. There were no significant associations between WML categories and other demographics or risk factors.

Table 6.1 Characteristics of the study population $(n=93)$

\begin{tabular}{l|c} 
Characteristics & All \\
\hline Sex, male/female & $56 / 37$ \\
Age, years & $57 \pm 11$ \\
Smoking & $27(29)$ \\
BMI, kg/m² & $28.8 \pm 5.5$ \\
Glucose, mmol/l & $5.9 \pm 1.1$ \\
Diabetes mellitus & $14(15)$ \\
Cholesterol, mmol/l & $5.4 \pm 1.1$ \\
Hypercholesterolemia & $23(25)$ \\
Creatinine, $\mu$ mol/l & $85.0(71.0-96.0)$ \\
24-hour SBP, mmHg & $152 \pm 21$ \\
24-hour DBP, mmHg & $93 \pm 12$ \\
24-hour MAP, mmHg & $113 \pm 14$ \\
24-hour PP, mmHg & $59 \pm 15$ \\
Heart rate, bpm & $75 \pm 11$ \\
Subcortical WML volume, mm ${ }^{3}$ & $138.23(8.38-590.62)$ \\
Periventricular WMLs, score & $0.50(0.00-2.25)$ \\
\hline Data are presented as mean \pm SD, number (\%), or median (interquartile range). BMI indicates body \\
mass index; SBP, systolic blood pressure (BP); DBP, diastolic BP; MAP, mean arterial pressure; PP, pulse \\
pressure; bpm, beats per minute; WML, white matter lesion.
\end{tabular}




\section{Genetic analysis}

In seven patients a second analysis was necessary to obtain all the genotypes. Genotype and allele frequencies of all polymorphisms (Table 6.2) were in HWE.

There were no statistically significant associations between the polymorphisms of the RAS or NOS3 genes and periventricular WML score. The same was true for the $A C E ~ I / D$ and the AGT $M^{235} T$ polymorphisms with respect to the subcortical WML volume. However, both the AGTR1 $A^{1166} \mathrm{C}$ and the NOS3 $\mathrm{G}^{894} \mathrm{~T}$ polymorphisms were significantly associated with subcortical WMLs (Table 6.3). When using the AA genotype as the reference category, the CC genotype of the AGTR1 $A^{1166} C$ polymorphism was inversely associated with the volume of subcortical WMLs. Similarly, when using the GG genotype of the NOS3 $\mathrm{G}^{894} \mathrm{~T}$ polymorphism as the reference category, the $\Pi T$ genotype was associated with the highest subcortical WML volumes.

Table 6.2 Genotype and allele frequencies of the studied polymorphisms.

\begin{tabular}{|c|c|c|c|c|c|}
\hline Polymorphism & & Genotype & & Allele & ncies \\
\hline AGT $M^{235} T$ & $\begin{array}{c}C C \\
16(17.2)\end{array}$ & $\begin{array}{c}C T \\
43(46.2)\end{array}$ & $\begin{array}{c}T T \\
34(36.6)\end{array}$ & $\begin{array}{c}C \\
0.403\end{array}$ & $\begin{array}{c}T \\
0.597\end{array}$ \\
\hline ACE I/D & $\begin{array}{c}\| \\
11(11.8)\end{array}$ & $\begin{array}{c}\text { ID } \\
49(52.7)\end{array}$ & $\begin{array}{c}\text { DD } \\
33(35.5)\end{array}$ & $\begin{array}{c}1 \\
0.382\end{array}$ & $\begin{array}{c}D \\
0.618\end{array}$ \\
\hline AGTR1 $A^{1166} C$ & $\begin{array}{c}\text { AA } \\
38(40.9)\end{array}$ & $\begin{array}{c}A C \\
49(52.7)\end{array}$ & $\begin{array}{c}C C \\
6(6.5)\end{array}$ & $\begin{array}{c}A \\
0.672\end{array}$ & $\begin{array}{c}C \\
0.328\end{array}$ \\
\hline NOS $G^{894} T$ & $\begin{array}{c}\mathrm{GG} \\
38(40.9)\end{array}$ & $\begin{array}{c}\mathrm{GT} \\
47(50.5)\end{array}$ & $\begin{array}{c}\text { TT } \\
8(8.6)\end{array}$ & $\begin{array}{c}G \\
0.661\end{array}$ & $\begin{array}{c}T \\
0.339\end{array}$ \\
\hline
\end{tabular}

After adjustment for age, DM and 24-hour PP (Table 6.3), the AGTR1 CC genotype remained independently and inversely associated with the subcortical WML volume. In addition, the volume of subcortical WMLs was significantly lower in carriers of the AC genotype compared to AA carriers. The NOS3 $\mathrm{G}^{894} \mathrm{~T}$ polymorphism remained associated with the subcortical WML volume on multivariate analysis, albeit only for the GT genotype. Analyses based on the risk alleles yielded comparable results, showing the highest volumes of subcortical WMLs with the AGTR1 A and the NOS3 T alleles (Table 6.3). There was no statistical interaction between the two polymorphisms. 
Table 6.3 Linear regression model for the AGTR1 $A^{1166} \mathrm{C}$ or NOS3 $\mathrm{G}^{894} \mathrm{~T}$ genotypes and alleles with subcortical WML volume.

\begin{tabular}{|c|c|c|}
\hline \multirow[b]{2}{*}{ Determinants } & \multicolumn{2}{|c|}{ Subcortical WML volume } \\
\hline & Univariate analysis & Multivariate analysis ${ }^{a}$ \\
\hline $\begin{array}{l}\text { AGTR1 } \mathrm{AC}^{\mathrm{b}} \\
\text { AGTR1 } \mathrm{CC}^{\mathrm{b}} \\
\text { AGTR1 } \mathrm{C}^{\mathrm{c}}\end{array}$ & $\begin{array}{c}-31.1(-75.8-13.6) \\
-147.0(-237.8--56.2) \\
-41.3(-74.2--8.5)\end{array}$ & $\begin{array}{l}-47.8(-85.8--9.8) \\
-112.6(-188.9--36.4) \\
-38.8(-66.1--11.4)\end{array}$ \\
\hline $\begin{array}{l}\text { NOS3 GT } \\
\text { NOS3 } T^{b} \\
\text { NOS3 } T^{\mathrm{c}}\end{array}$ & $\begin{array}{l}36.1(-10.1-82.2) \\
95.3(13.0-177.6) \\
37.3(4.5-70.1)\end{array}$ & $\begin{array}{l}43.3(4.5-82.1) \\
63.3(-10.3-136.8) \\
31.1(3.6-58.4)\end{array}$ \\
\hline
\end{tabular}

Data are presented as unstandardized $\beta$ (95\% confidence interval). The $\beta$ represents the change in log-transformed subcortical WML volume for each unit change in continuous risk factors and for a change from negative to positive for dichotomous risk factors.

${ }^{a}$ Adjusted for age, diabetes mellitus and 24-hour pulse pressure; ${ }^{b}$ AGTR1 AA or NOS3 GG genotypes were used as reference category, respectively; 'AGTR1 A or NOS3 G alleles were used as reference category, respectively.

\section{Discussion}

In the present study, we found the AGTR1 $A^{1166} \mathrm{C}$ as well as the NOS3 $\mathrm{G}^{894} \mathrm{~T}$ polymorphisms to be associated with silent WMLs in the subcortical white matter. When age, DM and BP were accounted for, lesion volume was lowest in the presence of an AGTR1 $C$ allele and in patients with the CC genotype, whereas it was highest in the presence of an NOS3 T allele.

The associations reported on here contradict the observations of most previous studies on the AGTR1, NOS3 and ACE gene polymorphisms. Firstly, the $C$ allele and the CC genotype of the AGTR1 $A^{1166} \mathrm{C}$ polymorphism have been associated with the severity of periventricular WMLs ${ }^{11}$ or an increased risk of incident ischemic stroke. ${ }^{18}$ Furthermore, evidence suggests that the $\mathrm{C}$ allele is an independent cardiovascular risk factor. ${ }^{19}$ Consequently, one would expect the $C$ allele rather than the A allele to be associated with subcortical WML volume. Secondly, others did not find an association between the NOS3 G ${ }^{894} \mathrm{~T}$ variant and WMLs on both MRI and computed tomography in patients with clinically evident cerebral SVD. ${ }^{5}$ Studies on ischemic stroke also failed to detect a relationship with this polymorphism ${ }^{20,21}$ or even reported an increased risk in patients homozygous for the $\mathrm{G}$ allele. ${ }^{22}$ Lastly, we were not able to replicate previous associations of the ACE D allele and the DD genotype with ischemic stroke ${ }^{23}$ or WMLs $^{7-10}$ in terms of lesion subtype and severity.

Inconsistencies in association studies can be attributed mainly to multiple hypothesis testing, heterogeneous study populations and inadequate power. ${ }^{24}$ Whereas the first two situations are not likely to explain our findings as we performed this study with a clear a priori hypothesis and selected our population 
using strict inclusion criteria, the third situation potentially does. Although, our study population is small, the cohort design enabled us to investigate the impact of genetic markers. This could help in identifying those patients who are at greatest risk and who may need (although this has yet to be proven) more aggressive treatment. Moreover, recent evidence suggests that the use of intermediate phenotypes and a 'high quality' of phenotyping allow smaller populations to be studied. ${ }^{5,25}$ Silent WMLs are an intermediate phenotype for cerebral SVD and ischemic stroke. ${ }^{25,26}$ Furthermore, we phenotyped WMLs according to subtype (subcortical and/or periventricular) and severity (lesion volume), and independently of the results of genotyping. By doing so, we improved the quality of phenotyping. Nevertheless, the small study population remains a limitation of the present study and confirmation in larger cohorts including case-control studies is needed.

Other potential sources of inconsistency between our data and those in the literature are the use of different rating scales for quantifying WMLs and differences in disease status. With respect to the latter, most studies focused on patients with clinical evidence of stroke rather than on silent disease. Since stroke is characterized by a continuing increased risk of death ${ }^{27}$, selection bias may have occurred by early death of patients carrying a high-risk allele. Indeed, several association studies observed lower frequencies of high-risk alleles in stroke patients compared to healthy controls. ${ }^{20,22}$ On the other hand, studies on the AGT $\mathrm{M}^{235} \mathrm{~T}$ polymorphism including ours were all negative. ${ }^{6,7,11}$ Remarkably, the latter studies focused all on silent WMLs. Thus, it is possible that the influence of genetic factors on the course of the disease, i.e., from silent abnormalities to clinically evident lesions varies.

The mechanisms behind the associations reported on here remain speculative, especially because the functional aspects of the genetic polymorphisms are not clear yet. On the other hand, it is possible that these polymorphisms are in linkage disequilibrium with another unidentified functional mutation nearby. In keeping with this, our group and others recently provided indirect evidence of a functional role. The AGTR1 C and the NOS3 T alleles were found to be associated with increased sensitivity to angiotensin $\|$ and reduced bioavailability of nitric oxide, respectively. ${ }^{17,28}$

We and others ${ }^{15}$ provide evidence that the genetic predisposition to WMLs is confined to specific brain areas. Very recently, the Rotterdam Scan Study showed an increased risk of subcortical but not periventricular WMLs in carriers of the apolipoprotein $\mathrm{E}$ (apoE) $\varepsilon 4$ allele of the apoE gene. ${ }^{15}$ Our data extend this observation by showing that genetic variants of other pathways mediating vascular function and morphology exhibit a similar predilection for the subcortical white matter. These observations are indicative of distinct subtypes of WMLs, which is supported by additional evidence. For instance, the periventricular white matter seems less resistant to the influence of hypertension and other vascular risk 
factors than the subcortical white matter..$^{13,15}$ Furthermore, the vascular architecture of the subcortical and periventricular white matter appears to be significantly different, the latter being an arterial watershed zone, lacking appropriate anastomoses..$^{12,29}$ Finally, cognitive impairment as a consequence of WMLs has been associated with lesions in the periventricular rather than the subcortical area. ${ }^{14}$

In summary, our data support the notion that genetic factors may explain the differences in the susceptibility of the cerebral white matter to hypertension. ${ }^{15}$ Furthermore, these data illustrate the value of intermediate phenotypes in studies on genotype-phenotype relationships. Prospective studies are now warranted, all the more since a recent study found the AGT $\mathrm{M}^{235} \mathrm{~T}$ polymorphism to be associated with the progression of WMLs rather than their presence per se. ${ }^{6}$ 


\section{References}

1. de Leeuw FE, de Groot JC, Oudkerk M, Witteman JC, Hofman A, van Gijn J, Breteler MM. Hypertension and cerebral white matter lesions in a prospective cohort study. Brain 2002;125:765-72.

2. Hassan A, Hunt BJ, O'Sullivan M, Parmar K, Bamford JM, Briley D, Brown MM, Thomas DJ, Markus HS. Markers of endothelial dysfunction in lacunar infarction and ischaemic leukoaraiosis. Brain 2003;126:424-32.

3. Carmelli D, DeCarli C, Swan GE, Jack LM, Reed T, Wolf PA, Miller BL. Evidence for genetic variance in white matter hyperintensity volume in normal elderly male twins. Stroke 1998;29:1177-81.

4. Turner ST, Jack CR, Fornage M, Mosley TH, Boerwinkle E, de Andrade M. Heritability of leukoaraiosis in hypertensive sibships. Hypertension 2004;43:483-7.

5. Hassan A, Gormley K, O'Sullivan M, Knight J, Sham P, Vallance P, Bamford J, Markus H. Endothelial nitric oxide gene haplotypes and risk of cerebral small-vessel disease. Stroke 2004;35:654-9.

6. Schmidt R, Schmidt H, Fazekas F, Launer L, Niederkorn K, Kapeller P, Lechner A, Kostner GM. Angiotensinogen polymorphism M235T, carotid atherosclerosis, and small-vessel disease-related cerebral abnormalities. Hypertension 2001;38:110-5.

7. Sierra C, Coca A, Gomez-Angelats E, Poch E, Sobrino J, de la Sierra A. Renin-angiotensin system genetic polymorphisms and cerebral white matter lesions in essential hypertension. Hypertension 2002;39:343-7.

8. Amar K, MacGowan S, Wilcock G, Lewis T, Scott M. Are genetic factors important in the aetiology of leukoaraiosis? Results from a memory clinic population. Int I Geriatr Psychiatry 1998;13:585-90.

9. Hassan A, Lansbury A, Catto AJ, Guthrie A, Spencer J, Craven C, Grant PJ, Bamford JM. Angiotensin converting enzyme insertion/deletion genotype is associated with leukoaraiosis in lacunar syndromes. J Neurol Neurosurg Psychiatry 2002;72:343-6.

10. Szolnoki Z, Somogyvari F, Kondacs A, Szabo M, Fodor L. Evaluation of the roles of common genetic mutations in leukoaraiosis. Acta Neurol Scand 2001;104:281-7.

11. Takami S, Imai Y, Katsuya T, Ohkubo T, Tsuji I, Nagai K, Satoh H, Hisamichi S, Higaki J, Ogihara T. Gene polymorphism of the renin-angiotensin system associates with risk for lacunar infarction. The ohasama study. Am J Hypertens 2000;13:121-7.

12. Pantoni L, Garcia JH. Pathogenesis of leukoaraiosis: A review. Stroke 1997;28:652-9.

13. Lindgren A, Roijer A, Rudling O, Norrving B, Larsson EM, Eskilsson J, Wallin L, Olsson B, Johansson BB. Cerebral lesions on magnetic resonance imaging, heart disease, and vascular risk factors in subjects without stroke. A population-based study. Stroke 1994;25:929-34.

14. de Groot JC, de Leeuw FE, Oudkerk M, van Gijn J, Hofman A, Jolles J, Breteler MM. Cerebral white matter lesions and cognitive function: The Rotterdam Scan Study. Ann Neurol 2000;47:145-51.

15. de Leeuw FE, Richard F, de Groot JC, van Duijn CM, Hofman A, Van Gijn J, Breteler MM. Interaction between hypertension, apoE, and cerebral white matter lesions. Stroke 2004;35:1057-60.

16. Rigat B, Hubert C, Corvol P, Soubrier F. PCR detection of the insertion/deletion polymorphism of the human angiotensin converting enzyme gene (dcp1) (dipeptidyl carboxypeptidase 1). Nucleic Acids Res 1992;20:1433.

17. Veldman BA, Spiering W, Doevendans PA, Vervoort G, Kroon AA, de Leeuw PW, Smits P. The glu298asp polymorphism of the NOS3 gene as a determinant of the baseline production of nitric oxide. J Hypertens 2002;20:2023-7.

18. Rubattu S, Di Angelantonio E, Stanzione R, Zanda B, Evangelista A, Pirisi A, De Paolis P, Cota L, Brunetti $E$, Volpe $M$. Gene polymorphisms of the renin-angiotensin-aldosterone system and the risk of ischemic stroke: A role of the A1166C/AT1 gene variant. J Hypertens 2004;22:2129-34. 
19. Benetos A, Gautier S, Ricard S, Topouchian J, Asmar R, Poirier O, Larosa E, Guize L, Safar M, Soubrier F, Cambien F. Influence of angiotensin-converting enzyme and angiotensin II type 1 receptor gene polymorphisms on aortic stiffness in normotensive and hypertensive patients. Circulation 1996;94:698-703.

20. MacLeod MJ, Dahiyat MT, Cumming A, Meiklejohn D, Shaw D, St Clair D. No association between glu/asp polymorphism of NOS3 gene and ischemic stroke. Neurology 1999;53:418-20.

21. Markus HS, Ruigrok Y, Ali N, Powell JF. Endothelial nitric oxide synthase exon 7 polymorphism, ischemic cerebrovascular disease, and carotid atheroma. Stroke 1998;29:1908-11.

22. Elbaz A, Poirier O, Moulin T, Chedru F, Cambien F, Amarenco P. Association between the glu298asp polymorphism in the endothelial constitutive nitric oxide synthase gene and brain infarction. The genic investigators. Stroke 2000;31:1634-9.

23. Casas JP, Hingorani AD, Bautista LE, Sharma P. Meta-analysis of genetic studies in ischemic stroke: Thirty-two genes involving approximately 18,000 cases and 58,000 controls. Arch Neurol 2004;61:1652-61.

24. Hingorani A. Resolving inconsistency in the results of genetic association studies of cardiovascular disease. Clin Sci (Lond) 2004;107:251-3.

25. Markus H. Genes for stroke. J Neuro/ Neurosurg Psychiatry 2004;75:1229-31.

26. Vermeer SE, Hollander M, van Dijk EJ, Hofman A, Koudstaal PJ, Breteler MM. Silent brain infarcts and white matter lesions increase stroke risk in the general population: The Rotterdam Scan Study. Stroke 2003;34:1126-9.

27. Brønnum-Hansen $H$, Davidsen $M$, Thorvaldsen P. Long-term survival and causes of death after stroke. Stroke 2001;32:2131-6.

28. Spiering W, Kroon AA, Fuss-Lejeune MM, Daemen MJ, de Leeuw PW. Angiotensin II sensitivity is associated with the angiotensin II type 1 receptor $A(1166) C$ polymorphism in essential hypertensives on a high sodium diet. Hypertension 2000;36:411-6.

29. Nonaka H, Akima M, Hatori T, Nagayama T, Zhang Z, Ihara F. Microvasculature of the human cerebral white matter: Arteries of the deep white matter. Neuropathology 2003;23:111-8. 
Renin-angiotensin system and nitric oxide synthase gene polymorphisms in relation to stroke

Léon H.G. Henskens

Abraham A. Kroon

Yvonne T. van der Schouw,

Paul M. Schiffers

Diederick E. Grobbee

Peter W. de Leeuw

Michiel L. Bots

Am J Hypertens 2007;20:764-70
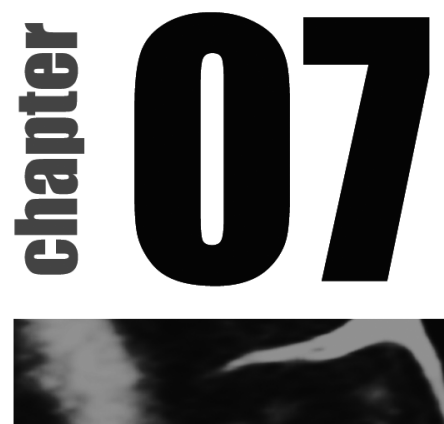


\section{Summary}

There is ample evidence that genetic factors contribute to cardiovascular disease risk. The present study aimed to assess the relation between polymorphisms of the angiotensin II type 1 receptor (AGTR1 $A^{1166} \mathrm{C}$ ) and endothelial nitric oxide synthase (NOS3 $\mathrm{G}^{894} \mathrm{~T}$ ) and the risk of stroke.

We performed a case-cohort study on all first fatal and non-fatal stroke events $(n=74)$ and a $10 \%$ random sample $(n=1,523)$ of a population-based cohort of women aged 49 70 years ( $n=15,236$; median follow-up 4.3 years). Uni- and multivariate unweighted Cox proportional hazards regression models were used to assess the relation between the polymorphisms, their interactions with coexisting risk factors and the risk of stroke.

The relation between the AGTR1 CC genotype and stroke risk (unadjusted hazard ratio $1.62 ; 95 \%$ confidence interval, $0.81-3.28$ ) was modified by increasing age ( $>56$ years: adjusted hazard ratio $2.77 ; 95 \%$ confidence interval, 1.17-6.56) and systolic blood pressure (>130 mmHg: adjusted hazard ratio 2.58; 95\% confidence interval, 1.12-5.93). The NOS3 $\mathrm{G}^{894} \mathrm{~T}$ polymorphism, however, was not associated with stroke risk.

In conclusion, in the presence of other coexisting risk factors the AGTR1 $\mathrm{A}^{1166} \mathrm{C}$ but not the NOS3 $\mathrm{G}^{894} \mathrm{~T}$ polymorphism increased the risk of stroke. The CC genotype may help identify those individuals who are at greatest risk and who may need (early) treatment and/or careful follow-up. 


\section{Introduction}

The burden of stroke in Westernized societies is high and in view of the ageing population estimates forecast a continuing rise in the incidence, prevalence and mortality of stroke in the next decades. ${ }^{1}$ To improve the detection of groups at particularly high risk, it is considered important to identify new determinants beyond conventional risk factors. Evidence is accumulating that genetic factors contribute to the risk of stroke. ${ }^{2}$ Some investigators have suggested that genetic factors which appear insignificant when occurring alone may increase susceptibility to stroke in the presence of other risk factors. ${ }^{3}$

Among potential candidate genes that predispose to stroke, those related to the renin-angiotensin system (RAS) and the endothelial nitric oxide (NO) synthase (NOS3) rank high, as both systems play an important role in vascular function and morphology. ${ }^{4}$ Accordingly, the angiotensin II type 1 receptor (AGTR1) $A^{1166} \mathrm{C}$ and the NOS3 $\mathrm{G}^{894} \mathrm{~T}$ polymorphisms have been implicated in the pathophysiology of cardiovascular events, including stroke..$^{5-8}$ Coexisting risk factors, such as hypertension and high cholesterol levels, seem to increase the effects of these polymorphisms $5,6,8$, though, the available evidence remains inconclusive. This prompted us to assess the influence of the AGTR1 $A^{1166} \mathrm{C}$ and NOS3 $G^{894} \mathrm{~T}$ polymorphisms, and their interaction with coexisting risk factors, on the risk of stroke in a large and relatively homogeneous cohort of women aged 49 to 70 years, who were followed up for a median of 4.3 years.

\section{Methods}

\section{Study population}

The study population consisted of participants of one of the two Dutch contributions to the European Prospective Investigation into Cancer and nutrition (Prospect-EPIC cohort). Study design and characteristics of the cohort population have been described in detail previously9. Briefly, a total of 17,357 women aged 49 to 70 years were included. At enrolment all women underwent a physical examination and filled out a general questionnaire relating to lifestyle and medical factors. In addition, a non-fasting blood sample was taken, which was fractionated into serum, citrated plasma, buffy coat and erythrocyte aliquots and stored under liquid nitrogen at minus $196^{\circ} \mathrm{C}$ for future research. Data on morbidity were obtained from the Dutch Centre for Health Care Information, which holds a standardized computerized register of hospital discharge diagnoses. All diagnoses were coded according to the International Classification of Diseases, Ninth Revision (ICD-9). Using the ICD-9 codes we categorized cerebrovascular disease of any kind (codes 430-438) and other cardiovascular diseases. 
Whenever multiple events occurred, the first diagnosis was taken as endpoint for analyses.

All women signed an informed consent form prior to study inclusion. The study was approved by the Institutional Review Board of the University Medical Center Utrecht.

\section{Design}

We applied a case-cohort design introduced by Prentice. ${ }^{10}$ First, all first fatal and non-fatal stroke events were selected that arose during follow-up until the first of January 2000. Next, from the 17,357 women in the entire cohort we randomly selected a sample of $10 \%$ (sub-cohort $n=1,736$ ). Women who did not consent to linkage with vital status registries or who were not traceable were not included. Women who reported a diagnosis of cardiovascular disease (ICD-9, codes 390459) at baseline, who had missing questionnaires, or who had missing blood or DNA samples were also excluded from the analyses. This resulted in 1,523 women in a random sample (sub-cohort) at baseline and a total number of 74 cerebrovascular events. After applying all exclusions, the entire cohort encompassed 15,236 women. For all case subjects follow-up ended at the date of diagnosis or at the date of death due to cardiovascular disease. Moving out of the Netherlands (two) and death due to causes other than cardiovascular disease (16) were considered censoring events. The remaining subjects were censored on the first of January 2000.

\section{General questionnaire and anthropometric measurements}

The general questionnaire contained questions on demographic characteristics, lifestyle habits, obstetric and gynecological history and past and current morbidity. Women were classified according to their smoking habits as current, past or never smokers. For current and past smokers, the number of pack-years was calculated as the average number of packs of cigarettes smoked per day multiplied by the total years of smoking. Systolic and diastolic blood pressure (BP) and heart rate were measured in duplicate, and mean values were calculated. Furthermore, height, weight and waist and hip circumferences were measured without shoes and wearing light indoor clothing. Body mass index (BMI) was defined as weight divided by height squared $\left(\mathrm{kg} / \mathrm{m}^{2}\right)$. Hypercholesterolemia or diabetes was defined as a self-reported physician diagnosis. Women were considered to be hypertensive when BP exceeded 140 $\mathrm{mmHg}$ systolic and/or $90 \mathrm{mmHg}$ diastolic, or when they were using antihypertensive medication. 


\section{Laboratory measurements}

Biochemical measurements were performed in all sub-cohort members and stroke cases using standard laboratory procedures. Total cholesterol was determined using an automated enzymatic procedure on a Vitros 250 (Johnson \& Johnson, Rochester, New York, USA). Low density lipid (LDL) and high density lipid (HDL) cholesterol were measured using a colorimetric assay on a Hitachi 904 (Johnson \& Johnson, Rochester, New York, USA).

\section{Genetic analysis}

Genetic analysis was performed at the Cardiovascular Genotyping (CAGT) laboratory of the Department of Internal Medicine of the University Hospital Maastricht. Genomic DNA was extracted from buffy coats with the use of the QIAamp ${ }^{\circledR}$ Blood Kit (Qiagen Inc., Valencia, California, USA). Genotyping of the AGTR1 $A^{1166} \mathrm{C}$ and the NOS3 $\mathrm{G}^{894} \mathrm{~T}$ polymorphisms was performed using a multilocus genotyping assay for candidate markers of cardiovascular disease risk and has been described in detail previously. ${ }^{11}$ Investigators involved in biochemical measurements and genotyping were blinded to the disease status of the participants.

\section{Statistical analysis}

Deviation from Hardy-Weinberg equilibrium (HWE) was tested using $\chi^{2}$ statistics comparing expected against observed genotype frequencies. Allele frequencies were estimated by gene counting. Despite the risk of heterogeneity, all stroke types (ICD-9, codes 430-438) were pooled and analyzed as one group because the small number of stroke events complicates reliable comparisons within and between distinct stroke phenotypes.

To investigate whether the AGTR1 and the NOS3 genotypes were risk factors for stroke, we created dummy variables considering the homozygous wild type genotype as reference category ( $A A$ and $G G$, respectively). For the analyses we used an unweighted Cox proportional hazards regression model as described by Prentice. ${ }^{10}$ This approach was specifically developed for case-cohort analyses using SAS statistical software (http://lib.stat.cmu.edu/general.robphreg). For the analysis of case-cohort data, the unweighted method of Prentice computes estimates that, compared to the other methods, resemble those from the full-cohort analysis most. With a sampling fraction $\geq 10 \%$, the results of the case-cohort analyses are similar to the full-cohort analyses. ${ }^{12}$

Using the same approach we checked for potential confounders, i.e., factors related to both stroke and the polymorphism of interest. In addition, we evaluated the presence of possible interactions (effect modification) between the polymorphisms and other coexisting (risk) factors with respect to stroke risk using 
multiplicative interaction terms. The following variables were considered as potential modifying factors: age (continuous), BMI (continuous), systolic and diastolic BP (continuous), HDL and LDL cholesterol (continuous), pack-years of smoking (continuous), hypertension (dichotomous), hypercholesterolemia (dichotomous), and diabetes (dichotomous). In case of a probability value $<0.10$ for the interaction term the model was explored further. For this purpose continuous variables were dichotomized using the median value as cut-off point. For those models that reached statistical significance, the interaction was also explored using a geometric (sliding mean) analysis, being less arbitrary. ${ }^{13}$ According to this approach, subgroups of 500 subjects were formed based on increasing values of the relevant modifying factor. Each subgroup differs from the preceding or succeeding subgroup by 10 individuals. In each subgroup a Cox regression model was carried out to explore the relation between the polymorphism and stroke. Because two adjacent subgroups differ by only 10 individuals (according to the increasing values of the modifying factor), hazard ratios change very smoothly.

Normally distributed variables are presented as mean $\pm S D$, variables with skewed distributions as median (interquartile ranges), and categorical variables as frequencies. Stroke risk is expressed as a hazard ratio (HR) with corresponding $95 \%$ confidence interval (Cl). A two-tailed probability value $<0.05$ was considered statistically significant. Statistical analyses were performed using the statistical software packages SPSS (version 11.5 for Windows, SPSS Inc.) and SAS (version 8.2, SAS Institute Inc.).

\section{Results}

\section{General characteristics}

Baseline characteristics of the study population are summarized in Table 7.1. The women $(n=1,597)$ were followed up for a median of 4.3 years (range 0.03-6.5). Of the 74 stroke events $42(57 \%)$ were classified as ischemic, $20(27 \%)$ as hemorrhagic and $12(16 \%)$ as unspecified for subtype of stroke.

\section{Genotypes}

For technical reasons in 11 women the AGTR1 $A^{1166} \mathrm{C}$ and the NOS3 $G^{894} \mathrm{~T}$ genotypes could not be obtained. In the remaining women $(n=1,586)$, genotype and allele frequencies (Table 7.2) were consistent with the HWE, except for subcohort members with regard to the NOS3 polymorphism $\left(\chi^{2}=7.357 ; P=0.025\right)$. We repeated the genetic analysis of the NOS3 polymorphism in a random sample of 100 participants. In three individuals the initially obtained genotypes, i.e. GG or 
GT, were misclassified as GT or GG, respectively. The TT genotype showed complete concordance.

Table 7.1 Baseline characteristics of the case-cohort according to stroke status.

\begin{tabular}{|c|c|c|c|}
\hline & Total cohort $(n=1,597)$ & Stroke present $(n=74)$ & Stroke absent $(n=1,523)$ \\
\hline $\begin{array}{l}\text { Age, years } \\
\text { Height, cm } \\
\text { BMI, } \mathrm{kg} / \mathrm{m}^{2} \\
\text { Waist, cm } \\
\text { Waist to hip ratio } \\
\text { SBP, mmHg } \\
\text { DBP, mmHg } \\
\text { Heart rate, bpm } \\
\text { Cholesterol, mmol/l: } \\
\text { Total } \\
\text { LDL } \\
\text { HDL } \\
\text { Hypertension } \\
\text { Hypercholestrolemia } \\
\text { Diabetes } \\
\text { Smoking: } \\
\text { Current } \\
\text { Past } \\
\text { Never } \\
\text { Pack-years } \\
\text { Menopause experience } \\
\text { Age at menopause, years } \\
\text { Follow-up time, years }\end{array}$ & $\begin{aligned} & 57.3 \pm 6.1 \\
& 164.2 \pm 6.0 \\
& 25.8 \pm 4.0 \\
& 83.2 \pm 9.9 \\
& 0.79 \pm 0.06 \\
& 133 \pm 20 \\
& 79 \pm 11 \\
& 74 \pm 11 \\
& \\
& 5.9 \pm 1.0 \\
& 3.9 \pm 0.9 \\
& 1.6 \pm 0.4 \\
& 19.2 \\
& 4.4 \\
& 2.2 \\
& 23.4 \\
& 34.2 \\
& 42.4 \\
& 1.4(0.0-11.7) \\
& 87.4 \\
& 47.5 \pm 5.7 \\
& 4.3(3.2-5.3)\end{aligned}$ & $\begin{array}{c}60.8 \pm 6.0 \\
163.0 \pm 5.9 \\
26.7 \pm 4.2 \\
86.6 \pm 9.8 \\
0.81 \pm 0.06 \\
145 \pm 24 \\
83 \pm 11 \\
74 \pm 12 \\
6.1 \pm 1.2 \\
4.2 \pm 1.1 \\
1.5 \pm 0.4 \\
33.8 \\
14.9 \\
1.4 \\
32.4 \\
24.3 \\
43.3 \\
1.6(0.0-17.2) \\
95.3 \\
48.6 \pm 5.9 \\
2.3(1.4-3.6)\end{array}$ & $\begin{array}{c}57.1 \pm 6.1 \\
164.3 \pm 6.0 \\
25.8 \pm 3.9 \\
83.0 \pm 9.8 \\
0.79 \pm 0.06 \\
133 \pm 20 \\
79 \pm 11 \\
73 \pm 11 \\
5.9 \pm 1.0 \\
3.9 \pm 0.9 \\
1.6 \pm 0.4 \\
18.5 \\
3.9 \\
2.2 \\
23.0 \\
34.7 \\
42.3 \\
1.3(0.0-11.6) \\
87.0 \\
47.5 \pm 5.7 \\
4.3(3.3-5.3)\end{array}$ \\
\hline
\end{tabular}

Table 7.2 Genotype and allele frequencies of the AGTR1 $A^{1166} \mathrm{C}$ and the NOS3 $\mathrm{G}^{894} \mathrm{~T}$ polymorphisms according to stroke status.

\begin{tabular}{|c|c|c|c|}
\hline Genetic variant & Stroke present $(n=74)$ & Stroke absent $(n=1,512)$ & Unadjusted HR (95\% CI) \\
\hline & & & \\
\hline Genotype, n (\%)AA & $33(44.6)$ & $710(47.0)$ & $\begin{array}{l}\text { Reference } \\
\end{array}$ \\
\hline $\begin{array}{r}A C \\
C C\end{array}$ & $30(40.5)$ & $659(43.6)$ & $\begin{array}{l}0.95(0.58-1.58) \\
1.62(0.81-3.28)\end{array}$ \\
\hline Allele, $\% \quad C$ & $\begin{array}{l}11(14.9) \\
35.1\end{array}$ & $\begin{array}{c}143(9.4) \\
31.2\end{array}$ & $1.62(0.81-3.28)$ \\
\hline NOS3 $G^{894} \mathrm{~T}$ & & & \\
\hline Genotype, n (\%)GG & $34(45.9)$ & $654(43.3)$ & Reference \\
\hline GT & $35(47.3)$ & $716(47.4)$ & $0.94(0.58-1.53)$ \\
\hline TT & $5(6.8)$ & $142(9.4)$ & $0.69(0.27-1.78)$ \\
\hline Allele, \% & 30.4 & 33.1 & \\
\hline
\end{tabular}

AGTR1 indicates angiotensin II type 1 receptor; NOS3, endothelial nitric oxide synthase; n, number; $\mathrm{HR}$, hazard ratio; $\mathrm{Cl}$, confidence interval. 


\section{Relation with stroke}

In the entire population $(n=1,586)$, neither the AGTR1 nor the NOS3 genotypes were associated with the risk of stroke of any kind, although risk tended to increase in the presence of the AGTR1 CC genotype (Table 7.2).

However, analyses of interactions indicated that the relation between the AGTR1 $\mathrm{A}^{1166} \mathrm{C}$ polymorphism and stroke differed by age and systolic BP ( $P$ value of interaction terms $<0.10)$. Accordingly, subgroup analysis, adjusted for age, obesity and pack-years of smoking, showed that in women above the median age of 56 years the $C C$ genotype was independently associated with the risk of stroke (adjusted HR 2.77; 95\% Cl, 1.17-6.56; Table 7.3). Similarly, in women who had a systolic BP above $130 \mathrm{mmHg}$ (median), the risk of stroke increased in the presence of the CC genotype (adjusted HR 2.58; $95 \% \mathrm{Cl}, 1.12-5.93$; Table 7.3). Comparable results were found when using sliding mean analyses, i.e., without applying cut-off points (Figures 7.1 and 7.2, respectively). In other words, for the same age or the same level of elevated pressure, a CC subject runs a far greater risk than an AA individual. In women below the median age of 56 years or below the median systolic BP of $130 \mathrm{mmHg}$, the AGTR1 $\mathrm{A}^{1166} \mathrm{C}$ polymorphism was not related to the risk of stroke (Table 7.3). A similar pattern was observed when univariate analyses were repeated for ischemic stroke separately. Hemorrhagic strokes, however, were not explored further because their number was too small to allow reliable comparisons.

Table 7.3 Relation of the AGTR1 $\mathrm{A}^{1166} \mathrm{C}$ polymorphism with stroke in strata of relevant modifiers.

\begin{tabular}{|c|c|c|}
\hline Modifier & Strata ${ }^{a}$ & Adjusted HR $(95 \% \mathrm{Cl})^{\mathrm{bc}}$ \\
\hline Age & $\begin{array}{l}\leq 56 \text { years } \\
>56 \text { years }\end{array}$ & $\begin{array}{l}0.37(0.05-2.87) \\
2.77(1.17-6.56)\end{array}$ \\
\hline SBP & $\begin{array}{l}\leq 130 \mathrm{mmHg} \\
>130 \mathrm{mmHg}\end{array}$ & $\begin{array}{l}\text { No cases with } C C \\
2.58(1.12-5.93)\end{array}$ \\
\hline
\end{tabular}

Using the same approach with regard to the NOS3 $\mathrm{G}^{894} \mathrm{~T}$ polymorphism, analyses of interactions indicated that the relation with stroke differed by age and LDL cholesterol ( $P$ value of interaction terms $<0.10$ ). However, subgroup analyses revealed no significant association between the NOS3 polymorphism and stroke (Table 7.4). 


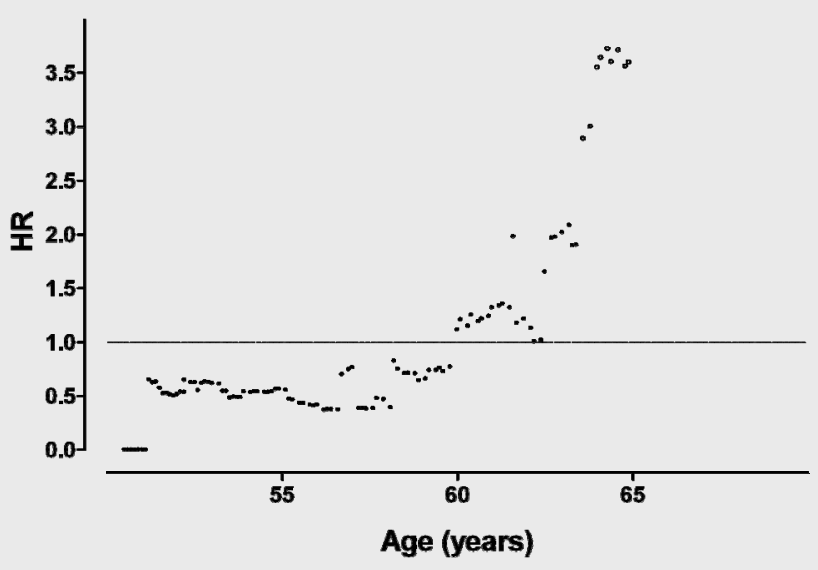

Figure 7.1 Sliding mean analysis of the interaction between the AGTR1 CC genotype and age with respect to the risk of stroke.

HR indicates hazard ratio. Each point represents the unadjusted HR (CC vs. AA genotypes) of 500 individuals (subgroup) according to age, and differs from the preceding or succeeding point by 10 individuals. Open points represent a significant $(P<0.05)$ unadjusted HR.

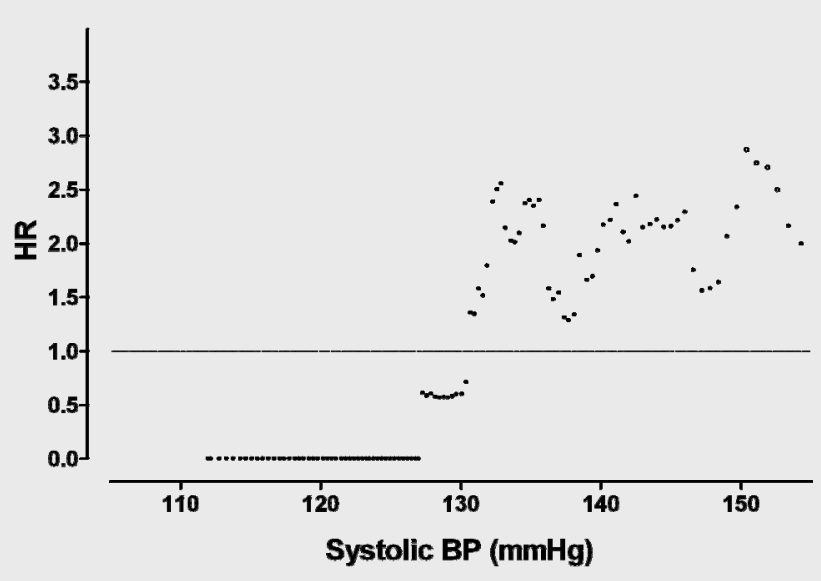

Figure 7.2 Sliding mean analysis of the interaction between the AGTR1 CC genotype and systolic blood pressure with respect to the risk of stroke.

HR indicates hazard ratio; BP, blood pressure. Each point represents the unadjusted HR (CC vs. AA genotypes) of 500 individuals (subgroup) according to systolic BP, and differs from the preceding or succeeding point by 10 individuals. Open points represent a significant $(P<0.05)$ unadjusted HR. 
Table 7.4 Relation of the NOS3 $\mathrm{G}^{894} \mathrm{~T}$ polymorphism with stroke in strata of relevant modifiers.

\begin{tabular}{|c|c|c|}
\hline Modifier & Strata ${ }^{a}$ & Adjusted HR $(95 \% \mathrm{CI})^{\mathrm{bc}}$ \\
\hline Age & $\begin{array}{l}\leq 56 \text { years } \\
>56 \text { years }\end{array}$ & $\begin{array}{l}2.48(0.59-10.5) \\
0.41(0.09-1.77)\end{array}$ \\
\hline LDL cholesterol & $\begin{array}{l}\leq 3.87 \mathrm{mmol} / \mathrm{l} \\
>3.87 \mathrm{mmol} / \mathrm{l}\end{array}$ & $\begin{array}{l}0.73(0.16-3.40) \\
0.87(0.25-3.09)\end{array}$ \\
\hline
\end{tabular}

\section{Discussion}

This prospective study in a large population-based cohort of women aged 49 to 70 years found that the relation between the AGTR1 $A^{1166} \mathrm{C}$ polymorphism and stroke was modified by coexisting risk factors, illustrating the importance of geneenvironment interactions. The stroke risk associated with the CC genotype increased only with increasing age or elevated systolic BP. The NOS3 G ${ }^{894} \mathrm{~T}$ polymorphism, however, was not related to the risk of stroke.

The present analysis, which is based on the large Prospect-EPIC cohort ${ }^{9}$, focused on women who were 49 to 70 years of age and who were likely to have coexisting risk factors. Data collection was prospective, before the diagnosis of stroke and equal for all participants, assuring the comparability of the cases and the randomly selected sub-cohort. ${ }^{10}$ Moreover, with a sampling fraction $\geq 10 \%$, the results of a case-cohort analysis are similar to those of a full-cohort analysis. ${ }^{12}$ For a multifactorial and late-onset trait like stroke ${ }^{14}$, this provides a valid approach to evaluate the relation between genetic factors and the risk of stroke while taking into account coexisting factors.

Nevertheless, the present study had some limitations, such as the relatively short period of follow-up and the heterogeneous group of strokes. With respect to the latter, the small number of strokes - a consequence of the study design complicates meaningful comparisons within and between distinct stroke phenotypes. Moreover, the possibility that the ICD-9 misclassified strokes, because coding depends on subjective interpretation of medical records and assignment of appropriate codes, justifies the pooling of all stroke events. ${ }^{15}$ However, taking into account the heterogeneity thus introduced, we performed additional exploratory analyses on ischemic strokes separately. This yielded, within the context of the statistical limitations, comparable results. The number of hemorrhagic strokes, however, was too small to allow reliable analyses. Furthermore, although the RAS and NO synthase play an important role in vascular function and morphology ${ }^{4}$, one should bear in mind that it remains unclear whether the investigated 
polymorphisms represent a functional change in physiology. Yet, other investigators have recently provided indirect evidence of functionality. The AGTR1 $\mathrm{C}$ and the NOS3 $\mathrm{T}$ alleles were found to be associated with increased sensitivity to angiotensin II and reduced bioavailability of NO, respectively. ${ }^{11,16}$

In the present study, the risk of stroke associated with the AGTR1 $A^{1166} \mathrm{C}$ polymorphism was modified by age and systolic BP, the latter suggesting a vascular pathology. However, the mechanisms behind these findings remain speculative. First, the CC genotype was a risk factor for stroke in women above a median age of 56 years, but not in younger ones. This may indicate an agerelated penetrance of the polymorphism, whereas at a younger age compensatory mechanisms may counterbalance a genetic predisposition. Compensatory mechanisms may become insufficient with advancing age. Figure 7.1 supports this concept, showing that the risk of stroke according to the CC-genotype is clearly age-dependent, starting from the age of 60 years. Furthermore, additional risk factors may become more prominent. Second, our data show that, from a BP of approximately $130 \mathrm{mmHg}$ systolic, for the same level of elevated pressure a CC subject runs a far greater risk than an AA individual. In accordance with this threshold effect, elevated BP could act as a mediator of the unfavorable genotype. Indeed, none of the stroke patients who had a systolic BP below $130 \mathrm{mmHg}$ was carrying the CC genotype. In line with this, higher systolic BP values have been observed in subjects carrying the CC genotype. ${ }^{6}$ Moreover, three studies have reported that the risk of stroke associated with the $C C$ genotype or the $C$ allele was particularly or exclusively increased in the presence of hypertension. 5,6,17 Our data confirm and extend these observations in terms of blood pressure, population structure and study design. A very recent study observed a weak association between at least one copy of the $C$ allele and brain infarction. ${ }^{7}$ The association was not modified by a history of hypertension. However, the genotype frequencies in controls did not comply with the HWE, inflating the chance of a false-positive association. ${ }^{18}$ Similar to the potentially modifying effects of age and systolic BP, it is possible that other coexisting factors, not documented in the present study yet related to both stroke and the $A^{1166} \mathrm{C}$ variant, account for the observed association. Third, the possibility that the relation between the CC genotype and stroke results from selection bias cannot be ruled out, because only women with a first-ever stroke were eligible for inclusion in the present analysis. Ultimately, the pathogenesis of stroke is complex and involves many genes, lifestyle and environmental factors and their interactions. ${ }^{14}$ As such, it is possible that the presence of coexisting risk factors is a prerequisite for an unfavorable genotype to increase someone's susceptibility to stroke.

Our findings on the NOS3 $\mathrm{G}^{894} \mathrm{~T}$ polymorphism are consistent with previous studies that failed to detect a relation with stroke. ${ }^{19-21}$ However, the distribution of the NOS3 genotypes in the sub-cohort deviated from HWE. Although the selection of the sub-cohort was random, this could have led to an artificial 
phenotype group. Consequently, genotypes associated with such a phenotype will be selected as well, and their distribution will not be certain to fit the HWE. Ultimately, a population will never be exactly in HWE as we, for instance, cannot exclude the presence of mutation or migration and selection according to genotype. ${ }^{22}$ The possibility that the distribution of NOS3 genotypes deviated from HWE as a result of genotyping errors is unlikely, and cannot be revealed by testing for deviations from HWE. ${ }^{23}$

In conclusion, this prospective study in a population-based cohort of women aged 49 to 70 years confirms that the CC genotype of the AGTR1 $A^{1166} \mathrm{C}$ polymorphism does increase the risk of stroke, but only in the presence of other coexisting risk factors. Since the $A^{1166} \mathrm{C}$ variant has also been associated with preclinical cerebrovascular disease ${ }^{24}$, we hypothesize that the polymorphism remains important from silent to clinically evident stroke. As silent brain infarction increases the risk of future stroke ${ }^{25}$, we hypothesize that the CC genotype can help identify those individuals who are at greatest risk and who may need (early) treatment and/or careful follow-up. However, this remains to be determined in populations with a long follow-up and well-phenotyped stroke. 


\section{References}

1. Feigin VL, Lawes CM, Bennett DA, Anderson CS. Stroke epidemiology: A review of populationbased studies of incidence, prevalence, and case-fatality in the late 20th century. Lancet Neurol 2003;2:43-53.

2. Hassan A, Markus HS. Genetics and ischaemic stroke. Brain 2000;123:1784-812.

3. Szolnoki Z, Somogyvari F, Kondacs A, Szabo M, Fodor L, Bene J, Melegh B. Evaluation of the modifying effects of unfavourable genotypes on classical clinical risk factors for ischaemic stroke. J Neurol Neurosurg Psychiatry 2003;74:1615-20.

4. Yan C, Kim D, Aizawa T, Berk BC. Functional interplay between angiotensin II and nitric oxide; cyclic GMP as a key mediator. Arterioscler Thromb Vasc Bio/2003;23:26-36.

5. Rubattu S, Di Angelantonio E, Stanzione R, Zanda B, Evangelista A, Pirisi A, De Paolis P, Cota L, Brunetti $E$, Volpe $M$. Gene polymorphisms of the renin-angiotensin-aldosterone system and the risk of ischemic stroke: A role of the A1166C/AT1 gene variant. J Hypertens 2004;22:2129-34.

6. Hindorff LA, Heckbert SR, Tracy R, Tang Z, Psaty BM, Edwards KL, Siscovick DS, Kronmal RA, Nazar-Stewart V. Angiotensin II type 1 receptor polymorphisms in the cardiovascular health study: Relation to blood pressure, ethnicity, and cardiovascular events. Am J Hypertens 2002;15:1050-6.

7. Brenner D, Labreuche J, Poirier O, Cambien F, Amarenco P. Renin-angiotensin-aldosterone system in brain infarction and vascular death. Ann Neuro/2005;58:131-8.

8. Elbaz A, Poirier O, Moulin T, Chedru F, Cambien F, Amarenco P. Association between the glu298asp polymorphism in the endothelial constitutive nitric oxide synthase gene and brain infarction. The genic investigators. Stroke 2000;31:1634-9.

9. Boker LK, van Noord PA, van der Schouw YT, Koot NV, Bueno de Mesquita HB, Riboli E, Grobbee DE, Peeters PH. Prospect-EPIC Utrecht: Study design and characteristics of the cohort population. European prospective investigation into cancer and nutrition. Eur J Epidemio/2001;17:1047-53.

10. Prentice RL. A case-cohort design for epidemiologic cohort studies and disease prevention trials. Biometrika 1986;73:1-11.

11. Veldman BA, Spiering W, Doevendans PA, Vervoort G, Kroon AA, de Leeuw PW, Smits P. The glu298asp polymorphism of the NOS 3 gene as a determinant of the baseline production of nitric oxide. J Hypertens 2002;20:2023-7.

12. Onland-Moret $N C$, van der $A D$, van der Schouw $Y T$, Buschers $W$, Elias $S G$, van Gils $C H$, Koerselman J, Roest M, Grobbee DE, Peeters PH. Analysis of case-cohort data: A comparison of different methods. J Clin Epidemio/ 2007;60:350-5.

13. Chau NP, Safar ME, Weiss YA, London GM, Simon AC, Milliez PL. Relationships between cardiac output, heart rate and blood volume in essential hypertension. Clin Sci Mol Med 1978;54: $175-80$.

14. Rubattu S, Giliberti R, Volpe M. Etiology and pathophysiology of stroke as a complex trait. Am J Hypertens 2000;13:1139-48.

15. Kokotailo RA, Hill MD. Coding of stroke and stroke risk factors using international classification of diseases, revisions 9 and 10. Stroke 2005;36:1776-81.

16. Spiering W, Kroon AA, Fuss-Lejeune MM, Daemen MJ, de Leeuw PW. Angiotensin II sensitivity is associated with the angiotensin II type 1 receptor $A(1166) C$ polymorphism in essential hypertensives on a high sodium diet. Hypertension 2000;36:411-6.

17. Szolnoki Z, Havasi V, Talian G, Bene J, Komlosi K, Somogyvari F, Kondacs A, Szabo M, Fodor L, Bodor A, Melegh B. Angiotensin II type-1 receptor A1166C polymorphism is associated with increased risk of ischemic stroke in hypertensive smokers. J Mo/ Neurosci 2006;28:285-90.

18. Schaid DJ, Jacobsen SJ. Biased tests of association: Comparisons of allele frequencies when departing from Hardy-Weinberg proportions. Am J Epidemio/ 1999;149:706-11.

19. Hassan A, Gormley K, O'Sullivan M, Knight J, Sham P, Vallance P, Bamford J, Markus H. Endothelial nitric oxide gene haplotypes and risk of cerebral small-vessel disease. Stroke 2004;35:654-9.

20. Markus HS, Ruigrok Y, Ali N, Powell JF. Endothelial nitric oxide synthase exon 7 polymorphism, ischemic cerebrovascular disease, and carotid atheroma. Stroke 1998;29:1908-11. 
21. MacLeod MJ, Dahiyat MT, Cumming A, Meiklejohn D, Shaw D, St Clair D. No association between glu/asp polymorphism of NOS3 gene and ischemic stroke. Neurology 1999;53:418-20.

22. Shoemaker J, Painter I, Weir BS. A bayesian characterization of Hardy-Weinberg disequilibrium. Genetics 1998;149:2079-88.

23. Zou GY, Donner A. The merits of testing Hardy-Weinberg equilibrium in the analysis of unmatched case-control data: A cautionary note. Ann Hum Genet 2006;70:923-33.

24. Henskens LH, Kroon AA, van Boxtel MP, Hofman PA, de Leeuw PW. Associations of the angiotensin II type 1 receptor A1166C and the endothelial NO synthase G894T gene polymorphisms with silent subcortical white matter lesions in essential hypertension. Stroke 2005;36:1869-73.

25. Vermeer SE, Hollander M, van Dijk EJ, Hofman A, Koudstaal PJ, Breteler MM. Silent brain infarcts and white matter lesions increase stroke risk in the general population: The Rotterdam Scan Study. Stroke 2003;34:1126-9. 
Aortic stiffness is associated with silent cerebral small-vessel disease in hypertensive patients

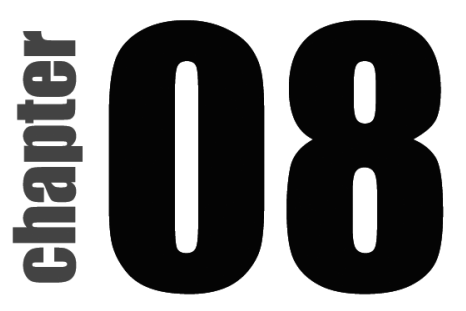

Léon H.G. Henskens

Abraham A. Kroon

Robert J. van Oostenbrugge

Ed H.B.M. Gronenschild

Monique M.J.J. Fuss-Lejeune

Paul A.M. Hofman

Jan Lodder

Peter W. de Leeuw

Hypertension, accepted for publication

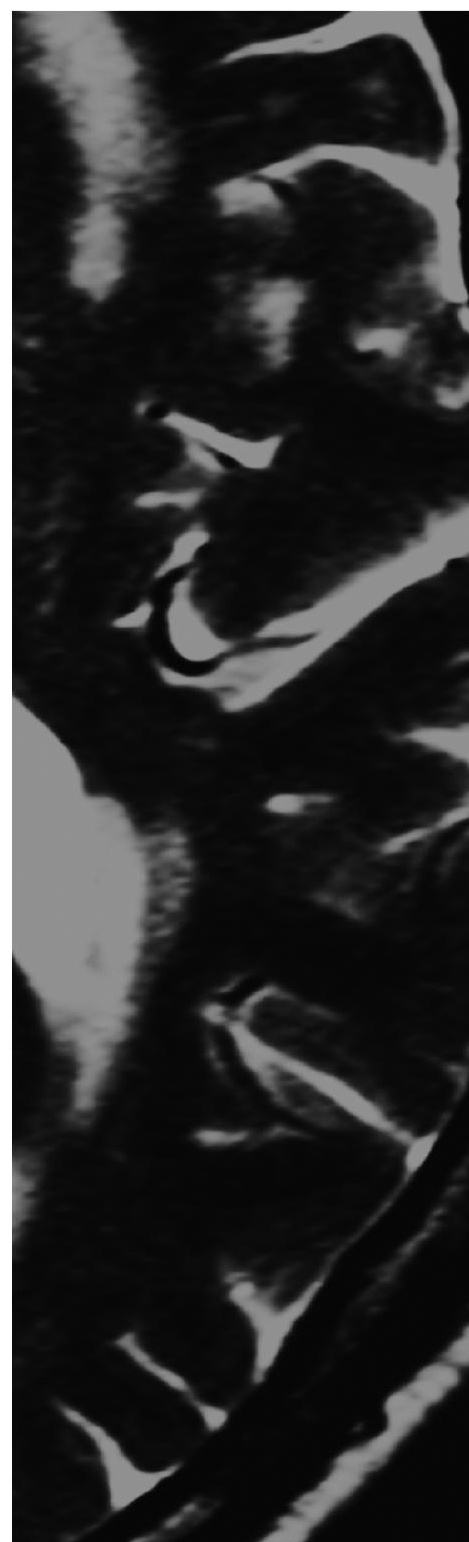




\section{Summary}

Aortic stiffness predicts an excess risk of stroke, supposedly via cerebral small-vessel disease. Because white matter hyperintensities, silent lacunar infarcts and brain microbleeds, as markers of cerebral small-vessel disease on neuroimaging, may precede overt cerebrovascular disease, we assessed whether aortic stiffness is also related to such lesions.

In 167 hypertensive patients (85 males) without a history of cardio- or cerebrovascular disease, a mean age of $51.8 \pm 13.1$ years, and untreated office blood pressure levels of $169 \pm 25 / 104 \pm 12 \mathrm{mmHg}$, we determined aortic pulse wave velocity, office and ambulatory 24-hour pulse pressure (off-medication), as well as the volume of white matter hyperintensities and the presence of lacunar infarcts and microbleeds using brain magnetic resonance imaging. Linear and logistic regression analyses were performed to assess the relationships between the arterial stiffness measures and brain lesions.

Aortic stiffness and pulse pressure were significantly related to each of the brain lesions in univariate analyses $(P<0.05)$. Multivariate analyses, adjusted for age, sex, brain volume, mean arterial pressure and heart rate, showed that a higher pulse wave velocity was significantly associated with a greater volume of white matter hyperintensities (unstandardized regression coefficient, $0.041 ; 95 \%$ confidence interval 0.005-0.078; $P<0.05$ ) and the presence of lacunar infarcts (odds ratio [per standard deviation increase in pulse wave velocity], 1.78; 95\% confidence interval 1.06-2.99; $P<0.05)$, but not with microbleeds. The models for pulse pressure failed to reach statistical significance in multivariate analyses.

In conclusion, aortic stiffness is independently associated with cerebral small-vessel disease in hypertensive patients without a history of cardio- or cerebrovascular disease. 


\section{Introduction}

The arterial system gradually stiffens because of the shared effects of ageing, high blood pressure (BP) and other vascular risk factors. ${ }^{1}$ Arterial stiffness can be assessed by non-invasive pulse wave velocity (PWV) measurements. ${ }^{2}$ In particular, the velocity of the carotid-femoral or aortic pulse wave appears to be of prognostic importance, and is considered to be the gold-standard for assessing arterial stiffness. ${ }^{3}$ Several studies, in both population- and patient-based cohorts, have demonstrated a strong association between increased aortic PWV and excess risk of cardiovascular complications, including stroke. ${ }^{4-9}$ Whether the risk of stroke is mediated by large- and/or small-vessel disease is not known, but the previously reported increased risk of stroke in the presence of preclinical cerebral microvascular disease, i.e., white matter hyperintensities (WMHs), silent lacunar infarcts (LACs), and/or brain microbleeds (BMBs), suggests small-vessel disease involvement. ${ }^{10,11}$ O'Rourke and Safar hypothesized that cerebral microvascular disease results from the damaging forces of abnormal flow pulsations extending into small cerebral arteries as a consequence of arterial stiffening. ${ }^{12}$ However, the relationship between arterial stiffness and cerebral small-vessel disease has not been investigated in great detail and studies have yielded conflicting results. ${ }^{13-15}$

The present study was undertaken to assess the associations between aortic PWV and WMHs, LACs and BMBs as markers of silent cerebral-small vessel disease on magnetic resonance imaging (MRI) of the brain, in a cohort of hypertensive patients without a history of symptomatic cardio- or cerebrovascular disease. We also included the peripheral pulse pressure (PP), being a widely accepted surrogate marker for arterial stiffness.

\section{Methods}

\section{Participants}

The selection of patients has been described in detail elsewhere (Figure B.1, Appendix B). ${ }^{16}$ Briefly, patients who were referred for the evaluation of their hypertension to our outpatient department were eligible for inclusion in the present study. As part of the routine work-up, which included ambulatory BP monitoring (ABPM) over a 24-hour period, standard 12-lead electrocardiography, aortic PWV measurements, and routine laboratory investigations, patients were asked to discontinue their antihypertensive medication for at least two weeks. An experienced internist decided based on the patients' clinical information provided by the referring physician and independent of the study whether is was possible to stop temporarily the antihypertensive medication. In addition, patients consented to a repeat ABPM (also off-medication) and an MRI of the brain. All participants, aged 20-82 years, had no indication of secondary hypertension or 
chronic renal failure, no documented diabetes, ischemic or valvular heart disease, no atrial fibrillation, no history of transient ischemic attacks or stroke, and no diagnosis of obstructive sleep apnea syndrome.

The Medical Ethics Committee of the Maastricht University Medical Centre approved the study and written informed consent was obtained from all participants.

\section{Hemodynamic measurements}

Conventional office BP was measured at the hospital by sphygmomanometry (Korotkoff phases I and V). After at least five minutes of rest, three consecutive measurements were taken at the non-dominant arm, with the participant seated, and always by the same trained investigator (L.H.). We calculated the PP and the mean arterial pressure (MAP) from the corresponding systolic BP (SBP) and diastolic BP (DBP) using the following formulas: $P P=S B P-D B P$ and $M A P=D B P+((S B P-D B P) / 3)$. The mean of the second and third measurements was used in the analyses.

Ambulatory BP was monitored non-invasively over a 24-hour period using validated SpaceLabs 90207 or 90217 devices (SpaceLabs Medical Inc., Redmond, Washington, USA), as described in detail elsewhere. ${ }^{16}$ The monitoring sessions were repeated with a median interval of seven (interquartile range 5-9) days, because the assessment of the 24-hour BP profile on the basis of a single ABPM has been shown to be less reliable. ${ }^{17}$ Based on both recordings we calculated the mean 24-hour SBP, MAP, DBP and PP using the Pressure Import and Export software version 1.4.0. (Instrument Development Engineering and Evaluation [IDEE], Maastricht University, 2005; http://www-id.unimaas.nl). The betweenABPM repeatability coefficient, calculated according to the method of Bland and Altman (twice the standard deviation [SD] of the differences between the duplicate recordings) ${ }^{18}$ and expressed as a percentage of the nearly maximal variation (four times the SD of the average of the two recordings), was $17 \%$ for the 24-hour PP, indicating acceptable reproducibility. ${ }^{19}$ Repeatability coefficients for the 24-hour SBP, MAP and DBP were 20\%, 21\% and 20\%, respectively.

Regional arterial stiffness was assessed by measuring the carotid-femoral or aortic PWV with the participant in the supine position, applying the validated and reproducible foot-to-foot velocity method. ${ }^{2}$ An automatic device (Complior, Colson, France) measured the time delay (t) between the rapid upstroke of the feet of simultaneously recorded waveforms, obtained transcutaneously over the right common carotid artery and the right femoral artery. The distance (D) traveled by the pulse waves was estimated by measuring the distance between the two recording sites over the body surface with a tape measure. Aortic PWV was calculated automatically as D/t $(\mathrm{m} / \mathrm{s})$. The mean of at least 10 measurements with a good upstroke was used in the analyses. A single trained technician (M.F-L.), who was blinded to the participants' clinical data, performed all PWV 
measurements. The intra-observer agreement, assessed in a random sample of 15 subjects, was very good with an intraclass correlation coefficient (ICC) of $0.88 .{ }^{20}$ All but 15 of the participants were off antihypertensive therapy at the time of the aortic PWV measurements. In these patients BP-lowering treatment was started again immediately after performing the ABPMs (as recommended by the patients' internist), but before the aortic PWV could be assessed.

\section{Brain magnetic resonance imaging}

Brain MRI (Intera 1.5-T, Philips Medical Systems, Best, The Netherlands) was performed to obtain axial T2-weighted, fluid-attenuated inversion recovery (FLAIR) and $\mathrm{T} 2{ }^{*}$-weighted gradient echo (GE) images as detailed recently. ${ }^{16}$

White matter hyperintensities were identified as hyperintense areas in the periventricular and deep white matter on both T2-weighted and FLAIR images (for an example see Figure A.1, Appendix A). Because visual (i.e., categorical) WMH rating scales apply arbitrary cut-offs to define lesion severity, display ceiling effects and poor discrimination of absolute lesion volumes, and have limited observer reliability ${ }^{21}$, we semi-automatically quantified the WMH volume (WMHV). Moreover, volumetric measurements were found to be more sensitive in detecting differences between clinical groups. ${ }^{21}$ A detailed description of the quantification of the WMHV, including fully automatic brain volume (BV) measurements, is given in Appendix D.

A single trained observer (L.H.), blinded to the participants' age, sex and clinical data, performed all quantitative WMH-assessments, after reaching satisfactory agreement with an experienced neuroradiologist (P.H.). Reliability analyses, carried out on a random sample of 20 scans, yielded excellent inter- and intra-observer agreement (ICCS 0.97 and 0.99 , respectively). ${ }^{20}$ Furthermore, twenty randomly selected patients were scanned and rescanned with repositioning to evaluate the scan-rescan effects on the WMHV- and BV-measurements. The scan-rescan volumes also showed excellent agreement (both ICCs 0.99).

Two experienced vascular neurologists (R.v.O. and J.L.) assessed all scans for the presence of silent LACs and BMBs, independently and blinded to the participants' age, sex and clinical data. LACs were defined as small (diameter 3-15 mm), sharply demarcated hyperintense lesions on T2-weighted images with corresponding foci of FLAIR low signal intensity, and assessed in the basal ganglia, internal capsule, thalamus (i.e., those sites limited to the vascular territories of the lenticulostriate, anterior choroidal and thalamoperforant arteries) and/or brainstem (for an example see Figure A.2.1, Appendix A). We distinguished LACs from equally sized perivascular spaces using the FLAIR images, infarcts being characterized by a central cavitation of low signal intensity with a surrounding higher-intensity rim of gliotic tissue.

BMBs were defined as punctate (diameter $<5 \mathrm{~mm}$ ), homogeneous foci of low signal intensity on $\mathrm{T} 2^{*}$-weighted GE images and assessed throughout the brain, 
i.e., brainstem, cerebellum, basal ganglia, corona radiata and cortico-subcortical gray and white matter (for an example see Figure A.3, Appendix A). Symmetric hypointensities in the globi pallidi, likely to represent calcification or iron deposition, and sulcal flow voids from cortical vessels were disregarded. ${ }^{16}$

The inter-observer agreement, expressed as Cohen's Kappa, was 0.51 for LACs and 0.69 for BMBs, signifying moderate to substantial agreement. ${ }^{22}$ However, in case of disagreement between the two observers, lesions were always ascertained by consensus.

\section{Risk factors}

Information on lifestyle habits, past and current morbidity (including current treatment), and hypertension history (including the self-reported age of diagnosis and previous use of antihypertensive medication), were obtained by interview and verified by inspection of recently started medical records. Smoking was classified as never, past or current. Alcohol consumption was estimated in units intake per day. The duration of hypertension was estimated as the time (in months) passed since the self-reported age of diagnosis until inclusion in the study.

Height and weight were measured without shoes and wearing light indoor clothing to determine body mass index (BMl, $\left.\mathrm{kg} / \mathrm{m}^{2}\right)$.

Venous blood samples, routinely drawn after an overnight fast, were analyzed for serum creatinine, serum total cholesterol and high-density lipoprotein (HDL) cholesterol levels, and plasma glucose levels using standard laboratory procedures.

\section{Statistical analysis}

To detect group differences between unpaired data we applied the independent samples $t$-test for normally distributed variables, the Mann-Whitney $U$ test for variables with skewed distributions, and the Pearson $\chi^{2}$ statistic or Fisher's exact test for categorical variables.

We assessed the associations of the arterial stiffness measures with WMHs (both in terms of volume and severity [third tertile vs. lower two tertiles]), LACs and BMBs by means of linear or logistic regression analyses, whenever appropriate. Regression models were adjusted for age and sex (and BV in case of WMHs) (model 1), and additionally for MAP and heart rate ${ }^{5,7,23}$ (model 2). Significant models were then further explored with additional adjustments for the use of BPlowering medication during PWV measurements $(n=15)$, previous antihypertensive treatment, $\mathrm{BMI}$, smoking status and the ratio of total/HDL cholesterol. ${ }^{5,7}$ Covariates were forced into the models simultaneously (enter procedure).

Because age is an important determinant of arterial stiffness, we repeated the regression analyses with respect to WMHVs for participants younger $(n=83)$ and for those older $(n=84)$ than the median age of 52.7 years. 
To illustrate the relationship between arterial stiffness measures and the volume of WMHs, we produced plots of the predicted WMHVs versus the aortic PWV or PP. The predicted WMHVs are the volumes predicted by the regression equation between PWV (or PP) and the untransformed WMHVs, adjusted for age, sex and BV. First, we obtained the predicted WMHVs for the total study population. Subsequently, we obtained the predicted WMHVs for participants younger $(n=83)$ and for those older $(n=84)$ than the median age of 52.7 years in separate analyses.

Normally distributed variables are presented as mean \pm standard deviation (SD), variables with skewed distributions as median with interquartile ranges (IQR), and categorical variables as frequencies. Unstandardized regression coefficients and odds ratios are presented with corresponding 95\% confidence intervals. A twotailed probability value $<0.05$ was considered statistically significant. Analyses were performed using the statistical software packages SPSS (version 11.0.4 for Macintosh, SPSS Inc., Chicago, Illinois, USA) and Prism (version 4.00 for Windows, GraphPad Software Inc., San Diego, California, USA).

\section{Results}

\section{Characteristics}

Altogether, we included 167 patients in the present study. Based on the untreated office BP levels we diagnosed 159 (95\%) participants with hypertension. Eight (5\%) participants had normal BP levels, even though the referring diagnosis was hypertension. The characteristics of the study population according to tertiles of aortic PWV are summarized in Table 8.1. Older age, male sex, longstanding hypertension, higher office and ambulatory BP levels (including $\mathrm{PP})$, and higher serum creatinine and plasma glucose levels, were significantly associated with increasing tertiles of aortic PWV ( $P=0.049$ or less).

\section{Arterial stiffness and silent cerebral small-vessel disease}

Brain MRI was performed with a median interval of 10 (IQR 2-17) days from the hemodynamic measurements.

The WMHV and the number of severe WMHs, LACs and BMBs increased from the first to the third tertile of aortic PWV (Table 8.1).

Linear regression analyses, performed after WMHV had been logarithmically transformed because of skewed distribution, showed that higher aortic PWV was significantly associated with a greater volume of WMHs, independent of age, sex, $B V, M A P$ and heart rate (all models $P<0.05$; Table 8.2). Furthermore, the relation between aortic PWV and WMHV remained statistically significant for both participants younger $(n=83$; unstandardized regression coefficient, $0.074 ; 95 \%$ $\mathrm{Cl}, 0.027-0.122)$ and for participants older $(n=84$; unstandardized regression 
coefficient, $0.065 ; 95 \% \mathrm{Cl}, 0.017-0.112$ ) than the median age of 52.7 years (both models $P<0.01)$. On univariate logistic regression analyses we found aortic PWV to be significantly related to WMHs (third tertile vs. lower two tertiles), LACs and BMBs (all $P<0.01$ ). However, in the adjusted models (1 and 2) the associations attenuated and only the relation with LACs remained statistically significant. Every SD increase in aortic PWV was associated with a 1.78 higher likelihood of LACS ( $P<0.05$; Model 2, Table 8.2).

Table 8.1 Characteristics of the study population according to tertiles of arterial pulse wave velocity.

\begin{tabular}{|c|c|c|c|c|c|}
\hline \multirow[b]{2}{*}{ Parameter } & \multirow[b]{2}{*}{ All (167) } & \multicolumn{3}{|c|}{ Aortic PWV tertiles } & \multirow[b]{2}{*}{$p$} \\
\hline & & $<10.4 \mathrm{~m} / \mathrm{s}(55)$ & $10.4-12.5 \mathrm{~m} / \mathrm{s}(56)$ & $>12.5 \mathrm{~m} / \mathrm{s}(56)$ & \\
\hline \multicolumn{6}{|l|}{ Anthropometrics } \\
\hline Age, years & $51.8 \pm 13.1$ & $43.9 \pm 12.7$ & $51.5 \pm 11.9$ & $59.8 \pm 9.6$ & $<0.001$ \\
\hline Sex, male/female & $85 / 82$ & $24 / 31$ & $25 / 31$ & $36 / 20$ & 0.048 \\
\hline Weight, kg & $79.9 \pm 16.0$ & $77.7 \pm 15.1$ & $79.5 \pm 15.8$ & $82.4 \pm 16.8$ & 0.299 \\
\hline $\mathrm{BMI}, \mathrm{kg} / \mathrm{m}^{2}$ & $27.5 \pm 4.1$ & $27.0 \pm 4.2$ & $27.7 \pm 4.5$ & $27.8 \pm 3.8$ & 0.519 \\
\hline \multicolumn{6}{|l|}{ Lifestyle factors } \\
\hline Current smoking & $33(20)$ & $10(18)$ & $14(25)$ & $9(16)$ & 4.464 \\
\hline$>2$ alcoholic units per day & $26(16)$ & $6(11)$ & $6(11)$ & $14(25)$ & 0.058 \\
\hline \multicolumn{6}{|l|}{ Hypertension history } \\
\hline Duration, months & $39(13-120)$ & $19(10-59)$ & $53(19-164)$ & $58(12-139)$ & 0.005 \\
\hline Previous antihypertensive treatment & $131(78)$ & $39(71)$ & $44(79)$ & $48(86)$ & 0.165 \\
\hline \multicolumn{6}{|l|}{ Hemodynamic measurements } \\
\hline Office SBP, mmHg & $169 \pm 25$ & $156 \pm 19$ & $171 \pm 24$ & $181 \pm 24$ & $<0.001$ \\
\hline Office MAP, mmHg & $126 \pm 15$ & $118 \pm 13$ & $127 \pm 14$ & $131 \pm 14$ & $<0.001$ \\
\hline Office DBP, mmHg & $104 \pm 12$ & $100 \pm 12$ & $106 \pm 11$ & $106 \pm 12$ & 0.008 \\
\hline Office PP, mmHg & $66 \pm 20$ & $57 \pm 13$ & $65 \pm 20$ & $75 \pm 20$ & $<0.001$ \\
\hline Office heart rate, bpm & $75 \pm 12$ & $74 \pm 10$ & $74 \pm 11$ & $78 \pm 13$ & 0.106 \\
\hline 24h SBP, mmHg & $150 \pm 18$ & $141 \pm 16$ & $152 \pm 15$ & $159 \pm 19$ & $<0.001$ \\
\hline 24h MAP, mmHg & $112 \pm 13$ & $107 \pm 12$ & $113 \pm 10$ & $117 \pm 14$ & $<0.001$ \\
\hline 24h DBP, mmHg & $93 \pm 12$ & $90 \pm 11$ & $94 \pm 10$ & $96 \pm 13$ & 0.015 \\
\hline 24h PP, mmHg & $57 \pm 12$ & $51 \pm 9$ & $58 \pm 12$ & $62 \pm 12$ & $<0.001$ \\
\hline $24 \mathrm{~h}$ heart rate, bpm & $76 \pm 9$ & $75 \pm 9$ & $75 \pm 9$ & $77 \pm 10$ & 0.262 \\
\hline Aortic PWV, m/s & $12.0 \pm 2.9$ & $9.2 \pm 0.8$ & $11.4 \pm 0.6$ & $15.3 \pm 2.3$ & $<0.001$ \\
\hline \multicolumn{6}{|l|}{ Biochemical measurements (fasting) } \\
\hline Creatinine, $\mu \mathrm{mol} / / \mathrm{l}$ & $82(71-94)$ & $80(68-91)$ & $79(71-91)$ & $88(74-102)$ & 0.049 \\
\hline Glucose, mmol/l & $5.3 \pm 0.6$ & $5.2 \pm 0.5$ & $5.3 \pm 0.6$ & $5.5 \pm 0.6$ & 0.007 \\
\hline Total/HDL cholesterol ratio & $4.4(3.4-6.5)$ & $4.0(3.4-4.8)$ & $4.7(3.4-5.6)$ & $4.6(3.5-5.7)$ & 0.077 \\
\hline \multicolumn{6}{|l|}{ Brain MRI } \\
\hline $\mathrm{BV}, \mathrm{cm}^{3}$ & $1268 \pm 125$ & $1290 \pm 130$ & $1249 \pm 124$ & $1264 \pm 119$ & 0.238 \\
\hline WMHV, $\mathrm{cm}^{3}$ & $0.81(0.36-2.93)$ & $0.46(0.22-1.15)$ & $0.74(0.34-1.80)$ & $2.06(0.69-8.59)$ & $<0.001$ \\
\hline WMHs (third tertile) & $56(33)$ & $10(18)$ & $15(27)$ & $31(55)$ & $<0.001$ \\
\hline LACs & $36(22)$ & $8(15)$ & $8(14)$ & $20(36)$ & 0.007 \\
\hline BMBs & $28(17)$ & $5(9)$ & $9(16)$ & $14(25)$ & 0.080 \\
\hline
\end{tabular}

Data are presented as mean $\pm S D$, number $(\%)$, or median (interquartile range). PWV indicates pulse wave velocity; BMI, body mass index; SBP, systolic blood pressure; MAP, mean arterial pressure; DBP, diastolic blood pressure; PP, pulse pressure; HDL, high-density lipoprotein; MRI, magnetic resonance imaging; BV, brain volume; WMHV, white matter hyperintensity volume; WMHs, white matter hyperintensities; LACs, lacunar infarcts; BMBs, brain microbleeds.

a $P$ values are for overall differences across tertiles ( $P$ for trend). 
On additional adjustments for vascular risk factors (exploration of significant models) the regression models of both WMHV (unstandardized regression coefficient, $0.043 ; 95 \%$ confidence interval [CI] 0.006-0.080) and LACs (odds ratio [per SD increase in $\mathrm{PWV}$ ], $1.21 ; 95 \% \mathrm{Cl} 1.00-2.14)$ remained statistically significant $(P<0.05)$.

The associations of the office and ambulatory 24-hour pulse pressures with cerebral small-vessel disease were in general weaker than those observed for aortic PWV and failed to reach statistical significance in fully adjusted analyses (model 2, Table 8.2).

Table 8.2 Relationship between arterial stiffness indices and WMHs, LACs and BMBs.

\begin{tabular}{|c|c|c|c|}
\hline Brain MRI & Aortic PWV & Office PP & 24-hour PP \\
\hline \multicolumn{4}{|l|}{ WMHs } \\
\hline \multicolumn{4}{|l|}{ WMHV } \\
\hline Unadjusted & $0.126(0.095-0.157)^{c}$ & $0.016(0.012-0.021)^{c}$ & $0.021(0.013-0.029)^{c}$ \\
\hline Model 1 & $0.071(0.037-0.104)^{c}$ & $0.008(0.003-0.013)^{a}$ & $0.009(0.001-0.017)^{a}$ \\
\hline Model 2 & $0.041(0.005-0.078)^{a}$ & $0.003(-0.003-0.009)$ & $-0.001(-0.010-0.008)$ \\
\hline \multicolumn{4}{|l|}{$3^{\text {rd }}$ tertile } \\
\hline Unadjusted & $2.98(1.96-4.54)^{c}$ & $2.89(1.95-4.27)^{c}$ & $2.58(1.77-3.76)^{c}$ \\
\hline Model 1 & $1.79(1.10-2.91)^{a}$ & $1.52(0.95-2.44)$ & $1.72(1.10-2.68)^{a}$ \\
\hline Model 2 & $1.53(0.88-2.66)$ & $0.94(0.48-1.83)$ & $0.90(0.50-1.62)$ \\
\hline \multicolumn{4}{|l|}{ LACs } \\
\hline Unadjusted & $2.16(1.48-3.17)^{c}$ & $1.65(1.16-2.34)^{a}$ & $1.49(1.04-2.11)^{a}$ \\
\hline Model 1 & $2.22(1.40-3.52)^{b}$ & $1.49(0.97-2.30)$ & $1.33(0.89-1.99)$ \\
\hline Model 2 & $1.78(1.06-2.99)^{a}$ & $1.38(0.80-2.38)$ & $0.93(0.55-1.56)$ \\
\hline \multicolumn{4}{|l|}{ BMBs } \\
\hline Unadjusted & $1.77(1.21-2.61)^{b}$ & $2.10(1.42-3.10)^{c}$ & $1.76(1.18-2.62)^{b}$ \\
\hline Model 1 & $1.31(0.83-2.08)$ & $1.72(1.07-2.75)^{a}$ & $1.47(0.92-2.35)$ \\
\hline Model 2 & $1.13(0.67-1.91)$ & $0.85(0.44-1.66)$ & $0.93(0.52-1.68)$ \\
\hline
\end{tabular}

Data are presented as unstandardized regression coefficients (for WMHV) and odds ratios (per standard deviation [SD] increase in PWV [SD=2.9 $\mathrm{m} / \mathrm{s}$ ], office PP [SD=20 $\mathrm{mmHg}$ ], or 24-hour PP [SD=12 mmHg]) with corresponding 95\% confidence intervals. MRI indicates magnetic resonance imaging; PWV, pulse wave velocity; PP, pulse pressure; WMHs, white matter hyperintensities; WMHV, white matter hyperintensity volume; LACs, lacunar infarcts; BMBs, brain microbleeds.

Model 1: adjusted for age and sex (and BV in case of WMHs).

Model 2: additionally adjusted for office MAP and office heart rate (aortic PWV and office PP) or 24hour MAP and 24-hour heart rate (24-hour PP). ${ }^{a} P<0.05 ;{ }^{b} P<0.01 ;{ }^{c} P<0.001$.

Plots of the predicted WMHVs versus the aortic PWV or PP (Figure 8.1) illustrate that the volume of WMHs increased with increasing PWV and PP levels. Furthermore, with higher age the associations were stronger, but the splay of the distribution was greater. Because the regression equations are specific for each group, the models produce group-specific predicted WMHVs. Consequently, the data points of the younger and older age groups do not match those of the total study population. 

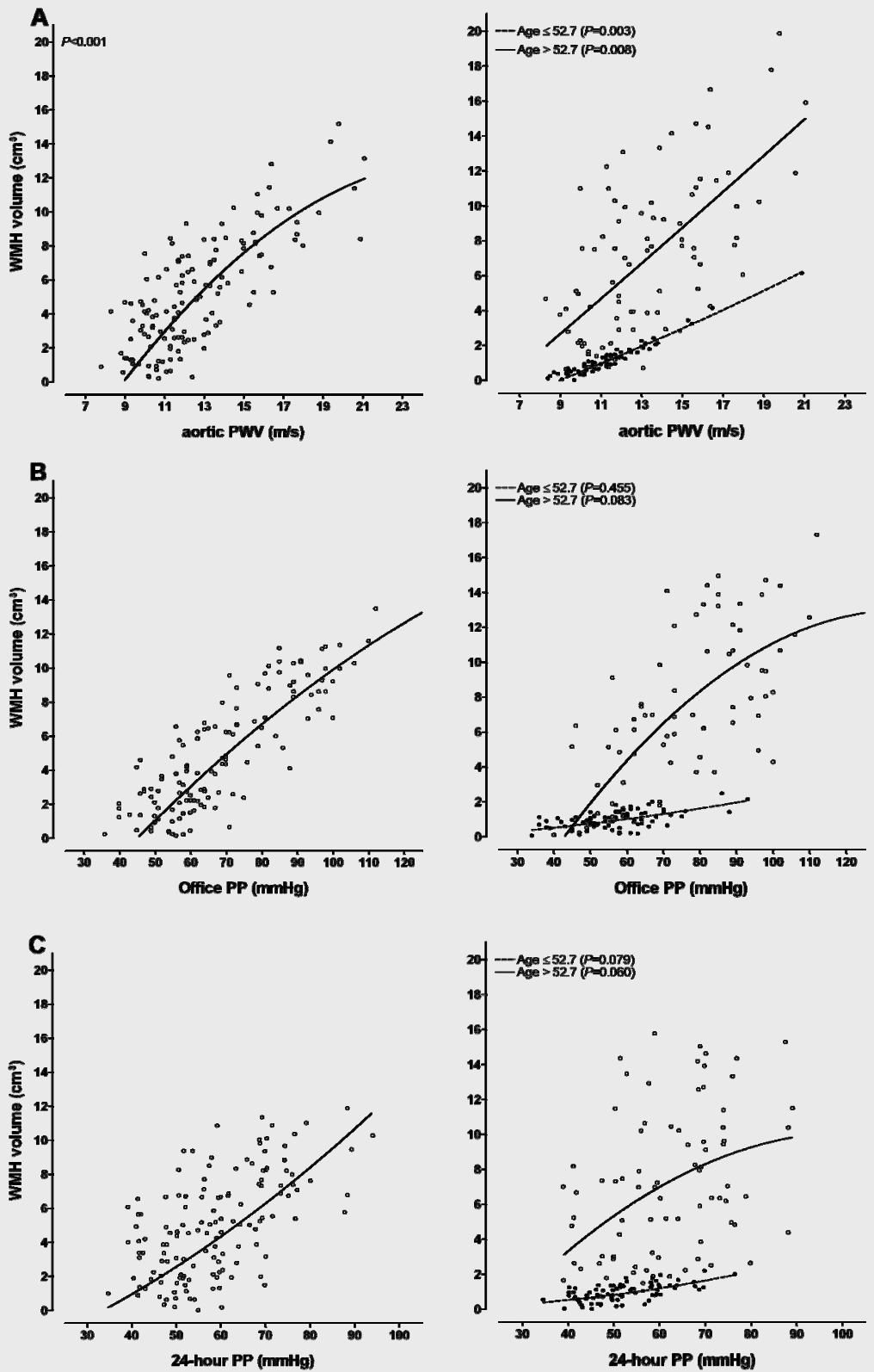

Figure 8.1 Scatter plots illustrating the relationships of aortic PWV (panel A), office PP (panel B) and ambulatory 24-hour PP (panel C) with the predicted WMHV for the total population and stratified for age (median age of 52.7 years used as cut-off point), while adjusting for age, sex and $\mathrm{BV} ; \quad P$ values indicate significance levels for the corresponding linear regression analyses (using log-transformed WMHV). WMH indicates white matter hyperintensity; aPWV, aortic pulse wave velocity; PP, pulse pressure. 


\section{Discussion}

The present study demonstrates that in hypertensive patients without a history of cardio- and cerebrovascular disease the aortic PWV is positively associated with the extent of WMHs and the presence of silent LACs, independently of age, MAP and other vascular risk factors.

We observed independent associations between aortic PWV and markers of silent cerebral small-vessel disease. Every SD increase in aortic PWV was associated with a 1.78 higher likelihood of LACs in adjusted analyses. The relation between aortic stiffness and the volume of WMHs was continuous, without distinct thresholds and continued down to PWV levels well within the normal range. Notably, in participants younger than the median age of 52.7 years the association between aortic stiffness and WMHV, though weaker, was present as well, which might reflect accelerated vascular ageing in the presence of hypertension. ${ }^{24}$ Previously, the relationship between arterial stiffness and cerebral microvascular disease has been investigated by assessing brachial-ankle PWV and arterial compliance. The results were, however, conflicting. While some investigators reported that, in elderly subjects, stiffer arteries were significantly associated with higher grades of $\mathrm{WMHs}^{13,15}$, others failed to find such an association for silent brain infarcts, yet in a younger and predominantly normotensive population. ${ }^{14}$

The present study is the first to address the relation between arterial stiffness and BMBs. Although the frequency of microbleeds increased from $9 \%$ in the first tertile of aortic PWV to $25 \%$ in the third tertile, and higher levels of PWV and PP were significantly associated with the presence of BMBs on univariate regression analyses, the associations lost their significance on multivariate analyses. The number of patients with BMBs was, however, small. Hence, the relationship between arterial stiffness and BMBs remains to be determined in adequately powered and preferably longitudinal studies.

We found aortic PWV but not peripheral PP to be associated with WMHs and LACs. This difference can be attributed to the population's age and to differential effects of steady (MAP) and pulsatile (PP) components of BP on target organs. Firstly, our study population is relatively young with half of the participants being younger than 52.7 (median) years of age. Although peripheral PP increases with age, the steepest rise occurs after the age of 50 years. ${ }^{25}$ Furthermore, peripheral $\mathrm{PP}$ is a consequence rather than a cause of arterial stiffness, and as such only an indirect measure of arterial stiffness. In young subjects (age $<50$ years) PP is considerably amplified between the aorta and the brachial artery, making PP higher in peripheral than in central arteries (i.e., the aorta). ${ }^{26,27}$ Because of this socalled PP amplification, which reduces with increasing age, peripheral PP does not reliably reflect central PP in young subjects. ${ }^{27}$ In addition, the distensibility of the aorta, an elastic artery, decreases with age, whereas the distensibility of the muscular brachial artery is unrelated to age. ${ }^{28}$ As such, PP may be a reliable 
marker of arterial stiffening and related cardiovascular disease in elderly only. Aortic PWV, on the other hand, is a direct measure that increases gradually with age and, hence, better reflects central arterial stiffening. ${ }^{28,29}$ Accordingly, we found PWV to be associated with WMHs in our younger participants as well. Secondly, it has been suggested that an increased PP is a predictor of cardiac rather than cerebrovascular disease. ${ }^{30,31}$ Verdecchia et al. demonstrated that MAP but not PP predicts the risk of future stroke. ${ }^{31}$ In the present study, the associations between PP and cerebral microvascular damage disappeared on adjustments for the MAP. Mean arterial pressure is determined mainly by peripheral microvascular resistance and might thus better reflect damage to the cerebral microcirculation than PP. Conversely, aortic PWV remained significantly related to WMHV and LACs after controlling for the MAP.

The mechanisms linking arterial stiffness and (silent) cerebrovascular disease are complex and not well understood. Moreover, and contrary to large-artery stiffness, the role of small-artery stiffness has been studied less extensively. ${ }^{32}$ It has been hypothesized that cerebral small-vessel disease results from abnormal flow pulsations into the brain microcirculation as a consequence of aortic stiffening. ${ }^{12}$ The brain is under normal conditions continuously and passively perfused at highvolume flow throughout systole and diastole. Because vascular resistance and pulse wave reflection are very low, pulsations of pressure and flow extend well into the (micro)vascular bed. ${ }^{12}$ Exposure to highly pulsatile pressure and augmented flow, which exist in the carotid and vertebral arteries as a result of arterial stiffening, may thus lead to microvascular damage. ${ }^{12,33}$ In line with this hypothesis, reduced arterial wall compliance of large arteries has been associated with narrowing of retinal arterioles ${ }^{34}$, which, in turn, has been related to the presence of WMHs and may reflect the state of the cerebral microcirculation. ${ }^{35}$

The present study has limitations. Firstly, our study sample was relatively small, and with a cross-sectional study design, association does not imply causation. Accordingly, our observations need confirmation in longitudinal and adequately powered studies. Secondly, our study is carried out in a selected group of hypertensive patients referred to a university hospital, limiting the generalizability of our findings to other populations.

Strengths of our study are that we included several markers of silent cerebral small-vessel disease, that the volumetric assessment of WMHs enabled us to explore the relation with arterial stiffness in continuous rather than in (arbitrary) categorical analyses, and that the associations were not biased by a history of symptomatic cardio- or cerebrovascular disease.

In conclusion, we observed robust but cross-sectional associations between aortic stiffness and both WMHs and LACs. However, long-term follow-up studies are needed to evaluate whether arterial stiffening really causes cerebral small-vessel disease, and eventually stroke. Because both aortic stiffening and silent cerebral small-vessel disease increase the risk of future stroke $e^{7-9,11}$, it is reasonable to 
consider that long-term reduction in arterial stiffness will reduce the risk of silent and eventually symptomatic cerebrovascular disease. We found faster aortic PWV to be associated with older age, male sex, longstanding hypertension, higher BP levels, and higher creatinine, cholesterol and glucose levels. Consequently, arterial stiffness can be regarded as a summary measure for vascular damage caused by coexisting vascular risk factors. ${ }^{1}$ This implies, however, a multifactorial approach aimed at treating all reversible risk factors ${ }^{36}$, and, ultimately, prevention of progression of silent into clinically evident cerebrovascular disease. 


\section{References}

1. Benetos A, Waeber B, Izzo J, Mitchell G, Resnick L, Asmar R, Safar M. Influence of age, risk factors, and cardiovascular and renal disease on arterial stiffness: Clinical applications. Am J Hypertens 2002;15:1101-8.

2. Asmar R, Benetos A, Topouchian J, Laurent P, Pannier B, Brisac AM, Target R, Levy BI. Assessment of arterial distensibility by automatic pulse wave velocity measurement. Validation and clinical application studies. Hypertension 1995;26:485-90.

3. Laurent S, Boutouyrie P. Arterial stiffness: A new surrogate end point for cardiovascular disease? J Nephro/2007;20 Suppl 12:S45-50.

4. Blacher J, Asmar R, Djane S, London GM, Safar ME. Aortic pulse wave velocity as a marker of cardiovascular risk in hypertensive patients. Hypertension 1999;33:1111-7.

5. Boutouyrie P, Tropeano Al, Asmar R, Gautier I, Benetos A, Lacolley P, Laurent S. Aortic stiffness is an independent predictor of primary coronary events in hypertensive patients: A longitudinal study. Hypertension 2002;39:10-5.

6. Hansen TW, Staessen JA, Torp-Pedersen C, Rasmussen S, Thijs L, Ibsen H, Jeppesen J. Prognostic value of aortic pulse wave velocity as index of arterial stiffness in the general population. Circulation 2006;113:664-70.

7. Mattace-Raso FU, van der Cammen TJ, Hofman A, van Popele NM, Bos ML, Schalekamp MA, Asmar R, Reneman RS, Hoeks AP, Breteler MM, Witteman JC. Arterial stiffness and risk of coronary heart disease and stroke: The Rotterdam Study. Circulation 2006;113:657-63.

8. Sutton-Tyrrell K, Najjar SS, Boudreau RM, Venkitachalam L, Kupelian V, Simonsick EM, Havlik R, Lakatta EG, Spurgeon H, Kritchevsky S, Pahor M, Bauer D, Newman A. Elevated aortic pulse wave velocity, a marker of arterial stiffness, predicts cardiovascular events in well-functioning older adults. Circulation 2005;111:3384-90.

9. Laurent S, Katsahian S, Fassot C, Tropeano Al, Gautier I, Laloux B, Boutouyrie P. Aortic stiffness is an independent predictor of fatal stroke in essential hypertension. Stroke 2003;34:1203-6.

10. Boulanger JM, Coutts SB, Eliasziw M, Gagnon AJ, Simon JE, Subramaniam S, Sohn CH, Scott J, Demchuk AM. Cerebral microhemorrhages predict new disabling or fatal strokes in patients with acute ischemic stroke or transient ischemic attack. Stroke 2006;37:911-4.

11. Vermeer SE, Hollander M, van Dijk EJ, Hofman A, Koudstaal PJ, Breteler MM. Silent brain infarcts and white matter lesions increase stroke risk in the general population: The Rotterdam Scan Study. Stroke 2003;34:1126-9.

12. O'Rourke MF, Safar ME. Relationship between aortic stiffening and microvascular disease in brain and kidney: Cause and logic of therapy. Hypertension 2005;46:200-4.

13. Duprez DA, De Buyzere ML, Van den Noortgate N, Simoens J, Achten E, Clement DL, Afschrift M, Cohn JN. Relationship between periventricular or deep white matter lesions and arterial elasticity indices in very old people. Age Ageing 2001;30:325-30.

14. Matsumoto M, Inoue K, Moriki A. Associations of brachial-ankle pulse wave velocity and carotid atherosclerotic lesions with silent cerebral lesions. Hypertens Res 2007;30:767-73.

15. Ohmine T, Miwa Y, Yao H, Yuzuriha T, Takashima Y, Uchino A, Takahashi-Yanaga F, Morimoto $S$, Maehara Y, Sasaguri T. Association between arterial stiffness and cerebral white matter lesions in community-dwelling elderly subjects. Hypertens Res 2008;31:75-81.

16. Henskens LH, van Oostenbrugge RJ, Kroon AA, de Leeuw PW, Lodder J. Brain microbleeds are associated with ambulatory blood pressure levels in a hypertensive population. Hypertension 2008;51:62-68.

17. Manning G, Rushton L, Donnelly R, Millar-Craig MW. Variability of diurnal changes in ambulatory blood pressure and nocturnal dipping status in untreated hypertensive and normotensive subjects. Am J Hypertens 2000;13:1035-8.

18. Bland JM, Altman DG. Statistical methods for assessing agreement between two methods of clinical measurement. Lancet 1986;1:307-10.

19. Thijs L, Staessen J, Fagard R, Zachariah P, Amery A. Number of measurements required for the analysis of diurnal blood pressure profile. J Hum Hypertens 1994;8:239-44. 
20. Bartko JJ. Measurement and reliability: Statistical thinking considerations. Schizophr Bull 1991;17:483-9.

21. van Straaten EC, Fazekas F, Rostrup E, Scheltens P, Schmidt R, Pantoni L, Inzitari D, Waldemar G, Erkinjuntti T, Mantyla R, Wahlund LO, Barkhof F. Impact of white matter hyperintensities scoring method on correlations with clinical data. The LADIS study. Stroke 2006;37:836-40.

22. Landis JR, Koch GG. The measurement of observer agreement for categorical data. Biometrics 1977;33:159-74.

23. Wilkinson IB, MacCallum H, Hupperetz PC, van Thoor CJ, Cockcroft JR, Webb DJ. Changes in the derived central pressure waveform and pulse pressure in response to angiotensin $\|$ and noradrenaline in man. J Physio/2001;530:541-50.

24. Paini A, Boutouyrie $P$, Calvet $D$, Tropeano Al, Laloux B, Laurent S. Carotid and aortic stiffness: Determinants of discrepancies. Hypertension 2006;47:371-6.

25. Franklin SS, Gustin W, Wong ND, Larson MG, Weber MA, Kannel WB, Levy D. Hemodynamic patterns of age-related changes in blood pressure. The Framingham Heart Study. Circulation 1997;96:308-15.

26. Safar ME, Levy BI, Struijker-Boudier $\mathrm{H}$. Current perspectives on arterial stiffness and pulse pressure in hypertension and cardiovascular diseases. Circulation 2003;107:2864-9.

27. Wilkinson IB, Franklin SS, Hall IR, Tyrrell S, Cockcroft JR. Pressure amplification explains why pulse pressure is unrelated to risk in young subjects. Hypertension 2001;38:1461-6.

28. van der Heijden-Spek JJ, Staessen JA, Fagard RH, Hoeks AP, Boudier HA, van Bortel LM. Effect of age on brachial artery wall properties differs from the aorta and is gender dependent: A population study. Hypertension 2000;35:637-42.

29. O'Rourke MF, Staessen JA, Vlachopoulos C, Duprez D, Plante GE. Clinical applications of arterial stiffness; definitions and reference values. Am J Hypertens 2002;15:426-44.

30. Benetos A, Safar M, Rudnichi A, Smulyan H, Richard JL, Ducimetieere P, Guize L. Pulse pressure: A predictor of long-term cardiovascular mortality in a French male population. Hypertension 1997;30:1410-5.

31. Verdecchia P, Schillaci G, Reboldi G, Franklin SS, Porcellati C. Different prognostic impact of 24-hour mean blood pressure and pulse pressure on stroke and coronary artery disease in essential hypertension. Circulation 2001;103:2579-84.

32. Laurent $S$, Boutouyrie $P$. Recent advances in arterial stiffness and wave reflection in human hypertension. Hypertension 2007;49:1202-6.

33. Hirata K, Yaginuma T, O'Rourke MF, Kawakami M. Age-related changes in carotid artery flow and pressure pulses: Possible implications for cerebral microvascular disease. Stroke 2006;37:2552-6.

34. Cheung N, Islam FM, Jacobs DR, Jr., Sharrett AR, Klein R, Polak JF, Cotch MF, Klein BE, Ouyang $P$, Wong TY. Arterial compliance and retinal vascular caliber in cerebrovascular disease. Ann Neuro/2007;62:618-24.

35. Wong TY, Klein R, Sharrett AR, Couper DJ, Klein BE, Liao DP, Hubbard LD, Mosley TH. Cerebral white matter lesions, retinopathy, and incident clinical stroke. JAMA 2002;288:67-74.

36. Mancia G. Total cardiovascular risk: A new treatment concept. J Hypertens 2006;24(suppl 2: S17-24. 
${ }_{180} 1$ 
Ambulatory blood pressure, asymptomatic cerebrovascular damage and cognitive function in essential hypertension

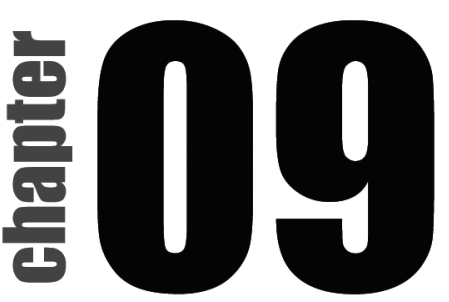

Martin P.J. van Boxtel Léon H.G. Henskens Abraham A. Kroon Paul A.M. Hofman Ed H.B.M. Gronenschild Jelle Jolles

Peter W. de Leeuw 


\section{Summary}

Prolonged exposure to elevated blood pressure can lead to both structural (white matter lesions or infarctions) and functional changes in the brain. We studied in previously diagnosed essential hypertensive individuals if diurnal blood pressure variation and ambulatory blood pressure profile (daytime, nighttime and 24-hour blood pressure averages) were related to evidence of white matter lesions, the presence of 'silent' lacunar infarcts, and cognitive performance.

A group of 86 patients (mean age $57.4 \pm 10$ years, range $40-80$ years) were first screened for hypertension related organ damage and underwent 24-hour ambulatory blood pressure monitoring, magnetic resonance imaging of the brain, and a comprehensive neurocognitive assessment. Age and ambulatory blood pressure profile were related to more periventricular, but not subcortical white matter lesions, and to the presence of lacunar infarcts on magnetic resonance imaging. After correction for demographical group differences, no association was found between nighttime dipping of blood pressure on the one hand and both white matter lesion load and cognitive parameters (verbal memory, sensorimotor speed, cognitive flexibility) on the other. The presence of lacunar infarcts, however, predicted lower performance on verbal memory. Furthermore, daytime and 24hour pulse pressure averages were associated with periventricular white matter lesions, whereas systolic blood pressure and mean arterial pressure for daytime, nighttime and 24hour periods were higher in patients with lacunar infarcts.

In conclusion, notwithstanding the large variability of white matter lesions in this sample the evidence of a connection between diurnal blood pressure variation and early targetorgan damage in the brain was not convincing. However, the ambulatory blood pressure profile may be predictive of cerebral lesion type. 


\section{Introduction}

Hypertensive individuals are at risk for target-organ damage, including in the brain. In hypertension, atherosclerotic changes occur in the large and small cerebral arteries, together with a reduced autoregulation of cerebral blood flow. 1,2 Hypertension not only increases the risk of stroke, it has also been associated with the prevalence of subcortical and periventricular white matter lesions (WMLs), as observed with magnetic resonance imaging (MRI). ${ }^{3}$ The presence of WMLs is a prognostic factor for the development of stroke $e^{4,5}$ and, on a functional level, with cognitive impairment ${ }^{6}$, particularly when attentional processes, speed of information processing ${ }^{7}$ and frontal lobe function is involved. ${ }^{8}$ The etiology of WMLs is still poorly understood, but seems to be related to small-vessel disease, demyelinisation, and the occurrence of cerebral ischemia.9.10 Apart from hypertension ${ }^{3}$, other risk factors for WMLs are age, diabetes, and a history of stroke or heart disease. ${ }^{11}$ White matter lesions also appear to be very common in healthy older individuals. ${ }^{11}$ In essential hypertension, the presence of WMLs has been associated with the duration ${ }^{3,12}$ and severity of this condition ${ }^{13,14}$, the lack of blood pressure (BP) control in treated patients ${ }^{15,16}$, and an exaggerated decline in nocturnal BP. ${ }^{17,18}$ However, recent studies on ambulatory BP monitoring (ABPM) and WMLs did not replicate the latter finding, but rather stressed the severity of elevated $\mathrm{BP}^{19}$ and a blunted fall in nocturnal heart rate. ${ }^{14}$ In addition, steady and pulsatile components of daytime, nighttime and 24-hour BP have gained increased interest in the prediction of WMLs, lacunar infarcts (LACS) and stroke. $^{20,21}$ So far, studies on hypertension and WMLs have been focusing primarily on older patient groups. Moreover, the description of WMLs in terms of subtype (subcortical, or periventricular) and quantity has often been rather crude. This may complicate drawing conclusions from these studies because the etiology of WML subtypes may actually differ. ${ }^{22}$ Improved methods to quantify WML subtypes have become available and have been validated and studied in large population samples. ${ }^{23}$ For example, based on a strict WML scoring protocol, periventricular WMLs were associated with lower psychomotor speed and general cognitive function in 1,077 individuals from the Rotterdam Scan Study, aged 60 years and older ${ }^{24}$, while subcortical WMLs were related with depressed mood. ${ }^{25}$ In addition, periventricular WMLs were associated with a three-fold greater reduction in general cognitive functioning (Mini-Mental State Examination) after a mean follow-up duration of 7.3 years. ${ }^{26}$

We designed the present study in untreated, asymptomatic, middle-aged to older essential hypertensive individuals, in order to identify possible relationships between ambulatory BP, cerebral damage (WMLs or LACs) on magnetic resonance imaging (MRI), and the cognitive performance in different functional domains. For this purpose, the diurnal BP profile was derived from ambulatory BP recordings, the subtype and quantity of WMLs were determined according to a 
well-established protocol ${ }^{24}$, and a comprehensive battery of cognitive tests was administered to evaluate the potential consequences of diurnal BP variation on cognitive function and cerebral WML load.

\section{Methods}

\section{Subjects}

Participants for this study were recruited from the hypertension outpatient clinic at the department of internal medicine of the Maastricht University Medical Centre. A group of 105 patients, aged between 40 and 80 years, and who were previously diagnosed with essential hypertension, were selected for this study. Exclusion criteria were clinically documented ischemic or valvular heart disease, congestive heart failure, cerebrovascular accidents or transient ischemic attacks, chronic renal failure (serum creatinine $>150 \mu \mathrm{mol} / \mathrm{l}$ ), secondary hypertension, or claustrophobia (MRI investigation). In all patients, antihypertensive medication was discontinued three weeks prior to the clinical assessments. None of the participants developed adverse events during the drug-free episode. The study was approved by the local Medical Ethics Committee and all patients gave their informed consent in writing.

\section{Blood pressure measurement}

Non-invasive ABPMs (SpaceLabs 90217; Spacelabs Inc., Redmond, Washington, USA) were obtained on weekdays, starting early in the morning. Measurements were taken at the non-dominant arm, every 15 minutes during the day and every 30 minutes at night. Patients were instructed to adhere to their normal daily activities and regular sleeping hours. For analysis, daytime episodes were defined from 0900 hours until 2100 hours, and nighttime episodes from 0100 hour until 0600 hours, according to the guidelines of the European Society of Hypertension (ESH). ${ }^{27}$ Blood pressure and heart rate averages, and diurnal BP rhythm were determined for these episodes. Recordings were not edited.

\section{Magnetic resonance imaging and white matter lesion scoring}

Magnetic resonance imaging scans were made on a 1.5 Tesla Philips Intera NT. The scan protocol included axial proton density (PD), T2-weighted fast spin-echo (FSE), and T2-weighted fluid-attenuated inversion recovery (FLAIR) sequences. All scans were analyzed off-line in order to obtain estimates of the total volume of subcortical WMLs, the extent of periventricular WMLs and the presence of silent LACs (for an example of WMLs see Figure A.1; for LACs see Figure A.2.1, Appendix A). The WMLs were scored according to the Rotterdam Scan Study scale 
(Table E.2, Appendix E). ${ }^{24}$ For this purpose the axial PD, T2-weighted, and FLAIR image stacks were aligned side-by-side in synchrony, on a computer screen, using custom software (E.G.; image-processing software package GIANT [General Imaging and Analysis Tools]; Department of Psychiatry and Neuropsychology, Maastricht University, Maastricht, The Netherlands) on a Macintosh G3 computer. This program allowed systematic inspection of the synchronized image stacks and manual demarcation of regions of interest (ROIs). At each level, subcortical WMLs were scored using predefined ROI masks, i.e., circles with a diameter of 2, 6, and $12 \mathrm{~mm}$, respectively. Lesions were first identified on the FLAIR image, then confirmed and traced on both other images at the same axial level. If a lesion was present on all three images, the mask that matched the ROI best was fitted over the lesion. After inspection and delineation of all subcortical WMLs in a stack the program generated an output file containing the number and size of all lesions at each level of the scan. These data were transferred to a standard spreadsheet to yield a total subcortical WML volume score for each patient. In this procedure, ROls were inflated to spheres with the same diameter, with corresponding volumes of 4.2, 113 and $905 \mathrm{~mm}^{3}$, respectively. Subcortical WMLs were processed by one medical investigator (M.v.B.) after satisfactory intra-class correlations between 0.81 and 0.98 had been reached. ${ }^{28}$ These were based on the independent assessments of subsequent series of 10 random stacks by this investigator and an experienced neuroradiologist (P.H.). Next, the overall subcortical WML volume was calculated. Periventricular WML severity, ranging between 0 and 3, was scored separately for frontal and occipital regions ('caps') and the medial periventricular lining ('bands'), which were then summed to an overall periventricular WML score (Table E.2, Appendix E). ${ }^{24}$ Finally, the presence of other cerebrovascular lesions (LACS) was identified in a separate session by the neuroradiologist (P.H.).

\section{Cognitive assessment}

All participants underwent a 1.5-hour cognitive assessment by an experienced neuropsychological assistant. Different tests were used to probe several aspects of cognitive function, including memory, attention, sensorimotor speed and cognitive processing speed, according to procedures outlined briefly below and described in more detail elsewhere. ${ }^{29}$ The same battery of tests has been employed in the Rotterdam Scan Study. ${ }^{24}$

The Word Learning Task (WLT) is based on the Auditory Verbal Learning Test ${ }^{30}$ and evaluates the ability to acquire and retain new verbal information (15 monosyllabic words). The total number of correctly reproduced words in five repeated learning trials is recorded, in addition to the maximum score in five trials and the number of correctly reproduced words after 20 minutes. The Concept Shifting Task (CST) evaluates behavioral planning and evaluation. ${ }^{31}$ A person's 
ability to alternate two psychological concepts during task performance is measured, in this case cancellation of 16 empty circles arranged in a larger circle (task 0 ), and circles that contain numbers (A), letters (B), or both (C), in correct order. Task $C$ is considered the more complex 'switch' task. The outcome is the time required to complete each task. Susceptibility to language interference was measured in the Stroop Color Word Test (SCWT), consisting of three subtasks: (I) color word naming, (II) color naming and (III), naming of color words printed in a different color ('interference task'). SCWT-III is often used as a test of attentional capacity, which shows robust effects of chronological age. ${ }^{32}$

\section{Other assessments}

Other variables related to cardiovascular risk were assessed during the first study visit. Blood samples were drawn in the morning from fasting patients for assessment of total cholesterol and glucose levels. Hypercholesterolemia was defined as a total cholesterol level exceeding $6.5 \mathrm{mmol} / \mathrm{l}$ and/or the use of lipidlowering drugs. Diabetes mellitus (DM) was considered to be present in case of fasting plasma glucose levels above $6.9 \mathrm{mmol} / \mathrm{l}$ and/or the reported use of oral anti-diabetic drugs, or insulin. The height and weight of patients as measured and body mass index (BMI) was calculated. Physical activity was defined as the total hours spent on physical exercise during one week and actual smoking status (yes/no) was recorded. Furthermore, we collected post hoc the duration of hypertension history and antihypertensive medication use from the medical records of all participants in order to assess possible confounding of these variables on the results of the study.

\section{Data reduction and statistical analysis}

Average levels of systolic BP (SBP), diastolic BP (DBP), mean arterial pressure $(\mathrm{MAP})$, pulse pressure (PP) and heart rate were computed for daytime, nighttime and 24-hour episodes, using a custom computer program available at the Department of Internal Medicine. According to the Verdecchia criterion, participants were classified as nondippers when the reduction in both their systolic and diastolic nighttime BP was $<10 \%$ of the average daytime levels ${ }^{33}$, while others were classified as dippers. In addition, dipping quantity was expressed as the relative decrease in MAP from daytime to nighttime episode (relative dipping).

Three domains of cognitive performance were defined: memory, sensorimotor speed, and cognitive flexibility. ${ }^{34-36}$ Compound domain scores were computed for each individual, based on the Z-transformed raw scores in the total sample. In this way, a reduction in performance outcome parameters can be achieved while the robustness of the underlying cognitive construct is improved. ${ }^{37,38}$ Next, the average Z-score was obtained from tests included in the compound performance index. The memory score was derived from the total and delayed-recall scores of 
the WLT, the cognitive flexibility score was calculated as the average of the C-version of the CST and subtask III of the SCWT, and sensorimotor speed thus combined scores on the $0, A$ and B versions of the CST and subtask I of the SCWT. ${ }^{39}$ In data presentation, plus or minus signs were inverted to make positive values reflect a better than average and negative values a worse than average performance.

First, comparisons were made between both dipper categories, including the cardiovascular risk factor variables and all variables that were used in the analyses. Appropriate tests were used to detect group differences (groupwise $t$ tests for normally distributed continuous variables, Mann-Whitney $U$ tests for variables with skewed distributions, or $\chi^{2}$ tests for variables with a restricted number of classes). Using general linear model (GLM) analysis, dipper groups were compared on cognitive test scores, with control for significant pre-existent group differences (only educational level; no cardiovascular risk factors were used). Due to the skewed distribution of WML data, subcortical WML volumes and periventricular WML scores were broken down into tertile groups ${ }^{12}$, with cut-off values at 33.5 and $402.1 \mathrm{~mm}^{3}$ for subcortical WML volumes, and 0.5 and 1.5 for periventricular WML scores. Periventricular WMLs were also analyzed as a dichotomous feature (present/absent). Next, subcortical WMLs (tertiles), periventricular WMLs (tertiles, present/absent) and LAC (present/absent) groups were compared using GLM on cognitive test performance and BP variables (mean daytime, nighttime and 24-hour, and relative dipping of MAP), with control for age as covariate. As some authors have suggested that the relationship between nocturnal dipping and organ damage is U-shaped ${ }^{19,40}$, we also trichotomized post hoc the day/night MAP difference to test differences in WML load and cognitive outcome in these groups. Analyses were performed with SPSS 11.5 for Windows (SPSS Inc., Chicago, USA), using an alpha level of 0.05 .

\section{Results}

Of 105 persons included in this study, MRI data of nine persons were unavailable or considered inadequate due to claustrophobia (one), premature withdrawal from the study (four), or movement artifacts (four). Four patients under 40 were not included in the analysis. Of the remaining 92 patients, another six patients were excluded because ABPM data were insufficient (less than $70 \%$ successful readings), leaving 86 patients with complete data for analysis. Table 9.1 presents the descriptive statistics of the study sample. Mean age of the group was 57 years (range 40-80) and 60\% was male. 
Table 9.1 Descriptive statistics by dipping status.

\begin{tabular}{|c|c|c|c|}
\hline & \multicolumn{2}{|c|}{ Dipper status } & \multirow[b]{2}{*}{ All (86) } \\
\hline & Nondipper (13) & Dipper (73) & \\
\hline Age, years & $55.4 \pm 8.5$ & $57.7 \pm 10.3$ & $57.4 \pm 10.0$ \\
\hline Sex, male/female & $10 / 3$ & $42 / 31^{a}$ & 52 / 34 \\
\hline Education, 1-8 & $2.5 \pm 1.3$ & $3.9 \pm 2.1^{d}$ & $3.7 \pm 2.0$ \\
\hline Smoking & 31 & $31^{a}$ & 31 \\
\hline Physical activity, hours & $6.2 \pm 5.0$ & $7.8 \pm 6.4^{b}$ & $7.6 \pm 6.2$ \\
\hline $\mathrm{BMI}, \mathrm{kg} / \mathrm{m}^{2}$ & $28.5 \pm 4.7$ & $28.9 \pm 5.5$ & $28.9 \pm 5.4$ \\
\hline Diabetes mellitus & 15 & $14^{\mathrm{a}}$ & 14 \\
\hline Hypercholesterolemia & 15 & $23^{a}$ & 22 \\
\hline \multicolumn{4}{|l|}{ Daytime BP, mmHg: } \\
\hline SBP & $159 \pm 17$ & $155 \pm 19$ & $156 \pm 18$ \\
\hline DBP & $101 \pm 15$ & $97 \pm 12$ & $97 \pm 12$ \\
\hline MAP & $121 \pm 14$ & $117 \pm 13$ & $117 \pm 14$ \\
\hline PP & $58 \pm 11$ & $59 \pm 13$ & $59 \pm 12$ \\
\hline Heart rate, bpm & $83 \pm 16$ & $80 \pm 12$ & $80 \pm 13$ \\
\hline \multicolumn{4}{|l|}{ Night-time $\mathrm{BP}, \mathrm{mmHg}$ : } \\
\hline SBP & $157 \pm 21$ & $132 \pm 17^{e}$ & $136 \pm 20$ \\
\hline DBP & $98 \pm 16$ & $78 \pm 11^{e}$ & $81 \pm 14$ \\
\hline MAP & $118 \pm 16$ & $97 \pm 13^{e}$ & $100 \pm 15$ \\
\hline $\mathrm{PP}$ & $59 \pm 14$ & $54 \pm 11$ & $54 \pm 12$ \\
\hline Heart rate, bpm & $69 \pm 11$ & $67 \pm 11$ & $67 \pm 11$ \\
\hline \multicolumn{4}{|l|}{ 24-hour BP, mmHg: } \\
\hline SBP & $159 \pm 17$ & $148 \pm 18^{c}$ & $150 \pm 18$ \\
\hline DBP & $100 \pm 14$ & $91 \pm 11^{d}$ & $92 \pm 12$ \\
\hline MAP & $120 \pm 14$ & $111 \pm 13^{c}$ & $112 \pm 13$ \\
\hline $\mathrm{PP}$ & $59 \pm 12$ & $57 \pm 12$ & $58 \pm 12$ \\
\hline Heart rate, bpm & $78 \pm 14$ & $75 \pm 11$ & $75 \pm 11$ \\
\hline MAP dipping, \% & $2.2 \pm 5.7$ & $16.6 \pm 5.8^{e}$ & $14.4 \pm 7.8$ \\
\hline Subcortical WMLs, mm³ & $1158 \pm 2702$ & $1029 \pm 2235^{b}$ & $1048 \pm 2294$ \\
\hline Periventricular WMLs, 0-9 & $1.85 \pm 2.13$ & $1.36 \pm 1.70^{b}$ & $1.43 \pm 1.77$ \\
\hline Lacunar infarcts, present/absent & $3 / 10$ & $14 / 59^{a}$ & $17 / 69$ \\
\hline Sensorimotor speed, Z-score & $-0.34 \pm 1.17$ & $0.06 \pm 0.60$ & $0.00 \pm 0.91$ \\
\hline Cognitive flexibility, Z-score & $-0.53 \pm 1.27$ & $0.09 \pm 0.80^{c(N S)}$ & $0.00 \pm 0.72$ \\
\hline Memory, Z-score & $-0.23 \pm 0.86$ & $0.04 \pm 0.96$ & $0.00 \pm 0.95$ \\
\hline
\end{tabular}

Data are presented as mean \pm SD or number. BMI indicates body mass index; $\mathrm{BP}$, blood pressure; SBP, systolic BP; DBP, diastolic BP; MAP, mean arterial pressure; PP, pulse pressure; bpm, beats per minute; WMLs, white matter lesions; NS, not significant. Univariate group differences were tested with groupwise $t$ tests, unless indicated otherwise. ${ }^{a} \chi^{2}$ test; ${ }^{b}$ Mann-Whitney $U$ test. ${ }^{c} P \leq 0.05$; ${ }^{d} P \leq 0.01$; ${ }^{e} P \leq 0.001 ; P$ values of general linear model (GLM) with control for education as covariate are given between parentheses.

\section{Nondipping}

Thirteen (15\%) participants were classified as nondipper. As may be expected, when dipping status categories were compared, all nighttime and 24-hour BP levels, with the exception of $\mathrm{PP}$, were higher $(P<0.001$ and $P<0.05$, respectively) and the relative nighttime dipping of the MAP lower $(P<0.001)$ in the nondipper group. Dippers received higher education $(t=3.200, P<0.01)$, and performed 
better on cognitive flexibility $(t=2.338, P<0.05)$. The latter difference disappeared, however, when dipper groups were compared with control for educational level $(F(1,84)=1.957, N S)$. Age, sex, presence of cardiovascular risk factors, average heart rate, WML scores, presence of LACs, and both other cognitive measures did not differ between dipper groups.

\section{Blood pressure}

Of the patients in the lowest subcortical WML volume tertile, 17 (20\%) had none, or only one small subcortical WML on their MRI scan. Periventricular WMLs and LACs were present in $56(65 \%)$ and 17 (20\%) patients, respectively (Tables 9.2a and $9.2 b)$.

Table 9.2a Descriptive statistics by subcortical and periventricular white matter lesion tertiles.

\begin{tabular}{|c|c|c|c|c|c|c|}
\hline & \multicolumn{3}{|c|}{ Subcortical WML volume, $\mathrm{mm}^{3}$} & \multicolumn{3}{|c|}{ Periventricular WML score (0-9) } \\
\hline & $<33.5(30)$ & $33.5-402.1(28)$ & $\geq 402.1(28)$ & $0.0(30)$ & $0.5-1.5(26)$ & $>1.5(30)$ \\
\hline Age, years & $52.5 \pm 9.3$ & $57.1 \pm 7.4$ & $62.8 \pm 10.5^{e}$ & $53.1 \pm 8.5$ & $55.4 \pm 9.3$ & $63.3 \pm 9.3^{e}$ \\
\hline Sex, male/female & $18 / 12$ & $17 / 11$ & $17 / 11^{\mathrm{a}}$ & $17 / 13$ & $16 / 10$ & $19 / 11^{a}$ \\
\hline Education, 1-8 & $4.3 \pm 1.8$ & $3.4 \pm 2.2$ & $3.2 \pm 2.0$ & $4.1 \pm 1.9$ & $3.4 \pm 2.0$ & $3.5 \pm 2.1$ \\
\hline Smoking & 40 & 30 & $21^{\mathrm{a}}$ & 38 & 23 & $30^{\mathrm{a}}$ \\
\hline Physical activity, hours & $7.6 \pm 6.9$ & $7 \pm 5.3$ & $8.2 \pm 6.5^{b}$ & $7.2 \pm 7.1$ & $6.9 \pm 5.8$ & $8.7 \pm 5.7^{b}$ \\
\hline $\mathrm{BMI}, \mathrm{kg} / \mathrm{m}^{2}$ & $29 \pm 5.1$ & $27.9 \pm 5.6$ & $29.7 \pm 5.4$ & $29.8 \pm 5.9$ & $28.1 \pm 4.8$ & $28.7 \pm 5.3$ \\
\hline Diabetes mellitus & 3 & 21 & $18^{\mathrm{a}}$ & 10 & 27 & $7^{a}$ \\
\hline Hypercholesterolemia & 27 & 14 & $25^{\mathrm{a}}$ & 13 & 35 & $20^{\mathrm{a}}$ \\
\hline \multicolumn{7}{|l|}{ Daytime BP, mmHg: } \\
\hline SBP & $157 \pm 19$ & $151 \pm 19$ & $160 \pm 17$ & $150 \pm 20$ & $156 \pm 14$ & $161 \pm 19$ \\
\hline DBP & $99 \pm 14$ & $96 \pm 12$ & $97 \pm 12$ & $97 \pm 14$ & $98 \pm 9$ & $97 \pm 13$ \\
\hline MAP & $118 \pm 14$ & $115 \pm 14$ & $118 \pm 13$ & $115 \pm 16$ & $117 \pm 10$ & $119 \pm 14$ \\
\hline PP & $58 \pm 14$ & $55 \pm 10$ & $63 \pm 12$ & $53 \pm 10$ & $58 \pm 9$ & $65 \pm 14^{\mathrm{e}(\mathrm{NS})}$ \\
\hline Heart rate, bpm & $80 \pm 14$ & $83 \pm 13$ & $78 \pm 11$ & $82 \pm 12$ & $81 \pm 10$ & $77 \pm 15$ \\
\hline \multicolumn{7}{|l|}{ Night-time BP, mmHg: } \\
\hline SBP & $135 \pm 19$ & $132 \pm 22$ & $140 \pm 19$ & $130 \pm 20$ & $136 \pm 19$ & $141 \pm 20$ \\
\hline DBP & $82 \pm 15$ & $80 \pm 14$ & $82 \pm 12$ & $81 \pm 15$ & $81 \pm 12$ & $82 \pm 13$ \\
\hline MAP & $100 \pm 15$ & $98 \pm 16$ & $102 \pm 14$ & $98 \pm 17$ & $100 \pm 13$ & $103 \pm 15$ \\
\hline $\mathrm{PP}$ & $53 \pm 11$ & $52 \pm 11$ & $59 \pm 13$ & $49 \pm 9$ & $55 \pm 11$ & $59 \pm 14^{\mathrm{d}(\mathrm{NS})}$ \\
\hline Heart rate, bpm & $66 \pm 11$ & $71 \pm 12$ & $64 \pm 8^{e}$ & $68 \pm 10$ & $68 \pm 9$ & $65 \pm 13$ \\
\hline \multicolumn{7}{|l|}{ 24-hour BP, mmHg: } \\
\hline SBP & $150 \pm 18$ & $146 \pm 20$ & $155 \pm 15$ & $144 \pm 20$ & $150 \pm 15$ & $156 \pm 17^{\mathrm{e}(\mathrm{NS})}$ \\
\hline DBP & $93 \pm 13$ & $91 \pm 12$ & $93 \pm 11$ & $92 \pm 14$ & $93 \pm 9$ & $92 \pm 12$ \\
\hline MAP & $113 \pm 13$ & $110 \pm 14$ & $114 \pm 12$ & $110 \pm 16$ & $112 \pm 10$ & $115 \pm 13$ \\
\hline PP & $56 \pm 13$ & $55 \pm 10$ & $62 \pm 12$ & $52 \pm 10$ & $58 \pm 10$ & $64 \pm 14^{\mathrm{e}(\mathrm{NS})}$ \\
\hline Heart rate, bpm & $74 \pm 12$ & $79 \pm 12$ & $73 \pm 9$ & $77 \pm 10$ & $76 \pm 9$ & $73 \pm 13$ \\
\hline MAP dipping, \% & $15.2 \pm 7.8$ & $14.5 \pm 7.3$ & $13.6 \pm 8.3$ & $14.9 \pm 6.5$ & $14.9 \pm 7.9$ & $13.6 \pm 8.9$ \\
\hline Sensorimotor speed, Z-score & $0.23 \pm 0.47$ & $0.00 \pm 0.60$ & $-0.24 \pm 0.95^{\mathrm{e}(\mathrm{NS})}$ & $0.17 \pm 0.53$ & $0.09 \pm 0.53$ & $-0.24 \pm 0.95$ \\
\hline Cognitive flexibility, Z-score & $0.28 \pm 0.70$ & $-0.02 \pm 0.72$ & $-0.28 \pm 1.17$ & $0.33 \pm 0.66$ & $0.04 \pm 0.59$ & $-0.37 \pm 1.19^{\mathrm{d}(\mathrm{NS})}$ \\
\hline Memory, Z-score & $0.11 \pm 0.99$ & $-0.07 \pm 0.91$ & $-0.04 \pm 0.96$ & $0.29 \pm 0.83$ & $-0.16 \pm 1.07$ & $-0.14 \pm 0.92$ \\
\hline \multicolumn{7}{|c|}{ 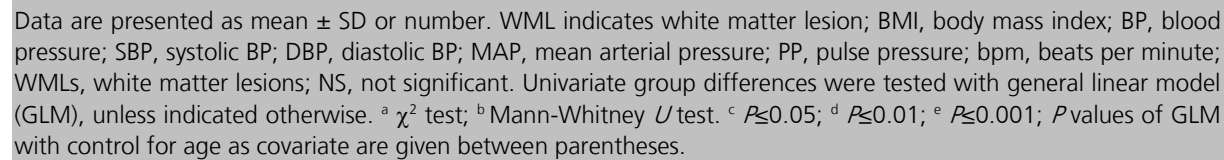 } \\
\hline
\end{tabular}


Table 9.2b Descriptive statistics by periventricular white matter lesion status and lacunar infarct status.

\begin{tabular}{|c|c|c|c|c|}
\hline & \multicolumn{2}{|c|}{ Periventricular WMLs } & \multicolumn{2}{|c|}{ Lacunar infarcts } \\
\hline & Absent (30) & Present (56) & Absent (69) & Present (17) \\
\hline Age, years & $53.1 \pm 8.5$ & $59.6 \pm 10.1^{d}$ & $56.2 \pm 9.7$ & $61.9 \pm 10.3^{c}$ \\
\hline Sex, male/female & $17 / 13$ & $35 / 21^{a}$ & 39 / 30 & $13 / 4^{a}$ \\
\hline Education, 1-8 & $4.1 \pm 1.9$ & $3.4 \pm 2.1$ & $3.8 \pm 2$ & $3.2 \pm 2.1$ \\
\hline Smoking & 38 & $27^{a}$ & 34 & $18^{a}$ \\
\hline Physical activity, hours & $7.2 \pm 7.1$ & $7.8 \pm 5.8^{b}$ & $8 \pm 6.6$ & $6 \pm 4.3^{b}$ \\
\hline $\mathrm{BMI}, \mathrm{kg} / \mathrm{m}^{2}$ & $29.8 \pm 5.9$ & $28.4 \pm 5.1$ & $29.4 \pm 5.6$ & $26.9 \pm 3.8$ \\
\hline Diabetes mellitus & 10 & $16^{a}$ & 9 & $35^{\text {ad }}$ \\
\hline Hypercholesterolemia & 13 & $27^{\mathrm{a}}$ & 23 & $18^{\mathrm{a}}$ \\
\hline \multicolumn{5}{|l|}{ Daytime BP, mmHg: } \\
\hline SBP & $150 \pm 20$ & $159 \pm 17^{\mathrm{C}(\mathrm{NS})}$ & $153 \pm 18$ & $166 \pm 18^{(\mathrm{c})}$ \\
\hline DBP & $97 \pm 14$ & $97 \pm 11$ & $96 \pm 11$ & $101 \pm 17$ \\
\hline MAP & $115 \pm 16$ & $118 \pm 12$ & $116 \pm 13$ & $124 \pm 16^{(\mathrm{c})}$ \\
\hline PP & $53 \pm 10$ & $62 \pm 13^{\mathrm{e}(\mathrm{C})}$ & $57 \pm 12$ & $64 \pm 14^{\mathrm{c}(\mathrm{NS})}$ \\
\hline Heart rate, bpm & $82 \pm 12$ & $79 \pm 13$ & $80 \pm 12$ & $79 \pm 15$ \\
\hline \multicolumn{5}{|l|}{ Night-time BP, mmHg: } \\
\hline SBP & $130 \pm 20$ & $138 \pm 19$ & $133 \pm 19$ & $146 \pm 20^{(c)}$ \\
\hline DBP & $81 \pm 15$ & $81 \pm 13$ & $80 \pm 11$ & $86 \pm 20$ \\
\hline MAP & $98 \pm 17$ & $101 \pm 14$ & $98 \pm 13$ & $108 \pm 19^{\mathrm{c}(\mathrm{C})}$ \\
\hline PP & $49 \pm 9$ & $57 \pm 12^{\mathrm{d}_{(\mathrm{NS})}}$ & $53 \pm 12$ & $60 \pm 11^{\mathrm{c}(\mathrm{NS})}$ \\
\hline Heart rate, bpm & $68 \pm 10$ & $67 \pm 11$ & $68 \pm 11$ & $65 \pm 11$ \\
\hline \multicolumn{5}{|l|}{ 24-hour BP, mmHg: } \\
\hline SBP & $44 \pm 20$ & $153 \pm 16^{\mathrm{C}(\mathrm{NS})}$ & $147 \pm 17$ & $161 \pm 17^{\mathrm{d}(\mathrm{d})}$ \\
\hline DBP & $92 \pm 14$ & $93 \pm 11$ & $91 \pm 10$ & $97 \pm 17$ \\
\hline MAP & $110 \pm 16$ & $113 \pm 12$ & $110 \pm 12$ & $119 \pm 16^{\mathrm{cd})}$ \\
\hline PP & $52 \pm 10$ & $61 \pm 12^{\mathrm{e}(\mathrm{C})}$ & $56 \pm 11$ & $64 \pm 13^{\mathrm{C}(\mathrm{NS})}$ \\
\hline Heart rate, bpm & $77 \pm 10$ & $74 \pm 12$ & $75 \pm 11$ & $74 \pm 13$ \\
\hline MAP dipping, $\%$ & $14.9 \pm 6.5$ & $14.2 \pm 8.4$ & $14.8 \pm 7.7$ & $13.2 \pm 8$ \\
\hline Sensorimotor speed, Z-score & $0.17 \pm 0.53$ & $-0.09 \pm 0.79$ & $0.08 \pm 0.68$ & $-0.3 \pm 0.8$ \\
\hline Cognitive flexibility, Z-score & $0.33 \pm 0.66$ & $-0.18 \pm 0.97^{\mathrm{C}(\mathrm{NS})}$ & $0.1 \pm 0.82$ & $-0.43 \pm 1.13^{\mathrm{C}(\mathrm{NS})}$ \\
\hline Memory, Z-score & $0.29 \pm 0.83$ & $-0.15 \pm 0.98^{\mathrm{C}(\mathrm{NS})}$ & $0.14 \pm 0.92$ & $-0.58 \pm 0.88^{d_{(}()}$ \\
\hline
\end{tabular}

Data are presented as mean \pm SD or number. WMLs indicates white matter lesions; BMI, body mass index; BP, blood pressure; SBP, systolic BP; DBP, diastolic BP; MAP, mean arterial pressure; PP, pulse pressure; bpm, beats per minute; NS, not significant. Univariate group differences were tested with general linear model (GLM), unless indicated otherwise. ${ }^{a} \chi^{2}$ test; ${ }^{b}$ Mann-Whitney $U$ test. ${ }^{c} P \leq 0.05$; d $P \leq 0.01$; e $P \leq 0.001 ; P$ values of GLM with control for age as covariate are given between parentheses.

Age was associated with higher subcortical WML volume, the presence as well as the severity of periventricular WMLs and more evidence of LACs on MRI $(\mathrm{F}(2,83)=9.090, P<0.001 ; \mathrm{F}(1,84)=9.116, P<0.01 ; \mathrm{F}(2,83)=10.532, P<0.001 ;$ and $F(1,84)=4.645, \quad P<0.05$, respectively). Higher daytime and 24-hour SBP and daytime, nighttime and 24-hour PP were related to both the presence and the severity of periventricular WMLs. Furthermore, daytime, nighttime and 24-hour averages of SBP, MAP and PP were associated with presence of LACs. After controlling for age in the analysis, these relationships remained significant for 
daytime and 24-hour PP with respect to the presence of periventricular WMLs, whereas differences between severity groups (tertiles) disappeared (Tables 9.2a and 9.2b). Systolic BP and MAP for daytime, nighttime and 24-hour periods remained significantly associated with LACs (Table 9.2b). Again, evidence of cerebral damage was unrelated to relative dipping of the MAP at night. Higher subcortical WML load was related to lower scores on sensorimotor speed, whereas cognitive flexibility and verbal memory scores decreased with the presence or the severity of periventricular WMLs and LACs (all at $P<0.05$ ). However, none of these associations remained significant after correction for age in the model, except for verbal memory. In persons with evidence of LACs this score remained significantly lower after adjustment for age, when compared with controls $(F(1,84)=6.693, P<0.05)$.

We performed additional analyses on historical data in both dipper categories about hypertension duration (8.8 vs. 9.2 years in dippers/nondippers, respectively), the number of antihypertensive medications taken prior to ABPM (1.9 vs. 1.8) and duration of past antihypertensive medication usage (4.7 vs. 3.6 years): no significant differences were apparent in these data. Finally, a post hoc comparison of WML load and cognitive variables based on tertiles of day/night MAP dipping did not reveal evidence for a nonlinear relationship between nondipping and WML load or cognitive function.

\section{Discussion}

To the best of our knowledge, this study is the first to investigate the relationship between ambulatory BP and a combination of both morphological and functional characteristics of brain structures that are engaged in cognitive performance, using ABPM, MRI and a comprehensive battery of cognitive tests. We linked the evidence of early cerebral damage (subcortical and periventricular WMLs, or presence of LACs) to diurnal blood pressure variation, ambulatory BP profile and indicators of neurocognitive functioning in previously diagnosed essential hypertensive individuals. Nondipping during the night was unrelated to both cognitive variables and imaging parameters, after appropriate control for possible confounders (i.e., difference in educational level). Age was a strong indicator of subcortical WMLs, periventricular WMLs, and LAC prevalence on MRI. When age differences were accounted for, differences in either daytime and 24-hour PP on the one hand, and daytime, nighttime and 24-hour SBP and MAP on the other, remained statistically significant between periventricular WML and LAC groups, respectively. However, the associations between cognitive function and imaging measures disappeared, except for a significant difference in memory function between individuals with and without LACs. 
The results of previous studies concerning the prevalence of WMLs in patients with hypertension are equivocal, which may be related, at least in part, to differences in patient selection and MRI scoring systems. ${ }^{41}$ As pointed out by Sierra and others, most studies have been performed in older individuals, or populations with a wide age range. ${ }^{14}$ When these investigators studied a group of 66 never-treated hypertensive patients between 50 and 60 years of age they did find higher levels of ambulatory BP in a group characterized by WML presence, compared to non-WML controls, but no between-group differences were apparent in the nocturnal BP fall. In agreement with the latter findings, both dipping status and relative MAP dipping were unrelated to cerebral pathology in the present study. In the Japanese population, nondipping but also extreme dipping have repeatedly been associated with silent cerebrovascular disease, such as WMLs and LACs. ${ }^{42}$ Studies in Caucasian populations though are limited and their results are not beyond dispute. ${ }^{14,43-45}$ Most of these were limited in size ${ }^{14,45}$ or lesions were described in terms of presence or absence only. ${ }^{14,43}$ Furthermore, with respect to the classification of dipping, there is no consensus on what BP variable to use (SBP, DBP or MAP), which cut-off values are optimal and how data should be presented (relative dipping or dipping status). Studies, and patient groups within studies, may also differ with respect to the duration of hypertension and treatment history of which reliable information can be difficult to obtain. Hypertension history or the duration of antihypertensive medication did not affect our results. Still, methodological differences such as described here can complicate the comparison of our findings with those of aforementioned studies. On a final note, some authors suggested that repeated ABPM may yield more accurate assessment of dipper status and thus improve the use of diurnal BP variation in risk assessment. ${ }^{46,47}$ Therefore, the consequences of diurnal BP variations on the brain remain to be elucidated further, at least in Caucasians.

Previously, others reported ABPM to be superior to casual BP measurements in predicting hypertension-induced cerebrovascular disease. ${ }^{13}$ In addition, ambulatory MAP and PP recently gained increased interest in the prediction of silent and symptomatic stroke. ${ }^{14,20,21}$ Driven by this line of evidence, we assessed the effects of the ambulatory BP profile on WMLs and LACs. When age differences were accounted for, presence of periventricular WMLs was associated with daytime and 24-hour PP, whereas SBP and MAP for daytime, nighttime and 24-hour periods were highest in patients with LACs. Otherwise, ambulatory BP profile did not predict severity of both periventricular and subcortical WMLs. Intriguingly, these findings suggest that the steady (MAP) and pulsatile (PP) components of BP predispose to different forms of small-vessel disease related white matter abnormalities. Others have hypothesized that small penetrating cerebral arteries are particularly vulnerable to the adverse effects of a steady BP overload (MAP), causing small LACs. ${ }^{20,21}$ According to this hypothesis and in line with our findings, some authors recently suggested that daytime, nighttime and 
24-hour MAP were major determinants for the formation of silent cerebral infarctions, mostly LACs. ${ }^{20}$ The blood supply of the periventricular white matter is dependent on endarteries which lack appropriate anastomoses. ${ }^{48}$ This arterial watershed zone is highly vulnerable to ischemia during hypotensive periods, especially in hypertensive patients with impaired cerebral autoregulation. ${ }^{49}$ Since a high PP reflects an increased arterial stiffness ${ }^{50}$, we speculate that the penetrating cerebral arteries of hypertensive patients with high PP are less potent in their response to hypotension, increasing the risk of developing periventricular WMLs. Recent findings of Sierra et al. are compatible with this notion. They reported higher values of PP, including office, daytime, nighttime and 24-hour averages, among hypertensive patients with periventricular WMLs, compared to those without. ${ }^{14}$ The present results, however, remain to be confirmed in a well-defined, larger population. On multivariate analysis, the ambulatory BP profile remained significantly associated with the presence, but not with the severity of periventricular WMLs. To our knowledge, there is no consensus with respect to lesion definition. It is likely that differences in lesion definition may account for this inconsistency, because when continuous data are dichotomized the remaining variance becomes less informative.

The absence of an association between nondipping and cognitive performance does not comply with earlier observations that we made in a study on 115, community dwelling, largely normotensive individuals of approximately the same age range (29-81 years). ${ }^{51}$ In that study, nondippers were characterized by lower scores on both memory and sensorimotor speed measures. This inconsistency could indicate that the diurnal BP rhythm of our patients depends for some part on hypertension induced cerebral abnormalities, i.e., reverse causality, which we assume to be not, or less, present in community residents. ${ }^{52}$ However, it remains elusive why we failed to replicate earlier findings. Our results also disagree with a recent study in patients with a blunted decline in nighttime BP who showed poorer cognitive performance. ${ }^{53}$ However, patients in this study had long-standing hypertension (17.3 \pm 4.9 years, range 10-26), cognitive performance was assessed using the standard Mini-Mental State Examination, and only 26 patients were included.

White matter lesion extent was unrelated to cognitive performance parameters, which is in contrast to the findings of the Rotterdam study where periventricular WML load was associated with lower information processing speed and general cognitive functioning. ${ }^{24}$ Results, however, are in line with a smaller population study in 123 older (64-74) individuals that failed to find a linear association between WML load (measured according to a comparable protocol) and cognitive performance measures ${ }^{12}$, and with recent work by Sierra et al. who reported no differences in memory between hypertensive patients with and without periventricular WMLs. ${ }^{54}$ On the other hand, the present study confirmed recent findings from the Rotterdam study where silent brain infarcts (202 out of 217 
were LACs) were associated with a greater decline in memory performance, in particular when these were located in the thalamus. ${ }^{55}$

In conclusion, there was no relationship between diurnal BP rhythm and evidence of structural or functional cerebral damage in this population of hypertensive individuals. Our study was relatively small, but given the substantial variability in WMLs in this hypertensive population (over $62 \%$ having overt white matter changes) we cautiously conclude that an association between WMLS and cognition will in no case be very robust. Still, our data suggest that the ambulatory BP profile may predict lesion type in early asymptomatic cerebral abnormalities. 


\section{References}

1. Starr JM, Whalley LJ. Senile hypertension and cognitive impairment: An overview. J Hypertens 1992;10 (Suppl 2):S31-S42.

2. Manolio TA, Olson J, Longstreth WT. Hypertension and cognitive function: Pathophysiologic effects of hypertension on the brain. Curr Hypertens Rep 2003;5:255-61.

3. de Leeuw FE, de Groot JC, Oudkerk M, Witteman JC, Hofman A, van Gijn J, Breteler MM. Hypertension and cerebral white matter lesions in a prospective cohort study. Brain 2002;125:765-72.

4. Longstreth WT, Jr., Manolio TA, Arnold A, Burke GL, Bryan N, Jungreis CA, Enright PL, O'Leary D, Fried L. Clinical correlates of white matter findings on cranial magnetic resonance imaging of 3301 elderly people. The Cardiovascular Health Study. Stroke 1996;27:1274-82.

5. Breteler MBB, van Swieten JC, Bots ML, Grobbee DE, Claus JJ, van den Hout JHW, van Harskamp F, Tanghe HLJ, de Jong PTVM, van Gijn J, Hofman A. Cerebral white matter lesions, vascular risk factors, and cognitive function in a population-based study: The Rotterdam study. Neurology 1994;44:1246-52.

6. Gunning-Dixon FM, Raz N. The cognitive correlates of white matter abnormalities in normal aging: A quantitative review. Neuropsychology 2000;14:224-32.

7. Ylikoski R, Ylikoski A, Erkinjuntti T, Sulkava R, Raininko R, Tilvis R. White matter changes in healthy elderly persons correlate with attention and speed of mental processing. Arch Neurol 1993;50:818-24.

8. Pantoni L, Leys D, Fazekas F, Longstreth WT, Jr., Inzitari D, Wallin A, Filippi M, Scheltens P, Erkinjuntti T, Hachinski V. Role of white matter lesions in cognitive impairment of vascular origin. Alzheimer Dis Assoc Disord 1999;13 (Suppl 3):S49-54.

9. Pantoni L, Garcia JH. Cognitive impairment and cellular/vascular changes in the cerebral white matter. Ann N Y Acad Sci 1997;826:92-102.

10. Skoog I. A review on blood pressure and ischaemic white matter lesions. Dement Geriatr Cogn Disord 1998;9 (Suppl 1):13-9.

11. Pantoni L, Garcia JH. The significance of cerebral white matter abnormalities 100 years after Binswanger's report. A review. Stroke 1995;26:1293-301.

12. Soderlund $H$, Nyberg L, Adolfsson R, Nilsson LG, Launer LJ. High prevalence of white matter hyperintensities in normal aging: Relation to blood pressure and cognition. Cortex 2003;39:1093-105.

13. Shimada K, Kawamoto A, Matsubayashi K, Ozawa T. Silent cerebrovascular disease in the elderly: Correlation with ambulant pressure. Hypertension 1990;16:692-99.

14. Sierra C, de La Sierra A, Mercader J, Gomez-Angelats E, Urbano-Marquez A, Coca A. Silent cerebral white matter lesions in middle-aged essential hypertensive patients. I Hypertens 2002;20:519-24.

15. Fukuda $\mathrm{H}$, Kitani $M$. Differences between treated and untreated hypertensive subjects in the extent of periventricular hyperintensities observed on brain MRI. Stroke 1995;26:1593-97.

16. Liao D, Cooper L, Cai J, Toole JF, Bryan NR, Hutchinson RG, Tyroler HA. Presence and severity of cerebral white matter lesions and hypertension, its treatment, and its control. The ARIC study. Atherosclerosis Risk In Communities study. Stroke 1996;27:2262-70.

17. Shimada K, Kawamoto A, Matsubayashi K, Nishinaga M, Kimura S, Ozawa T. Diurnal blood pressure variations and silent cerebrovascular damage in elderly patients with hypertension. J Hypertens 1992;10:875-78.

18. Kario K, Matsuo T, Kobayashi H, Imiya M, Matsuo M, Shimada K. Nocturnal fall of blood pressure and silent cerebrovascular damage in elderly hypertensive patients. Advanced silent cerebrovascular damage in extreme dippers. Hypertension 1996;27:130-35.

19. Kario K, Pickering TG, Matsuo T, Hoshide S, Schwartz JE, Shimada K. Stroke prognosis and abnormal nocturnal blood pressure falls in older hypertensives. Hypertension 2001;38:852-7.

20. Kario K, Ishikawa J, Eguchi K, Morinari M, Hoshide S, Ishikawa S, Shimada K. Sleep pulse pressure and awake mean pressure as independent predictors for stroke in older hypertensive patients. Am J Hypertens 2004;17:439-45. 
21. Verdecchia P, Schillaci G, Reboldi G, Franklin SS, Porcellati C. Different prognostic impact of 24-hour mean blood pressure and pulse pressure on stroke and coronary artery disease in essential hypertension. Circulation 2001;103:2579-84.

22. Fazekas F, Schmidt R, Scheltens P. Pathophysiologic mechanisms in the development of agerelated white matter changes of the brain. Dement Geriatr Cogn Disord 1998;9 (Suppl 1):2-5.

23. Scheltens P, Erkinjunti T, Leys D, Wahlund LO, Inzitari D, del Ser T, Pasquier F, Barkhof F, Mantyla R, Bowler J, Wallin A, Ghika J, Fazekas F, Pantoni L. White matter changes on CT and MRI: An overview of visual rating scales. European task force on age-related white matter changes. Eur Neurol 1998;39:80-89.

24. de Groot JC, de Leeuw FE, Oudkerk M, van Gijn J, Hofman A, Jolles J, Breteler MM. Cerebral white matter lesions and cognitive function: The Rotterdam Scan Study. Ann Neurol 2000;47:145-51.

25. de Groot JC, de Leeuw FE, Oudkerk M, Hofman A, Jolles J, Breteler MM. Cerebral white matter lesions and depressive symptoms in elderly adults. Arch Gen Psychiatry 2000;57: 1071-76.

26. De Groot JC, De Leeuw FE, Oudkerk M, Van Gijn J, Hofman A, Jolles J, Breteler MM. Periventricular cerebral white matter lesions predict rate of cognitive decline. Ann Neurol 2002;52:335-41.

27. O'Brien E, Asmar R, Beilin L, Imai Y, Mallion JM, Mancia G, Mengden T, Myers M, Padfield P, Palatini P, Parati G, Pickering T, Redon J, Staessen J, Stergiou G, Verdecchia P. European society of hypertension recommendations for conventional, ambulatory and home blood pressure measurement. J Hypertens 2003;21:821-48.

28. Bartko JJ, Carpenter WT. On the methods and theory of reliability. Journal of Nervous and Mental Disease 1975;163:307-17.

29. Jolles J, Houx PJ, van Boxtel MPJ, Ponds RWHM. Maastricht aging study: Determinants of cognitive aging. Maastricht: Neuropsych Publishers; 1995.

30. Brand N, Jolles J. Learning and retrieval rate of words presented auditory and visually. J Gen Psychol 1985;112:201-10.

31. Houx PJ, Vreeling FW, Jolles J. Age-associated cognitive decline is related to biological life events. In: Alzheimer's disease: basic mechanisms, diagnosis and therapeutic strategies.: Chichester, Wiley; 1991.

32. Houx PJ, Jolles J, Vreeling FW. Stroop interference: Aging effects assessed with the stroop colorword test. Exp Aging Res 1993;19:209-24.

33. Verdecchia P, Schillaci G, Porcelatti C. Dippers versus non-dippers. J Hypertens 1991;9 (Suppl 8):S42-S44.

34. Van Boxtel MPJ, Langerak K, Houx PJ, Jolles J. Self-reported physical activity, subjective health, and cognitive performance in older adults. Exp Aging Res 1995;22:363-79.

35. La Rue A. Aging and neuropsychological assessment. New York: Plenum Press; 1992.

36. Lezak MD. Neuropsychological assessment. 4th ed. New York: Oxford University Press; 2004

37. Salthouse TA. Mechanisms of age-cognition relations in adulthood. Hillsdale, NJ: Lawrence Erlbaum Associates; 1992.

38. Van Boxtel MPJ, Buntinx F, Houx PJ, Metsemakers JFM, Knottnerus JA, Jolles J. The relation between morbidity and cognitive performance in a normal aging population. J Geront 1998;53A:M146-M54.

39. La Rue A. Neuropsychology assessment procedures. In: Aging and neuropsycological assessment. New York: Plenum Press; 1992.

40. Manabe Y, Murakami T, Iwatsuki K, Narai H, Warita H, Hayashi T, Shoji M, Imai Y, Abe K. Nocturnal blood pressure dip in CADASIL. J Neurol Sci 2001;193:13-6.

41. Kivipelto $M$, Soininen $H$, Tuomilehto J. Hypertension and white matter lesions of the brain. J Hypertens 2002;20:387-9.

42. Kario K, Shimada K, Pickering TG. Abnormal nocturnal blood pressure falls in elderly hypertension: Clinical significance and determinants. J Cardiovasc Pharmacol 2003;41 (Suppl 1):S61-6.

43. Sander D, Winbeck K, Klingelhofer J, Conrad B. Extent of cerebral white matter lesions is related to changes of circadian blood pressure rhythmicity. Arch Neuro/2000;57:1302-07. 
44. Kukla C, Sander D, Schwarze J, Wittich I, Klingelhofer J. Changes of circadian blood pressure patterns are associated with the occurrence of lacunar infarction. Arch Neuro/ 1998;55:683-8.

45. Chamorro A, Pujol J, Saiz A, Vila N, Vilanova JC, Alday M, Blanc R. Periventricular white matter lucencies in patients with lacunar stroke. A marker of too high or too low blood pressure? Arch Neuro/ 1997;54:1284-8.

46. Cuspidi C, Macca G, Michev I, Salerno M, Fusi V, Severgnini B, Corti C, Meani S, Valerio C, Magrini $F$, Zanchetti A. Short-term reproducibility of nocturnal non-dipping pattern in recently diagnosed essential hypertensives. Blood Press 2002;11:79-83.

47. Manning G, Rushton L, Donnelly R, Millar-Craig MW. Variability of diurnal changes in ambulatory blood pressure and nocturnal dipping status in untreated hypertensive and normotensive subjects. Am J Hypertens 2000;13:1035-8.

48. Pantoni L, Garcia JH. Pathogenesis of leukoaraiosis: A review. Stroke 1997;28:652-9.

49. Bakker SL, de Leeuw FE, de Groot JC, Hofman A, Koudstaal PJ, Breteler MM. Cerebral vasomotor reactivity and cerebral white matter lesions in the elderly. Neurology 1999;52:578-83.

50. Struijker Boudier HA, Cohuet GM, Baumann M, Safar ME. The heart, macrocirculation and microcirculation in hypertension: A unifying hypothesis. J Hypertens 2003;21 (Suppl 3): S19-23.

51. Van Boxtel MPJ, Gaillard C, Houx PJ, Buntinx F, de Leeuw PW, Jolles J. Is non-dipping in 24-hour ambulatory blood pressure related to cognitive dysfunction? J Hypertens 1998;16:1425-32.

52. Kario K, Shimada K. Change in diurnal blood pressure rhythm due to small lacunar infarct. Lancet 1994;344:200.

53. Bellelli G, Frisoni GB, Lucchi E, Guerini F, Geroldi C, Magnifico F, Bianchetti A, Trabucchi M. Blunted reduction in night-time blood pressure is associated with cognitive deterioration in subjects with long-standing hypertension. Blood Press Monit 2004;9:71-76.

54. Sierra C, De La Sierra A, Salamero M, Sobrino J, Gomez-Angelats E, Coca A. Silent cerebral white matter lesions and cognitive function in middle-aged essential hypertensive patients. $A m ~ J$ Hypertens 2004;17:529-34.

55. Vermeer SE, Prins ND, den Heijer T, Hofman A, Koudstaal PJ, Breteler MM. Silent brain infarcts and the risk of dementia and cognitive decline. N Eng/ J Med 2003;348:1215-22. 
148 
Detection of silent cerebrovascular disease refines risk stratification of hypertensive patients

Léon H.G. Henskens

Robert J. van Oostenbrugge

Abraham A. Kroon

Paul A.M. Hofman

Jan Lodder

Peter W. de Leeuw

\section{Submitted}
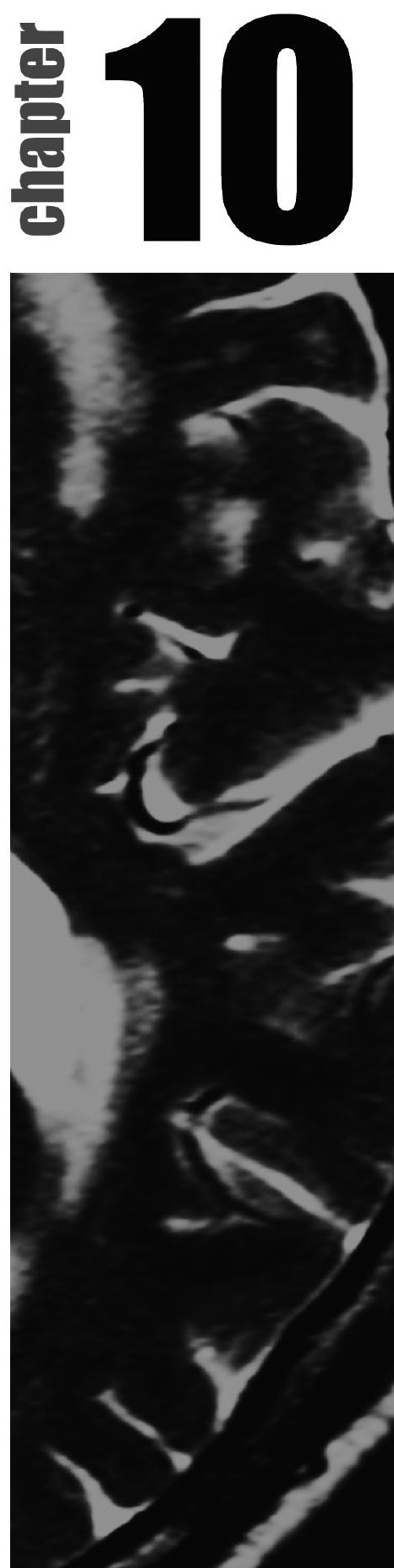


\section{Summary}

Detection of preclinical hypertension-related cardio-renal damage has been recommended in the identification of patients at risk of cardiovascular complications. The inclusion of eventual silent cerebrovascular disease as an additional marker of hypertensive organ involvement might refine risk stratification.

In 192 hypertensive patients (98 males) without a history of cardio- and cerebrovascular disease, a mean age of $51.6 \pm 12.3$ years, and untreated office blood pressure levels of $170 \pm 23 / 104 \pm 12 \mathrm{mmHg}$, we obtained detailed information on preclinical cardiac (left ventricular hypertrophy), renal (microalbuminuria and/or impaired kidney function) and cerebrovascular damage (white matter hyperintensities, infarcts and/or microbleeds), and estimated the associated cardiovascular risk based on the presence of common cardiovascular risk factors.

Hypertensive organ damage involved the heart in 41 (21\%), the kidneys in 50 (26\%), and the brain in $84(44 \%)$ participants. When considering only patients with demonstrable cardiac and/or renal damage $(n=72), 42$ subjects (58\%) had also silent cerebrovascular disease. Of the remaining 120 participants without cardio-renal damage 42 (35\%) had brain damage. In other words, half of all patients with silent cerebrovascular disease were classified as having no organ (i.e., cardio-renal) involvement. The cardiovascular risk score of patients without cardio-renal but with brain damage was significantly higher than that

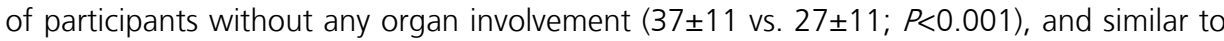
the risk score of those with cardio-renal damage (38 $\pm 14 ; P>0.05)$.

In conclusion, these data suggest that silent cerebrovascular disease should be recognized as an additional, independent and prognostically relevant marker of preclinical hypertensive organ damage. 


\section{Introduction}

The (timely) detection of silent hypertension-related organ damage will become increasingly important in the identification of patients who are at risk of cardiovascular complications. Currently, hypertension guidelines mainly recognize the heart and kidneys as the crucial target-organs affected by high blood pressure (BP). ${ }^{1,2}$ However, one may question whether the detection of preclinical cardiac and renal damage, manifested as left ventricular hypertrophy (LVH) and microalbuminuria or impaired renal function, sufficiently covers the risk associated with hypertension, or leaves a significant number of high-risk patients unnoticed, e.g., because silent damage to other organs such as the brain remains undetected.

Silent cerebrovascular disease (SCD), which can be identified on brain magnetic resonance imaging (MRI) as white matter hyperintensities (WMHs), silent brain infarcts (SBIs) and brain microbleeds (BMBs), is a frequent observation in hypertensive patients $\mathrm{s}^{3-5}$ and can be used as an intermediate endpoint for stroke $\mathrm{e}^{6,7}$. Accordingly, we assessed whether the detection of SCD as a marker of hypertensive brain damage, in addition to cardiac and renal risk markers, refines the identification of subjects at increased risk of cardiovascular complications. To this end, we obtained detailed information on hypertension-related, preclinical damage of the heart, kidneys and brain, and estimated the associated cardiovascular risk ${ }^{8}$ in a cohort of hypertensive patients without manifest cardioand cerebrovascular disease.

\section{Methods}

\section{Participants}

Between July 2004 and September 2006, all patients referred to our outpatient department for evaluation of their hypertension were asked to participate in the present study. The routine work-up included a standard 12-lead electrocardiography, echocardiography, a timed urine collection over a 24-hour period and routine laboratory investigations. Only patients who were currently off antihypertensive medication as part of the routine investigations, were eligible for inclusion, and had to consent to an MRI of the brain. In addition, participants had to fulfill the following criteria: (1) men or women aged 18-90 years; (2) no indication from history-taking, physical examination or routine laboratory tests of secondary hypertension; (3) no evidence of chronic renal failure (serum creatinine concentration $>150 \mu \mathrm{mol} / \mathrm{l}$ on $>2$ occasions); (4) no diabetes, i.e., the current use of oral antidiabetic drugs or insulin; (5) no clinically documented ischemic or valvular heart disease or electrocardiographic evidence of atrial fibrillation; (6) no 
history of transient ischemic attacks and ischemic or hemorrhagic stroke; (7) no diagnosis of obstructive sleep apnea syndrome. All participants gave written informed consent and the Medical Ethics Committee of the Maastricht University Medical Centre approved the study. Altogether, 218 patients consented to participate in the present study. Details on screening, eligibility and inclusion in the study have been described elsewhere (Figure B.1, Appendix B). ${ }^{3}$

\section{Risk factors}

Conventional office BP was measured at the hospital by sphygmomanometry (Korotkoff phases I and V). After at least five minutes of rest, three consecutive measurements were taken at the non-dominant arm, with the participant seated, and always by the same trained investigator (L.H.). Blood pressures are reported as the mean of the second and third measurements. Heart rate was obtained by palpation of the radial artery. Hypertension was defined as an untreated office $\mathrm{BP} \geq 140 \mathrm{mmHg}$ systolic and/or $\geq 90 \mathrm{mmHg}$ diastolic, and graded as mild (140-159 mmHg systolic and/or 90-99 mmHg diastolic), moderate (160-179 and/or 100-109) or severe ( $\geq 180$ and/or $\geq 110$ ) according to current guidelines. ${ }^{2}$ Height and weight were measured without shoes and wearing light indoor clothing to determine body mass index (BMI, $\left.\mathrm{kg} / \mathrm{m}^{2}\right)$.

Venous blood samples, routinely drawn after an overnight fast, were analyzed for serum creatinine, serum total cholesterol and high-density lipoprotein (HDL) cholesterol levels, and plasma glucose levels using standard laboratory procedures. Hypercholesterolemia was considered to be present in subjects who either used lipid-lowering drugs or had untreated total cholesterol levels $>6.5 \mathrm{mmol} / \mathrm{l}^{2}$

Information on lifestyle habits, past and current morbidity (including current treatment), and hypertension history (including the self-reported age of diagnosis, previous use of antihypertensive medication, and duration of treatment), were obtained by interview and verified by inspection of recently started medical records. The duration of hypertension was estimated as the time (in months) passed since the self-reported age of diagnosis until inclusion in the study. Smoking was classified as never, past or current.

\section{Silent cerebrovascular disease}

Brain MRI was performed on a 1.5-T clinical MR-system (Intera, Philips Medical Systems, Best, The Netherlands) using a standard quadrature head coil. The standardized imaging protocol consisted of T2-weighted fast spin echo (repetition time [TR] 4820 ms; echo time [TE] 100 ms; echo train length [ETL] 12; flip angle 90\%; field of view [FOV] $230 \mathrm{~mm}$; acquisition matrix 512X512), fluid-attenuated inversion recovery (FLAIR) (TR 8000 ms; TE 120 ms; inversion time 2000 ms; ETL 23 ;FOV 230 mm; acquisition matrix 256X256 [reconstructed to 512X512]) and T2*-weighted gradient echo (TR 736 ms; TE 23 ms; flip angle 15\%; 
FOV $230 \mathrm{~mm}$; acquisition matrix 256X256) sequences in the axial plane, producing 24 slices with a thickness of $5 \mathrm{~mm}$ and a $0.5 \mathrm{~mm}$ interslice gap.

White matter hyperintensities (for an example see Figure A.1, Appendix A) were identified on T2-weighted and FLAIR images and classified according to Fazekas et al. into hyperintensities of the deep, subcortical white matter (DWMH) and periventricular hyperintensities (PVH) (Table E.1, Appendix E) $)^{9}$ We considered WMHs to be advanced in case of DWMH grades 2 or 3 (i.e., beginning confluence of foci or large confluent areas) and/or PVH grade 3 (i.e., irregular hyperintensities extending into the deep white matter). Histopathological data indicate that these advanced lesions reflect ischemic brain damage. ${ }^{10}$

Silent brain infarcts were identified as sharply demarcated hyperintense lesions (diameter $\geq 3 \mathrm{~mm}$ ) on T2-weighted images with corresponding foci of FLAIR low signal intensity, and assessed throughout the brain, i.e., brainstem, cerebellum, basal ganglia, thalamus, deep and subcortical white matter, and the cortex. ${ }^{11}$ We distinguished SBls from (equally sized) enlarged perivascular spaces using the FLAIR images, infarcts being characterized by a central cavitation of low signal intensity with a surrounding higher-intensity rim of gliotic tissue. See Figure A.2 (Appendix A) for examples of SBls.

Brain microbleeds were defined as punctate (diameter $<5 \mathrm{~mm}$ ), homogeneous foci of low signal intensity on $\mathrm{T} 2{ }^{*}$-weighted GE images ${ }^{12}$ and assessed throughout the brain, i.e., brainstem, cerebellum, basal ganglia, corona radiata and corticosubcortical gray and white matter. ${ }^{3}$ Symmetric hypointensities in the globi pallidi, likely to represent calcification or iron deposition, and sulcal flow voids from cortical vessels were disregarded. ${ }^{12}$ Figure A.3 (Appendix A) depicts some examples of BMBs.

We considered SCD to be present in case of advanced WMHs, SBIs, BMBs, or any combinations, on the assumption that these lesions reflect generalized cerebral microvascular damage related to high BP. 10,13,14 Nevertheless, we also performed analyses for each lesion type separately.

Two experienced vascular neurologists (R.v.O. and J.L.) rated all scans, independently and blinded to the participants' age, sex and clinical status. The inter-rater reliability, expressed as Cohen's Kappa, was 0.76 for advanced WMHs, 0.38 for SBls and 0.68 for BMBs, signifying substantial agreement for WMHs and BMBs, but poor agreement for SBIs. ${ }^{15}$ However, in case of disagreement between the 2 raters, lesions were always ascertained by consensus.

\section{Cardiac damage}

We considered cardiac damage to be present in case of LVH assessed by means of echocardiography.

Left ventricular (LV) mass, assessed by two-dimensional M-mode and Doppler echocardiography (Sonos 5500, Hewlett-Packard, Andover, MA), was estimated 
by a team of four cardiologists (as part of the routine investigations) according to Devereux's formula (Penn convention) ${ }^{16}$ and indexed to body surface area. The LV dimensions and wall thicknesses were measured according to current recommendations. ${ }^{17}$ Echocardiographic LVH was defined as an LV mass index (LVMI) $>115 \mathrm{~g} / \mathrm{m}^{2}$ for men and $>95 \mathrm{~g} / \mathrm{m}^{2}$ for women. ${ }^{17}$ Re-analysis of 30 randomly selected echocardiograms by a fifth cardiologist, not involved in the routine assessments and blinded to the participants' clinical status, indicated good reproducibility of the assessments of LVMI. The intra- and inter-rater intraclass correlation coefficients ${ }^{18}$ were 0.90 and 0.87 , respectively.

\section{Renal damage}

Hypertension-related renal damage was considered to be present in case of microalbuminuria and/or impaired renal function. ${ }^{2}$

The urinary albumin excretion (UAE) was measured in a timed 24-hour urine collection by means of nephelometry (BN ProSpec ${ }^{\circledR}$ System, Dade Behring Inc.), with a detection limit of $2.2 \mathrm{mg} / \mathrm{l}$. In our laboratory, intra- and inter-assay coefficients of variation are $<7.0 \%$. Microalbuminuria was defined as a UAE $>30$ and $<300 \mathrm{mg} / 24 \mathrm{~h} .^{2}$ Reproducibility of the UAE measurements, i.e., test-retest reliability, was assessed in a random sample of 30 patients with duplicate urine collections (48-hours collection period). The test-retest intraclass correlation coefficient was $0.93 .^{18}$

Renal function was considered to be impaired in case of an increased fasting serum creatinine level ( $\geq 107 \mu \mathrm{mol} / \mathrm{l}$ for women; $\geq 115 \mu \mathrm{mol} / \mathrm{l}$ for men) and/or an estimated creatinine clearance (Cockroft-Gault equation) $<60 \mathrm{ml} / \mathrm{min}$, as proposed in current hypertension guidelines. ${ }^{2}$ Reproducibility analysis of serum creatinine concentrations in a random sample of 30 patients with duplicate blood samples (median [interquartile range] time interval between assessments 23 [13-28] days) yielded a test-retest intraclass correlation coefficient of $0.91 .{ }^{18}$

\section{Cardiovascular risk}

To quantify the cardiovascular risk associated with cardiac, renal or silent brain damage, we calculated each participant's sex-specific risk of death from cardiovascular disease (including stroke) according to Pocock et al. ${ }^{8}$ The risk score has been modeled on a large cohort of hypertensive patients from the INdividual Data ANalysis of Antihypertensive intervention trials (INDANA) database. Component risk factors included in the present study were age, cigarette smoking, untreated SBP, total cholesterol concentration, height, creatinine concentration, and echocardiographic LVH. Because silent brain lesions have been shown to increase the risk of future stroke $6,7,19$, we also included SCD in the risk score, yielding an extra three points when present (similar to the score of LVH). 


\section{Statistical analysis}

To detect group differences between unpaired data we applied the independent samples $t$-test for normally distributed variables and the Pearson $\chi^{2}$ statistic or Fisher's exact test for categorical variables. Regression analysis was used to evaluate independency of associations, where appropriate.

Normally distributed variables are presented as mean \pm standard deviation (SD), variables with skewed distributions as median with interquartile range (IQR), and categorical variables as frequencies. A two-tailed probability value $<0.05$ was considered statistically significant. Probability values were corrected for multiple comparisons according to Hochberg's procedure, where appropriate. Analyses were performed using the statistical software package SPSS (version 11.0.4 for Macintosh, SPSS Inc.).

\section{Results}

\section{Study population}

Of the 218 participants who were investigated, 192 (88\%) had complete data on hypertension-related damage of the heart, kidneys and brain. Patients with missing data were significantly older $(58.8 \pm 13.2$ vs. $51.6 \pm 12.3$ years; $P=0.006)$ than those with complete data, but did not differ regarding sex (46\% male vs. $51 \% ; P=0.640)$, BP levels $(170 \pm 31 / 102 \pm 13$ vs. $170 \pm 23 / 104 \pm 12 ; P=0.928 / 0.404)$ and other characteristics (data not shown). The characteristics of the 192 participants are summarized in Table 10.1. At the time of inclusion in the study the median duration of hypertension was 44 (IQR 14-130) months during which 159 (83\%) patients had been on antihypertensive treatment for a median duration of 24 (IQR 6-60) months. Based on the untreated office pressures we diagnosed $183(95 \%)$ patients with hypertension. Thirty-eight (20\%) patients were classified as mild, 63 (33\%) as moderate and $82(43 \%)$ as severe hypertensive. Nine (5\%) participants had normal BP levels, even though the referring diagnosis was hypertension.

Furthermore, 62 (32\%) participants had hypercholesterolemia of whom $22(11 \%)$ used lipid lowering medication. Twelve (6\%) subjects received antithrombotic treatment. 
Table 10.1 Characteristics of the study population.

$\begin{array}{lc}\text { Characteristics } & \text { All (192) } \\ \text { Sex, male/female } & 98 / 94 \\ \text { Age, years } & 51.6 \pm 12.3 \\ \text { Age range, years } & 20-83 \\ \text { Height, cm } & 169.7 \pm 9.5 \\ \text { BMl, kg/m² } & 28.1 \pm 5.0 \\ \text { Office BP, mmHg: } & \\ \text { SBP } & 170 \pm 23 \\ \text { DBP } & 104 \pm 12 \\ \text { Heart rate, bpm } & 75 \pm 12 \\ \text { Current smoker } & 36(20) \\ \text { Glucose, mmol/l } & 5.4 \pm 0.7 \\ \text { Creatinine, } \mu \text { mol/l } & 82 \text { (70 - 95) } \\ \text { Total cholesterol, mmol/l } & 5.9(5.1-6.5) \\ \text { Data are presented as mean } \pm \text { SD, number (\%), or median (interquartile range). BMl indicates body } \\ \text { mass index; BP, blood pressure; SBP, systolic BP; DBP, diastolic BP; bpm, beats per minute. }\end{array}$

\section{Prevalence of hypertension-related organ damage}

The median time intervals between brain MRI and echocardiography and laboratory investigations were 27 (IQR 11-69) and 14 (IQR 8-22) days, respectively. The frequencies of hypertensive organ damage of the heart, the kidneys and the brain are presented in Table 10.2.

Table 10.2 Frequencies of silent damage of the heart, kidneys and brain $(n=192)$.

\begin{tabular}{l|l|c|}
\hline Silent organ damage & $n$ & Frequency $^{a}$ \\
\hline Heart (LVH) & 41 & $21(16-27)$ \\
\hline Kidneys & 50 & $26(20-32)$ \\
$\quad$ Microalbuminuria & 37 & $19(14-25)$ \\
CrCl <60 ml/min & 14 & $7(4-11)$ \\
Increased SCrC & 13 & $7(3-10)$ \\
\hline Brain & 84 & $44(37-51)$ \\
Advanced WMHs & 39 & $20(15-26)$ \\
SBls & 56 & $29(23-36)$ \\
BMBs & 29 & $15(10-20)$ \\
\hline
\end{tabular}

$\mathrm{n}$ indicates number of patients; LVH, echocardiographic left ventricular hypertrophy; $\mathrm{CrCl}$, creatinine clearance; SCrC, serum creatinine concentration; WMHs, white matter hyperintensities; SBls, silent brain infarcts; BMBs, brain microbleeds. ${ }^{a}$ Percentage ( $95 \%$ confidence interval).

\section{Silent brain damage relative to cardiac and renal damage}

A total of 114 (59\%) participants had evidence of hypertension-related damage to the heart, kidneys and/or brain. Figure 10.1 depicts the distribution and overlap of organ involvement (for details see legends to the figure). When we only 
considered the 72 patients with demonstrable cardiac and/or renal damage 42 subjects (58\%) had also SCD (Figure 10.1A). Of the remaining 120 participants without cardio-renal damage $42(35 \%)$ had SCD, which is half of all patients with SCD and $22 \%$ of all participants evaluated for organ involvement. Using the same approach, we observed similar patterns for advanced WMHs, SBls and BMBs separately (Figures 10.1B, 10.1C and 10.1D, respectively). Alternatively, we observed weak associations between SCD and both LVMI and UAE when analyzed as continuous variables (Table 10.3).

A
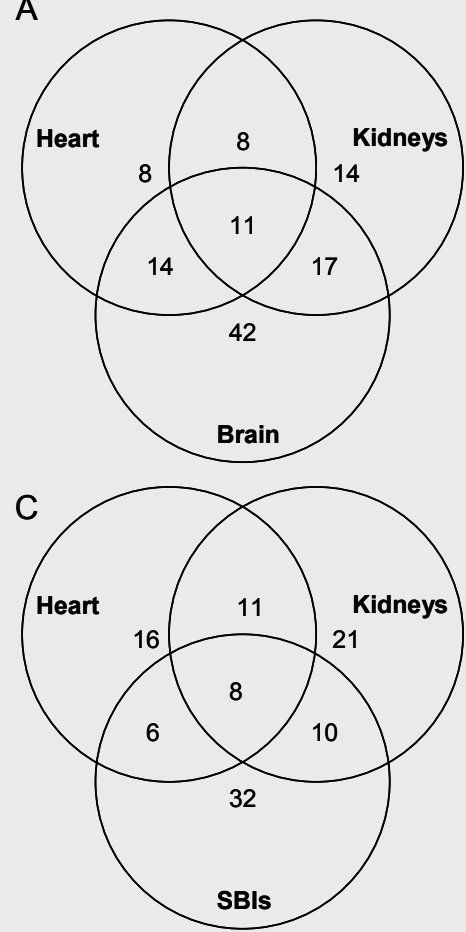

$\mathrm{B}$
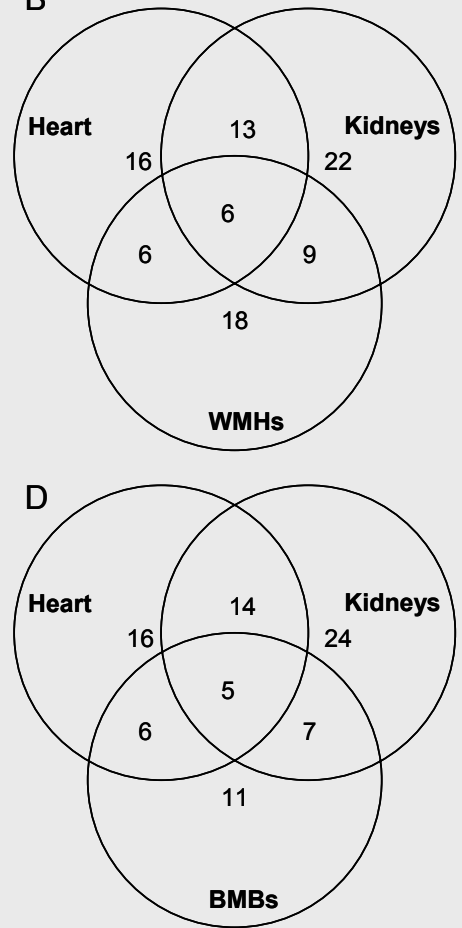

Figure 10.1 Distribution and overlap of hypertension-related organ damage to the heart, kidneys and brain (panel A), specified for advanced white matter hyperintensities (WMHs) (panel B), specified for silent brain infarcts (SBIs) (panel C), and specified for brain microbleeds (BMBs) (panel D).

For panel A: When considering only patients with demonstrable cardiac and/or renal damage $(n=72)$, as recommended by current guidelines ${ }^{2}, 42(58 \%)$ subjects had also silent cerebrovascular disease (SCD). However, another 42 patients with SCD were classified as having no organ involvement. This is: (1) $35 \%$ of all participants without cardio-renal damage $(n=120)$; (2) $50 \%$ of all patients with SCD $(n=84)$; (3) $37 \%$ of all patients with hypertensive organ damage of the heart, kidneys and/or brain $(n=114)$; (4) $22 \%$ of all patients evaluated for the presence of hypertensive organ damage $(n=192)$. Similar figures are observed for WMHs, SBIs and BMBs (as can be extracted from the panels B to D). 
Table 10.3 Associations of left ventricular mass index and urinary albumin excretion with silent ischemic brain damage $(n=192)$.

\begin{tabular}{|c|c|c|c|c|}
\hline \multirow[b]{2}{*}{ Brain lesion type } & \multicolumn{2}{|c|}{ LVMI $\left(\mathrm{g} / \mathrm{m}^{2}\right)$} & \multicolumn{2}{|c|}{ Log-UAE (mg/24h) } \\
\hline & Unadjusted & Adjusted $^{\mathrm{a}}$ & Unadjusted & Adjusted $^{a}$ \\
\hline Advanced WMHs & $1.02(1.00-1.03)^{b}$ & $1.01(0.99-1.03)$ & $2.78(1.27-6.06)^{b}$ & $3.86(1.44-10.34)^{c}$ \\
\hline SBIS & $1.02(1.00-1.03)^{b}$ & $1.01(1.00-1.03)$ & $1.76(0.88-3.57)$ & $1.71(0.81-3.61)$ \\
\hline BMBs & $1.03(1.00-1.04)^{c}$ & $1.02(1.00-1.04)^{b}$ & $1.43(0.60-3.43)$ & $1.24(0.46-3.32)$ \\
\hline SCD & $1.03(1.01-1.04)^{c}$ & $1.02(1.01-1.04)^{c}$ & $1.72(0.88-3.37)$ & $1.86(0.88-3.92)$ \\
\hline \multicolumn{5}{|c|}{$\begin{array}{l}\text { Data are presented as odds ratios ( } 95 \% \text { confidence interval). LVMI indicates left ventricular mass } \\
\text { index; Log-UAE, log-transformed urinary albumin excretion; WMHs, white matter hyperintensities; } \\
\text { SBls, silent brain infarcts; BMBs, brain microbleeds; SCD, silent cerebrovascular disease. }{ }^{a} \text { Adjusted for } \\
\text { age and sex. }{ }^{b} P<0.05 ;{ }^{c} P<0.01 \text {. }\end{array}$} \\
\hline
\end{tabular}

\section{Cardiovascular risk associated with hypertension-related organ damage}

Patients with evidence of hypertensive organ damage (heart, kidneys and/or brain) had a significantly higher cardiovascular risk score than those without organ damage ( $38 \pm 13$ vs. $27 \pm 11, P<0.001$; Table 10.4). More specifically, the risk score of the patients without cardio-renal damage but with SCD (37 \pm 11$)$ was significantly higher than that of participants without any organ involvement $(P<0.001)$, and similar to the score of those with cardio-renal damage $(38 \pm 14$; $P>0.05)$. We repeated these analyses after excluding markers of cardiac, renal and brain damage (i.e., echocardiographic LVH, creatinine concentration and SCD) from the risk score and found again that in contrast to participants without organ damage the risk scores of both patients with only SCD and cardio-renal involvement were significantly higher $(26 \pm 11$ vs. $32 \pm 11 \quad[P<0.05]$ and $33 \pm 13$ $[P<0.01]$, respectively).

Participants without cardio-renal but with brain damage differed from those with cardio-renal damage only in BP levels $(165 \pm 19 / 101 \pm 12$ versus $183 \pm 23 / 107 \pm 12$, $P<0.05)$ but not in other risk factors (Table 10.4). Neither were there differences in the duration of hypertension, previous use of cardiovascular (including antihypertensive) treatment, or presence of hypercholesterolemia. 
Table 10.4 Differences in cardiovascular risk and risk factors between participants with hypertensionrelated cardio-renal damage and those with silent cerebrovascular disease $(n=192)$.

\begin{tabular}{|c|c|c|c|c|}
\hline \multirow[b]{2}{*}{ Characteristics } & \multirow[b]{2}{*}{ No organ damage (78) } & \multicolumn{3}{|c|}{ Organ damage (114) } \\
\hline & & All & Cardio-renal (72) & SCD only (42) \\
\hline Cardiovascular risk score ${ }^{a}$ & $27 \pm 11$ & $38 \pm 13^{d}$ & $38 \pm 14^{d}$ & $37 \pm 11^{d}$ \\
\hline Sex, male/female & $44 / 34$ & $54 / 60$ & $31 / 41$ & 23/19 \\
\hline Age, years & $47.1 \pm 10.4$ & $54.7 \pm 12.6^{d}$ & $54.4 \pm 13.7^{c}$ & $55.1 \pm 10.4^{c}$ \\
\hline Height, cm & $171.2 \pm 8.3$ & $168.7 \pm 10.1$ & $167.8 \pm 10.0$ & $170.2 \pm 10.2$ \\
\hline $\mathrm{BMI}, \mathrm{kg} / \mathrm{m}^{2}$ & $27.8 \pm 4.1$ & $28.2 \pm 5.5$ & $27.8 \pm 5.2$ & $28.9 \pm 6.0$ \\
\hline \multicolumn{5}{|l|}{ Office $\mathrm{BP}, \mathrm{mmHg}$ : } \\
\hline SBP & $160 \pm 18$ & $176 \pm 24^{d}$ & $183 \pm 23^{d}$ & $165 \pm 19^{f}$ \\
\hline DBP & $102 \pm 12$ & $105 \pm 12$ & $107 \pm 12^{b}$ & $101 \pm 12^{e}$ \\
\hline Heart rate, bpm & $74 \pm 12$ & $75 \pm 12$ & $75 \pm 11$ & $77 \pm 13$ \\
\hline Current smoker & $15(19)$ & $21(18)$ & $15(21)$ & $6(14)$ \\
\hline Glucose, mmol/l & $5.3 \pm 0.6$ & $5.4 \pm 0.7$ & $5.4 \pm 0.8$ & $5.5 \pm 0.5$ \\
\hline Creatinine, $\mu \mathrm{mol} / \mathrm{l}$ & $81(70-91)$ & $82(71-99)$ & $81(69-103)$ & $84(73-94)$ \\
\hline Total cholesterol, mmol// & $5.8(5.1-6.3)$ & $5.9(5.2-6.5)$ & $5.8(5.2-6.6)$ & $6.0(5.2-6.5)$ \\
\hline
\end{tabular}

Data are presented as mean $\pm S D$, number $(\%)$, or median (interquartile range). SCD indicates silent cerebrovascular disease; BMI, body mass index; BP, blood pressure; SBP, systolic BP; DBP, diastolic BP; bpm, beats per minute. ${ }^{a}$ According to Pocock et $\mathrm{al}^{8} . P_{<}{ }^{b} 0.05,{ }^{c} 0.01$ or ${ }^{d} 0.001$ vs. "No organ damage ". $P<{ }^{e} 0.05,{ }^{f} 0.001$ vs. "Cardio-renal damage". $P$ values are corrected for multiple comparisons according to Hochberg's procedure.

\section{Discussion}

This study suggests that the addition of SCD as a marker of hypertensive targetorgan damage refines the identification of patients at increased risk of cardio- and cerebrovascular complications.

To the best of our knowledge, no previous study has assessed the additional value of SCD in the stratification of hypertension-related cardiovascular risk beyond currently recommended markers of preclinical hypertensive cardiac and renal damage.

Although almost $60 \%$ of our patients with demonstrable cardiac and/or renal damage had also brain damage, which is similar to the frequencies observed in two other European hypertensive cohorts investigating the relation between LVH and asymptomatic cerebral damage ${ }^{4,5}$, half of the patients with SCD were classified as having no organ involvement. This is an important observation because these "undetected" patients had a significantly higher risk to die from cardiovascular complications within the next five years than subjects without any organ involvement. Hence, it is possible that patients with "undetected" SCD are unrightfully considered to be low(er)-risk patients when applying current hypertension guidelines, ${ }^{2}$ and, consequently, receive suboptimal treatment.

These data, supported by the weak associations between SCD and both LVMI and 
UAE, also illustrate that the absence of damage in one or more organs does not exclude the involvement of other organs. The reason for this is unclear but probably involves many factors, among others, age, type and severity of risk factors, coexistence of unfavorable factors, and vascular characteristics of the involved organs.

Other observations also support a role for SCD in stratifying cardiovascular risk. Firstly, the risk score of patients without cardio-renal but with "undetected" brain damage was similar to that of those participants with cardio-renal involvement. However, patients with cardio-renal damage had more advanced hypertensive disease, both in terms of number of organs involved and level of BP. In other words, for the same level of elevated BP it seems that the risk of SCD is higher than that of preclinical cardiac and/or renal damage. Secondly, the frequencies of WMHs, SBIs and BMBs in our cohort were two to three times higher than those reported in the general population. ${ }^{20-22}$ Thirdly, the frequency of SCD was almost twice as high as that of preclinical cardiac and renal damage. Although the applied criteria to define organ damage could have influenced the observed frequencies, all have been widely accepted and intended to identify substantial damage. Fourthly, WMHs, SBIs and BMBs are all precursors of (recurrent) stroke ${ }^{6,7}$, emphasizing the importance of detecting silent manifestations of cerebrovascular disease.

Our data suggest that current cardiovascular risk stratification in hypertensive patients is inadequate. Yet, our finding that the inclusion of SCD refines the identification of patients at risk of cardiovascular complications in excess to markers of cardio-renal damage needs confirmation in long-term follow-up studies. These studies should also evaluate the additional value of other markers of hypertensive organ damage, such as arterial stiffening and preclinical atherosclerosis. Furthermore, it is possible that patients in whom cardio-renal damage has been ruled out are treated less intensively as would be in the presence of SCD. In our study 35\% of these patients free of organ damage had actually silent brain damage. Data of the Perindopril Protection Against Recurrent Stroke Study (PROGRESS) suggest that active BP lowering stops or delays the progression of WMHs and SBIs in patients with cerebrovascular disease.23,24 On the other hand, other investigators have questioned the safety of BP reduction in patients with (silent) cerebrovascular disease, i.e., an increased risk of further ischemic damage as a result of treatment-induced cerebral hypoperfusion. ${ }^{25}$ Yet, whether such a J-curved phenomenon exists, is still a matter of debate. Therefore, clinical trials in hypertensive patients should evaluate the effects and safety of antihypertensive (and other cardiovascular) treatment on the development and/or progression of SCD.

The present study has limitations. The cross-sectional design limits us in drawing conclusions on the real prognostic relevance of hypertensive organ damage in general and that of SCD in particular. As a substitute of prognosis, we estimated 
the cardiovascular risk, being aware of the methodological limitations involved in the use of cardiovascular risk scales. ${ }^{26}$ We applied the risk score of Pocock et al. because this scale has been modeled on a large number of (un)treated hypertensive patients with a wide age range, including both European and North American populations. ${ }^{8}$ Another potential limitation is that the screening for hypertensive cardiac and renal damage was performed as part of the routine investigations, which might have introduced some bias as a result of heterogeneous and missing data. Missing of data was associated with older age, but because the frequencies of both cardio-renal and silent brain damage increase with advancing age, it is not likely that this will have influenced our results. Furthermore, our study is carried out in a selected group of hypertensive patients referred to a university hospital that lacks a local, preferably community-based, control population. This limits us in drawing conclusions about the frequencies of preclinical cardiac, renal and brain damage, and in generalizing the findings to other populations without further ado. Notwithstanding, the frequencies of WMHs, SBIs and BMBs were in between those reported in the general population and stroke patients ${ }^{20-22}$, suggestive of being related to the hypertension. Finally, tests for the detection of microalbuminuria, renal impairment and LVH are more widely available than MRI, which might defer the use of WMHs, SBIs and BMBs as additional markers of hypertensive organ damage, even though the present findings indicate their potential prognostic relevance.

Strengths of our study are that, unlike earlier studies, the present report includes WMHs, SBls as well as BMBs, covering all relevant hypertension-related silent cerebrovascular damage, and that we related this SCD to both preclinical cardiac and renal damage. Moreover, we did not include subjects with manifest vascular disease, thereby reducing the possibility that our observations resulted from reverse causality.

In conclusion, this study indicates that SCD, in addition to and in the same way as preclinical cardio-renal damage, should be involved in the risk stratification of hypertensive patients, as SCD seems to be a prognostically important marker of hypertensive organ damage. 


\section{References}

1. Chobanian AV, Bakris GL, Black HR, Cushman WC, Green LA, Izzo JL, Jr., Jones DW, Materson BJ, Oparil S, Wright JT, Jr., Roccella EJ. The seventh report of the Joint National Committee on prevention, detection, evaluation, and treatment of high blood pressure: The JNC 7 report. JAMA 2003;289:2560-72.

2. Mancia G, De Backer G, Dominiczak A, Cifkova R, Fagard R, Germano G, Grassi G, Heagerty AM, Kjeldsen SE, Laurent S, Narkiewicz K, Ruilope L, Rynkiewicz A, Schmieder RE, Boudier HA, Zanchetti A. 2007 guidelines for the management of arterial hypertension: The task force for the management of arterial hypertension of the European Society of Hypertension (ESH) and of the European Society of Cardiology (ESC). J Hypertens 2007;25:1105-87.

3. Henskens LH, van Oostenbrugge RJ, Kroon AA, de Leeuw PW, Lodder J. Brain microbleeds are associated with ambulatory blood pressure levels in a hypertensive population. Hypertension 2008;51:62-68.

4. Selvetella G, Notte A, Maffei A, Calistri V, Scamardella V, Frati G, Trimarco B, Colonnese C, Lembo G. Left ventricular hypertrophy is associated with asymptomatic cerebral damage in hypertensive patients. Stroke 2003;34:1766-70.

5. Sierra C, de la Sierra A, Pare JC, Gomez-Angelats E, Coca A. Correlation between silent cerebral white matter lesions and left ventricular mass and geometry in essential hypertension. $\mathrm{Am} J$ Hypertens 2002;15:507-12.

6. Boulanger JM, Coutts SB, Eliasziw M, Gagnon AJ, Simon JE, Subramaniam S, Sohn CH, Scott J, Demchuk AM. Cerebral microhemorrhages predict new disabling or fatal strokes in patients with acute ischemic stroke or transient ischemic attack. Stroke 2006;37:911-4.

7. Vermeer SE, Hollander M, van Dijk EJ, Hofman A, Koudstaal PJ, Breteler MM. Silent brain infarcts and white matter lesions increase stroke risk in the general population: The Rotterdam Scan Study. Stroke 2003;34:1126-9.

8. Pocock SJ, McCormack V, Gueyffier F, Boutitie F, Fagard RH, Boissel JP. A score for predicting risk of death from cardiovascular disease in adults with raised blood pressure, based on individual patient data from randomised controlled trials. BMJ 2001;323:75-81.

9. Fazekas F, Chawluk JB, Alavi A, Hurtig HI, Zimmerman RA. MR signal abnormalities at $1.5 \mathrm{~T}$ in Alzheimer's dementia and normal aging. Am J Roentgeno/ 1987;149:351-6.

10. Fazekas F, Kleinert R, Offenbacher H, Schmidt R, Kleinert G, Payer F, Radner H, Lechner $H$. Pathologic correlates of incidental MRI white matter signal hyperintensities. Neurology 1993;43:1683-9.

11. Vermeer SE, Koudstaal PJ, Oudkerk M, Hofman A, Breteler MM. Prevalence and risk factors of silent brain infarcts in the population-based Rotterdam Scan Study. Stroke 2002;33:21-5.

12. Wardlaw JM, Lewis SC, Keir SL, Dennis MS, Shenkin S. Cerebral microbleeds are associated with lacunar stroke defined clinically and radiologically, independently of white matter lesions. Stroke 2006;37:2633-6.

13. Fazekas F, Kleinert R, Roob G, Kleinert G, Kapeller P, Schmidt R, Hartung HP. Histopathologic analysis of foci of signal loss on gradient-echo $\mathrm{T} 2{ }^{*}$-weighted $\mathrm{MR}$ images in patients with spontaneous intracerebral hemorrhage: Evidence of microangiopathy-related microbleeds. $\mathrm{Am} \mathrm{J}$ Neuroradiol 1999;20:637-42.

14. Fisher CM. The arterial lesions underlying lacunes. Acta Neuropathol (Berl) 1968;12:1-15.

15. Landis JR, Koch GG. The measurement of observer agreement for categorical data. Biometrics 1977;33:159-74.

16. Devereux RB, Reichek N. Echocardiographic determination of left ventricular mass in man Anatomic validation of the method. Circulation 1977;55:613-8.

17. Lang RM, Bierig M, Devereux RB, Flachskampf FA, Foster E, Pellikka PA, Picard MH, Roman MJ, Seward J, Shanewise JS, Solomon SD, Spencer KT, Sutton MS, Stewart WJ. Recommendations for chamber quantification: A report from the American Society of Echocardiography's guidelines and standards committee and the chamber quantification writing group, developed in conjunction with the European Association of Echocardiography, a branch of the European Society of Cardiology. J Am Soc Echocardiogr 2005; 18:1440-63. 
18. Bartko JJ. Measurement and reliability: Statistical thinking considerations. Schizophr Bull $1991 ; 17: 483-9$.

19. Vermeer SE, Prins ND, den Heijer T, Hofman A, Koudstaal PJ, Breteler MM. Silent brain infarcts and the risk of dementia and cognitive decline. N Eng/ J Med 2003;348:1215-22.

20. Cordonnier C, Al-Shahi Salman R, Wardlaw J. Spontaneous brain microbleeds: Systematic review, subgroup analyses and standards for study design and reporting. Brain 2007;130:1988-2003.

21. Vermeer SE, Longstreth WT, Jr., Koudstaal PJ. Silent brain infarcts: A systematic review. Lancet Neuro/ 2007;6:611-9.

22. Launer LJ. Epidemiology of white matter lesions. Top Magn Reson Imaging 2004;15:365-7.

23. Dufouil C, Chalmers J, Coskun O, Besancon V, Bousser MG, Guillon P, MacMahon S, Mazoyer B, Neal B, Woodward M, Tzourio-Mazoyer N, Tzourio C. Effects of blood pressure lowering on cerebral white matter hyperintensities in patients with stroke: The PROGRESS (Perindopril Protection Against Recurrent Stroke Study) magnetic resonance imaging substudy. Circulation 2005;112:1644-50.

24. Hasegawa Y, Yamaguchi T, Omae T, Woodward M, Chalmers J. Effects of perindopril-based blood pressure lowering and of patient characteristics on the progression of silent brain infarct: The Perindopril Protection Against Recurrent Stroke Study (PROGRESS) CT substudy in Japan. Hypertens Res 2004;27:147-56.

25. Birns J, Markus H, Kalra L. Blood pressure reduction for vascular risk: Is there a price to be paid? Stroke 2005;36:1308-13.

26. Blacher J, Asmar R, Djane S, London GM, Safar ME. Aortic pulse wave velocity as a marker of cardiovascular risk in hypertensive patients. Hypertension 1999;33:1111-7. 
164 
General discussion
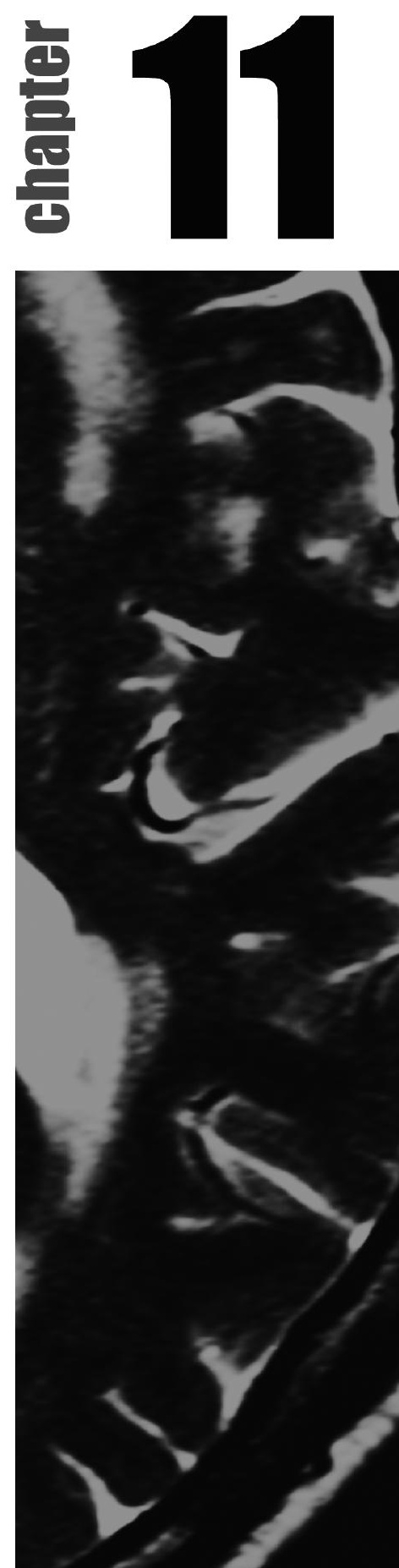


\section{Summary}

The general aim of the work described in this thesis was to assess whether silent cerebrovascular disease should be considered as an additional marker of target-organ damage in patients with hypertension.

The different studies focused on (1) the relationship between ambulatory blood pressure profiles and white matter hyperintensities, silent brain infarcts and brain microbleeds on brain magnetic resonance imaging, with a special focus on abnormal nocturnal blood pressure patterns, (2) the influence of genetic variants of pathways modulating vascular function and morphology on the susceptibility of the brain to develop (silent) cerebrovascular damage (for instance via high blood pressure), (3) the link between arterial stiffness, a summary measure for vascular damage caused by coexisting risk factors (including high blood pressure and genetic factors), and cerebral small-vessel disease, and, finally, (4) the clinical relevance of silent cerebrovascular disease in terms of cognitive performance, and in terms of the additional value of searching for white matter hyperintensities, silent brain infarcts and brain microbleeds besides recognized markers of hypertensive cardiac and/or renal damage in stratifying cardiovascular risk of hypertensive patients.

In this chapter we will put our findings into perspectives against relevant issues related to the topics mentioned above. The chapter closes with suggestions for future research and the main conclusions of this thesis. 


\section{Introduction}

Hypertension is an important, worldwide public-health challenge because of its high frequency and concomitant risks of cardiovascular, renal and cerebrovascular disease, and death. ${ }^{1}$ Globally, hypertension affects $25-30 \%$ of the adult population, and even up to $60-70 \%$ of those beyond the seventh decade of life. ${ }^{2}$ Notably, the incidence of hypertension is still increasing. ${ }^{1}$ On the other hand, hypertension is one of the best modifiable risk factors for cardio- and cerebrovascular disease. Keeping this in mind, the timely detection of silent organ damage is important in the identification of hypertensive patients who are at risk of cardiovascular complications. Current guidelines for the management of arterial hypertension limit the search for preclinical hypertensive organ damage to the heart and kidneys. ${ }^{3}$ The question now is whether this sufficiently covers the risk associated with hypertension, or leaves a significant number of high-risk patients unnoticed because silent damage to other organs remains undetected. In this thesis we focused on the brain as a potential target-organ in hypertension. Whether silent cerebrovascular disease should be considered as an additional risk marker of hypertension-related target-organ damage in the risk stratification of hypertensive patients depends on (1) how frequently silent cerebrovascular damage, i.e., white matter hyperintensities (WMHs), silent brain infarcts (SBIs), and brain microbleeds (BMBs), occurs in hypertensive patients, (2) the strength of the association with blood pressure (BP), (3) the degree in which such damage leads to concomitant disease and/or increases the risk of major cardio- and cerebrovascular complications, and (4) whether treatment is able to prevent the development of new or the progression of existing damage. In the following sections we will discuss these issues.

\section{Frequency of silent cerebrovascular disease in hypertensive patients}

Silent cerebrovascular disease is not an infrequent finding in patients with hypertension. We found advanced WMHs to be present in 20\%, SBIs in $29 \%$ and BMBs in about $15 \%$ of our participants (Chapter 10), these frequencies being approximately three times higher than those reported in the general population. ${ }^{4-6}$ Considering the high frequency of microbleeds in our hypertensive population and the robust associations with BP (Chapter 5), we propose that BMBs should be recognized, in addition to WMHs and SBIs, as a marker of hypertensive brain damage. When we considered WMHs, SBIs and BMBs together, $44 \%$ of the participants had evidence of silent cerebrovascular disease, showing that silent cerebrovascular disease is a common condition in hypertensive patients. 
Moreover, this frequency was also almost twice as high as that observed for preclinical cardiac and renal damage (Table 10.2). Notably, we collected a mixed population of hypertensive patients (i.e., with a wide range of BP levels), four percent having normal BP levels (albeit that the referring diagnosis was hypertension), $20 \%$ being classified as mild, 33\% as moderate, and $43 \%$ as severe hypertensives.

Importantly, the frequencies of WMHs, SBls and BMBs are substantially higher than the five percent prevalence of symptomatic stroke estimated in a collaborative study of population-based cohorts across Europe. ${ }^{7}$ In line with this, calculations, based on the prevalence and annual risk of symptomatic stroke in subjects with SBIs, indicate that more than half of all ischemic strokes annually may be preceded by SBIs. ${ }^{8}$ As another example, exploratory analyses of SBI incidence in the United States suggested that, in 1998, over 10 million Americans developed new SBls compared to only 700,000 new ischemic strokes ${ }^{9}$, further emphasizing that stroke is just the "tip-of-the-iceberg".

\section{Blood pressure and silent cerebrovascular disease}

We observed robust associations of daytime and nighttime BP levels with WMHs, lacunar infarcts (LACs) as well as BMBs (Chapters 3, 4 and 5). This is in agreement with the relatively few but positive studies on high ambulatory BP levels in patients displaying severe WMHs or SBls on brain magnetic resonance imaging (MRI). ${ }^{10-19}$ Only three, rather small, studies were carried out in hypertensive populations ${ }^{16,18,19}$, and no study thus far investigated the relationship between BMBs and ambulatory BP levels.

An important observation of our study, which extends previously published data, is that the relationships between the volume of WMHs and ambulatory BP levels, whether daytime, nighttime or 24-hour, are continuous, without evidence of distinct thresholds, and continue down to BP levels well within the normotensive range (Chapter 3). This dose-effect of $\mathrm{BP}$ on the $\mathrm{WMH}$ volume (WMHV), though cross-sectional, is supportive of a causal relationship between increasing BP levels and the development of silent cerebrovascular disease. The few studies that investigated progression of WMHs and SBIs over time (using both baseline and follow-up MRI scanning), observed higher office BP levels in patients in whom WMHs progressed and new SBls developed (follow-up ranging between two and five years). ${ }^{20-24}$ A small Japanese study in hypertensive patients reported the opposite, recording lower diastolic BP in those patients who developed SBIs during follow-up. ${ }^{25}$ Goldstein and colleagues were the first, and so far the only investigators, who assessed longitudinally the BP-WMH relationship using ABPM. They found in a group of 155 healthy elderly individuals who were followed up for five years that small increases in the awake but not asleep systolic BP were 
associated with a greater volume of WMHs. ${ }^{26}$ The latter, however, is not in line with cross-sectional evidence of a close association between nocturnal BP and the presence of WMHs. ${ }^{16,17}$ Hence, there is a need for adequately powered, long-term follow-up studies, investigating the relationships between ambulatory BP, abnormal BP profiles, and the progression of WMHs, SBIs and BMBs.

In view of the possibility that lowering BP might prevent (silent) cerebrovascular disease, it could be relevant to further distinguish between subtypes of lesions. For instance, we observed a distinction between periventricular and deep WMHs (Chapter 3) and between LACs and TIs (Chapter 4) in terms of ambulatory BP levels. The volume of periventricular $\mathrm{WMHs}$ increased steeply with higher BP levels, whereas the deep WMHV did so only modestly. Similarly, LACs were associated with BP whereas TIs failed to do so. These observations are suggestive of a differential effect of high BP on the brain (micro)circulation. Hypertension leads to microvascular arteriolosclerosis (i.e., thickening of the vessel wall with luminal narrowing), lengthening and tortuosity of microvessels, and impaired cerebrovascular autoregulation. ${ }^{27}$ This increases the risk of cerebral hypoperfusion and vessel occlusion. Particularly vulnerable to the adverse effects of high BP are the periventricular white matter and the deep brain regions (i.e., basal ganglia, internal capsule, thalamus) because these regions are vascularized by long endarteries with a relatively low perfusion pressure that lack appropriate anastomoses and supply blood to arterial watershed zones. ${ }^{28}$ Conversely, Tls mostly occur in the vascular territory of larger brain vessels, in which mechanisms other than (or besides) high BP may play a more prominent role, e.g. atherothrombosis and cardio-embolism. ${ }^{29}$ Likewise, deep WMHs have been found to differ from those in the periventricular region regarding vascular risk factors, progression rate and clinical consequences. ${ }^{30}$ Accordingly, it is possible that BP-lowering therapy will benefit most in terms of reducing the development of new or the progression of existing periventricular WMHs and LACs, whereas deep WMHs and Tls may require additional or different preventive measures.

In our studies on the relationship between BP and cerebral damage we focused specifically on the nocturnal BP, because there is data to suggest that this is a strong predictor of cardiovascular complications, over and above the daytime BP. ${ }^{31}$ In addition to a high daytime BP, we observed robust and independent associations between high nocturnal BP levels and the extent of WMHs and the presence of LACs and BMBs (Chapters 3, 4 and 5), which corroborates previous findings. ${ }^{10-19}$ This underscores the additional importance of the nocturnal BP level, and, hence, a high 24-hour BP load. Yet, whether the nocturnal BP is more important in the development of silent cerebrovascular damage than the daytime pressure remains to be determined in longitudinal studies.

The associations are less consistent in terms of nocturnal BP dipping. Initially, subjects were divided into those who showed a normal decline of the nocturnal $\mathrm{BP}$ of $10 \%$ or more relative to the daytime BP (i.e., dippers), and those who failed 
to do so (i.e., nondippers). Nondipping has been associated with increased frequencies of WMHs and SBIs. ${ }^{11,14,17,32,33}$ However, others failed to find such associations ${ }^{10,16}$, or reported the opposite, i.e., more severe WMHs and more silent infarcts in the presence of extreme nocturnal BP dips beyond $20 \% .18,34,35$ The associations of extreme dipping with WMHs and SBls have been observed only in Japanese populations and could not be replicated in Caucasian cohorts, including ours. Moreover, the use of abnormal nocturnal BP dipping as a predictor of hypertensive organ damage and cardiovascular risk is not beyond dispute. With respect to the classification of dipping, there is no general consensus on what $\mathrm{BP}$ variable to use (i.e., SBP, DBP, MAP or a combination of such indices), how the awake and asleep periods should be defined, which cut-off values are optimal, and how data should be presented (i.e., relative BP dip or dipping status). We showed (Chapter 2) that, irrespective of the classification used (i.e., different definitions of awake-asleep and different BP indices), both the relative dip and the dipping status were poorly reproducible phenomena, which influenced also the relationship between nondipping and measures of cardio-renal damage. This may explain for some part the inconsistent results mentioned above. From all these data, we conclude that the relationship between BP and silent cerebrovascular disease is best described by the awake, asleep and 24-hour BP averages rather than abnormal patterns in the nocturnal BP decline.

The relationship between BP and silent cerebrovascular disease is likely to be influenced by coexisting risk factors. The findings of Chapter 6 and Chapter 7 suggest that genetic variants of pathways involved in vascular function and morphology increase the susceptibility of the brain (micro)circulation to the adverse effects of high BP. Knowledge of genetic and also other risk factors that enhance the effects of high BP may be of importance in the timely identification of patients that need (early or intensive) BP-lowering treatment.

\section{Clinical significance of silent cerebrovascular disease}

The search for preclinical cerebrovascular damage is justified only when its detection contributes significantly to the management of patients at risk of cerebro- and cardiovascular complications.

We found that hypertensive patients with periventricular WMHs or LACs performed below average on neurocognitive testing, but the associations were not very robust, even though we used specific tests in three functional domains, i.e., verbal memory, sensorimotor speed and cognitive flexibility (Chapter 9). Apart from the small study sample, and the use of a semi-quantitative WMH rating scale, the weak relations can also be explained by the relatively mild degree of brain damage detected in our participants. Data from large population-based studies showed that minimal damage is almost invariably present in otherwise 
healthy elderly. ${ }^{6}$ In other words, mild degrees of brain damage are a normal finding in the ageing brain. However, evidence is accumulating that moderate-tosevere damage, and that occurring early in life (e.g., that associated with hypertension), may not be so benign. Cross-sectional studies have shown strong correlations between advanced silent cerebral small-vessel disease and cognitive impairment (particularly in terms of speed of mental processing, attention, and executive functions), impaired mobility and balance, disturbances of gait, urinary incontinence, mood disturbances and depressive symptoms, and decreased activity of daily living functionality, all being responsible for substantial disability later in life. ${ }^{36,37}$ Accordingly, it has been suggested that most of the cognitive and functional consequences of high BP are mediated by the development of silent cerebrovascular damage. ${ }^{36}$ The data in Chapter 9 support this by showing modest but significant associations between ambulatory BP and cerebral damage, and, in turn, between cerebral damage and cognitive performance.

Perhaps the most important result of last decade's research into WMHs, SBIs, and recently also BMBs is the demonstration that these lesions are markers of poor prognosis. Data from the Rotterdam Scan Study, a prospective, population-based study in over 1,000 elderly residents of Rotterdam, The Netherlands, have evidently shown that severe WMHs and SBls increase the risk of future stroke three- to five-fold, more than double the risk of dementia, and increase significantly the risk of (cardiovascular) death ${ }^{38-40}$ Moreover, subjects with a symptomatic stroke and MRI-evidence of silent cerebrovascular damage run an increased risk of infarct growth and stroke recurrence, have a poorer clinical outcome, and a high risk of bleeding associated with anticoagulation or thrombolysis. ${ }^{4,37}$ Importantly, this risk of concomitant disease and stroke is of the same extent as the risk of cardiovascular complications associated with left ventricular hypertrophy. ${ }^{41}$ Nevertheless, silent cerebrovascular disease remains an underestimated and, in our opinion, underappreciated marker of hypertensive target-organ damage. It is, however, unknown whether the detection of silent cerebrovascular damage adds to the prediction of cardiovascular risk already provided by cardio-renal assessments. Therefore, we assessed whether the inclusion of silent cerebrovascular disease, i.e., advanced WMHs, SBIs, BMBs or any combinations of these lesions as an additional marker of hypertensive organ damage might refine the risk stratification of our hypertensive patients, besides the recommended cardio-renal assessments (Chapter 10). Half of all participants with silent cerebrovascular disease were classified as having no (i.e., cardio and/or renal) damage. However, and importantly, this group had a significantly higher cardiovascular risk than participants without any organ involvement (i.e., heart, kidneys and brain), and a similar risk as those with demonstrable cardio-renal damage. When adhering, for instance, to the current guidelines for the management of arterial hypertension of the European Society of Hypertension, this could lead to an underestimation of the cardiovascular risk in patients 
classified as having no organ (cardio-renal) damage but with "undetected" silent brain damage, and hence a different (and potentially suboptimal) treatment strategy. ${ }^{3}$ Even though our study is cross-sectional, this shows that a substantial number of patients with an increased risk of cardiovascular complications is "missed" when limiting the search for preclinical hypertensive organ damage to the heart and kidneys only.

\section{Treatment and prevention of silent cerebrovascular disease}

A crucial issue is whether treatment of high BP is able to prevent silent and, ultimately, symptomatic cerebrovascular disease with its high disability and mortality rates. Our findings of a continuous relationship between higher BP levels and greater WMHVs (Chapter 3) suggest that BP may be a suitable target to reduce the burden of WMHs and other silent ischemic brain damage. Because of the irreversible character it is not to be expected that lowering BP will lead to regression of silent cerebrovascular damage. It seems, however, highly relevant to prevent the progression of small, clinically insignificant lesions into severe damage as this harbors the highest risk of developing into concomitant disease and cerebrovascular complications. ${ }^{37}$

It has been shown that patients with successfully treated hypertension had a lower risk of WMHs than subjects with untreated, irregularly treated, or treated but poorly controlled hypertension. ${ }^{42,43}$ These data support the hypothesis that lowering BP can reduce the burden of silent cerebrovascular disease. Accordingly, data from the MRI and CT substudies of the Perindopril Protection Against Recurrent Stroke Study (PROGRESS), a randomized, placebo-controlled trial of BPlowering in patients with a history of stroke or transient ischemic attack, suggest that an active BP-lowering regimen stops or delays the progression of WMHs and SBIs. ${ }^{44,45}$ Similar findings were obtained in an MRI study, which included 92 hypertensive patients from another randomized, placebo controlled trail on BPlowering, i.e., the Study on COgnition and Prognosis in the Elderly (SCOPE), and 41 untreated normotensive controls. This study observed a significant linear trend for progression of WMHs, with the placebo group having the highest change in WMHV, followed by the active treatment group and then normotensive participants. ${ }^{46}$ Besides these promising results, no other data on the effects of antihypertensive treatment on the development and progression of silent cerebrovascular disease are currently available and, to the best of our knowledge, neither will be in the near future.

A recent systematic review on pooled data from randomized, controlled trials, measuring the effects of BP reduction on cognitive performance, reported that modest reductions in BP were associated with improvement on screening tests for global cortical function and memory. ${ }^{47}$ Contrary to this beneficial effect of 
antihypertensive treatment, the same review demonstrated that subcortical executive function and learning capacity, i.e., cognitive domains mainly affected by WMHs and $\mathrm{LACs}^{48}$, continued to deteriorate despite or, as the authors hypothesized, because of the BP reduction. This finding parallels the results of studies showing a similar negative effect of lowering BP on the occurrence of WMHs. ${ }^{49,50}$ Accordingly, the safety of indiscriminate BP reduction has been questioned, particularly in hypertensive patients with (silent) cerebrovascular disease. ${ }^{51}$ The main hypothesis explaining these observations is that hypertension impairs cerebrovascular autoregulation, resulting in transient falls in cerebral blood flow during episodes of lower BP. Brain perfusion may be compromised to such an extent that ischemia occurs. ${ }^{50}$ This hypoperfusion-hypothesis offers ground for another intriguing theory, that higher BP levels, and by extension the nondipping pattern, are necessary to maintain brain perfusion in subjects with hypertensive brain damage, a phenomenon that is also seen after symptomatic stroke. Until the hypothesis of this J-shaped relation, i.e., a greater lesion burden with both high and (too) low BPs, will be rejected, overaggressive treatment may not be recommended. This treatment paradox further supports the use of silent cerebrovascular disease as a marker of hypertensive target-organ damage that may also be important in the decision of which therapeutic approach to follow.

Ultimately, (silent) cerebrovascular disease is a heterogeneous entity that involves many risk factors. Even though hypertension is the best modifiable risk factor, this implies a multifactorial and multidisciplinary approach aimed at treating all reversible risk factors in order to prevent the development of new lesions and/or the progression of silent into overt cerebrovascular disease. ${ }^{52}$

\section{Implications for future research}

The data from this thesis integrated with those from the literature support the view that silent cerebrovascular disease is not an incidental finding in hypertensive patients, but harbors a high risk of concomitant disease and future cardio- and cerebrovascular complications. Nevertheless, adequately powered, long-term follow-up studies are needed to further detail the relations between ambulatory BP (including abnormal BP profiles) and WMHs, SBIs and BMBs. Currently, we are carrying out a two-year follow-up (including repeat ABPM and brain MRI) in the participants described in the chapters 3, 4, 5, 8 and 10 . The first results are to be expected in 2009. These data will shed more light on the cause-effect relationships between BP levels (including the J-curved phenomenon), the effect of antihypertensive therapy, and the development of new and/or progression of existing silent ischemic brain damage. Furthermore, in close cooperation with other groups (departments of Neurology and Clinical Immunology) we have initiated several substudies in which we will assess the role of endothelial 
dysfunction, vascular inflammation and endothelial progenitor cells in cerebral small-vessel disease, to gain a better inside in the complex mechanisms underlying WMHs, SBIs and BMBs.

The impact of hypertension on an individual's health status warrants the search for new markers to identify high-risk patients in a preclinical phase when damage to target-organs is preventable or still reversible. In the case of hypertensive patients, identification of new, disease-specific blood-borne markers and other markers of hypertensive organ damage, e.g. retinal microvascular abnormalities and preclinical atherosclerosis, is essential for improvement of risk stratification. Identification of genetic factors that predispose to brain damage (for instance via gene-environment interactions as shown in the Chapters 6 and 7) is also meaningful as these could help in selecting out patients at particularly high risk of cardiovascular complications and who may need careful follow-up and/or (early, preventive) treatment. Prospective studies should also evaluate the value and costutility of implementing new risk markers against those currently available.

There is clearly a need for intervention trials in hypertensive patients with and without silent cerebrovascular damage and who have not had a stroke yet. These trials should assess the effects and safety of antihypertensive (and ultimately also other cardiovascular) treatment on the development and/or progression of WMHs, SBIs and BMBs. For instance, for WMHs it has been estimated that 195 subjects with confluent lesions (which are most likely to show progression) would be required per treatment arm to demonstrate a $20 \%$ reduction in the rate of disease progression over a three-year period..$^{53}$

Preferably, future studies, and perhaps also existing ones, should (re)determine the volume of WMHs rather than arbitrarily categorize hyperintensities, in particular when investigating lesion progression. Visual rating scales display ceiling effects, have poor discrimination of absolute lesion volumes, and are less sensitive to detect (small) differences between clinical groups. ${ }^{54}$ Furthermore, new and improving MRI techniques such as diffusion weighted imaging and higher field strengths will allow the detection of very subtle changes in otherwise normal appearing brain tissue (e.g., altered fluid dynamics) and the visualization of anatomical structures with greater detail than possible so far with conventional neuroimaging. ${ }^{55,56}$

With these challenges ahead, there is still a large field of research to be explored. This may eventually lead to new insights in the pathophysiology, changes in the diagnostic approach, and more effective pharmacological treatment strategies in the prevention of WMHs, SBIs and BMBs, and their consequences in hypertensive patients. 


\section{Main conclusions}

I. The ambulatory BP profile is well reproducible for daytime, nighttime and 24-hour BP averages, but poorly reproducible regarding day-night BP differences (nocturnal BP dipping) (Chapter 2 and Appendix C).

II. Ambulatory BP levels, whether daytime, nighttime or 24-hour, are independently related to a greater volume of periventricular and, to a lesser extent, deep WMHs. Importantly, the relationships are continuous, without evidence of distinct thresholds, and continue down to BP levels within the normotensive range (Chapter 3).

III. High BP may differentially affect the risk of periventricular and deep WMHs and of LACs and Tls. It is possible that BP-lowering therapy will benefit most in terms of reducing the development of new or the progression of existing periventricular WMHs and LACs, whereas deep WMHs and Tls may require additional or different preventive measures (Chapters 3 and 4 ).

IV. Brain microbleeds are a frequent observation in hypertensive patients and are closely related to ambulatory BP levels during the day and in particular during the night. Microbleeds should be recognized as an additional marker of hypertension-related cerebrovascular damage (besides WMHs and LACs) (Chapter 5).

V. Genetic factors may increase the susceptibility of the brain to the adverse effects of cardiovascular risk factors, especially high BP, predisposing to silent and symptomatic cerebrovascular disease (Chapters 6 and $\rceil$.

VI. Arterial stiffness can be regarded as a summary measure for generalized vascular damage integrating and mediating the adverse effects of coexisting vascular risk factors (including high BP and genetic factors) on the cerebral (micro)circulation (Chapter 8).

VII. Hypertension-related silent cerebral damage is associated with both higher ambulatory BP levels and reduced neurocognitive functioning, although the associations with cognition are not very robust (Chapter 9 ).

VIII. Silent cerebrovascular disease, next to and in the same way as preclinical cardio-renal damage, is an independent and prognostically important risk marker that refines risk stratification of hypertensive patients (Chapter 10). 


\section{References}

1. Kearney PM, Whelton M, Reynolds K, Muntner P, Whelton PK, He J. Global burden of hypertension: Analysis of worldwide data. Lancet 2005;365:217-23.

2. Staessen JA, Wang J, Bianchi G, Birkenhager WH. Essential hypertension. Lancet 2003;361: 1629-41.

3. Mancia G, De Backer G, Dominiczak A, Cifkova R, Fagard R, Germano G, Grassi G, Heagerty AM, Kjeldsen SE, Laurent S, Narkiewicz K, Ruilope L, Rynkiewicz A, Schmieder RE, Boudier HA, Zanchetti A. 2007 guidelines for the management of arterial hypertension: The task force for the management of arterial hypertension of the European Society of Hypertension (ESH) and of the European Society of Cardiology (ESC). J Hypertens 2007;25:1105-87.

4. Cordonnier C, Al-Shahi Salman R, Wardlaw J. Spontaneous brain microbleeds: Systematic review, subgroup analyses and standards for study design and reporting. Brain 2007;130:1988-2003.

5. Vermeer SE, Longstreth WT, Jr., Koudstaal PJ. Silent brain infarcts: A systematic review. Lancet Neuro/ 2007;6:611-9.

6. Launer LJ. Epidemiology of white matter lesions. Top Magn Reson Imaging 2004;15:365-7.

7. Di Carlo A, Launer LJ, Breteler MM, Fratiglioni L, Lobo A, Martinez-Lage J, Schmidt R, Hofman A. Frequency of stroke in europe: A collaborative study of population-based cohorts. ILSA working group and the neurologic diseases in the elderly research group. Italian Longitudinal Study on Aging. Neurology 2000;54:S28-33.

8. Prabhakaran S, Wright CB, Yoshita M, Delapaz R, Brown T, DeCarli C, Sacco RL. Prevalence and determinants of subclinical brain infarction: The Northern Manhattan Study. Neurology 2008;70:425-30.

9. Leary MC, Saver JL. Annual incidence of first silent stroke in the united states: A preliminary estimate. Cerebrovasc Dis 2003;16:280-5.

10. Chamorro A, Pujol J, Saiz A, Vila N, Vilanova JC, Alday M, Blanc R. Periventricular white matter lucencies in patients with lacunar stroke. A marker of too high or too low blood pressure? Arch Neuro/ 1997;54:1284-8.

11. Goldstein IB, Bartzokis G, Hance DB, Shapiro D. Relationship between blood pressure and subcortical lesions in healthy elderly people. Stroke 1998;29:765-72.

12. O'Sullivan C, Duggan J, Lyons S, Thornton J, Lee M, O'Brien E. Hypertensive target-organ damage in the very elderly. Hypertension 2003;42:130-5.

13. Puisieux F, Monaca P, Deplanque D, Delmaire C, di Pompeo C, Monaca C, Leys D, Pruvo JP, Dewailly P. Relationship between leuko-araiosis and blood pressure variability in the elderly. Eur Neuro/ 2001;46:115-20.

14. Schwartz GL, Bailey KR, Mosley T, Knopman DS, Jack CR, Jr., Canzanello VJ, Turner ST. Association of ambulatory blood pressure with ischemic brain injury. Hypertension 2007;49:1228-34.

15. Shimada K, Kawamoto A, Matsubayashi K, Ozawa T. Silent cerebrovascular disease in the elderly. Correlation with ambulatory pressure. Hypertension 1990;16:692-9.

16. Sierra C, de La Sierra A, Mercader J, Gomez-Angelats E, Urbano-Marquez A, Coca A. Silent cerebral white matter lesions in middle-aged essential hypertensive patients. J Hypertens 2002;20:519-24.

17. Yamamoto Y, Akiguchi I, Oiwa K, Hayashi M, Kimura J. Adverse effect of nighttime blood pressure on the outcome of lacunar infarct patients. Stroke 1998;29:570-6.

18. Kario K, Matsuo T, Kobayashi H, Imiya M, Matsuo M, Shimada K. Nocturnal fall of blood pressure and silent cerebrovascular damage in elderly hypertensive patients. Advanced silent cerebrovascular damage in extreme dippers. Hypertension 1996;27:130-5.

19. Fagher $B$, Valind $S$, Thulin T. End-organ damage in treated severe hypertension: Close relation to nocturnal blood pressure. J Hum Hypertens 1995;9:605-10.

20. Longstreth WT, Jr., Arnold AM, Beauchamp NJ, Jr., Manolio TA, Lefkowitz D, Jungreis C, Hirsch $\mathrm{CH}, \mathrm{O}$ 'Leary $\mathrm{DH}$, Furberg CD. Incidence, manifestations, and predictors of worsening white matter on serial cranial magnetic resonance imaging in the elderly: The Cardiovascular Health Study. Stroke 2005;36:56-61. 
21. Raz N, Rodrigue KM, Kennedy KM, Acker JD. Vascular health and longitudinal changes in brain and cognition in middle-aged and older adults. Neuropsychology 2007;21:149-57.

22. Veldink JH, Scheltens $P$, Jonker $C$, Launer LJ. Progression of cerebral white matter hyperintensities on MRI is related to diastolic blood pressure. Neurology 1998;51:319-20.

23. Schmidt R, Fazekas F, Kapeller P, Schmidt H, Hartung HP. MRI white matter hyperintensities: Three-year follow-up of the Austrian Stroke Prevention Study. Neurology 1999;53:132-9.

24. Gouw AA, van der Flier WM, Fazekas F, van Straaten EC, Pantoni L, Poggesi A, Inzitari D, Erkinjuntti T, Wahlund LO, Waldemar G, Schmidt R, Scheltens P, Barkhof F. Progression of white matter hyperintensities and incidence of new lacunes over a 3-year period: The Leukoaraiosis and Disability Study. Stroke 2008;39:1414-20.

25. Shintani S, Shiigai T, Arinami T. Subclinical cerebral lesion accumulation on serial magnetic resonance imaging (MRI) in patients with hypertension: Risk factors. Acta Neurol Scand 1998;97:251-6.

26. Goldstein IB, Bartzokis G, Guthrie D, Shapiro D. Ambulatory blood pressure and the brain: A 5year follow-up. Neurology 2005;64:1846-52.

27. Lammie GA. Hypertensive cerebral small vessel disease and stroke. Brain Patho/2002;12:358-70.

28. De Reuck J. The human periventricular arterial blood supply and the anatomy of cerebral infarctions. Eur Neuro/ 1971;5:321-34.

29. Jackson C, Sudlow C. Are lacunar strokes really different? A systematic review of differences in risk factor profiles between lacunar and nonlacunar infarcts. Stroke 2005;36:891-901.

30. Sachdev P, Wen W. Should we distinguish between periventricular and deep white matter hyperintensities? Stroke 2005;36:2342-3.

31. Fagard RH, Celis H, Thijs L, Staessen JA, Clement DL, De Buyzere ML, De Bacquer DA. Daytime and nighttime blood pressure as predictors of death and cause-specific cardiovascular events in hypertension. Hypertension 2008;51:55-61.

32. Sander D, Winbeck K, Klingelhofer J, Conrad B. Extent of cerebral white matter lesions is related to changes of circadian blood pressure rhythmicity. Arch Neuro/2000;57:1302-7.

33. Shimada K, Kawamoto A, Matsubayashi K, Nishinaga M, Kimura S, Ozawa T. Diurnal blood pressure variations and silent cerebrovascular damage in elderly patients with hypertension. $J$ Hypertens 1992;10:875-8.

34. Watanabe N, Imai Y, Nagai K, Tsuji I, Satoh H, Sakuma M, Sakuma H, Kato J, Onodera-Kikuchi N, Yamada M, Abe F, Hisamichi S, Abe K. Nocturnal blood pressure and silent cerebrovascular lesions in elderly Japanese. Stroke 1996;27:1319-27.

35. Kario K, Pickering TG, Matsuo T, Hoshide S, Schwartz JE, Shimada K. Stroke prognosis and abnormal nocturnal blood pressure falls in older hypertensives. Hypertension 2001;38:852-7.

36. Inzitari M, Pozzi C, Rinaldi LA, Masotti G, Marchionni N, Di Bari M. Cognitive and functional impairment in hypertensive brain microangiopathy. J Neurol Sci 2007;257:166-73.

37. Pantoni L. Leukoaraiosis: From an ancient term to an actual marker of poor prognosis. Stroke 2008;39:1401-3.

38. Ikram MA, Vernooij MW, Vrooman HA, Hofman A, Breteler MM. Brain tissue volumes and small vessel disease in relation to the risk of mortality. Neurobiol Aging 2007; epub.

39. Vermeer SE, Hollander M, van Dijk EJ, Hofman A, Koudstaal PJ, Breteler MM. Silent brain infarcts and white matter lesions increase stroke risk in the general population: The Rotterdam Scan Study. Stroke 2003;34:1126-9.

40. Vermeer SE, Prins ND, den Heijer T, Hofman A, Koudstaal PJ, Breteler MM. Silent brain infarcts and the risk of dementia and cognitive decline. N Eng/ J Med 2003;348:1215-22.

41. Vakili BA, Okin PM, Devereux RB. Prognostic implications of left ventricular hypertrophy. Am Heart J 2001;141:334-41.

42. Fukuda $\mathrm{H}$, Kitani M. Differences between treated and untreated hypertensive subjects in the extent of periventricular hyperintensities observed on brain MRI. Stroke 1995;26:1593-7.

43. de Leeuw FE, de Groot JC, Oudkerk M, Witteman JC, Hofman A, van Gijn J, Breteler MM. Hypertension and cerebral white matter lesions in a prospective cohort study. Brain 2002;125:765-72. 
44. Dufouil C, Chalmers J, Coskun O, Besancon V, Bousser MG, Guillon P, MacMahon S, Mazoyer B, Neal B, Woodward M, Tzourio-Mazoyer N, Tzourio C. Effects of blood pressure lowering on cerebral white matter hyperintensities in patients with stroke: The PROGRESS (Perindopril Protection Against Recurrent Stroke Study) magnetic resonance imaging substudy. Circulation 2005;112:1644-50.

45. Hasegawa Y, Yamaguchi T, Omae T, Woodward M, Chalmers J. Effects of perindopril-based blood pressure lowering and of patient characteristics on the progression of silent brain infarct: The Perindopril Protection Against Recurrent Stroke Study (PROGRESS) CT substudy in Japan. Hypertens Res 2004;27:147-56.

46. Firbank MJ, Wiseman RM, Burton EJ, Saxby BK, O'Brien J T, Ford GA. Brain atrophy and white matter hyperintensity change in older adults and relationship to blood pressure: Brain atrophy, WMH change and blood pressure. J Neuro/2007;254:713-21.

47. Birns J, Morris R, Donaldson N, Kalra L. The effects of blood pressure reduction on cognitive function: A review of effects based on pooled data from clinical trials. I Hypertens 2006;24:1907-14.

48. Inzitari D. Leukoaraiosis: An independent risk factor for stroke? Stroke 2003;34:2067-71.

49. de Leeuw FE, de Groot JC, Oudkerk M, Witteman JC, Hofman A, van Gijn J, Breteler MM. A follow-up study of blood pressure and cerebral white matter lesions. Ann Neuro/ 1999;46: 827-33.

50. van Dijk EJ, Breteler MM, Schmidt R, Berger K, Nilsson LG, Oudkerk M, Pajak A, Sans S, de Ridder M, Dufouil C, Fuhrer R, Giampaoli S, Launer LJ, Hofman A. The association between blood pressure, hypertension, and cerebral white matter lesions: Cardiovascular determinants of dementia study. Hypertension 2004;44:625-30.

51. Birns J, Markus H, Kalra L. Blood pressure reduction for vascular risk: Is there a price to be paid? Stroke 2005;36:1308-13.

52. Mancia G. Total cardiovascular risk: A new treatment concept. J Hypertens 2006;24 (Suppl 2):S17-24.

53. Schmidt R, Scheltens P, Erkinjuntti T, Pantoni L, Markus HS, Wallin A, Barkhof F, Fazekas F. White matter lesion progression: A surrogate endpoint for trials in cerebral small-vessel disease. Neurology 2004;63:139-44.

54. van Straaten EC, Fazekas F, Rostrup E, Scheltens P, Schmidt R, Pantoni L, Inzitari D, Waldemar G, Erkinjuntti T, Mantyla R, Wahlund LO, Barkhof F. Impact of white matter hyperintensities scoring method on correlations with clinical data. The LADIS study. Stroke 2006;37:836-40.

55. Taylor WD, Bae JN, MacFall JR, Payne ME, Provenzale JM, Steffens DC, Krishnan KR. Widespread effects of hyperintense lesions on cerebral white matter structure. Am J Roentgenol 2007;188:1695-704.

56. Cho ZH, Kang CK, Han JY, Kim SH, Kim KN, Hong SM, Park CW, Kim YB. Observation of the lenticulostriate arteries in the human brain in vivo using 7.0T MR angiography. Stroke 2008;39:1604-6. 
Appendix
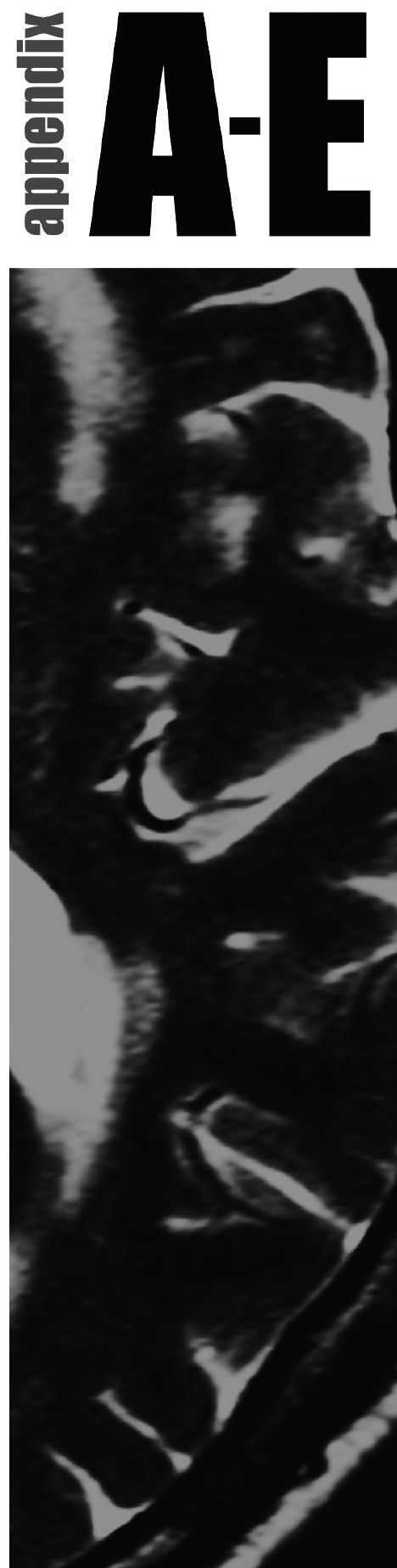


\section{Appendix A}

Magnetic resonance imaging of white matter hyperintensities, silent brain infarcts and brain microbleeds

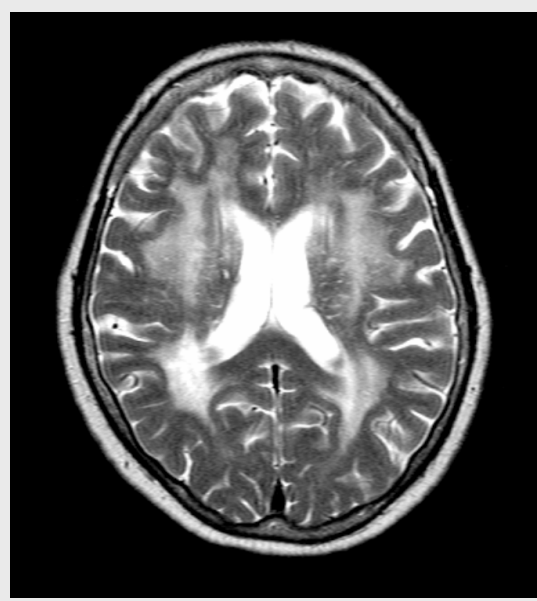

A.1.1

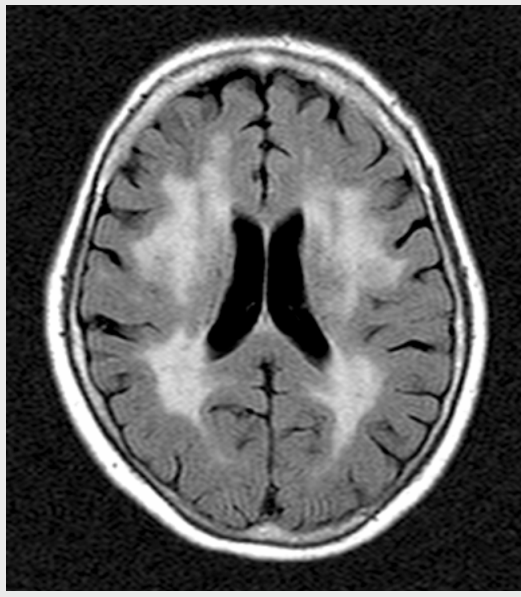

A.1.2

Figure A.1 Example of severe white matter hyperintensities on T2-weighted (panel A.1.1) and corresponding fluid-attenuated inversion recovery (FLAIR) (panel A.1.2) magnetic resonance imaging sequences. Hyperintensities extend from the regions surrounding the lateral ventricles (periventricular regions) into the deep, subcortical white matter. 

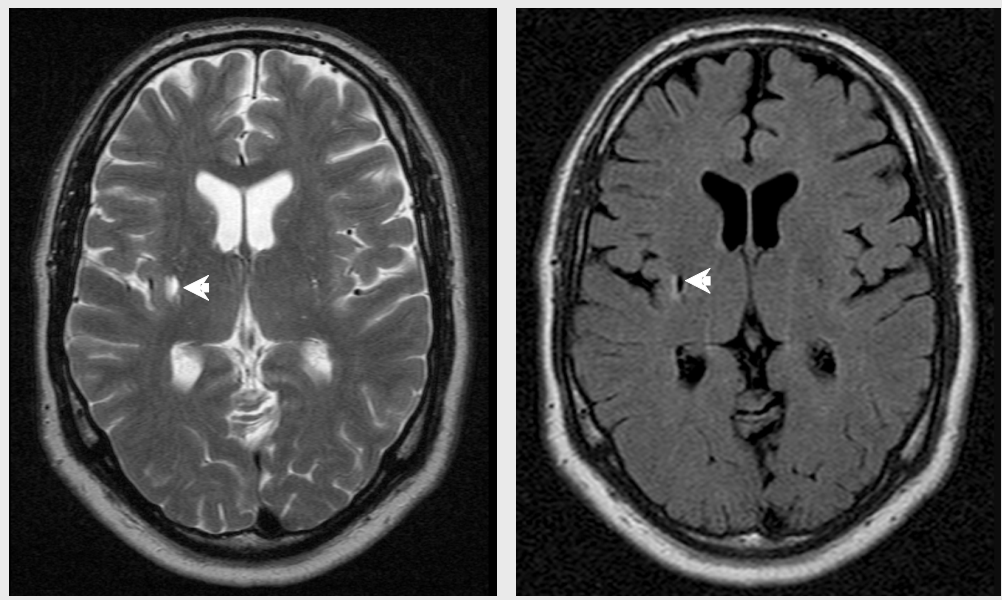

A.2.1
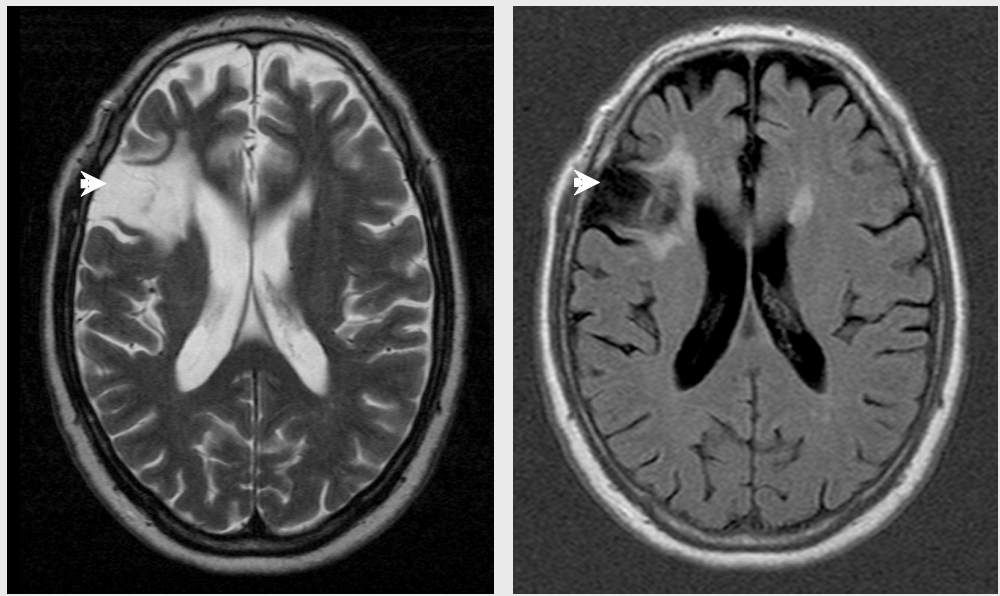

A.2.2

Figure A.2 Examples of silent brain infarcts on T2-weighted (left image) and corresponding fluidattenuated inversion recovery (FLAIR; right image) magnetic resonance imaging sequences. Panel A.2.1 indicates a silent lacunar infarct in the basal ganglia (white arrow heads); note the hyperintense rim surrounding the lacune characteristic for infarction (gliotic tissue). Panel A.2.2 shows a silent territorial infarct involving both the cortex and the subcortical white matter (white arrow heads). 


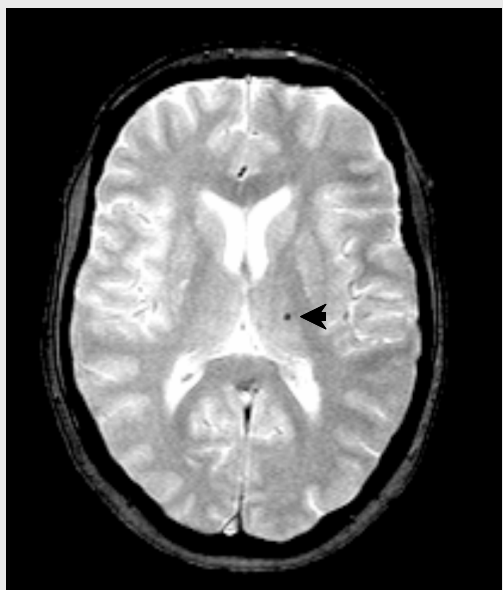

A.3.1

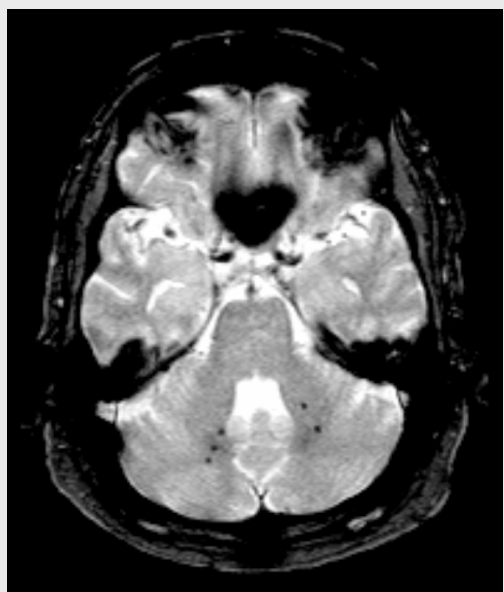

A.3.2

Figure A.3 Examples of brain microbleeds on $\mathrm{T} 2{ }^{*}$-weighted gradient echo magnetic resonance imaging sequence. The punctate signal loss (hemosiderin-laden macrophages) is characteristic of microbleeds. Panel A.3.1 indicates a single microbleed (black arrow head) in the basal ganglia. Panel A.3.2 indicates five microbleeds in the cerebellum. 


\section{Appendix B}

\section{Selection and inclusion of participants (chapters 3, 4, 5, 8, and 10)}

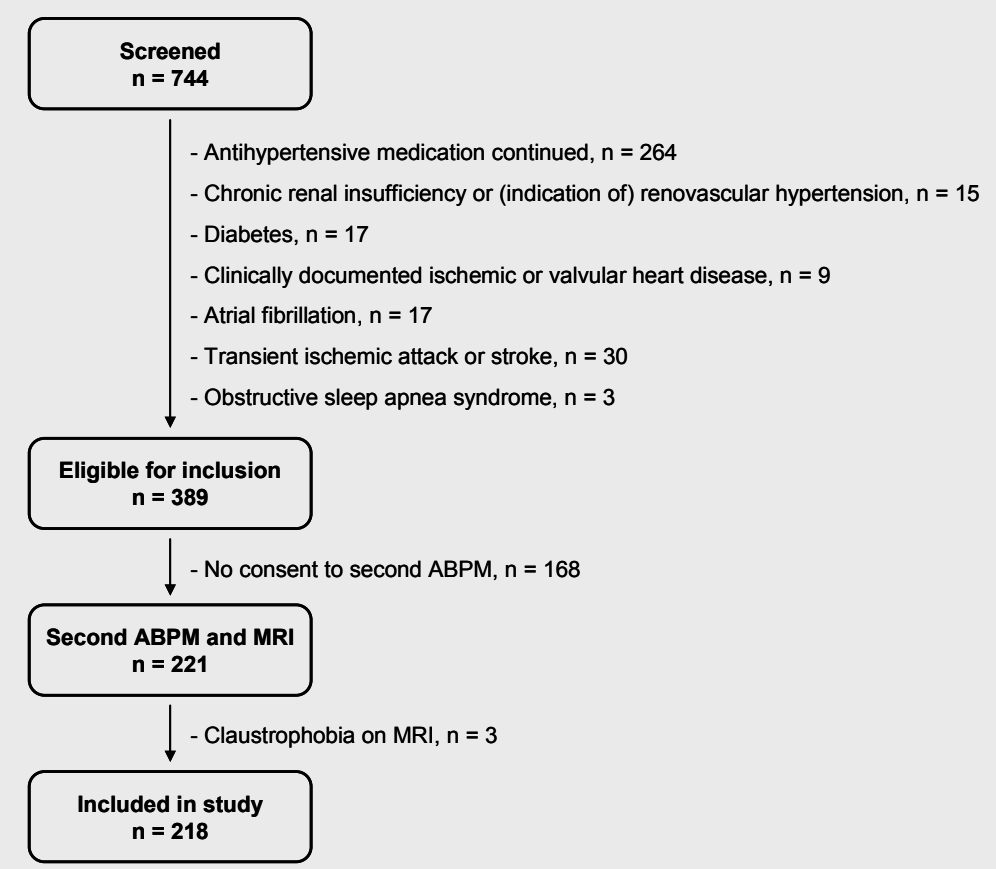

Figure B.1 Flow diagram of the number of patients screened, those eligible for inclusion into the study, and those who eventually consented to participate. 


\section{Appendix C}

\section{Reproducibility of ambulatory blood pressure components using the narrow diary time method}

\section{Methods}

The participant's awake (daytime) and asleep (nighttime) periods were determined by excluding a 2-hour transition period around the reported rising and retiring times, i.e., the so-called narrow diary time method. The reproducibility of the 24-hour, awake and asleep blood pressure (BP) levels, and the relative nocturnal BP dip, was determined according to Bland and Altman by calculating coefficients of repeatability, defined as twice the standard deviation (SD) of the differences between the duplicate recordings. ${ }^{1}$ To enable comparisons between the different BP components, the repeatability coefficients were expressed as a percentage of the nearly maximal variation, calculated as four times the SD of the average of the two recordings. ${ }^{2}$ High percentages of nearly maximal variation indicate considerable variation between the repeated recordings, reflecting lower reproducibility. To determine the reproducibility of the nocturnal hypertension status and the nondipping pattern we investigated the number of participants who confirmed their initial classification on the second ambulatory BP monitoring (ABPM). Kappa statistics were applied to evaluate the consistency of these classifications. According to Landis and Koch, kappa values below 0.40 signify poor, 0.40 to 0.59 moderate, 0.60 to 0.79 substantial, and values above 0.80 outstanding reproducibility. ${ }^{3}$ Differences between related BP data were assessed using the paired-samples $t$-test or McNemar's test whenever appropriate.

\section{Results}

Differences in mean 24-hour, awake and asleep BP levels, and the relative nocturnal BP dip between the first and second ABPM were small (all $<0.5 \mathrm{mmHg}$ ) and not statistically significant (Table C.1, P 0.05 ). The repeatability coefficient (expressed as a percentage of the nearly maximal variation) of the relative nocturnal BP dip was higher than that of the 24-hour, awake as well as asleep BPs (Table C.1), indicating lower reproducibility.

One-hundred-and-fifty-four (72.3\%) participants confirmed their initial nocturnal hypertension status on the second ABPM, 24 (11.3\%) were normotensive on both sessions and 35 (16.4\%) showed a variable nocturnal normotension/hypertension pattern (Figure C.1). The nocturnal hypertension status was moderately 
reproducible (Table C.1, Cohen's kappa 0.48). Fifteen (7.0\%) subjects showed a nondipping pattern on both sessions, 169 (79.4\%) confirmed their initial dipping status and 29 (13.6\%) showed a variable dipping/nondipping pattern (Figure C.2). The dipping status was also moderately reproducible (Table C.1, Cohen's kappa 0.43). Differences in proportions of nocturnal hypertensives as well as nondippers between the first and second ABPM were non-significant (Table C.1, P 0.05 ).

Table C.1 Reproducibility of ambulatory blood pressure components.

\begin{tabular}{|c|c|c|c|c|}
\hline \multirow[b]{2}{*}{ BP component } & \multicolumn{3}{|c|}{ Ambulatory $\mathrm{BP}^{\mathrm{a}}$} & \multirow[b]{2}{*}{ Reproducibility ${ }^{b}$} \\
\hline & First & Second & Combined & \\
\hline \multicolumn{5}{|l|}{ 24-hour BP, mmHg: } \\
\hline SBP & $150.3 \pm 18.5$ & $150.3 \pm 18.3$ & $150.3 \pm 17.9$ & $16.4(22.9)$ \\
\hline MAP & $112.3 \pm 13.2$ & $112.3 \pm 13.2$ & 112.3 & $11.8(22.9)$ \\
\hline DBP & $93.3 \pm 11.8$ & $93.2 \pm 11.9$ & 11.6 & $10.4(22.4)$ \\
\hline \multicolumn{5}{|l|}{ Awake BP, mmHg: } \\
\hline SBP & $155.6 \pm 18.7$ & $156.0 \pm 18.8$ & $155.8 \pm 18.6$ & $18.3(24.6)$ \\
\hline MAP & $116.8 \pm 13.4$ & 117.0 & 116. & $13.1(25.2)$ \\
\hline DBP & $97.4 \pm 12.1$ & $97.4 \pm 12.2$ & $97.4 \pm 11.9$ & $11.4(23.9)$ \\
\hline \multicolumn{5}{|l|}{ Asleep BP, mmHg } \\
\hline SBP & $131.3 \pm 20.1$ & $131.1 \pm 18.7$ & $131.2 \pm 18.8$ & $19.0(25.3)$ \\
\hline MAP & $96.4 \pm 14.5$ & $96.5 \pm 13.5$ & 13.6 & $14.4(26.5)$ \\
\hline DBP & $78.9 \pm 12.8$ & $79.2 \pm 11.9$ & $79.0 \pm 11.9$ & $13.2(27.7)$ \\
\hline Relative nocturnal BP (MAP) dip, \% & $17.5 \pm 8.0$ & $17.4 \pm 7.3$ & $17.5 \pm 7.1$ & $11.6(40.8)$ \\
\hline \multicolumn{5}{|l|}{ Nocturnal hypertension: } \\
\hline Yes & $168(78.9)$ & $175(82.2)$ & $154(72.3)^{c}$ & 0.48 \\
\hline No & $45(21.1)$ & $38(17.8)$ & $59(2$ & \\
\hline \multicolumn{5}{|l|}{ Nocturnal nondipping: } \\
\hline Yes & $34(16.0)$ & $25(11.7)$ & $15(7.0)^{d}$ & 0.43 \\
\hline No & $179(84.0)$ & $188(88.3)$ & $198(93.0)$ & \\
\hline \multicolumn{5}{|c|}{$\begin{array}{l}\text { Data are presented as mean } \pm \text { SD or number (\%). BP indicates blood pressure; SBP, systolic BP, MAP, } \\
\text { mean arterial pressure; DBP, diastolic BP. a Ambulatory BP levels of the first and second monitoring } \\
\text { session, and on the basis of both ABPMs (combined). Differences in continuous as well as categorical } \\
\text { ambulatory BP components between the first and second monitoring session were all non-significant } \\
\text { (P>0.05, paired samples } t \text {-test and McNemar's test, respectively). }{ }^{b} \text { Reproducibility of ambulatory BP } \\
\text { components expressed as the Bland-Altman coefficient of repeatability (\% of nearly maximal } \\
\text { variation) for continuous data, and Cohen's kappa for categorical data. }{ }^{c} \text { Nocturnal hypertension } \\
\text { present on both ABPMs. }{ }^{d} \text { Nondipping pattern present on both ABPMs. }\end{array}$} \\
\hline
\end{tabular}




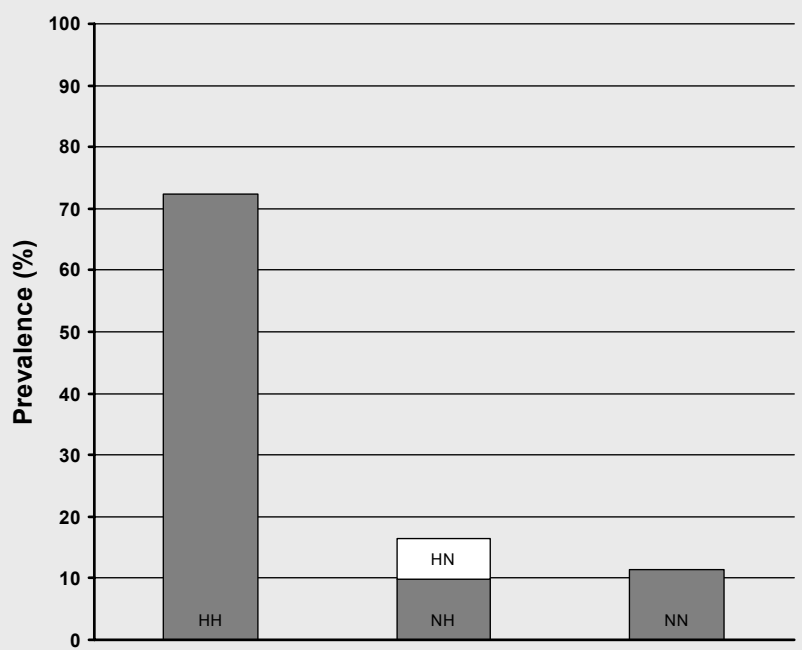

Figure C.1 Reproducibility of the nocturnal hypertension status. HH indicates hypertensive on both ABPMs $(72.3 \%)$; $H N$, hypertensive on the first, normotensive on the second ABPM $(6.5 \%) ; \mathrm{NH}$, normotensive on the first, hypertensive on the second ABPM $(9.9 \%)$; NN, normotensive on both ABPMs (11.3\%). 


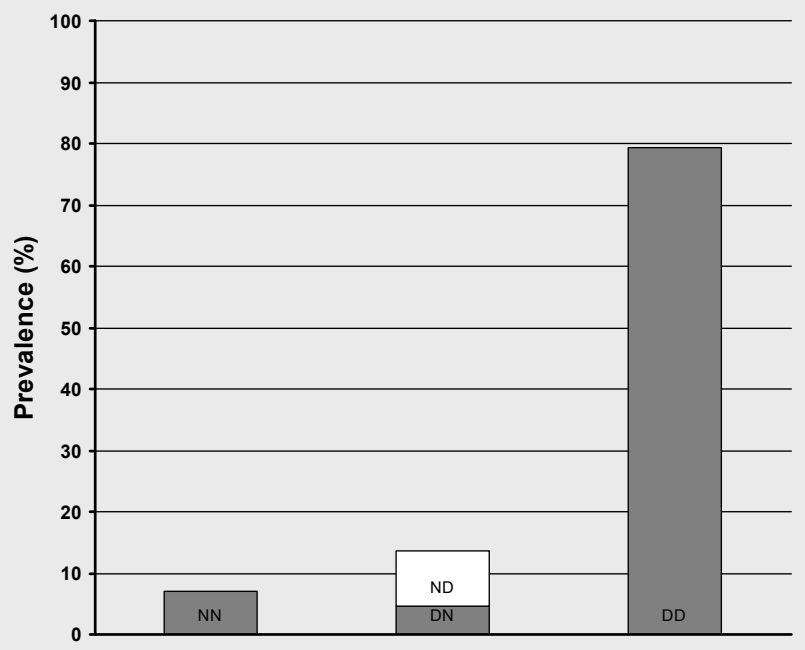

Figure C.2 Reproducibility of the nocturnal dipping pattern. NN indicates nondipper on both ABPMs (7.0\%); ND, nondipper on the first, dipper on the second ABPM (8.9\%); DN, dipper on the first, nondipper on the second ABPM (4.7\%); DD, dipper on both ABPMs (79.4\%).

\section{Conclusions}

In summary, the reproducibility of the mean 24-hour, awake and asleep BPs was acceptable (concordance ranging between 22.4 and $27.7 \%$ of nearly maximal

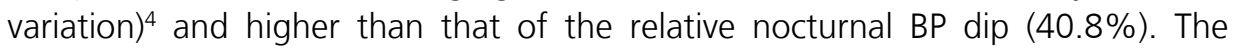
nocturnal hypertension status as well as the dipping pattern were moderately reproducible (Cohen's kappa 0.48 and 0.43 , respectively). ${ }^{3}$ Therefore, and because an increasing number of BP readings improves the reliability of ambulatory BP components ${ }^{5}$, all analyses will be performed on the basis of both ABPMs. That is, we calculate the mean for continuous BP data and classify participants as nocturnal hypertensive or nondipper when they confirm their initial status on the second ABPM; otherwise subjects will be labelled as normotensive or dipper, respectively. 


\section{References}

1. Bland JM, Altman DG. Statistical methods for assessing agreement between two methods of clinical measurement. Lancet 1986;1:307-10.

2. Staessen J, Bulpitt CJ, O'Brien E, Cox J, Fagard R, Stanton A, Thijs L, Van Hulle S, Vyncke G, Amery A. The diurnal blood pressure profile. A population study. Am J Hypertens 1992;5: 386-92.

3. Landis JR, Koch GG. The measurement of observer agreement for categorical data. Biometrics 1977;33:159-74.

4. Thijs L, Staessen J, Fagard R, Zachariah P, Amery A. Number of measurements required for the analysis of diurnal blood pressure profile. J Hum Hypertens 1994;8:239-44.

5. Fotherby MD, Potter JF. Reproducibility of ambulatory and clinic blood pressure measurements in elderly hypertensive subjects. J Hypertens 1993;11:573-9. 


\section{Appendix D}

\section{Quantification of white matter hyperintensity volumes}

\section{Magnetic resonance imaging}

Brain MRI was performed on a 1.5-T clinical MR-system (Intera, Philips Medical Systems, Best, The Netherlands) using a standard quadrature head coil. The standardized imaging protocol consisted of T2-weighted fast spin echo (repetition time [TR] 4820 ms; echo time [TE] 100 ms; echo train length [ETL] 12; flip angle 90\%; field of view [FOV] $230 \mathrm{~mm}$; acquisition matrix 512X512) and fluidattenuated inversion recovery (FLAIR) (TR 8000 ms; TE 120 ms; inversion time 2000 ms; ETL 23; FOV 230 mm; acquisition matrix 256X256 [reconstructed to $512 \times 512])$ sequences in the axial plane, producing 24 slices with a thickness of 5 $\mathrm{mm}$ and a $0.5 \mathrm{~mm}$ interslice gap.

\section{Quantification of white matter hyperintensities}

All imaging data were transferred to a Macintosh workstation and analyzed for white matter hyperintensity and brain volumes, using the in-house developed (E.G.) image-processing software package GIANT (General Imaging and Analysis Tools; Department of Psychiatry and Neuropsychology, Maastricht University, Maastricht, The Netherlands).

Images were preprocessed by standardization of the MRI intensity scale for both FLAIR and T2-weighted scan data. ${ }^{1}$ For deriving the parameters (training) we used a random selection of 16 data sets. The result of this nonlinear intensity transformation is a consistent correspondence between intensity and tissue meaning for all our MRI data. The next step was to derive the parameters describing the region of white matter hyperintensities (WMHs) in a twodimensional feature space (scatter plot) in which one axis was defined by the T2 intensity and the other axis by the FLAIR intensity. For this training step, the WMHs were manually segmented by one of us (L.H.) in 10 other randomly selected data sets. In the scatter plot the WMHs showed up as a cluster with high signal intensities for both T2 and FLAIR.

The actual quantification of WMHs was performed semi-automatically. The axial FLAIR and T2 image stacks were displayed and aligned side by side in synchrony on the computer monitor, and the contrast and brightness were automatically optimized. This allowed visual inspection of the scan data and easy identification of WMHs. In each slice, a WMH had to be indicated manually by clicking in its 
region. This position served as a seed point for a region growing operation based on the parameters derived in the above training step. The volume of this WMH was calculated as the segmented area times the slice thickness including the interslice gap.

White matter hyperintensities connected to the lateral ventricles were defined as periventricular (PWMHs), otherwise, they were considered to be deep (DWMHs). We calculated the total volume of WMHs (TWMHV) by summing the volumes of the periventricular (PWMHV) and deep (DWMHV) WMHs.

Figure D.1 shows an example of the semi-automatic detection of periventricular and deep WMHs using GIANT.

The brain volume (BV), defined as the total volume of the white and grey matter, was derived fully automatically by means of skullstripping followed by tissue classification. Skullstripping was performed by a custom tool using both T2 and FLAIR data. The method is based on a series of mathematical morphology operations and active contours. ${ }^{2,3}$ Tissue classification involved thresholding by means of a probability function derived from the image histograms of the skullstripped data.

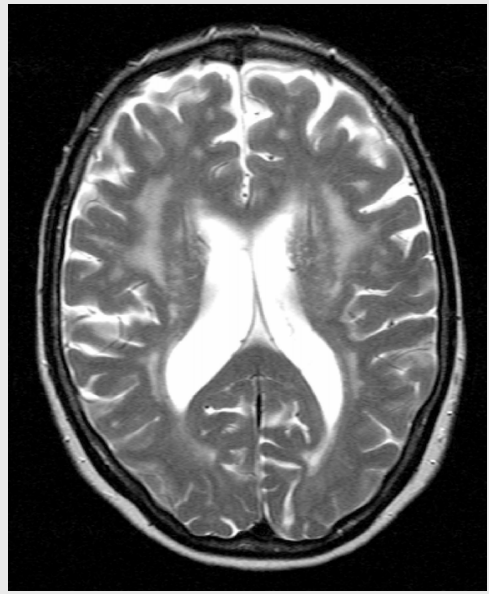

D.1.1

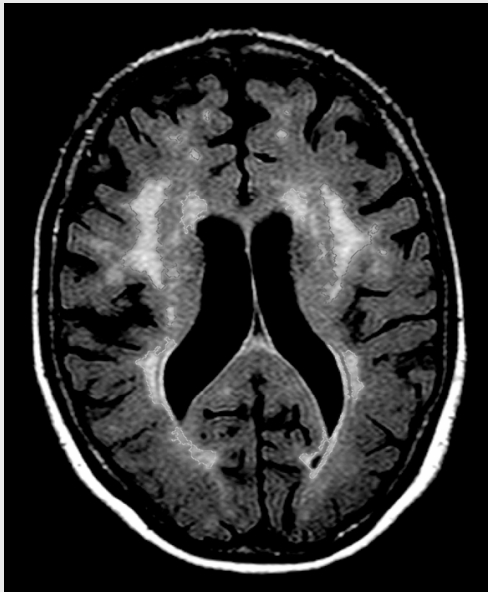

D.1.2

Figure D.1 T2-weighted (panel D.1.1) and corresponding fluid-attenuated inversion recovery (FLAIR) (panel D.1.2) magnetic resonance imaging sequences showing advanced hyperintensities in the periventricular and deep white matter. Panel D.1.2 shows the results of the semiautomatic detection of periventricular (turquoise) and deep (red) WMHs. 


\section{Reliability}

A single trained observer (L.H.), blinded to the participants' age, sex and clinical status, performed all quantitative WMH-assessments, after reaching satisfactory agreement with an experienced neuroradiologist (P.H.). Reliability analyses, carried out on a random sample of 20 scans, yielded very good inter- and intra-observer agreement (Table D.1). ${ }^{4}$ Furthermore, twenty randomly selected patients were scanned and rescanned with repositioning to evaluate the scan-rescan effects on the WMHV- and BV-measurements. The scan-rescan volumes showed very good agreement (Table D.1).

Table D.1 Reliability of white matter hyperintensity and brain volume quantification $(n=20)$

\begin{tabular}{l|c|c|c|}
\hline \multicolumn{3}{|c|}{ Agreement (ICC) } \\
\cline { 2 - 4 } Parameter & Inter-observer & Intra-observer & Scan-rescan \\
\hline WMHV & & & 0.99 \\
\hline Total & 0.97 & 0.99 & 0.99 \\
Periventricular & 0.97 & 0.99 & 0.99 \\
Deep & 0.96 & 0.99 & 0.99 \\
\hline BV & n.a. & n.a. & \\
\hline ICC indicates intraclass correlation coefficient; WMHV, white matter hyperintensitie volume; BV, brain \\
volume; n.a., not applicable (full automatic assessment).
\end{tabular}

In addition to the volumetric measurements (concurrent validity) two experienced vascular neurologists (R.v.O. and J.L.) classified, independently and blinded to the participants' age, sex and clinical status, WMHs semi-quantitatively (visually) according to Fazekas et al. into hyperintensities of the deep and subcortical white matter (DWMHs) and periventricular hyperintensities (PVHs) (for details on this rating scale see Table E.1, Appendix E). ${ }^{5}$ The inter-rater reliability, expressed as Cohen's kappa ${ }^{6}$, was 0.53 for PVHs, 0.67 for deep DWMHs and 0.63 for the overall $\mathrm{WMH}$ score (0 to 3 categories). In case of disagreement, lesions were always ascertained by consensus.

The scatterplots of Figure D.2 show the relationships between the Fazekas scores and WMHVs specified for periventricular, deep and total WMHs. ${ }^{7}$ Higher visual scores correlated with increasing volumes (Spearman's $\rho$ 0.80, 0.85 and 0.83, respectively), and, in line with earlier observations ${ }^{7}$, scatter increased with higher Fazekas scores. 

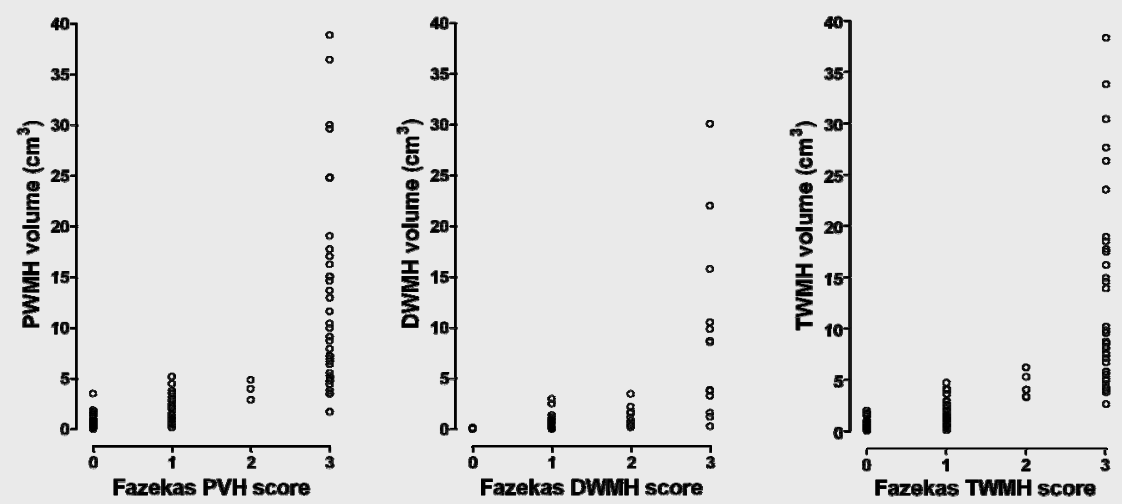

Figure D2 Scatter plots for the Fazekas scores with corresponding white matter hyperintensity volumes. PVH indicates periventricular hyperintensity; DWMH, deep white matter hyperintensity; TWMH, total white matter hyperintensity. Fazekas WMH scores are as shown in Table E.1 (Appendix E); TWMH = combination of PVH and DWMH. Spearman's $\rho$, quantifying the relationship between Fazekas scores and WMHVs, was $0.80,0.86$ and 0.83 for periventricular (D.2.1), deep (D.2.2) and total (D.2.3) WMHs, respectively.

\section{References}

1. Nyul LG, Udupa JK. On standardizing the MR image intensity scale. Magn Reson Med 1999;42:1072-81.

2. Dogdas B, Shattuck DW, Leahy RM. Segmentation of skull and scalp in 3-D human MRI using mathematical morphology. Hum Brain Mapp 2005;26:273-85.

3. Matsumoto S, Asato R, Okada T, Konishi J. Intracranial contour extraction with active contour models. J Magn Reson Imaging 1997;7:353-60.

4. Bartko JJ. Measurement and reliability: Statistical thinking considerations. Schizophr Bull 1991;17:483-9.

5. Fazekas F, Chawluk JB, Alavi A, Hurtig HI, Zimmerman RA. MR signal abnormalities at $1.5 \mathrm{~T}$ in Alzheimer's dementia and normal aging. Am J Roentgeno/ 1987;149:351-6.

6. Landis JR, Koch GG. The measurement of observer agreement for categorical data. Biometrics 1977;33:159-74.

7. van Straaten EC, Fazekas F, Rostrup E, Scheltens P, Schmidt R, Pantoni L, Inzitari D, Waldemar G, Erkinjuntti T, Mantyla R, Wahlund LO, Barkhof F. Impact of white matter hyperintensities scoring method on correlations with clinical data. The LADIS study. Stroke 2006;37:836-40. 


\section{Appendix E}

\section{Semi-quantitative white matter hyperintensity rating scales}

Table E.1 Fazekas scale for rating white matter hyperintensities ${ }^{1}$.

\begin{tabular}{|c|c|c|}
\hline WMHs & Rating & Characteristic \\
\hline PVH: & $\begin{array}{l}0 \\
1 \\
2 \\
3\end{array}$ & $\begin{array}{l}\text { Absence } \\
\text { "Caps" or pencil-thin lining } \\
\text { Smooth "halo" } \\
\text { Irregular PVH extending into the deep white matter }\end{array}$ \\
\hline DWMH: & $\begin{array}{l}0 \\
1 \\
2 \\
3\end{array}$ & $\begin{array}{l}\text { Absence } \\
\text { Punctate foci } \\
\text { Beginning confluence of foci } \\
\text { Large confluent areas }\end{array}$ \\
\hline
\end{tabular}

Table E.2 Rotterdam Scan Study scale for rating white matter hyperintensities ${ }^{2}$.

\begin{tabular}{|c|c|c|}
\hline WMLs & Rating & Characteristic \\
\hline \multirow{8}{*}{ PWML: } & & None \\
\hline & 1 & Pencil thin lining \\
\hline & 2 & Smooth halo \\
\hline & 3 & Large confluent \\
\hline & & $\begin{array}{l}\text { Periventricular WMLs are scored semiquantitatively en for three separate regions: } \\
\text { (1) Frontal caps: adjacent to frontal horns. }\end{array}$ \\
\hline & & (2) Bands: adjacent to the wall of the lateral ventricles. \\
\hline & & (3) Occipital caps: adjacent to the occipital horns. \\
\hline & & $\begin{array}{l}\text { The total periventricular WML score was calculated by adding the region-specific } \\
\text { scores (range 0-9). }\end{array}$ \\
\hline \multirow[t]{7}{*}{ SWML: } & : Diamete & r Subcortical WMLs were categorized, according to their maximum diameter (as \\
\hline & & appearing on the hard copy): \\
\hline & & (1) Small: $1-3 \mathrm{~mm}$. \\
\hline & & $\begin{array}{l}\text { (2) Medium: 3-10 mm. } \\
\text { (3) Large: }>10 \mathrm{~mm} \text {. }\end{array}$ \\
\hline & Number & Number of subcortical WMLs are rated per size category for the frontal, parietal, \\
\hline & & $\begin{array}{l}\text { occipital and temporal lobes. Distinction between lobes is according to anatomical } \\
\text { landmarks. }\end{array}$ \\
\hline & Volume & $\begin{array}{l}\text { Total subcortical WML volume is approximated }(\mathrm{ml}) \text { by assuming subcortical WMLs } \\
\text { sperical with diameters of } 2 \text { (lesion } 1-3 \mathrm{~mm}) 6(3-10 \mathrm{~mm}) \text { or } 12 \mathrm{~mm}(>10 \mathrm{~mm}) \text {. }\end{array}$ \\
\hline & & \\
\hline & dicate & white matter lesions; PWML, periventricular white matter lesion; SWML, subcortica \\
\hline
\end{tabular}




\section{References}

1. Fazekas F, Chawluk JB, Alavi A, Hurtig HI, Zimmerman RA. MR signal abnormalities at $1.5 \mathrm{~T}$ in Alzheimer's dementia and normal aging. Am J Roentgeno/ 1987;149:351-6.

2. de Groot JC, de Leeuw FE, Oudkerk M, van Gijn J, Hofman A, Jolles J, Breteler MM. Cerebral white matter lesions and cognitive function: The Rotterdam Scan Study. Ann Neurol 2000;47:145-51. 
196 
Summary 
Hypertension is an important, worldwide public-health challenge because of its high frequency and concomitant risks of cardiovascular, renal and cerebrovascular disease, and death. Globally, hypertension affects $25-30 \%$ of the adult population, and even up to $60-70 \%$ of those beyond the seventh decade of life. Moreover, the incidence of hypertension is still increasing. According to the World Health Organization (WHO), hypertension is estimated to cause over seven million premature deaths annually. Lowering blood pressure (BP) leads to a substantial reduction of the risk of fatal- and nonfatal cardio- and cerebrovascular complications. If, and to what extent, high BP should be lowered, depends on the degree of target-organ damage in vital organs like the heart and kidneys. In particular the presence of preclinical or silent damage (damage occurring without clinical symptoms) appears important. According to current guidelines for the management of arterial hypertension it is sufficient to determine the presence of cardiac (left ventricular hypertrophy [LVH]) and renal damage (microalbuminuria and impaired kidney function). It is, however, unclear whether the search for silent damage of other organs may improve the risk stratification of hypertensive patients who are most at risk of cardio- and cerebrovascular disease. In this thesis, we investigated whether white matter hyperintensities (WMHs), silent brain infarcts (SBIs) and brain microbleeds (BMBs) can be regarded as manifestations of hypertensive target-organ damage of the brain, and whether this damage is clinically relevant and of additional value in stratifying a patient's risk of cardioand cerebrovascular disease.

\section{Blood pressure and silent cerebrovascular disease}

Although it is well established that hypertension, besides age, is the most important and best modifiable risk factor for silent cerebrovascular disease, data on the relationship of WMHs and SBIs with BP levels per se are limited and lacking for BMBs.

We determined the BP levels and circadian BP profiles by ambulatory BP monitoring (ABPM) since ambulatory BP correlates closely with hypertensive organ damage and is superior to BP measured in the office in predicting cardiovascular risk. Despite this, the use of ABPM is not undisputed because of observations questioning the reproducibility of the derived BP profiles, the use of different methods to define daytime and nighttime periods, and because the assessment of BP profiles on the basis of a single ABPM is less reliable. Therefore, in Chapter 2 we studied the reproducibility and clinical relevance of nocturnal BP dipping in detail. To this end, we analyzed duplicate ambulatory BP recordings of a group of 150 untreated hypertensive patients to determine how different definitions of 
awake (daytime) and asleep (nighttime) periods and the use of different BP indices (systolic, diastolic, mean arterial pressure [MAP], or combinations of such indices) affected the extent of the nocturnal BP dip, the frequency of dippers and nondippers, and their respective reproducibility. Furthermore, we assessed the association of nondipping with left ventricular (LV) mass index (LVMI) and urinary albumin excretion (UAE) as markers of hypertensive cardio-renal damage. We found that the extent of the nocturnal BP dip and the distribution of dippers and nondippers varied significantly according to the definition of awake-asleep and/or the BP index used. Yet, and irrespective of the classification applied, both the relative nocturnal BP dip and the nondipper status were poorly reproducible. Accordingly, the strength of association between nondipping and LVMI or UAE differed according to the definition of awake-asleep and/or the BP index applied. On the basis of these data, and on the results of the reproducibility analyses of the daytime, nighttime and 24-hour BP averages (Appendix C), we decided to analyze all BP data (Chapters 3 to 6) using duplicate ABPMs. That is, we calculated the mean for continuous BP data and classified participants as nondipper when they confirmed their initial status on the second ABPM. Awake and asleep periods were determined according to the narrow diary time approach, excluding a 2-hour transition period around the participant's reported rising and retiring times.

In the chapters 3, 4 and 5 we addressed the relationships between untreated ambulatory BP profiles and the extent of WMHs, and the presence of SBIs and BMBs in a cohort of 218 newly referred hypertensive patients without a history of cardio- or cerebrovascular disease. In Chapter 3 we report on the association between ambulatory BP profiles and WMHs. Because previous studies adopted rather crude visual rating scales to categorize WMHs, we quantified their volume semi-automatically using in-house developed software, which yielded excellent inter- and intra-observer agreement. Furthermore, we distinguished between hyperintensities of the periventricular and deep white matter because others suggested different causes, different consequences and different progression rates between the two. Doing so, we demonstrated that higher 24-hour, awake, and asleep BP levels were independently related to a greater volume of periventricular and, to a lesser extent, deep WMHs. In other words, while the periventricular WMH volume (WMHV) increased steeply with higher BP levels, the volume of deep WMHs did so only modestly. Importantly, the relationships were continuous, without evidence of distinct thresholds, and continued down to BP levels well within the normotensive range. In Chapter 4 we addressed the associations between ambulatory BP and subtypes of SBls. A better understanding of the relation between BP and subtypes of SBls may be important in view of the potential benefits of lowering BP in the prevention of silent and, eventually, symptomatic cerebrovascular disease. Therefore, we aimed to further detail the $\mathrm{BP}-\mathrm{SBI}$ relationship by relating ambulatory BP to lacunar infarcts (LACs) and 
territorial infarcts (TIs) in subtype-specific analyses. It was found that higher ambulatory BP levels, whether daytime, nighttime or 24-hour, were independently and significantly associated with the presence of LACs. In agreement with this, we observed hypertensive cardio-renal damage, i.e., damage resulting from longstanding high BP levels, to be related to LACs as well. No associations, however, were found between TIs and either BP or hypertensive organ damage. These data suggest that hypertension differentially affects the risk of silent LACs and TIs. In Chapter 5 we assessed the relation between BP measured by ABPM and the presence of BMBs. Microbleeds are emerging as a new marker of hypertension-related cerebrovascular damage, but data on their relation with BP levels per se are lacking. The results showed that BMBs occurred in $16 \%$ of our hypertensive patients, which is about three times higher than the frequency reported in the general population. As with WMHs and LACs, higher daytime, nighttime and 24-hour BP levels were independently associated with the presence of microbleeds. More specifically, every standard deviation increase in BP was associated with a 1.8- to 1.9-fold higher likelihood of BMBs. The associations were somewhat stronger for the nocturnal BP compared to the BP during the day, and participants who were diagnosed with nocturnal hypertension had a five- to six-fold higher likelihood of displaying BMBs on MRI than those with normal nocturnal BP. We propose that BMBs, besides WMHs and LACs, should be regarded as a new marker of hypertensive brain damage. Taken together, the results described in the chapters 3, 4 and 5 suggest that hypertensive patients with a high daytime and especially high nighttime BP, i.e., a high 24-hour BP load, are more likely to develop silent WMHs, LACs and BMBs.

In addition to the absolute nocturnal BP level per se, we also studied whether reduced nocturnal BP dipping, in general considered to be a determinant of hypertension-related organ damage, is associated with greater WMHV, more SBIs, and more microbleeds (Chapters 3, 4 and 5). Therefore, we analyzed the nocturnal BP dip as a continuous rather than categorical (i.e., dippers vs. nondippers) variable, but failed to observe significant relationships between nocturnal BP dipping and any of the investigated brain lesions.

\section{Genetics and hypertensive cerebrovascular disease}

Genetic factors may increase the risk of (silent) cerebrovascular disease by predisposing to conventional risk factors or by modulating the effects of coexisting risk factors. Half of the risk of stroke cannot be explained by conventional risk factors, and genetic predisposition could well account for some of the unexplained risk. In Chapter 6 we conducted a genetic association study linking polymorphisms of the renin-angiotensin system (RAS) and the endothelial nitric oxide (NO) synthase (NOS3) with WMHs. White matter hyperintensities can 
be regarded as an intermediate phenotype for stroke. The RAS and NOS3 pathways are involved in vascular function and morphology and may increase the susceptibility of the cerebral (micro)circulation to the adverse effects of high BP. We included only hypertensive patients, yielding a relatively homogeneous population that we expected to be enriched for genes contributing to hypertension and an increased risk of WMHs. We found the angiotensin II type 1 receptor (AGTR1) $A^{1166} \mathrm{C}$ of the RAS and the NOS3 $\mathrm{G}^{894} \mathrm{~T}$ polymorphisms to be independently related to WMHs, but only for those in the deep, subcortical area. Other genetic variants of the RAS, i.e., those of angiotensinogen $\left(\mathrm{M}^{235} \mathrm{~T}\right)$ and the angiotensin-converting enzyme (insertion/deletion), were not associated with WMHs.

In Chapter 7 we tested the AGTR1 $\mathrm{A}^{1166} \mathrm{C}$ and the NOS3 $\mathrm{G}^{894} \mathrm{~T}$ polymorphisms for associations with incident stroke. In a large, population-based case-cohort study in over 1,500 women - representing a population of more 15,000 women - 74 strokes developed over a median follow-up period of 4.3 years. Stroke risk increased in the presence of the AGTR1 CC genotype, yet, only at a higher age or with an elevated systolic BP. The NOS3 G ${ }^{894} \mathrm{~T}$ polymorphism was not related to the risk of stroke. These data support the notion that genetic factors may, for some part, explain the differences in susceptibility of the brain to coexisting risk factors such as high BP, and illustrate the importance of gene-environment interactions. We hypothesize that genetic factors may help to identify those individuals who are at greatest risk of stroke and who may need careful follow-up or (early) treatment of coexisting risk factors.

\section{Arterial stiffness and silent cerebrovascular disease}

The arterial system gradually stiffens because of the shared effects of ageing, high $\mathrm{BP}$, genetic factors, and other (vascular) risk factors. Arterial stiffness, and especially a stiffened aorta, has been associated with an excess risk of stroke, supposedly via cerebral small-vessel disease. To explore whether aortic stiffness is associated with cerebral small-vessel disease, we assessed in Chapter 8 the relationship of aortic pulse wave velocity (PWV) and pulse pressure (PP), both established markers of arterial stiffness, with WMHs, LACs and BMBs. In 167 stroke-free hypertensive patients we found that both aortic PWV and PP were univariately associated with all three types of cerebral small-vessel disease. However, only aortic PWV, being a direct measure of aortic stiffness, remained positively associated with the extent of WMHs and the presence of silent LACs, independent of age, MAP and other risk factors. Higher PWV levels were also associated with older age, male sex, longstanding hypertension, higher BP levels, and higher creatinine, cholesterol and glucose levels, supporting the concept that arterial stiffness can be regarded as a summary measure for generalized vascular 
damage integrating the adverse effects of coexisting vascular risk factors on the vasculature. This vascular damage likely increases the risk of silent and symptomatic cerebrovascular disease.

\section{Clinical relevance of detecting hypertension-related silent cerebrovascular disease}

The search for preclinical cerebrovascular disease is only worthwhile when its detection will modify diagnostic and preventive strategies. For instance, timely detection of WMHs, LACs and/or BMBs in asymptomatic patients could help in identifying those individuals who are most at risk of developing stroke and who may need careful follow-up and/or treatment of risk factors.

In Chapter 9 we first evaluated the effects of WMHs and LACs on cognitive performance in a group of 86 previously diagnosed, middle-aged to older, essential hypertensive patients who were under regular control of their treated hypertension at our outpatient department. For this purpose, we performed an off-treatment ABPM, detected WMHs (periventricular and deep) and LACs, and assessed cognitive performance in three functional domains, i.e., verbal memory, sensorimotor speed and cognitive flexibility. In line with the findings of chapter 3, periventricular WMHs were related to higher levels of BP, whereas deep WMHs were not associated with BP. In general, cognitive functioning decreased with increasing severity of both periventricular and deep WMHs, but, when adjusted for age, the associations did not reach statistical significance anymore. Patients with LACs, on the other hand, had both higher BP levels and performed slightly but significantly below average on verbal memory, even in age adjusted analyses. Finally, in Chapter 10 we addressed the question whether the detection of silent cerebrovascular disease (i.e., advanced WMHs, SBls and/or BMBs) as an additional marker of hypertensive brain damage could improve or refine the risk stratification of hypertensive patients, besides the use of preclinical cardiac (i.e., echocardiographic $\mathrm{LVH}$ ) and renal risk markers (i.e., microalbuminuria and/or impaired kidney function) as recommended by current hypertension guidelines. In 192 hypertensive patients without a history of cardio- or cerebrovascular disease we found that hypertensive organ damage involved the heart in $21 \%$, the kidneys in $26 \%$, and the brain in $44 \%$ of the participants. When considering only patients with demonstrable cardiac and/or renal damage as recommended by current hypertension guidelines ( $n=72), 42$ subjects (58\%) had also silent cerebrovascular disease. Of the remaining 120 participants without cardio-renal damage 42 (35\%) had brain damage. Thus, half of all patients with silent cerebrovascular disease were classified as having no organ (i.e., cardio-renal) involvement. We calculated each group's risk of dying from cardiovascular disease (including stroke) within the next five years and found that the risk score of patients without cardio-renal 
but with brain damage was significantly higher than that of participants without any organ involvement (heart, kidneys and brain), but similar to the risk score of those with demonstrable cardio-renal damage. We conclude that silent cerebrovascular disease, next to and in the same way as preclinical cardio-renal damage, should be recognized as an independent and prognostically important risk marker that needs attention in the risk stratification of hypertensive patients. 


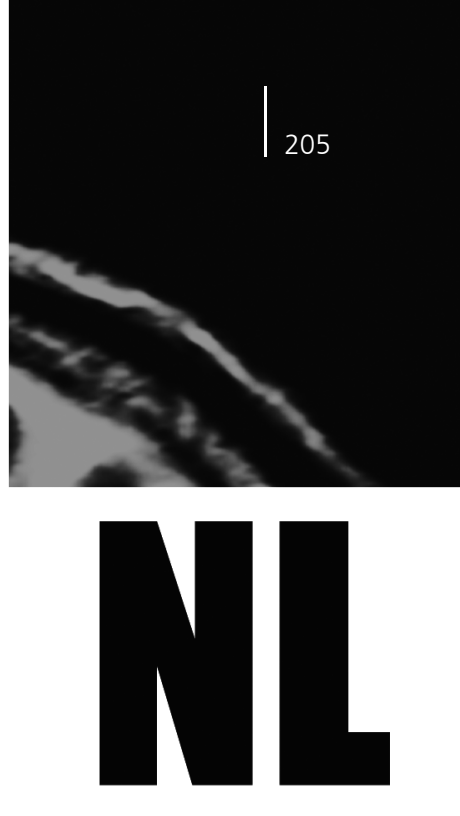

Samenvatting

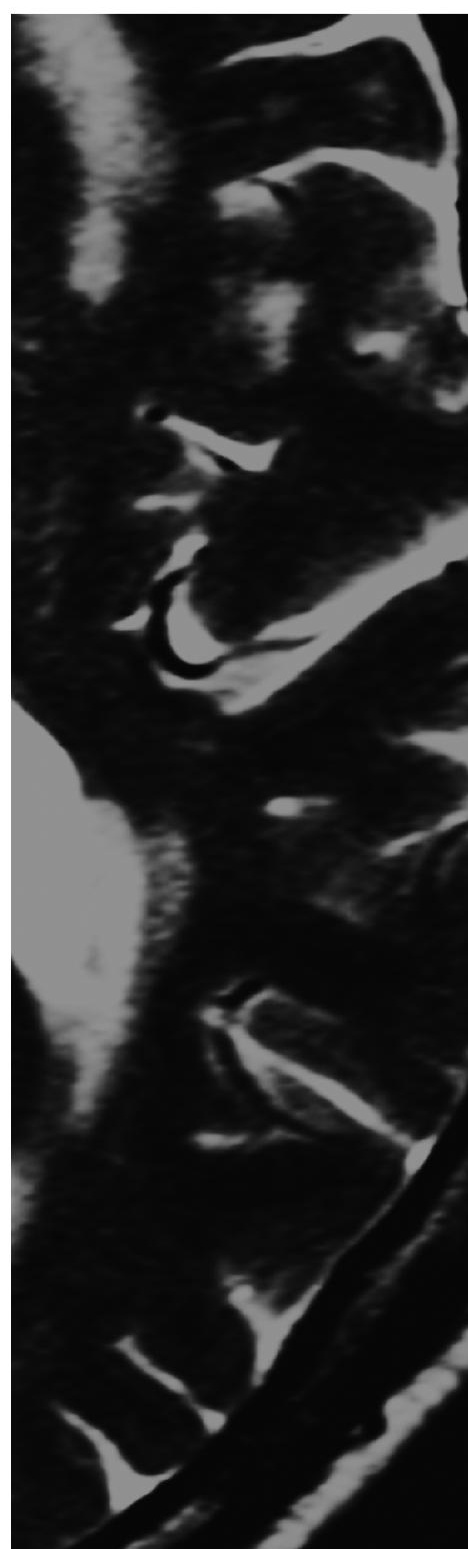


Hypertensie (verhoogde bloeddruk) is een belangrijk gezondheidsprobleem dat wereldwijd voorkomt en gepaard gaat met een verhoogd risico op hart- en vaatziekten. Ongeveer eenderde van de volwassen bevolking, en zelfs 60 tot $70 \%$ van de mensen ouder dan 70 jaar, heeft enige mate van hypertensie. Door de vergrijzing van de bevolking zal de incidentie en prevalentie van hypertensie de komende decennia sterk stijgen. Volgens schattingen van de Wereld Gezondheidsorganisatie (WHO) sterven jaarlijks wereldwijd meer dan zeven miljoen mensen aan de gevolgen van hoge bloeddruk. Behandeling van hypertensie leidt tot een aanzienlijke daling van het risico op het krijgen of fataal worden van hart- en vaatziekten. Of, en in welke mate, de verhoogde bloeddruk dient te worden verlaagd, hangt onder andere af van de hoeveelheid schade die door de hypertensie is ontstaan aan belangrijke organen als het hart en de nieren. Dit wordt ook wel eindorgaanschade genoemd. Met name het opsporen van zogenaamde preklinische of stille schade (beschadiging zonder dat symptomen optreden) is hierbij van belang. Volgens de huidige richtlijnen voor de behandeling van hypertensie is het voldoende om de aanwezigheid van cardiale (linker ventrikel hypertrofie, LVH) en renale schade (micro-albuminurie en gestoorde nierfunctie) te bepalen. Vooralsnog is onduidelijk of het onderzoeken van andere organen op eindorgaanschade bijdraagt aan het inschatten van het cardiovasculaire risico van hypertensiepatiënten. In dit proefschrift onderzochten wij in welke mate witte stof afwijkingen, stille infarcten en microbloedingen in de hersenen (voor voorbeelden zie Appendix A) een uiting zijn van door hypertensie veroorzaakte eindorgaanschade (cerebrovasculaire schade), en of deze eindorgaanschade van de hersenen klinisch relevant is, en bijdraagt aan een nauwkeuriger inschatting van het risico op hart- en vaatziekten.

\section{Bloeddruk en stille cerebrovasculaire aandoeningen}

Hypertensie is de belangrijkste behandelbare risicofactor voor het ontstaan van stille cerebrovasculaire aandoeningen zoals witte stof afwijkingen (afwijkingen door chronisch zuurstoftekort [=ischemie] in de witte stof van de hersenen), stille herseninfarcten en microbloedingen die zichtbaar gemaakt kunnen worden met behulp van magnetische resonantie beeldvorming (magnetic resonance imaging, MRI) van de hersenen. Er is echter weinig bekend over de relatie tussen deze stille MRI-afwijkingen en de hoogte van de bloeddruk.

In de studies beschreven in dit proefschrift hebben wij de bloeddruk gemeten met behulp van ambulante 24-uurs bloeddrukmetingen. Naast de hoogte van de bloeddruk overdag geven deze metingen ook een indruk van de bloeddruk tijdens de nacht, en over het dag-nacht beloop (ook wel dipping genoemd). Eerder onderzoek toonde aan dat ambulant gemeten bloeddrukken beter correleren met eindorgaanschade van het hart en de nieren en beter het risico op een toekomstig 
hart- of herseninfarct voorspellen dan de bloeddruk gemeten in de spreekkamer. Ondanks deze voordelen bestaat er ook scepsis over het gebruik van ambulante bloeddrukmeting. Zo zou een eenmalige 24-uurs bloeddrukmeting een matig betrouwbare indruk geven van de 24-uurs bloeddrukken en met name van het dag-nacht beloop van de bloeddruk. Enerzijds komt dit door het gebruik van veel verschillende definities voor de dag-en nachtwaarde van de bloeddruk, anderzijds doordat het dag-nacht beloop slecht reproduceerbaar is gebleken.

In Hoofdstuk 2 van dit proefschrift onderzochten wij de reproduceerbaarheid en de klinische relevantie van het dag-nacht beloop van de bloeddruk. In 150 tijdelijk onbehandelde hypertensiepatiënten verrichtten wij tweemaal een ambulante 24uurs bloeddrukmeting en bestudeerden vervolgens hoe de mate van nachtelijke bloeddrukdaling, de prevalentie van nondipping (dit is het niet of onvoldoende dalen van de bloeddruk tijdens de nacht als een maat voor een gestoord dagnacht beloop), en de reproduceerbaarheid van deze parameters wordt beïnvloed door het toepassen van enerzijds verschillende definities van de dag (wakker) en nacht (slapen), en anderzijds het gebruik van verschillende bloeddrukmaten (systolische, diastolische of gemiddelde bloeddruk, of een combinatie van deze bloeddrukmaten). Omdat nondipping lijkt samen te gaan met een verhoogd risico op hart- en vaatziekten onderzochten wij tevens of door het gebruik van verschillende dipping definities de relatie tussen nondipping en aan hypertensie gerelateerde eindorgaanschade beïnvloed wordt. Wij vonden dat zowel de mate waarmee de bloeddruk 's nachts daalt als de prevalentie van nondipping sterk varieert afhankelijk van de gekozen definitie. Onafhankelijk van de gebruikte definitie, bleek dat zowel de nachtelijke bloeddrukdaling als nondipping slecht reproduceerbare parameters zijn. Tevens bleek dat het gebruik van verschillende definities van invloed is op de relatie van nondipping met zowel linker ventrikel massa index (LVMI) als micro-albuminurie als maten voor respectievelijk cardiale en renale beschadiging door hoge bloeddruk. Naar aanleiding van deze bevindingen, en op basis van de resultaten van studies naar de reproduceerbaarheid van de gemiddelde dag, nacht en 24-uurs bloeddrukken (Appendix C), hebben wij besloten om de bloeddrukgegevens in de hoofdstukken 3 tot en met 6 te berekenen gebruik makend van twee 24-uurs ambulante bloeddrukmetingen. De dag, nacht en 24-uurs bloeddrukken worden hierbij berekend als het gemiddelde van beide metingen, en patiënten worden beschouwd als nondipper alleen dan wanneer het nondipping patroon aanwezig is op beide metingen. Dag en nacht wordt bepaald aan de hand van de door de deelnemers aangegeven tijdstippen waarop men 's avonds ging slapen, en waarop men 's ochtends wakker werd en opstond uit bed, met exclusie van een 2 uur durende transitie periode rondom deze tijdstippen.

In de hoofdstukken 3, 4 en 5 beschrijven wij de relatie tussen bloeddruk gemeten met 24-uurs ambulante bloeddrukmetingen en de mate van witte stof afwijkingen, de aanwezigheid van stille herseninfarcten, en de aanwezigheid van 
microbloedingen in 218 tijdelijk onbehandelde hypertensiepatiënten. Niemand van de deelnemers had een voorgeschiedenis met symptomatisch hart- en vaatlijden. In Hoofdstuk 3 bestudeerden wij de relatie tussen de ambulante bloeddruk (en daarvan afgeleide bloeddrukprofielen) en de ernst van witte stof afwijkingen. In het verleden hebben studies vooral gebruik gemaakt van zogenaamde visuele scoringsmethoden die de mate van witte stof afwijkingen indelen in categorieën (Appendix E) maar niet het volume kwantificeren. In tegenstelling tot deze eerdere studies hebben wij, met behulp van aan de Universiteit Maastricht ontwikkelde software, op een betrouwbare manier (met zeer goede intra- en inter-observator overeenkomst) het volume van witte stof afwijkingen bepaald. Bovendien hebben wij onderscheid gemaakt tussen enerzijds witte stof afwijkingen rondom de laterale ventrikels (zogenaamde periventriculaire witte stof afwijkingen) en anderzijds afwijkingen diep in de hersenen (zogenaamde diepe of subcorticale witte stof afwijkingen). Op deze wijze vonden wij dat hoe hoger de bloeddruk (zowel overdag, tijdens de nacht, als over de gehele 24 uur) des te groter het volume van periventriculaire en, in mindere mate, diepe witte stof afwijkingen. De relaties waren onafhankelijk van leeftijd, geslacht en andere invloedrijke factoren, continu en zonder duidelijke drempelwaarden, en zelfs aanwezig bij bloeddrukwaarden die wij momenteel als normaal beschouwen. In Hoofdstuk 4 onderzochten wij of de mate waarmee ambulant gemeten bloeddruk samenhangt met stille herseninfarcten afhangt van het type infarct. Zo vonden wij significant hogere bloeddrukken (dag, nacht en 24-uurs) in patiënten met kleine, diep in de hersenen gelegen, zogenaamde lacunaire herseninfarcten. De relatie was onafhankelijk van andere risicofactoren. Patiënten met een stil territoriaal infarct (meer oppervlakkig gelegen infarcering), daarentegen, hadden vergelijkbare bloeddrukken als deelnemers bij wie geen stille herseninfarcten werden gevonden. Cardio-renale eindorgaanschade (een aanwijzing voor langer bestaande hypertensie) bleek ook meer voor te komen bij de patiënten met lacunaire herseninfarcten ten opzichte van de deelnemers zonder stille herseninfarcten, terwijl dit niet het geval was voor patiënten met territoriale infarcten. Deze bevindingen suggereren dat de invloed van hypertensie met name bepalend is voor het risico van stille lacunaire herseninfarcten en minder of niet voor dat van territoriale infarcten. Dit is klinisch relevant wanneer men middels het verlagen van de verhoogde bloeddruk het optreden van stille en toekomstige symptomatische herseninfarcten wil voorkomen. Hoofdstuk 5 beschrijft de relaties tussen ambulante bloeddrukken en microbloedingen. Deze microbloedingen blijken vaker voor te komen bij personen met hypertensie, maar tot op heden is geen onderzoek verricht naar de relatie tussen deze bloedinkjes en bloeddruk. In ruim 16\% van de 218 hypertensiepatiënten die deelnamen aan onze studie vonden wij één of meerdere microbloedingen. Dit is drie keer zo vaak als de prevalentie waarmee microbloedingen voorkomen in de algemene bevolking. Net als witte stof afwijkingen en lacunaire herseninfarcten bleken ook 
microbloedingen onafhankelijk te zijn geassocieerd met hogere bloedrukken overdag, en daarnaast in het bijzonder met hogere bloeddrukken tijdens de nacht. Voor elke standaard deviatie die de bloeddruk toenam, steeg de kans op het vinden van een microbloeding met 80 tot $90 \%$. Patiënten met hypertensie tijdens de nacht hadden een vijf tot zes keer hogere kans op microbloedingen dan patiënten bij wie de bloeddruk 's nachts normaal was. De bevindingen suggereren dat microbloedingen, naast witte stof afwijkingen en stille lacunaire herseninfarcten, een vorm van aan hypertensie gerelateerde stille hersenschade zijn.

Wij vonden geen relatie tussen nondipping en de mate of aanwezigheid van witte stof afwijkingen, stille herseninfarcten en microbloedingen (Hoofdstukken 3, 4 en 5).

Samenvattend concluderen wij uit de resultaten van de hoofdstukken 3, 4 en 5 dat hypertensiepatiënten met een hoge bloeddruk overdag, en met name die patiënten met een hoge bloeddruk tijdens de nacht (dus diegenen met een continu verhoogde bloeddruk over de hele 24 uur) een verhoogd risico lopen op het ontwikkelen van stille ischemische hersenschade in de vorm van witte stof afwijkingen, lacunaire herseninfarcten en microbloedingen.

\section{Genetische aspecten van aan hypertensie gerelateerde cerebrovasculaire aandoeningen}

Traditionele risicofactoren, zoals veroudering, verhoogde bloeddruk en roken, bepalen voor ongeveer de helft het risico dat iemand loopt op het krijgen van (stille) cerebrovasculaire aandoeningen. Het onverklaarde risico wordt mogelijk (deels) bepaald door erfelijke aanleg. Hierbij spelen interacties met traditionele risicofactoren een belangrijke rol, bijvoorbeeld door de effecten van bepaalde factoren (zoals hoge bloeddruk) te versterken, of door de gevoeligheid van de circulatie (van onder andere hart, nieren en hersenen) voor bepaalde risicofactoren te vergroten. Hoofdstuk 6 toont de resultaten van een genetische associatie studie naar de relatie van genpolymorfismen van het renineangiotensine systeem (RAS) en het endotheel stikstof oxide synthase (NOS3) met witte stof afwijkingen. De RAS en NOS3 systemen spelen een belangrijke rol bij het in stand houden van de integriteit en functie van de vaatwand van bloedvaten. Afwijkingen in de genen verantwoordelijk voor deze systemen kunnen mogelijk de gevoeligheid van de vaatwand voor de negatieve effecten van bijvoorbeeld hypertensie vergroten. In deze studie, waaraan alleen hypertensiepatiënten deelnamen en waardoor genafwijkingen die bijdragen aan hypertensiegerelateerde witte stof afwijkingen waarschijnlijk vaker voorkomen, vonden wij dat zowel het $A^{1166} \mathrm{C}$ polymorfisme van de angiotensine II type 1 receptor (AGTR1) van het RAS als het NOS3 $\mathrm{G}^{894} \mathrm{~T}$ polymorfisme onafhankelijk 
samenhangen met de aanwezigheid van witte stof afwijkingen in de diepe, maar niet de periventriculaire witte stof. Andere genetische varianten van het RAS, zoals het angiotensinogeen $\mathrm{M}^{235} \mathrm{~T}$ en het angiotensine-converterend enzym insertie/deletie polymorfisme, waren niet geassocieerd met witte stof afwijkingen. Vervolgens onderzochten wij in Hoofdstuk 7 opnieuw de AGTR1 $\mathrm{A}^{1166} \mathrm{C}$ en NOS3 $\mathrm{G}^{894} \mathrm{~T}$ polymorfismen, maar $\mathrm{nu}$ in relatie tot het symptomatisch herseninfarct. Gebruik makend van een zogenaamde case-cohort opzet telden wij in ruim 1.500 vrouwen uit de algemene bevolking (deze groep vertegenwoordigd een groter cohort van meer dan 15.000 vrouwen) 74 nieuwe herseninfarcten over een periode van 4,3 jaar (mediane follow-up duur). De kans op een herseninfarct was groter voor deelneemsters met het AGTR1 CC genotype, echter, alleen in vrouwen met een hogere leeftijd of met een verhoogde systolische bloeddruk. De bevindingen uit de hoofdstukken 6 en 7 tonen aan dat genetische factoren een rol spelen bij het ontstaan van herseninfarcten door het moduleren van de effecten van of de gevoeligheid voor traditionele risicofactoren zoals veroudering en verhoogde bloeddruk, en illustreren daarmee het belang van gen-omgeving interacties bij cerebrovasculaire aandoeningen. Het opsporen van afwijkende genetische varianten zou op deze manier een belangrijke rol kunnen spelen bij het tijdig identificeren van die (hypertensie)patiënten die het grootste risico lopen op het krijgen van een herseninfarct, en bij wie intensieve controle en/of behandeling van aanwezige risicofactoren nodig is.

\section{Vaatstijfheid en stille cerebrovasculaire aandoeningen}

De gevolgen van veroudering, hoge bloeddruk, genetische factoren en andere (vasculaire) risicofactoren op de circulatie, uiten zich in een geleidelijke verstijving van de bloedvatwand, met name van slagaders (arteriën). Personen met een toegenomen arteriële stijfheid, en in het bijzonder van de aorta, hebben een sterk verhoogde kans om een herseninfarct door te maken. Omdat door verstijving van bloedvaten de hemodynamiek in het bloedvatstelsel verandert, wordt mogelijk ook de microcirculatie van de hersenen beschadigd. Deze microvasculaire schade uit zich in witte stof afwijkingen, lacunaire herseninfarcten en mogelijk ook microbloedingen. In Hoofdstuk 8 hebben wij de relatie tussen aortaverstijving en cerebrale microvasculaire schade verder uitgezocht. In 167 hypertensiepatiënten vonden wij dat zowel een toegenomen pulse wave velocity (PWV) en als ook een verhoogde polsdruk, beiden een maat voor arteriële verstijving, univariaat geassocieerd waren met alle typen cerebrale microvasculaire schade. Echter, alleen de associaties van PWV met het volume van witte stof afwijkingen en de aanwezigheid van lacunaire herseninfarcten bleven significant na correctie voor leeftijd, gemiddelde bloeddruk en andere vasculaire risicofactoren in multivariate analyses. Toegenomen PWV correleerde tevens met leeftijd, mannelijk geslacht, 
langer bestaande hypertensie, hogere bloeddrukwaarden, en verhoogde kreatinine, cholesterol en glucose waarden, wat aangeeft dat vaatverstijving een multifactorieel bepaald proces is. Deze vorm van vasculaire beschadiging integreert daarmee de negatieve effecten van al deze factoren en verhoogt op deze wijze waarschijnlijk het risico op stille en uiteindelijk symptomatische cerebrovasculaire aandoeningen.

\section{Klinische relevantie van aan hypertensie gerelateerde stille cerebrovasculaire aandoeningen}

Diagnostiek naar stille cerebrovasculaire aandoeningen in de klinische praktijk is alleen relevant wanneer dit leidt tot een verbetering van de risico-inschatting en een aanpassing in de wijze waarop patiënten worden behandeld en preventieve maatregelen worden getroffen. Het tijdig vaststellen van witte stof afwijkingen, lacunaire herseninfarcten en/of microbloedingen, bijvoorbeeld, kan bijdragen aan de identificatie van die patiënten die het grootste risico lopen op het ontwikkelen van een herseninfarct, en bij wie intensieve controle en behandeling van risicofactoren nodig is. Om de effecten van aan hypertensie gerelateerde witte stof afwijkingen en stille lacunaire herseninfarcten op het cognitief functioneren te onderzoeken, verrichtten wij 24-uurs ambulante bloeddrukmetingen (na tijdelijk staken van de bloeddrukverlagende medicatie), MRI-onderzoek van de hersenen, en gedetailleerd neuropsychologisch onderzoek (geheugenfunctie, aandacht, en snelheid waarmee praktische problemen worden opgelost) in 86 hypertensiepatiënten van middelbare en oudere leeftijd, die allen voor de behandeling van hun hypertensie op onze polikliniek onder controle waren. De resultaten van deze studie zijn beschreven in Hoofdstuk 9, en laten zien dat het cognitief functioneren af nam naarmate de ernst van zowel periventriculaire als diepe witte stof afwijkingen toenam. Echter, de relaties bleken niet statistisch significant na correctie voor leeftijd in de analyses. Patiënten met lacunaire herseninfarcten daarentegen, presteerden significant minder goed op het gebied van verbaal geheugen, hetgeen onafhankelijk was van leeftijd. Daarnaast bleken zowel periventriculaire witte stof afwijkingen en lacunaire herseninfarcten geassocieerd te zijn met hogere ambulante bloeddrukken. Deze bevindingen suggereren dat de cognitieve gevolgen van verhoogde bloeddruk het resultaat zijn van aan deze hypertensie gerelateerde stille cerebrovasculaire schade.

Vervolgens onderzochten wij, zoals beschreven in Hoofdstuk 10, of diagnostiek naar witte stof afwijkingen, stille herseninfarcten en/of microbloedingen bijdraagt aan een nauwkeuriger inschatting van het risico op hart- en vaatziekten in onze groep hypertensiepatiënten, als aanvulling op de aanbevolen onderzoeken naar door hypertensie veroorzaakte preklinische eindorgaanschade van het hart en de nieren. Wij vonden cardiale schade (dit wil zeggen LVH) bij 21\%, renale schade 
(micro-albuminurie en/of gestoorde nierfunctie) bij $26 \%$, en cerebrovasculaire schade bij $44 \%$ van de deelnemende patiënten. Wanneer wij, volgens de aanbevelingen van de huidige Europese richtlijnen voor de behandeling van hypertensie, alleen schade van hart en nieren beschouwden als aan hypertensie gerelateerde eindorgaanschade, bleek dat 42 van de 72 hypertensiepatiënten met cardiorenale eindorgaanschade (58\%) ook stille cerebrovasculaire schade hadden. Van de 120 overige patiënten zonder stille cardiorenale beschadiging, hadden 42 (35\%) personen alsnog cerebrovasculaire eindorgaanschade. Met andere woorden, de helft van alle patiënten met witte stof afwijkingen, stille herseninfarcten en/of microbloedingen werden volgens de huidige richtlijnen behandeld als zijnde vrij van eindorgaanschade. Dat dit mogelijk onterecht is, toonden wij aan door voor elke groep het risico op overlijden ten gevolge van hart- en vaatziekten (inclusief herseninfarcten) te berekenen. Wij vonden dat de risicoscore van patiënten zonder cardiorenale maar met cerebrovasculaire schade significant hoger was dan dat van de deelnemers zonder enige vorm van eindorgaanschade (hart, nieren en hersenen), maar gelijk aan de risicoscore van de patiënten met eindorgaanschade van het hart en de nieren. Op basis van deze bevindingen concluderen wij dat diagnostiek naar stille cerebrovasculaire aandoeningen in de vorm van witte stof afwijkingen, stille herseninfarcten en microbloedingen, als aanvulling op de reeds aanbevolen onderzoeken naar cardiorenale eindorgaanschade, kan bijdragen aan een betere inschatting van de kans op hart- en vaatziekten bij patiënten met hypertensie. 
214 
Dankwoord 


\section{Dankwoord}

Met het schrijven van dit dankwoord passeerden alle leuke momenten, frustraties, en hoogte- en dieptepunten van de afgelopen vijf jaar de revue. Ik kijk met heel veel plezier terug!

Ook al is het dankwoord niet het meest wetenschappelijke hoofdstuk van het proefschrift, doch zeker het meest (kritisch) gelezen. Daarvoor hoef ik geen wetenschappelijk bewijs te leveren. Desalniettemin is dit een heel belangrijk hoofdstuk. Namelijk, zonder de hulp van diegenen die ik hier zo meteen wil bedanken waren de eerdere hoofdstukken en dus dit boekje nooit tot stand gekomen.

Allereerst wil ik alle patiënten bedanken die belangeloos hun medewerking hebben verleend aan alle onderzoeken.

Dr. Wilko Spiering. Beste Wilko, hoe kan ik anders beginnen dan jou als eerste te bedanken? Bij jou (je was toen nog zelf promovendus) ben ik ergens in 1999 als tweedejaars student Geneeskunde aan dit "experiment" begonnen. Jouw enthousiasme, uitzonderlijke begeleiding en wetenschappelijke kennis hebben ook mij enthousiast voor het onderzoek gemaakt. Bij het opstarten van mijn eigen onderzoek heb ik veel profijt gehad van alles wat ik van jou geleerd heb. Met jou als lid van de corona eindigt hier vanmiddag bij de verdediging deze periode. Ik vind het een eer om jou erbij te hebben!

Prof. dr. Peter de Leeuw, promotor. Beste Peter, veelal keek u van de zijlijn toe, maar zoals het een goed coach beaamt, aanwijzingen gevend op de momenten dat het nodig was. Bedankt voor uw vertrouwen in me. Mede daardoor heb ik de diverse aspecten van het doen van wetenschappelijk onderzoek in de breedste zin van het woord ervaren. Deze ervaring zal me later zeker nog van pas komen.

Prof. dr. Jan Lodder, promotor. Beste Jan, jouw enthousiasme voor het onderzoek werkte aanstekelijk. Jouw ervaring en kennis over "cerebral small-vessel disease" is enorm. De snelheid waarmee je reageert mijn e-mails en verzoeken om manuscripten na te kijken is ongeëvenaard. Daarnaast wist je ook altijd een en ander te relativeren, of zoals jezelf zei toen een artikel weer eens werd afgewezen: "Léon, dan blijf je tenminste een aardige jongen". Ik weet zeker dat menigeen zich zo'n actieve promotor als jij bent alleen maar kan wensen. Bedankt daarvoor!

Dr. Bram Kroon, co-promotor. Beste Bram, als directe begeleider heb je me de ruimte gegeven om mijn eigen ideeën in mijn onderzoek te implementeren. Des te verder het onderzoek vorderde, des te meer betrokken en enthousiast je werd. 
Zeker het afgelopen jaar, waarin jij ook nog veel taken van Peter hebt overgenomen, heb ik heel prettig met je samengewerkt. Het bewijs ligt voor ons.

Dr. Robert van Oostenbrugge, co-promotor. Beste Robert, in het begin moest ik wennen aan jouw directe benaderingswijze, maar dit is juist een fijne manier om met elkaar samen te werken. Net als met Jan heb ik menig uurtje met jou achter het computerscherm doorgebracht om "witte vlekjes", "gaatjes" en "zwarte puntjes" te scoren. Het was jouw idee om de echo-gradient scan mee te nemen met als resultaat hoofdstuk 5, en wie weet in de follow-up nog wel meer. Bedankt!

Dr. Ed Gronenschild. Beste Ed, zonder jouw computerprogramma GIANT hadden we nooit de volumes van de witte stof afwijkingen kunnen bepalen. Jouw perfectionisme is onovertroffen. Bedankt voor je laagdrempeligheid om het computerprogramma steeds weer aan te passen aan mijn wensen. Ik hoop dat we in de toekomst nog vaker samen mogen werken.

Dr. Martin van Boxtel. Beste Martin, de hoofdstukken 6 en 9 in dit proefschrift zijn tot stand gekomen door jou. Bedankt dat ik gebruik mocht maken van jouw database en expertise. Ik heb er vertrouwen in dat ons recente project wederom tot een mooi resultaat zal leiden.

Dr. Michiel Bots, Julius Center for Health Sciences and Primary Care, Utrecht. Beste Michiel, bedankt dat ik gebruik mocht maken van de Utrechtse ProspectEPIC database met als resultaat hoofdstuk 7. Op die ene ochtend dat we hier in Maastricht op een hotelkamer de eerste berekeningen uitvoerden, ging de wereld van SPSS een heel stuk verder voor mij open. Bedankt daarvoor. Ook Dr. Yvonne van der Schouw en Prof. dr. Rick Grobbee wil ik bedanken voor de fijne samenwerking.

Verder wil ik de neuroradiologen Dr. Paul Hofman en Linda Postema-Jacobi bedanken voor de vele scans die zij klinisch beoordeeld hebben. Hier mogen ook Henk Schoenmakers en zijn team van de MRI niet ontbreken: Axel, Dorke, Eslina, Esther, Ettiene, Evelien, Janine, Kim, Liesbeth, Marietherese, Milenka, Roland, Shalah, Sjef, Sonja en Thea. Bedankt voor jullie hulp bij het scannen van alle patiënten. Rutger Haest dank ik voor het herbeoordelen van de echocardiografie data, wat mede leidde tot de publicatie van Chapter 2.

Het includeren van de patiënten had ik natuurlijk nooit alleen gekund. Beste Kim Bartels, Claudia Beyrus, Jeroen Hendriks, Heidi Jongen, Christel van de Nat en Suuske Vasbinder, duizendmaal dank voor het screenen van de meer dan 700 patiënten die in aanmerking kwamen voor deelname aan het onderzoek. De 
destijds vasculaire arts-assistenten Esther Boumans, Guy Mostard, Sarah-Joan Pinto, Wilko Spiering en Thomas Wierema, en natuurlijk ook de internisten Roger Rennenberg, Bram Kroon en Peter de Leeuw, ook jullie bedankt dat jullie de patiënten uiteindelijk bereid vonden om deel te nemen aan de studie.

Alle andere collega's van de vasculaire geneeskunde en het circulatielab kan ik natuurlijk niet vergeten. Werken met leuke collega's in een prettige omgeving is zeker niet onbelangrijk. Bedankt voor jullie collegialiteit, steun en vriendschap de afgelopen vijf jaar: Paul van der Baan, Esther Beeks, Dorien Bleeker, Stella Brand, Monique Fuss, Peggy Godding, Claudia de Haan, Boy Houben, Amy Jonk, Danielle Kauwenberg, Marieke van Onna, Ingrid Scheffers, Jolanda van Schooneveld, Kim van der Zander, en sinds kort Rianne Ronden en Barry van Varik. Een speciaal woordje van dank aan Willem Verberk. Willem, "hey loser", bedankt voor jouw humor, de vele gesprekken die we hebben gevoerd over ons werk en over allerlei andere zaken, en de congressen die we samen hebben meegemaakt. Dat alles heb ik na jouw vertrek best gemist. Ik hoop dat we elkaar in de toekomst nog vaak zullen zien.

Monique Lahaye. Beste Monique, ook jij verdient het om eens bedankt te worden. Ik heb je ontelbare keren gebeld met de vraag om weer een afspraak te plannen met Peter, Bram of het hele promotieteam (dat laatste is een schier onmogelijke opgave gebleken). Bedankt voor je inzet.

Graag wil ik ook van de gelegenheid gebruik maken om enkele personen te bedanken die meegewerkt hebben aan onderzoeken die niet in dit proefschrift beschreven zijn. Edwin Barten, Tos Berendschot, Klaas de Boer en Marion Machiels van de Oogheelkunde, bedankt voor al jullie hulp bij het maken van de retinafoto's in het kader van de microcirculatiestudie. De studenten Astrid Hendriks en Johan Juch, dank voor jullie hulp bij de slaapstudie. De huisartsen Frank Soomers en Jelle Stoffers, bedankt dat ik mijn eerste wetenschappelijke veldwerk mocht starten in jullie huisartsenpraktijk.

Tiny Wouters. Beste Tiny, jij kwam pas in beeld aan het einde van mijn promotietraject toen er een boekje gemaakt moest worden. Jouw ervaring en de drive om een foutloos boekje af te leveren zijn goud waard. Bedankt voor alle je (vrije) tijd die je in mijn boekje hebt gestoken.

De leden van de beoordelingscommissie, Prof. dr. Struijker Boudier, Prof. dr. Koudstaal, Dr. van Montfrans, Dr. Smeets, en Prof. dr. Wilmink wil ik bedanken voor het bestuderen en beoordelen van dit proefschrift.

Dan mijn huidige kamergenoten Jolanda van Golde, Matthijs Ruiter en Jean Scheijen. Met Jolanda en Matthijs heb ik ruim 3 jaar een kamer gedeeld, en 
samen hebben we vele wetenschappelijke en persoonlijke, hoogte- en dieptepunten, vreugde en frustraties met elkaar beleefd en, niet onbelangrijk, gedeeld. Lieve Jolanda, jouw enthousiasme, positieve instelling en doorzettingsvermogen zullen je altijd brengen daar waar je wilt komen; heel veel geluk met je gezin en veel succes met je werk. Beste Matthijs, heel erg bedankt dat je mijn paranimf wilt zijn. Heel veel succes met het afronden van je eigen promotie-onderzoek in het komende jaar, en ik kijk uit naar jouw boekje. Beste Jean, we waren maar kort kamergenoten, maar desalniettemin heb je ook bijgedragen aan dit boekje: de omslag is van jouw hand. Ik ben van mening dat het enthousiasme dat jij voor jouw vak hebt, iedere promovendus zou moeten hebben. Wie weet leidt het er nog toe dat je zelf ooit gaat promoveren. Ik weet in ieder geval zeker dat je dat kunt.

Ralf, Patricia, Dawid en Kacper. Jullie hebben me laten zien wat echt geluk betekent. Ralf, grote broer, bedankt dat je tijdens de laatste loodjes mijn paranimf wilt zijn.

Pap, mam. Dit is ook jullie boekje! Bedankt dat jullie er steeds weer zijn!

Marian. Alleen al je aanwezigheid is voldoende steun geweest tijdens de afgelopen jaren. Ik hou van je! 
222 


\section{Curriculum vitae}

Léon Henskens werd geboren op 8 april 1977 in Heerlen en groeide op in Bocholtz in Zuid-Limburg. In 1996 behaalde hij het VWO diploma aan het Katholiek Gymnasium Rolduc te Kerkrade. Aansluitend startte hij met de studie Gezondheidswetenschappen aan de Universiteit Maastricht, waar hij het propedeutisch examen behaalde in 1997. In datzelfde jaar werd hij ingeloot voor de studie Geneeskunde aan de Universiteit Maastricht. In 2001 behaalde hij het doctoraalexamen en in 2003 het artsexamen (cum laude). Vanaf het tweede studiejaar volgde hij het Onderzoekstraject Geneeskunde (OTG) bij de afdeling Interne Geneeskunde (prof. dr. P.W. de Leeuw) waar, onder de enthousiaste begeleiding van dr. W. Spiering, de interesse in wetenschappelijk onderzoek ontstond. Van oktober 2003 tot en met september 2008 werkte hij als promovendus bij de afdeling Interne Geneeskunde, Cardiovascular Research Institute Maastricht (CARIM), Universiteit Maastricht, onder leiding van dr. A.A. Kroon en prof. dr. P.W. de Leeuw, in nauwe samenwerking met dr. R.J. van Oostenbrugge en prof. dr. J. Lodder (afdeling Neurologie). In 2007 ontving hij een Research Project Grant van de Novartis Foundation for Cardiovascular Excelence voor het project "Cerebral microbleeds: a marker of hypertensive cerebral targetorgan damage?".

$\mathrm{Na}$ zijn promotie zal hij starten met de opleiding tot neuroloog. Hij woont samen met Marian Hommels. 


\section{List of publications}

Henskens $L H$, Spiering W, Stoffers HE, Soomers FL, Vlietinck RF, de Leeuw PW, Kroon AA. Effects of $A C E ~ I / D$ and AT1R $A^{1166} C$ polymorphisms on blood pressure in a healthy normotensive primary care population: first results of the Hippocrates study. J Hypertens. 2003;21:81-86.

Van Onna M, Kroon AA, Houben AJ, Koster D, Zeegers MP, Henskens LH, Plat AW, Stoffer HE, de Leeuw PW. Genetic risk of atherosclerotic renal artery disease: the candidate gene approach in a renal angiography cohort. Hypertension. 2004;44:448-453.

Spiering W, Henskens $L H$, Kroon AA, Stoffers HE, de Leeuw PW. Genetic contribution to the chronic effects of angiotensin II type 1 receptor blockade. Thesis W. Spiering. 2004.

Henskens $L H$, Kroon AA, van Boxtel MP, Hofman PA, de Leeuw PW. Associations of the angiotensin II type 1 receptor $A^{1166} \mathrm{C}$ and the endothelial nitric oxide synthase $G^{894} \mathrm{~T}$ gene polymorphisms with silent subcortical white matter lesions in essential hypertension. Stroke. 2005;36:1869-1873.

Van Boxtel MP, Henskens LH, Kroon AA, Hofman PA, Gronenschild EH, Jolles J, de Leeuw PW. Ambulatory blood pressure, asymptomatic cerebrovascular damage and cognitive function in essential hypertension. J Hum Hypertens. 2006;20:5-13.

Henskens $L H$, Kroon AA, van der Schouw YT, Schiffers PM, Grobbee DE, de Leeuw PW, Bots ML. Renin-angiotensin system and nitric oxide synthase gene polymorphisms in relation to stroke. Am J Hypertens. 2007;20:764-770.

Henskens LH, van Oostenbrugge RJ, Kroon AA, de Leeuw PW, Lodder J. Brain microbleeds are associated with ambulatory blood pressure levels in a hypertensive population. Hypertension. 2008;51:62-68.

Henskens $L H$, van Oostenbrugge RJ, Kroon AA, de Leeuw PW, Lodder J. Response to brain microbleeds, amyloid plaques, intellectual deterioration, and arterial stiffness. Hypertension. 2008;51:e21;letter to the editor.

Henskens LH, Kroon AA, van Oostenbrugge RJ, Haest RJ, Lodder J, de Leeuw PW. Different classifications of nocturnal blood pressure dipping affect the prevalence of dippers and nondippers and the relation with target-organ damage. J Hypertens. 2008;26:691-698.

Henskens LH, Kroon AA, van Oostenbrugge RJ, Gronenschild EH, Fuss-Lejeune MJ, Hofman PA, Lodder J, de Leeuw PW. Aortic stiffness is associated with silent cerebral small-vessel disease in hypertensive patients. Hypertension 2008. Accepted for publication.

Henskens $L H$, Kroon AA, van Oostenbrugge RJ, Gronenschild EH, Lodder J, de Leeuw PW. White matter hyperintensity volumes relate to ambulatory blood pressure levels in hypertensive patients. Submitted.

Henskens LH, van Oostenbrugge RJ, Kroon AA, de Leeuw PW, Lodder J. Silent lacunar but not territorial infarcts are related to ambulatory blood pressure levels in hypertensive patients. Submitted.

Henskens $L H$, van Oostenbrugge RJ, Kroon AA, Hofman PA, Lodder J, de Leeuw PW. Detection of silent cerebrovascular disease refines risk stratification of hypertensive patients. Submitted. 